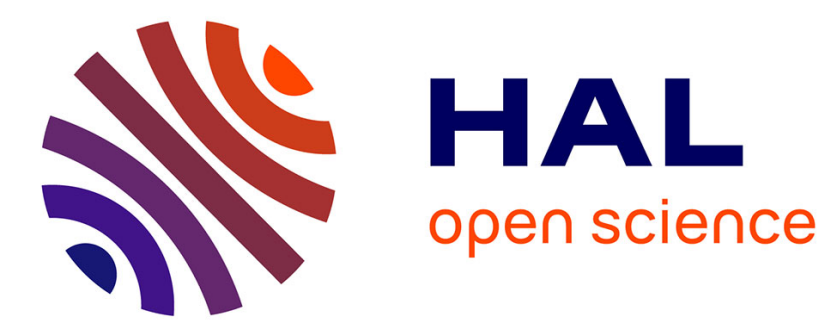

\title{
L'expérience migratoire au féminin : les Allemandes au Chili dans la seconde moitié du XIXe siècle
}

Pauline Bilot

\section{To cite this version:}

Pauline Bilot. L'expérience migratoire au féminin : les Allemandes au Chili dans la seconde moitié du XIXe siècle. Histoire. 2008. dumas-01258818

\section{HAL Id: dumas-01258818 https://dumas.ccsd.cnrs.fr/dumas-01258818}

Submitted on 15 Feb 2016

HAL is a multi-disciplinary open access archive for the deposit and dissemination of scientific research documents, whether they are published or not. The documents may come from teaching and research institutions in France or abroad, or from public or private research centers.
L'archive ouverte pluridisciplinaire HAL, est destinée au dépôt et à la diffusion de documents scientifiques de niveau recherche, publiés ou non, émanant des établissements d'enseignement et de recherche français ou étrangers, des laboratoires publics ou privés. 


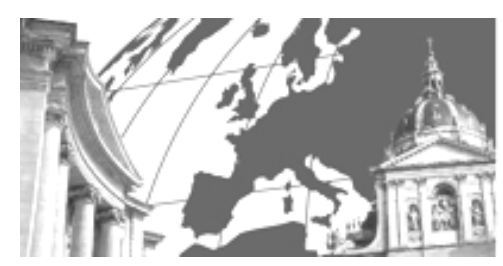
U - PANTHÉON - SORBONNE - 1

UFR 09 - Histoire

CRALMI - Centre de Recherches d'Histoire de l'Amérique latine et du Monde Ibérique

\section{LES ALLEMANDES AU CHILI}

dans la seconde moitié du XIX $X^{e}$ siècle

Mémoire de Master 2

«Histoire contemporaine des mondes étrangers et des relations internationales »

Présenté par Pauline BILOT

Sous la direction de la Pr. Annick LEMPÉRIÈRE

- Octobre 2008 - 
Au seuil de ce mémoire, je souhaiterais exprimer ma profonde reconnaissance envers Annick Lempérière, au nom de la confiance qu'elle m'a accordée dans la mise en place de cet échange France-Chili et de son soutien constant, en dépit de la distance, dans ce travail de recherche. Ma dette est grande également envers les Pr. Dr. Patricio Bernedo, directeur de l'Institut d'Histoire de la Pontificia Universidad Católica de Chile, Ana Maria Stuven, Ricardo Couyoumdjian et Pablo Whipple, pour leurs précieux et généreux conseils dans leur spécialité respective. Je tiens à remercier également, en souvenir d'une collaboration amicale, Christine Gleisner et Eduardo Carrasco de la Biblioteca e Archivo Emilio Held Winkler de la Liga ChilenoAlemana, ainsi que le personnel de la Biblioteca Nacional et de l'Archivo Nacional $d u$ Chili. Mes pensées vont également vers mes amis, historiens ou autres, de France, du Chili, d'Allemagne ou d'ailleurs, qui m'ont encouragé dans ce projet. Il m'importe surtout de rappeler l'immense affection que je porte à ma famille, qui m'a toujours assuré de son soutien inconditionnel dans chacun de mes choix, en particulier celui-ci, projet de recherche mais aussi de vie. Merci enfin à Antonio. 
"Les émigrantes sont devenues, à leur tour et à l'instar des hommes, les hérö̈nes de la route et des vagues, traversant des frontières dangereuses, avec, en plus, des enfants dans leurs jupes, et des samovars ou des matelas comme bagage ».

Nancy Green, Repenser les migrations, Paris, PUF, 2002, p. 112. 


\section{SOMMAIRE}

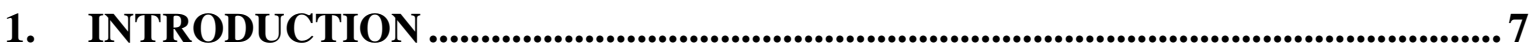

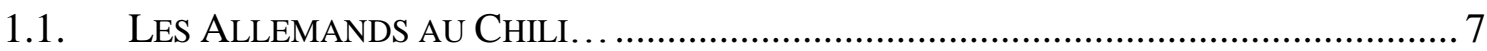

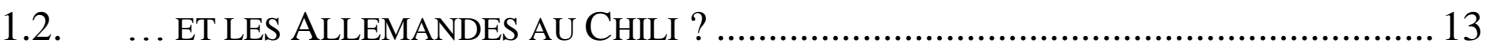

1.3. METHODES, OBJECTIFS ET PROBLEMATIQUES DE LA RECHERCHE........................... 14

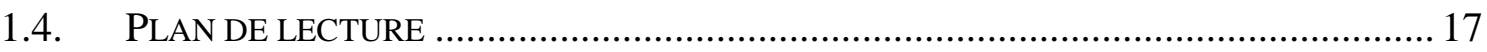

2. TRACES HISTORIOGRAPHIQUES ................................................................ 19

2.1. HISTORIOGRAPHIE DES MIGRATIONS ALLEMANDES AU CHILI .............................. 19

2.1.1. Les ouvrages commémoratifs germano-chiliens ....................................... 19

2.1.2. Les premières publications de sources ....................................................... 20

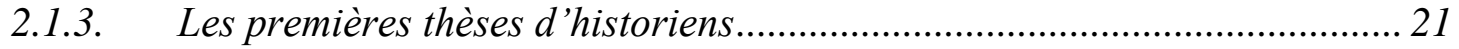

2.1.4. En Allemagne : la redécouverte du national............................................ 23

2.1.5. L'école historique chilienne entre tradition et révision.............................26 26

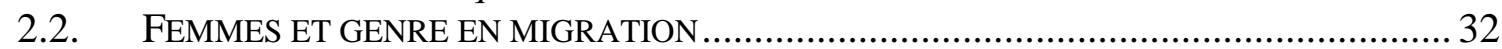

2.2.1. Des études migratoires longtemps androcentrées...................................... 33

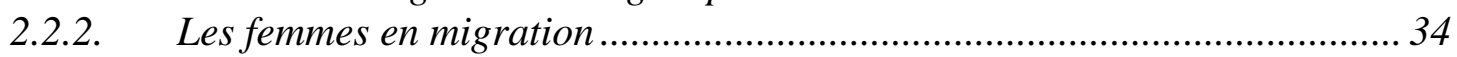

2.2.3. Genre en migration, migration de genre ..................................................... 37

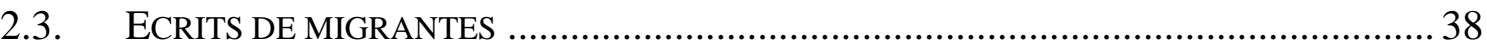

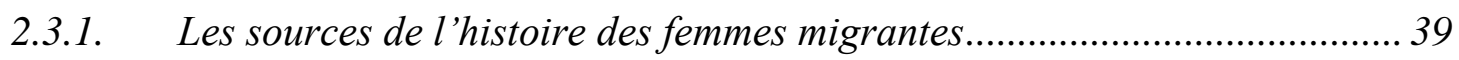

2.3.2. Des epistolières et diaristes................................................................. 41

\section{CONTOURS D'UN GROUPE SOCIAL : LES IMMIGRÉES ALLEMANDES}

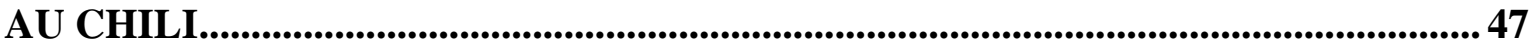

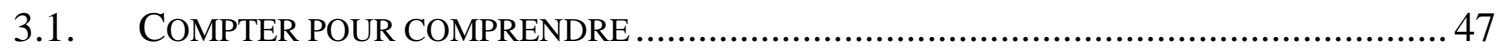

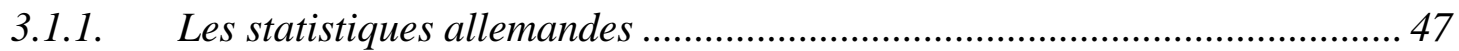

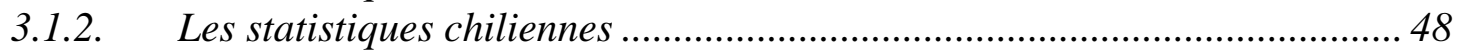

3.1.3. Comptes de chercheurs .............................................................................. 51

3.2. LES ORIGINES GEOGRAPHIQUES, RELIGIEUSES ET SOCIALES DU GROUPE................52

3.2.1. Des origines géographiques communes .................................................... 52

3.2.2. Des catégories sociales diverses mais une alphabétisation généralisée..... 53

3.3. UN GROUPE PARTICULIER : LES FEMMES SEULES ................................................56

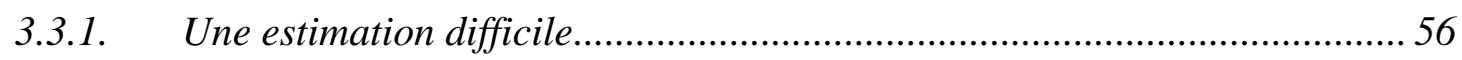

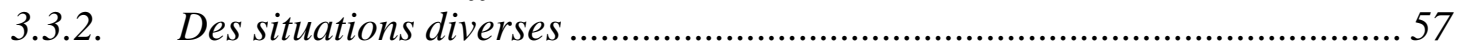

3.3.3. Un projet commun : le mariage et l'autonomisation. ...................................6 60

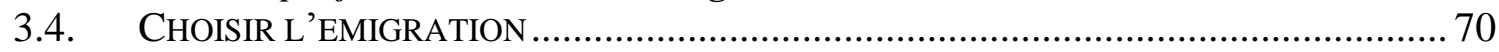

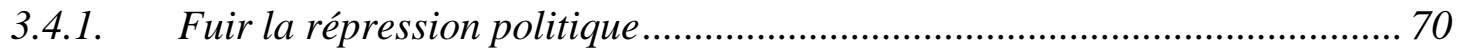

3.4.2. Echapper à la crise économique .................................................................. 71

3.4.3. Les femmes et la décision de migration....................................................... 74

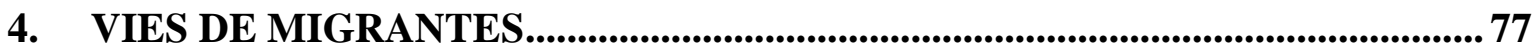

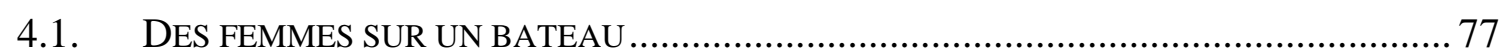

4.1.1. Les drames et difficultés d'une longue traversée ....................................... 78

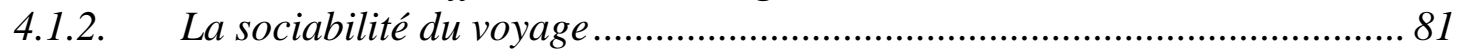

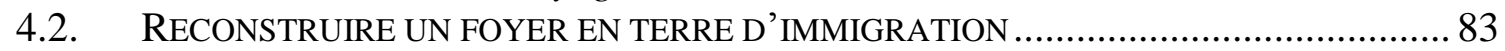

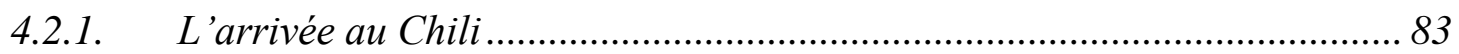

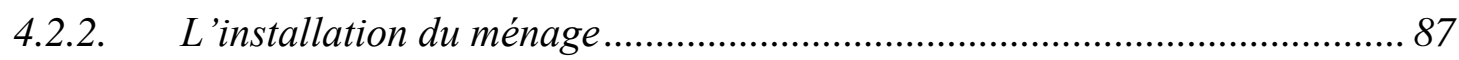

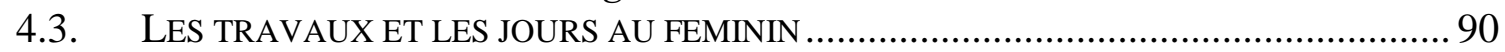




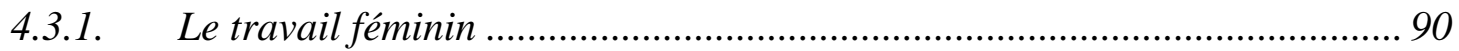

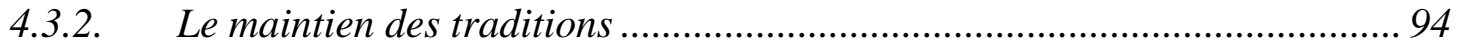

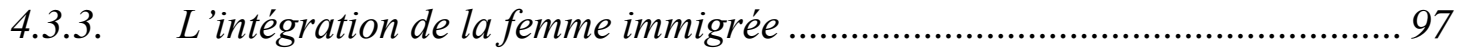

4.4. LE ROLE MATERNEL EN CONTEXTE MIGRATOIRE ................................................ 101

4.4.1. Des taux de fécondité et de mortalité infantile importants........................ 101

4.4.2. L'accouchement..................................................................................... 104

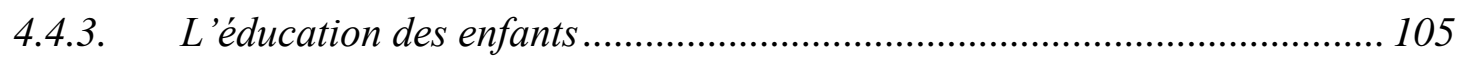

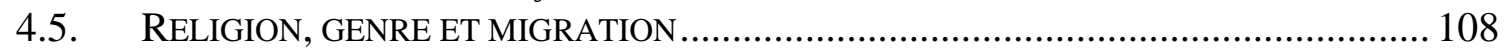

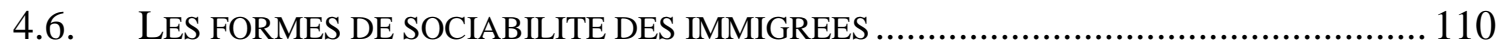

5. GENRE ET NATION DANS LE CONTEXTE DE MIGRATION .................... 114

5.1. LA LETTRE COMME RECOMPOSITION DU TISSU COMMUNAUTAIRE ...................... 114

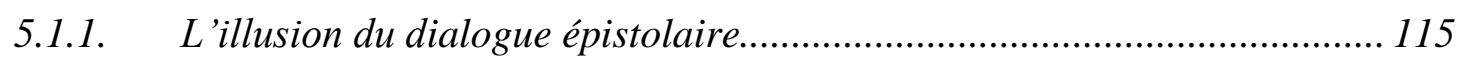

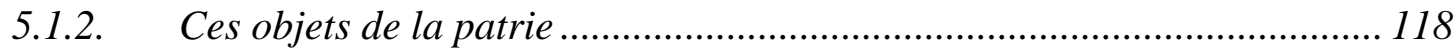

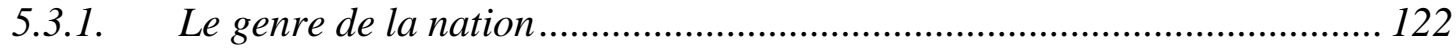

5.2. L'EMIGRATION OU LA DEFINITION DU NATIONAL................................................. 123

5.2.1. Une communauté nationale imaginée dans la migration.......................... 123

5.2.2. Le positionnement culturel entre nouveau et ancien Heimat ..................... 126

5.2.3. Travail féminin/travail masculin : le positionnement de genre.................. 131

5.3. PAYS D'IMMIGRATION/PAYS D'EMIGRATION : LIMITES ET FRONTIERES DE

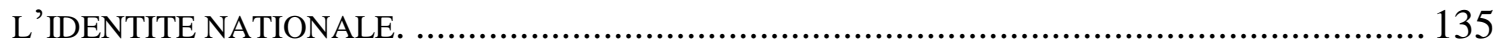

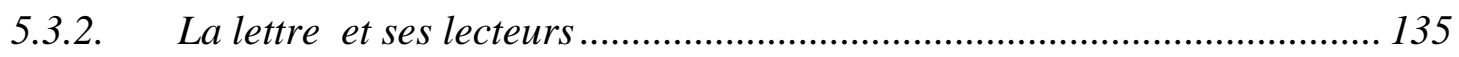

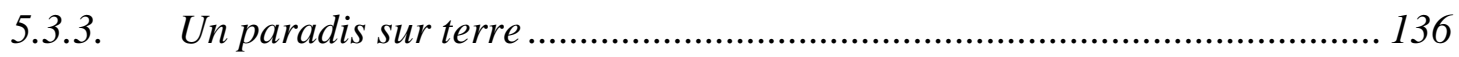

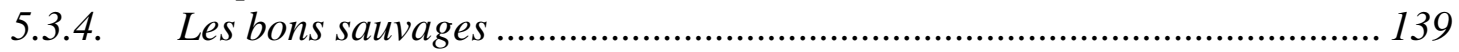

5.3.5. Une opposition de « races »................................................................. 143

6. CONCLUSION .................................................................................................................. 151

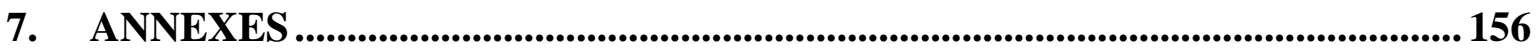

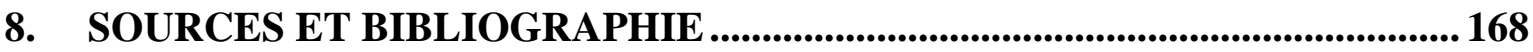

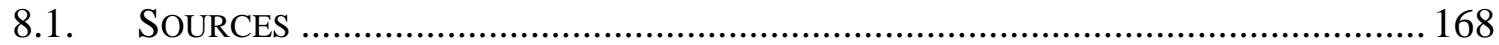

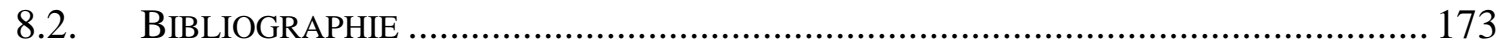




\section{INTRODUCTION}

L'émigration européenne du XIX ${ }^{\mathrm{e}}$ siècle représente sans doute l'un des mouvements de population les plus importants de l'histoire de l'humanité. Des guerres napoléoniennes à la Première Guerre mondiale, quelques 50 millions d'Européens auraient émigré outre Atlantique. Les États-Unis sont très tôt le premier pays récepteur, accueillant les deux tiers du courant, mais les pays d'Amérique latine ne sont pas en reste. Le Brésil et l'Argentine reçoivent plusieurs millions d'émigrants chacun, l'Uruguay quelques 500 000, le Chili 80000 et le Paraguay $30000^{1}$. Pierre Chaunu évoque ainsi une « seconde conquête humaine de l'Amérique latine par l'Europe » au XIX ${ }^{\mathrm{e}}$ siècle $^{2}$. Au sein de cette émigration européenne, la composante germanique représente environ $10 \%$. L'émigration allemande vers le Chili est, sur le même modèle, un phénomène mineur en comparaison à ses variantes nord-américaine, brésilienne ou argentine ${ }^{3}$. Quelques 5 millions d'Allemands auraient émigré entre 1815 et $1914^{4}$, l'immense majorité s'orientant vers les EtatsUnis, tandis qu'au Chili, ils auraient été une dizaine de milliers.

\subsection{Les Allemands au Chili...}

Si des Allemands ont émigré au Chili, c'est d'abord parce que le gouvernement chilien les y a invités, pour des raisons économiques, sociales et stratégiques. Depuis sa rupture avec l'Espagne en 1810, la République chilienne peine à contrôler le territoire qu'elle s'est assigné, luttant contre des prétentions étrangères, argentines, mais aussi anglaises et françaises, réelles ou fantasmées ${ }^{5}$. Les troubles viennent surtout d'éléments intérieurs. Une grande partie du territoire austral est en effet restée sous contrôle des tribus indiennes, les Mapuches, rendant la souveraineté territoriale du Chili fictive. L'administration républicaine est ainsi absente de Concepción à l'île de Chiloé, réalité que Jean-Pierre Blancpain a cartographiée de la manière suivante (carte 1).

\footnotetext{
${ }^{1}$ G. F. W. Young, The Germans in Chile: Immigration and Colonization, 1849-1914, New-York, Staten Island, Center for Migration Studies of N.Y, 1974, p. 1.

${ }^{2}$ P. Chaunu, Histoire de l'Amérique latine, Paris, PUF, Que sais-je?, 1949, p. 107.

${ }^{3}$ En réalité, plus que d'émigration allemande, il conviendrait d'évoquer une émigration germanophone. Parmi les « Allemands du Chili » s'intègrent en effet des Autrichiens - des Dalmates qui fuient le service dû à la double couronne - des Suisses, des populations germanophones de l'Europe de l'Est, des Balkans, de la Russie, et même des colonies africaines. $C f$. J.-P. Blancpain, "Origines et caractères des migrations germaniques en Amérique latine au XIX ${ }^{\mathrm{e}}$ siècle », Jahrbuch für Geschichte von Staat, Wirtschaft und Gesellschaft Lateinamerikas 25/1988, p. 354

${ }^{4} 5,573$ millions selon P. Marschalck, J. Dupâquier, « La grande mutation de la population allemande » dans J.-P. Bardet, J. Dupâquier, Histoire des populations de l'Europe, Tome II, Paris, Fayard, 1998, pp. 409 et 420.

${ }^{5}$ La pression des puissances étrangères s'est manifestée sur plusieurs territoires en Amérique latine, notamment dans le Nord du Mexique, occupé par les États-Unis dans les années 1840, et en Patagonie chilienne et argentine, sérieusement convoitée par les Français et les Anglais dès les années 1830.
} 


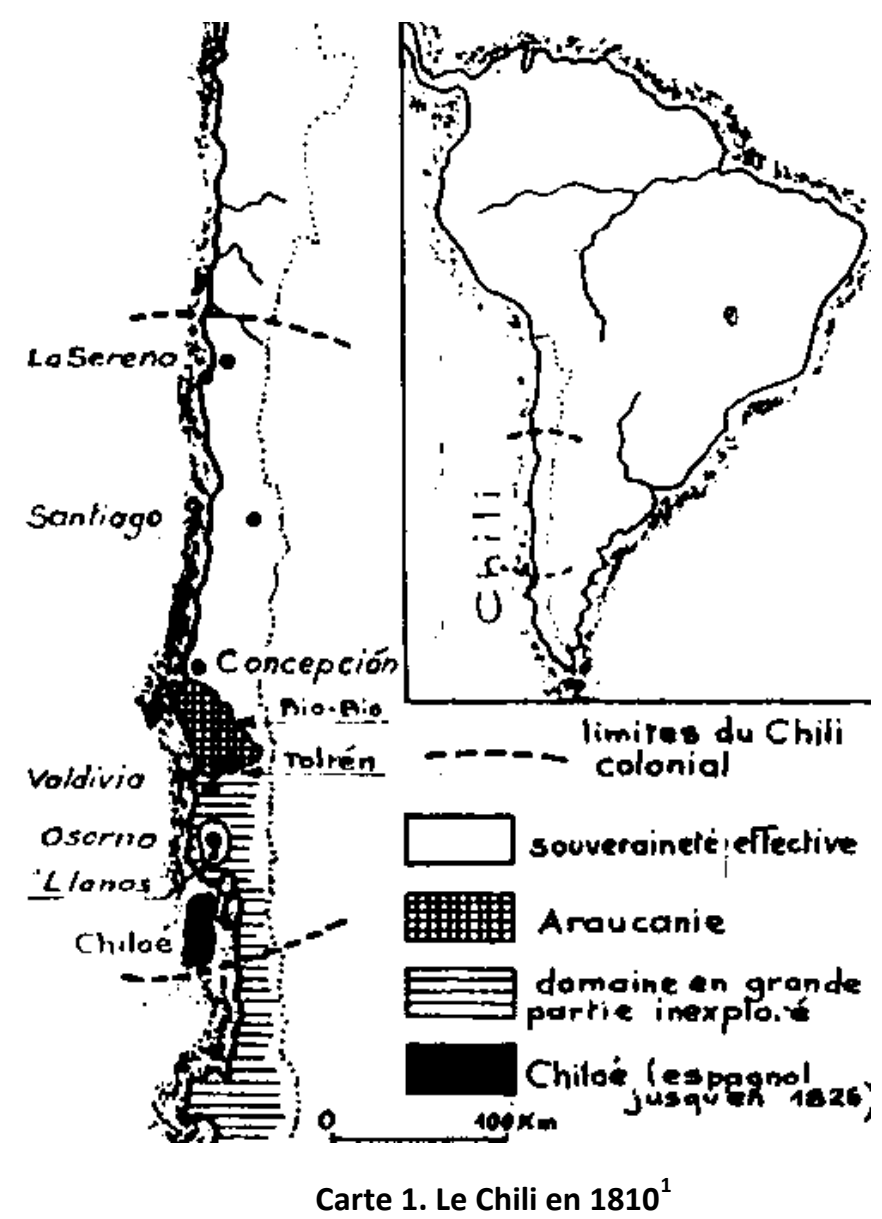

En réalité, en 1810, ce qui est appelé le «Chili » est une capitainerie générale encore très réduite, dépendante de la vice-royauté péruvienne, et donc bien loin de recouvrir le territoire que nous lui connaissons aujourd'hui. Il s'agit, pour la toute jeune République, de conquérir un territoire qui n'a jamais fait partie du Chili colonial. Soucieuse d'étendre sa souveraineté, elle développe alors des projets de colonisation, en direction des vastes territoires du Nord et du Sud, faisant sienne la citation du politique argentin contemporain Juan Bautista Alberti : «gouverner, c'est peupler $»^{2}$. Au Chili et en Amérique latine en général, dans de larges secteurs de l'élite politique, le désir d'expansion nationale s'associe à des projets d'immigration de main d'œuvre étrangère, dans l'objectif de développer les espaces vides qu'une faible démographie ne saurait combler ${ }^{3}$. A la motivation politique, s'ajoutent ainsi des justifications économiques. Alors consul du Chili à

\footnotetext{
${ }^{1}$ J.-P. Blancpain, Les Allemands au Chili (1816-1945), Köln, Bölhau Verlag, 1974, p. 4.

${ }^{2}$ Il restait en effet à prendre $144000 \mathrm{~km}^{2}$ au Nord de Copiapo, région riche en minéraux, $41000 \mathrm{~km}^{2}$ au Sud de Concepción, dans la région des Mapuche, $166000 \mathrm{~km}^{2}$ dans les régions de Valdivia et Llanquihue et $345000 \mathrm{~km}^{2}$ dans la région isolée de Magellan ou de Patagonie jusqu'au Cap Horn, $C f$. P. Bernedo, Bürgertum und Moderniesierungansätze in Chile im 19. Jahrhundert. Der Beitrag der Deutschen Einwanderer in Valdivia und La Frontera, Thèse de doctorat, Katolische Unversität Eichstätt, 1995, p. 62.

${ }^{3}$ En 1850, avec une population de 30,495 millions d'habitants et une superficie de $20573684 \mathrm{~km}^{2}$ (chiffre actuel du Population Reference Bureau, http://www.prb.org), la densité de l'Amérique latine était de 0,674 hab. $/ \mathrm{km}^{2}, C f$. François Chevalier, Histoire de l'Amérique latine, de l'Indépendance à nos jours, Nouvelle Clio, PUF, 1973, p. 129. La densité moyenne du Chili était, en 1865, de 3,1 hab. $/ \mathrm{km}^{2}$, Cf. Censo general de la República de Chile levantado el 19 de abril de 1865, Santiago, Impr. Nacional, 1866, p. 392.
} 
Hambourg, Vicente Pérez Rosales, communément reconnu comme le «père de la colonisation allemande au Chili » ${ }^{1}$, rédige un Essai sur le Chili dans lequel il expose les motivations de son gouvernement : le Chili, riche en ressources, manquait de main d'œuvre capable d'exploiter ce potentiel économique. Le problème du développement était directement lié au manque d'esprit d'entreprise et de formation de la population chilienne, explique-t-il' ${ }^{2}$. L'historien Tulio Halperin Donghi souligne ainsi que l'appel à l'immigration s'insère dans les projets libéraux de transformations économiques et sociales, tendances qui se sont accentuées au cours du XIX ${ }^{\mathrm{e}}$ siècle, lorsque les États-Unis démontrèrent que l'immigration pouvait contribuer au développement économique du pays ${ }^{3}$.

Les projets d'immigration chiliens datent des toutes premières années du processus d'Indépendance. En 1811, José Miguel Carrera propose de faire venir des immigrants irlandais qui collaboreront avec la cause indépendantiste ${ }^{4}$. De même, Bernardo O'Higgins fait approuver pendant son gouvernement divers projets, notamment en faveur des Anglais, des Irlandais et des Suisses. La Loi de protection de l'Industrie, en 1824, encourage l'installation d'étrangers, en échange d'exemptions diverses d'impôt pendant dix ans ${ }^{5}$. Considéré comme le meilleur candidat à l'immigration, l'Allemand emporte cependant la faveur des politiques. Issu d'un territoire fragmenté en une multitude d'États et de principautés, il ne risque pas en effet de servir de prétexte à une intervention de la part d'une super puissance à prétention colonialiste. Dans son rapport au gouvernement sur l'immigration étrangère, le député Benjamin Vicuña Mackenna explique ainsi que «l'avantage le plus positif que présente l'Allemand, dans la colonisation de l'Amérique ibérique, est de ne pas être le sujet de ces puissances maritimes orgueilleuses ou fantastiques qui, pour chacun de leurs citoyens, nous envoient un canon [...] $»^{6}$.

Les frères Philippi, Rudolf Amandus et Bernhard Eunom, originaires de la Hesse, sont les protagonistes de l'émigration allemande au Chili. Le premier, naturaliste au service du gouvernement chilien depuis les années 1830, et le second, aventurier matelot, sont deux Chiliens d'adoption. Bernhard Eunom a mené plusieurs explorations dans les territoires australs, au cours desquelles il redécouvre notamment le lac de Llanquihue, jusqu'à sa mort mystérieuse dans les territoires de Magellan en $1852^{7}$. C'est lui, qui, le premier, a l'idée de faire venir des Allemands pour coloniser les régions des rivières et des lacs, de Valdivia à Chiloé et qui, par l'intermédiaire de

\footnotetext{
${ }^{1}$ V. Pérez Rosales, Recuerdos del pasado (1814-1860), Santiago, Zig-Zag, 1943, 500 p.

${ }^{2}$ V. Pérez Rosales, Essai sur le Chili, Hambourg, F.H. Nestler \& Melle, 1857, p. 157 et 293.

${ }^{3}$ T. Halperin Donghi, Historia contemporánea de América Latina, Madrid, Alianza Editorial, 1981, pp. 220221.

${ }^{4}$ R. Couyoumdjian, A. Rebolledo, Bibliografía sobre el proceso inmigratorio en Chile, desde la Independencia hasta 1930, Santiago, Instituto Panamericano de Geografía e Historia, 1984, p. 121.

${ }^{5}$ Ibid., p. 132.

${ }^{6}$ B. Vicuña Mackenna, Bases del informe presentado al supremo gobierno sobre la inmigración extranjera, Santiago de Chile, Imprenta Nacional, 1865, p. 27.

${ }^{7}$ Il y aurait été assassiné par un indien. Pour une biographie extensive de B.E. Philippi, cf. G. Young, "Bernardo Philippi, Initiator of German Colonization in Chile", The Hispanic American Historical Review, 51-3/1971, pp. 478-496 et J.-P. Blancpain, Les Allemands au Chili, Op. Cit., p. 79-96.
} 
son frère, diffuse le projet en Allemagne. Les neuf premières familles allemandes, soit 34 personnes, arrivent à bord du «Catalina » le 25 août 1846, dans le cadre d'une colonisation privée encouragée par des figures du commerce international de Valparaiso ${ }^{1}$.

Les projets d'immigration officielle se concrétisent lorsque le gouvernement chilien promulgue, le 18 novembre 1845, la Loi de colonisation, par laquelle sont concédés à l'État 6000 cuadras de terrain afin d'y établir des colonies nationales et étrangères ${ }^{2}$. Le 27 juillet 1848, B.E. Philippi est nommé agent de colonisation en Allemagne, avec pour mission de mettre en œuvre la loi de $1845^{3}$. Il est chargé de procéder au recrutement de 150 à 200 familles d'agriculteurs et d'artisans destinés à la colonie témoin de Llanquihue. Les premiers colons qui débarquent sont tous protestants, en contradiction avec les instructions du gouvernement qui exigeait des catholiques. En Allemagne, Philippi n'était pas parvenu en effet à convaincre les prélats catholiques d'inciter leurs ouailles à l'émigration ${ }^{4}$. Il est remercié d'un exil déguisé dans les terres magellanes, avant d'être remplacé par Vicente Pérez Rosales, Intendant de Valdivia de 1850 à 1855, consul du Chili à Hambourg de 1855 à 1858.

Ainsi, au terme d'une préhistoire complexe et chaotique, faite de malentendus, de divergence d'intérêts et d'acquisitions frauduleuses au détriment des Mapuches ${ }^{5}$, le projet d'une immigration allemande au Chili a donc finalement pu se concrétiser sous la force de trois facteurs convergents : la volonté du gouvernement chilien, l'action d'individus pour amener ces colons directement au Chili et la prédisposition, chez ces colons potentiels, à l'émigration ${ }^{6}$.

L'émigration allemande au Chili connaît trois phases nettement identifiées par Jean-Pierre Blancpain, et qui correspondent à autant de migrations de nature et d'importance différente ${ }^{7}$. Dès

\footnotetext{
${ }^{1}$ Valparaiso, port principal du pays, est au XIX ${ }^{\mathrm{e}}$ siècle la porte sur le monde du Chili, prenant des airs de ville cosmopolite. Au début des années 1830, il compte 25000 habitants, selon le savant allemand Eduard Poeppig, dont 3000 étrangers. L'influence européenne y est marquée, l'opposant, dès les années 1820, à la traditionnelle Santiago, un contraste croqué par Marie Graham, fille et épouse anglaise d'officier marin qui séjourne au Chili de 1820 à 1823 . Aux côtés des Anglais et des Français s'y établissent les représentants des maisons commerciales hanséatiques, notamment hambourgeoises et brémoises. En 1822 ouvre la maison Schütte, Post et Cie, en 1824 la Stuven et en 1828 la Huth, Grüning et Cie. Dans les années 1830 se multiplient les enseignes allemandes, spécialisées dans l'import-export et le ravitaillement des navires de guerre et de commerce. $C f$. S. Villalobos, O. Silva, F. Silva (et al.), Historia de Chile, Santiago de Chile, Editorial Universitaria, 1974, p. 437 ; J.-P. Blancpain, Les Allemands au Chili, Op. Cit., pp. 20-23 ; R. Couyoumdjian, Chile y Gran Bretaña durante la Primera Guerra Mundial y la postguerra, 1914-1921, Santiago de Chile, Ed. Andrés Bello, 1986, p. 30 ; E. Poeppig, Reise in Chile, Peru und auf dem Amazonenstrome während der Jahre 1827-1832, Stuttgart, F.A. Brockhaus, 1960, tome 1, p. 72 et M. Graham, Diario de una residencia en Chile, Santiago, Andros, 2007 (1824), 514 p.

${ }^{2}$ R. Couyoumdjian, A. Rebolledo, Op. Cit., p. 132. Une cuadra est une parcelle d'environ 1,5ha, $C f$. L'entrée "cuadra" dans Nuevo Diccionario ejemplificado de Chilenismos y de otros usos diferenciales del Español de Chile, Valparaíso, 2006, Tomo I, p. 777.

${ }^{3}$ G. Young, «Bernardo Philippi », Op. Cit., pp. 488-489.

${ }^{4}$ Sur l'opposition des prélats catholiques allemands à l'émigration, $C f$. P. Bernedo, «Las Iglesias alemanas frente al problema de la emigración masiva, 1816-1914 », Historia 27/1993, p. 69-87.

${ }^{5}$ Cette préhistoire est détaillée dans J.-P. Blancpain, Les Allemands au Chili, Op. Cit., pp. 79-118.

${ }^{6}$ G. Young, The Germans in Chile, Op. Cit., p. 17.

${ }^{7}$ J.-P. Blancpain, Les Allemands au Chili, Op. Cit., pp. 185-188.
} 
1850, le quotidien El Araucano dégage en effet trois types d'immigrés : ceux recrutés par l'Etat, ceux venus pour le compte de particuliers et ceux qui ont émigré librement, ce dernier groupe concernant surtout la bourgeoisie de Valdivia et Osorno ${ }^{1}$.

Une première vague d'immigration va de 1846 à 1875. Elle commence avec l'immigration privée, bientôt relayée par l'immigration officielle encouragée par la Sociedad Nacional de Agricultura, créée en 1838. Elle est numériquement faible, mais socialement riche et diverse, composée de bourgeois, artisans et paysans, économiquement en risque de prolétarisation ou politiquement vaincus en Allemagne. C'est une immigration qui occupe les régions du Sud, à Valdivia et autour du lac Llanquihue ${ }^{2}$. On compte ainsi en 1870 quelques 3000 Allemands formant une «microsociété pionnière », selon le mot de Simon Collier ${ }^{3}$. A partir de 1875, cette première vague se tarit, sans doute par épuisement des réseaux géographiques et familiaux de recrutement.

La seconde vague reprend en 1882 jusqu'en 1890 et s'inscrit dans un projet d'immigration chilien multinational mené essentiellement par la Sociedad de Fomento Fabril, organisme de promotion du développement industriel et par l'intermédiaire de l'Agencia General de Colonización $e$ Immigración de Paris, deux institutions créées en 1883. Face aux risques que pourraient constituer d'éventuelles revendications de la part de la minorité ethnique allemande, relevant désormais de l'une des plus grandes puissances européennes récemment unifiée, le gouvernement chilien préfère miser sur la diversité nationale et encourager l'assimilation. Sont recrutés des ouvriers agricoles des marches orientales et des prolétaires berlinois, qui s'installent au sein de colonies étrangères entre le Bio-Bio et le Tolten. Suisses et Allemands côtoient alors Français, Basques, Espagnols, Italiens, mais aussi des colons nationaux. La dispersion géographique intentionnelle produit une intégration rapide, ce qui distingue nettement cette deuxième vague de la première, géographiquement isolée, concentrée et donc plus prompte à maintenir ses caractères d'origine.

De 1890 à 1914, l'émigration allemande se poursuit, mais se diffuse sur l'ensemble du territoire chilien, des régions minières du Norte Grande à la région de Magellan. Deux centres principaux se dégagent cependant à Chiloé et sur la Frontera, cette frontière interne jusqu'alors gardée par les indigènes. Après la première guerre mondiale, l'émigration est ponctuelle et numériquement insignifiante. Quelques Allemands viennent encore peupler Peñaflor, près de Santiago, en 1929, La Serena, au Nord, en 1946. Santiago et Valparaiso continuent à recevoir de maigres flux, plutôt de réfugiés que de réels immigrés, remarque Jean-Pierre Blancpain ${ }^{4}$. Il s'agit souvent d'un déplacement par obligation et non par choix, rendant l'insertion dans le pays d'accueil moins poussée et la perspective du retour toujours consciente et sensible à tout changement politique dans

\footnotetext{
${ }^{1}$ El Araucano, n8, p. 1137 cité dans G. Guarda, Nueva Historia de Valdivia, Santiago, Ed. Universidad Católica de Chile, 2001, p. 553.

${ }^{2} C f$. carte des colonies allemandes au Chili et de la colonie de Llanquihue en annexe.

${ }^{3}$ S. Collier, W. Satter, A History of Chile, 1808-2002, Second Edition, Cambridge University Press, 2004, p. 95 : "a pioneer micro-society".

${ }^{4}$ J.-P. Blancpain, Les Allemands au Chili, Op. Cit., p. 188.
} 
le pays d'origine. Le Chili a ainsi accueilli tour à tour des réfugiés juifs fuyant le régime hitlérien, puis, dans une moindre mesure, après la Seconde Guerre mondiale, ces mêmes nazis et criminels de guerre ${ }^{1}$.

Le courant migratoire allemand au Chili est donc multiple et complexe. Ses différentes variantes invitent à différencier les Allemands selon leur statut au Chili ${ }^{2}$. Les Deutschen sont des «Allemands » qui passent un temps délimité au Chili. Il peut s'agir du personnel diplomatique, de religieux, de scientifiques ou de voyageurs. Les Chile-Deutschen ou «Allemands du Chili », sont en revanche des citoyens Allemands, nés en Allemagne, qui conservent leur nationalité allemande, ne faisant que transiter par le Chili, où ils vivent cependant de manière prolongée ou définitive. Il s'agit des marchands d'import-export, des agents de compagnies maritimes, des banquiers, des hommes d'affaires, des docteurs et professeurs, des ingénieurs des mines et des industriels, mais également d'une main d'œuvre ouvrière ou semi-industrielle, dans les villes commerçantes de Valparaíso, Santiago et Concepción ou des régions minières du Nord. Enfin, les Deutschchilenen, les «Germano-chiliens » ou les Deutschstämmigen Chilenen ou Chilenen deutscher Herkunft, les «Chiliens d'origine allemande », désignent le groupe des immigrés Allemands au Chili, mais aussi leurs descendants. Ces derniers ont la nationalité chilienne, sont de langue maternelle espagnole, mais leur origine allemande reste identifiable par leur nom, voire leur apparence physique. Entre les Chile-Deutschen et les Deutschchilenen, Georg Young identifie un rapport proportionnel constant de deux-tiers pour un tiers en faveur des seconds ${ }^{3}$. Dans les années 1930, on compte en effet 9000 Chile-Deutsche pour 20000 à 30000 Deutschchilenen $^{4}$. A la même époque en Argentine, les Deutschargentinen, ou «Germano-argentins », sont estimés à 200000 individus et Argentina-Deutschen, ou «Allemands de l'Argentine», à 65000 . Au Brésil, les Deutschbrasilianen à 700000 et les Brasil-Deutschen à 95 000. Jean-Pierre Blancpain signale en effet des chiffres d'entrées approximatifs de 200000 Allemands pour le Brésil et 110000 en Argentine au XIX ${ }^{\mathrm{e}}$ siècle $^{5}$.

Dérisoire donc que cette immigration allemande en direction du Chili, mais si importante quant à ses conséquences. Rien n'est plus vrai que cette expression de Jean-Pierre Blancpain : «Au Chili, les Allemands ne se comptent pas, ils se pèsent». En effet, la présence et l'influence de l'immigration allemande au Chili est de nos jours encore perceptible, en particulier au Sud du pays, où l'on entend parler allemand. La culture et les traditions sont également préservées, à travers

\footnotetext{
${ }^{1}$ A. Lübke, „Welch ein Unterschied aber zwischen Europa und hier... “ Diskurstheoretische Überlegungen zu Nation, Auswanderung und kultureller Geschlechteridentität anhand von Briefen deutscher Chileauswanderinnen des 19. Jahrhunderts. Frankfurt am Main, London, IKO-Verlag, 2003, p. 13.

${ }^{2}$ G. Young, The Germans in Chile, Op. Cit., pp. 11-13.

${ }^{3}$ Ibid., p. 17.

${ }^{4}$ I. Wojak, Exil in Chile: Die deutsch-judische und politische Emigration wahrend des National socialismus, 1933-45, Berlin, Metropol Verlag, 1994, p. 130.

5 J.-P. Blancpain, Les Allemands au Chili, Op. Cit., p. 185.
} 
l'éducation, dans les écoles allemandes, et les institutions et associations, telles que l' "association germano-chilienne », le Deutsch-chilenischer Bund ou Liga chileno-alemana. Aujourd'hui, le Chili est l'un des pays étrangers qui compte, proportionnellement à sa population, le plus grand nombre d'écoles allemandes, les Deutsche Schule ${ }^{l}$. Or, dans le maintien de l'identité allemande au Chili est souvent mentionné le rôle des femmes. Ce sont elles qui enseignent la langue aux enfants, cuisinent les plats typiques et décorent la maison à la manière traditionnelle, expliquent brièvement les ouvrages. A travers cette évocation surgit alors une réalité encore peu étudiée : l'expérience migratoire de femmes allemandes au Chili.

\section{2. ... et les Allemandes au Chili ?}

«Sans aucun doute, l'émigration n'est pas exclusivement un problème masculin, dans la mesure où il a concerné aussi pour des décennies les rêves, les sacrifices, le labeur et l'intelligence de millions de femmes ", rappelle Paula Zaldivar, qui retrace l'expérience migratoire d'Italiennes au Chili au XX ${ }^{\mathrm{e}}$ siècle $^{2}$. Pourtant, nombreuses sont les études sur l'immigration allemande au Chili qui n'évoquent tout simplement pas les femmes et conjuguent au masculin : l'émigré, l'immigré, le migrant, et ici, l'Allemand et le Germano-chilien semblent être les uniques acteurs de cette histoire. L'expérience migratoire des Allemandes immigrées au Chili, mariées ou célibataires, est à peine mentionnée, si ce n'est au moment d'évoquer la vie familiale et privée, comme si la sphère domestique était la seule où la femme tenait un rôle digne d'intérêt... comme si la femme était un «supplément» à l'histoire générale, ironisait Virginia Woolf ${ }^{3}$. Le seul travail qui fait explicitement référence à la présence des femmes dans l'immigration allemande au Chili est celui du médecin Alfredo Neumann Kuschel. Il s'agit de la retranscription d'une intervention donnée en 1978 dans un établissement thermal du Sud du Chili ${ }^{4}$. En réalité, le travail de «réhabilitation» n'est qu'un vœu pieux. Sur les vingt-six pages de l'essai, vingt-et-une sont consacrées à un exposé général de l'histoire de l'émigration allemande, dont quatorze à une présentation générale des «pères » de la colonisation tels que Philippi ou Pérez Rosales, donc des hommes. A la vingt-etunième page, l'auteur annonce qu'il traitera le sujet. Il insiste longuement sur le manque de sources et d'informations, mais appelle à « reconnaître l'importance du rôle de la femme, toujours aux côtés de l'homme ", donnant un vibrant discours sur le soutien qu'elle représente, notamment dans le «partage des bons et mauvais moments », mais sans jamais fournir la moindre donnée historique. Il termine enfin par un portrait de la femme allemande, qui participa aux travaux de

\footnotetext{
${ }^{1}$ Cf. DS Chile : http://www.dschile.cl [consulté le 23 octobre 2007]. Sites des écoles allemandes au Chili.

${ }^{2}$ Paula Zaldívar Hurtado, Italia en sueños: identidad, imágenes y recuerdos de quince mujeres italianas en Chile, Santiago de Chile, Artecien/CIES-Roma, 1994, p. 21 : "Sin duda, la emigración no es exclusivamente un problema masculino, puesto que también ha involucrado por decenias los sueños, los sacrificios, la laboriosidad y la inteligencia de millones de mujeres".

${ }^{3}$ Virginia Woolf, Une chambre à soi, Paris, Denoël, 1995, 171 p.

${ }^{4}$ A. Neumann Kuschel, Presencia de la mujer en la Inmigración Alemana en el Sur de Chile. Algunos antecedentes históricos, Trabajo presentado en el Seminario de Termas de Puyehue, 4 de octubre de 1978.
} 
défrichage, au nettoyage et à la préparation du sol, à la mise en terre des premières semences, à la construction de la maison, l'éducation et la protection des enfants, la confection des vêtements, la cuisine et notamment la constitution des premiers stocks pour l'hiver, le nettoyage des laines et des premiers ovins...

«Faut-il alors s'étonner que les physionomies de ces femmes, que nous avons pu voir sur les photographies de ces premiers temps, paraissent dures, les lèvres serrées, les traits contractés, graves et le regard pénétrant et empli de la force intérieure qu'elles ont dû opposer aux multiples difficultés, au travail épuisant et aux malheurs, et de la volonté ferme de survivre et de dominer le cruel destin ?» ${ }^{1}$.

C'est la femme qui permet le maintien de la tradition, cultive les valeurs spirituelles, soutient le noyau familial, encourage tout le monde les longues nuits d'hiver, chante les chansons populaires, joue de la cithare, de l'harmonica ou du clavecin, qui prie également pour la famille, poursuit l'auteur. Au milieu du texte, il formule cette proposition : «Nous profitons de cette occasion pour donner l'idée à quelqu'un de rassembler toutes les informations et les antécédents qui se réfèrent à la femme depuis les premiers moments de la colonisation à nos jours $»^{2}$.

Le travail de Neumann Kuschel souffre, certes, d'un manque de rigueur historique, mais présente l'intérêt de pointer clairement, pour la première fois, un manque historiographique notoire. L'auteur ne prétend pas le combler mais bien ouvrir un chemin d'étude. En outre, ses descriptions invitent à s'interroger sur le discours qui est produit sur les Allemandes au Chili. Les images construites sur les femmes émigrées, migrantes et immigrées permettent de comprendre, en effet, les raisons de leur absence voire exclusion de la recherche historiographique. Trente ans plus tard, force est de constater que l'appel de Neumann Kuschel n'a toujours pas suscité de vocation. Ce travail espère donc en constituer une réponse partielle

\subsection{Méthodes, objectifs et problématiques de la recherche}

Il convient d'abord de définir les concepts sur lesquels s'appuient cette recherche, et en premier lieu, celui de migration. La migration se définit par «le fait de se mouvoir d'un espace d'origine à un espace d'accueil et de s'y installer pour une durée plus ou moins longue ${ }^{3}$. Plus que de phénomènes migratoires, on parlera de «processus » migratoire, à double sens, individuel et historique, comme le rappelle Georges Dupeux :

\footnotetext{
${ }^{1}$ A. Neumann Kuschel, Op. Cit., p. 23 : «Es de extrañarse entonces que la fisionomías de las mujeres que hemos tenido la oportunidad de ver en fotografías de esos primeros tiempos aparezcan duras, con los labios apretados, las facciones contraídas, serias y la mirada penetrante denotando la fuerza interior que han tenido que oponer a las múltiples dificultades, el trabajo agotador, las desgracias, con el firme deseo de subsistir y de dominar el cruel destino ?".

${ }^{2}$ Ibid., p. 24 : "Queremos aprovechar la oportunidad para dejar lanzada la idea de que alguien se ocupe de recoger todos los datos y antecedentes que se refieren a la mujer desde los primeros momentos de la colonización hasta nuestros días".

${ }^{3}$ C. Catarino et M. Morokvasic, « Femmes, genre, migration et mobilités » [en ligne], Revue Européenne des Migrations Internationales, 21-1/2005, Femmes, genre, migration et mobilités, pp. 7-27. Accessible à l'URL : http://remi.revues.org/document2534.html [consulté le 23 juin 2008]
} 
«[Le processus migratoire] couvre aussi bien l'individu de son lieu de résidence vers une communauté voisine qui lui offre du travail que le grand voyage intercontinental du groupe conscient et organisé. D'ailleurs, cette notion de processus ne s'applique pas qu'aux personnes qui y participent, elle s'applique aussi bien au déroulement temporel de ces migrations » ${ }^{1}$.

Une migration s'étudie donc, au niveau individuel comme collectif, dans sa dimension temporelle. C'est une « aventure qui est souvent collective... [mais] pourtant toujours particulière », soulignent Pierre Milza et Emile Témine ${ }^{2}$, invitant à prendre en compte les deux aspects du phénomène. Il y a bien un avant et un après de la migration, ce qui suppose de s'interroger sur l'entre-deux, temporel et spatial, qui marque toute expérience migratoire. Philippe Rygiel définit le migrant comme « le membre d'un groupe défini par son exterioricité à la société hôte, que symbolise le lien qui le rattache à un autre territoire que celui de la nation $»^{3}$. Il est un personnage qui fluctue en effet entre ces deux repères spatio-temporel, le pays de l'avant et le pays de l'après, tout comme son identité.

Cette identité s'affirme fortement chez les Allemandes immigrées au Chili dans le sens d'un souci constant de transmission et de conservation des traditions du pays d'origine. Notre intérêt s'est dans un premier temps centré sur le rôle de transmission et de conservation des traditions qu'ont joué les femmes. Ce dernier s'exprime par des activités concrètes comme la cuisine, la décoration intérieure et le maintien de la maison, l'apprentissage de la langue aux enfants. Ces réalités sont relativement bien documentées, contrairement à ce que pensait A. Neumann Kuschel. On en trouve trace non pas tellement dans les documents officiels, comme les archives des ministères ou des intendances chiliennes, mais dans les propres récits de ces femmes. Les Allemandes du Chili ont écrit des lettres, des journaux de vie et des souvenirs, autant de textes produits à partir de leur condition de femmes immigrées.

Compte tenu de la richesse de ce corpus de sources, il est apparu légitime, dans un second temps, d'étudier l'expérience de ces migrantes en elle-même, sans la limiter à leur rôle de gardiennes des traditions. En réalité, avec cette unique perspective, nous nous serions faits les avocats des théories patriarcales et libérales qui limitent la femme à un rôle de «gardienne de l'ordre et de la morale », comme mère et éducatrice des générations futures, dédiée «aux autres » ${ }^{4}$. L'expérience de ces femmes est suffisamment riche à elle seule pour mériter une recherche. En particulier, le travail qu'elles fournissent en contexte d'immigration constitue une donnée fondamentale du réaménagement des rôles sexuels au sein du couple, de la famille et de la communauté. Il convient d'en comprendre les circonstances, les enjeux et les conséquences, notamment en termes d'émancipation et d'intégration. Étudier une expérience de vie invite aussi à s'intéresser aux

\footnotetext{
${ }^{1}$ G. Dupeux, «Rapport général » dans Les migrations internationales de la fin du XVIIIe à nos jours, Paris, Editions du CNRS, 1980, p. 2.

${ }^{2}$ P. Milza et E. Témine, «Français d'ailleurs, peuple d'ici » dans Témine, Marseille Transit, Les passagers du Belsunce, Paris, Autrement, 1995, p. 4. Cités dans Green, p. 104.

${ }^{3}$ P. Rygiel, «Introduction» dans Natacha Lillo, Philippe Rygiel, Images et représentations du genre en migration. Mondes atlantiques $X I X^{\circ}-X X^{\circ}$ siècles. Actes de l'Histoire de l'Immigration, 7/2007, Paris, Publibook Université, 2007, p. 13.

${ }^{4}$ Carole Pateman, The Disorder of Women. Democracy, Feminism and Political Theory, Stanford, 1989, p. 25 .
} 
productions de l'esprit, aux discours et représentations mentales. Michel de Certeau rappelle en effet que l'historiographie, «l'écriture de l'histoire », porte en elle-même le paradoxe - et presque l'oxymoron - de mettre en relation deux termes antinomiques : le réel et le discours, qu'elle a pour tâche d'articuler ${ }^{1}$. Les textes des immigrées allemandes au Chili mettent en mots les représentations que ces femmes ont d'elles-mêmes, de la communauté, du pays d'immigration mais aussi du pays d'émigration. Ces écrits sont ainsi le creuset d'une identité nationale et culturelle, individuelle et collective, construite sur les concepts d'ethnicité, d'altérité, de communauté, de nationalité, de citoyenneté et de genre. Pour sonder cette construction identitaire, la correspondance, activité régulière que mènent les Allemandes du Chili, est un document de travail intéressant, comme «lien» constant à la patrie et à la communauté qui l'incarne, la famille ${ }^{2}$. Elle participe à la régénération de l'identité nationale et culturelle, une identité toujours en mouvement. Les textes apparaissent ainsi, dans leur ensemble, comme un réservoir de références fondamentales de la culture germano-chilienne.

Un groupe se situe au centre de l'étude : les Allemandes du Sud du Chili, c'est-à-dire de Valdivia à Puerto-Montt. Il existe également une émigration féminine à Valparaiso, dans le contexte du négoce international. Il s'agit d'épouses de commerçants qui émigrent temporairement, et leur perspective reste le retour à la patrie. Leurs textes ne revêtent donc pas les mêmes enjeux que ceux des immigrées dont la perspective est de refaire leur vie à l'étranger et d'y construire un avenir pour leur descendance. Le choix méthodologique n'empêche pas cependant les comparaisons avec les Allemandes de Valparaiso. La perspective comparative de ce travail est en réalité multiple. «Le champs des études migratoires se prête particulièrement bien à cet examen, explique Nancy Green. [...] L'immigration en elle-même est une situation de comparaison $»^{3}$. Les immigrées établissent ainsi une comparaison constante entre leur passé et leur présent, entre l'ancien et le nouveau pays, mais également à la société d'accueil et en particulier à ses femmes. Un second niveau de comparaison introduit la dimension diachronique de l'historien, notamment entre les différentes générations d'immigrées, afin d'analyser l'évolution des formes d'intégration et de maintien des traditions. Enfin, une troisième perspective consiste à comparer à d'autres groupes ethniques d'immigrées. Un parallèle avec les communautés espagnoles, basques, françaises, italiennes ou encore anglaises du Chili permettrait de dégager d'autant mieux les spécificités de la communauté allemande. Ainsi, comme le signalait Marc Bloch, « la comparaison a deux fonctions importantes :

\footnotetext{
${ }^{1}$ M. de Certeau, L'écriture de l'histoire, Paris, Gallimard, 1975, p. 5.

2 "Ecrire des lettres, c'est tisser des liens", $C f$. F. Simonet-Tenant, «Enquête sur la pratique des lettres personnelles»dans Brigitte Diaz et Jürgen Siess (dir.), L'épistolaire au féminin : correspondances de femmes, XVIIIe-XXe siècle, Caen, Presses Universitaires de Caen, p. 243.

3 N. L. Green, "L'Histoire comparative et le champ des études migratoires» dans Annales ESC, 6/novembre-décembre 1990, p. 1335.
} 
rechercher et comprendre les aspects spécifiques et généraux de chaque phénomènes, mais aussi aider à comprendre les causes et les origines des phénomènes $»^{1}$.

En outre, la comparaison en histoire des femmes est nécessaire. Il ne s'agit donc pas de faire l'histoire de «la» femme allemande immigrée au Chili. Gisella Bock appelle en ce sens à déconstruire la catégorie «femme», érigée par les féministes comme une catégorie sociale indistincte, celle de «l'autre sexe » et à interroger «les différences parmi les différences », pour proposer «une étude historique de l'altérité, des différences et des « inégalités entre les femmes elles-mêmes $»^{2}$. Comme l'histoire étudie les relations entre les hommes, il apparait nécessaire de rendre visible les relations de solidarité et de conflit entre les femmes elles-mêmes. Carmen Ramos avertit aussi que «la femme n'existe pas, mais il existe des femmes appartenant à divers groupes sociaux, à diverses ethnies, qui répondent à divers antécédents sociaux, familiaux et idéologiques spécifiques » ${ }^{3}$. De ce point de vue, les Allemandes émigrées au Chili offrent une grande variété de profils et de situations.

Nancy Green dégage ainsi trois modèles de comparaison dans le champ des études migratoires. La comparaison « linéaire » consiste à suivre l'émigré(e) de son lieu de départ à celui d'arrivée, de le comparer en quelque sorte entre un avant et un après. Le modèle «convergent » consiste à étudier les différentes populations immigrées d'un espace, par exemple une ville ou un pays, et ainsi déterminer des « succès » et des « échecs » quant à l'intégration et la mobilité sociale, deux notions toujours construites par comparaison. Les Allemands sont ainsi réputés moins intégrés que les Espagnols, et parmi eux, les Protestants que les Catholiques. Une analyse à plus fine échelle peut distinguer également les émigrés d'une même origine nationale en fonction de leur région d'origine. Enfin, les rares études construites sur le modèle divergent consistent à suivre un même groupe dans ses différentes filières migratoires. Les divergences ou similarités sont alors plutôt expliquées en fonction du pays d'arrivée. La perspective comparatiste de ce travail tente donc de mêler ces trois approches, dans les limites que présente la bibliographie disponible.

\subsection{Plan de lecture}

Cette étude propose, dans un premier temps, un aperçu historiographique sur le thème des Allemands au Chili. La place qui y est accordée est relativement importante et nécessaire. C'est un travail qui n'a jamais été réalisé en profondeur. Cette analyse montre qu'à l'époque où se sont réalisés les premiers travaux, les préoccupations propres à l'histoire des femmes et du genre

\footnotetext{
${ }^{1}$ Citré dans N. L. Green, « L’histoire comparative », Op. Cit., p. 136.

${ }^{2}$ G. Bock, "La Historia de la mujer y la historia de Género: aspectos de un debate internacional", Historia Social, 9/Invierno 1991, p. 57 : "un estudio histórico de la alteridad, de las diferencias y de las desigualdades entre las propias mujeres".

${ }^{3}$ C. Ramos Escandón, "La Nueva Historia, el feminismo y la mujer", en Género e historia : la historiografía sobre la mujer, 1992, p. 11 : "la mujer no existe, sino que existen mujeres pertenecientes a diversos grupos sociales, a diversas etnias, que responden a diversos antecedentes sociales, familiares e ideológicos específicos".
} 
n'avaient pas encore fait leur chemin. C'est en prenant appui sur un courant historiographique récent, analysant les femmes migrantes et plus généralement les thèmes de genre et migration, qu'a pu se réaliser cette recherche, courant dont nous proposons une analyse critique. Cette première partie se clôt sur une présentation détaillée des sources utilisées, les écrits des femmes immigrées. Dans un second temps, le travail s'attache à préciser les contours du groupe pour en déterminer et comprendre les caractéristiques. Ce chapitre avance prudemment un chiffre des Allemandes émigrées au Chili, les différencie par leur origine géographique, socio-économique et culturelle, mais également par leur état civil. Les Allemandes seules qui émigrent au Chili trouvent ici enfin une place et leur cas fait l'objet d'une étude spécifique. Enfin, nous tentons de comprendre quelles sont les motivations qui poussent à l'émigration, et comment la catégorie du genre peut illuminer le processus de décision. Après avoir défini les contours du groupe, il est possible de retracer l'expérience-même de ces migrantes. Le récit de ces «vies croisées » se présente sous forme chronologique, en commençant par le voyage, expérience marquante pour chacune de ces émigrées. Une fois l'installation réalisée, le travail féminin, le rôle maternel et religieux, la sociabilité des femmes enfin, reçoivent des contenus différents dans le contexte de la migration.

Enfin, une dernière partie s'intéresse aux productions écrites de ces femmes, pour démontrer que dans les lettres d'immigrées, c'est tout un ensemble de représentations mentales constitutives de l'identité, qui est un jeu. Le discours national du $\mathrm{XIX}^{\mathrm{e}}$ siècle et ses systèmes de représentations constituent un référent central pour ces épistolières. Ces dernières ne se positionnent pas seulement au sein de la communauté nationale d'émigrés allemands, mais aussi, résultat d'un discours occidental sur les sexes, le genre et le travail, comme femme, comme femme immigrée. 


\section{TRACES HISTORIOGRAPHIQUES}

L'émergence des migrations dans la recherche historique est relativement récente et date de la seconde moitié du $\mathrm{XX}^{\mathrm{e}}$ siècle. Auparavant, l'historiographie était fortement marquée par le «paradigme national ». En effet, la naissance de la discipline historique en Europe fut étroitement liée à la construction des États-nations. Les frontières nationales déterminèrent alors longtemps les limites intellectuelles, ce qui excluait d'emblée une étude des migrations, surtout internationales. «Les minorités et les immigrés étaient vus comme une offense à [1'] idéal d'une nation homogène et d'une pureté ethnique ou raciale » explique Rainer Ohliger ${ }^{1}$. De la même manière, ceux qui partaient trahissaient - «Il n'y a ni richesse ni force que d'hommes » disait Jean Bodin. Par conséquent, les émigrés ne méritaient plus de faire partie du grand récit national. Après la Seconde Guerre mondiale, la croissance rapide de l'économie, la décolonisation et le développement des pays du Tiers-monde ont intensifié les migrations internationales, amenant ainsi les observateurs à s'interroger sur leur passé. Parallèlement, l'émergence de l'histoire sociale, mettant fin à l'hégémonie de l'historicisme et de sa concentration sur l'Etat et la politique, permit l'ouverture intellectuelle des frontières. Dans un premier temps, les recherches portèrent massivement sur l'émigration européenne aux États-Unis, avant de s'élargir à d'autres espaces, notamment l'Amérique latine. Dans ce contexte, l'émigration allemande au Chili a fait l'objet d'études historiques dans les années 1970. Elle fut d'abord interprétée comme le déplacement d'une main d'œuvre au sein d'un marché du travail international gouverné par la loi de l'offre et de la demande. La lecture historiographique était par conséquent fortement androcentrée. La variante féminine de ce courant peut être analysée à l'appui d'un corpus historiographique récent sur les rapports entre genre et migration.

\subsection{Historiographie des migrations allemandes au Chili}

L'émigration ou immigration allemande au Chili est l'objet d'une abondante littérature, d'inégale qualité. Il existe une importante bibliographie d'ordre " commémoratif », essentiellement germano-chilienne, des publications de vulgarisation et finalement, peu de textes scientifiques.

\subsubsection{Les ouvrages commémoratifs germano-chiliens}

Une grande partie des ouvrages sont d'ordre que l'on pourrait qualifier de «commémoratif » ou «auto-complaisant», provenant de milieux germano-chiliens, c'est à dire de descendants d'immigrés allemands au Chili, qui écrivent en allemand et proposent une lecture providentielle du

\footnotetext{
${ }^{1}$ R. Ohliger, «L'histoire de l'immigration en Allemagne : des défis historiographiques et culturels », Hommes \& Migrations, $\mathrm{n}^{\circ}$ 1255, mai-juin 2005, p. 54.
} 
processus qu'ont connu leurs aïeux. Il ne s'agit pas cependant de nier la valeur documentaire de ces écrits. Ils sont loquaces sur les acteurs et les faits de l'époque et témoignent du souci de perpétuer la mémoire de l'émigration, en exaltant le sentiment d'appartenance commune. Il s'agit d'une bibliographie relativement datée, concentrée sur les années $1890-1930^{1}$, mais qui trouve ses prolongements directs dans des éditions commémoratives plus récentes, à l'occasion d'anniversaires des colonies, des écoles ou des associations germano-chiliennes ${ }^{2}$.

\subsubsection{Les premières publications de sources}

$\mathrm{Au}$ sein de cette bibliographie, se distinguent les publications de documents historiques tels que correspondances, journaux, généalogies ou mémoires, et notamment les Geschichtliche Monatsblätter, publiés de 1916 à 1918 à Osorno par Georg Schwarzenberg. Son œuvre est poursuivie par sa fille Ingeborg (1914-2005), épouse Schmalz, qui dirige la publication des six volumes des Dokumente zur Geschichte der deutschen Einwanderung/ Documentos para la historia de la inmigración Alemana, de 1970 à 1973. Généalogiste reconnue, Ingeborg Schwarzenberg a publié dans diverses revues spécialisées, notamment la Revista de Estudios Históricos de l'Institut chilien de recherches généalogiques, et a constitué un fonds de quelques cent-quarante livres de registre de données, un fichier généalogique et une bibliothèque personnelle spécialisée ${ }^{3}$. Elle a également collaboré, non sans divergence de point de vue, avec le représentant d'une autre grande famille germano-chilienne, Emilio Held Winkler (1898-1996), auteur ou éditeur de dix-huit publications contenant plus de cinq mille documents originaux ${ }^{4}$. Son legs aux archives qui portent son nom est divers : liste des passagers de bateaux avec noms des premiers immigrants, liste des premiers mariages célébrés après l'arrivée au Chili, certificat de naissance des premiers enfants nés dans la nouvelle patrie, correspondances originales de familles d'Allemagne et du Chili, journaux de vie, vieilles Bibles, arbres généalogiques, livres, journaux, etc. Le travail de

\footnotetext{
${ }^{1}$ Entre autres : H. Kunz, Chile und die deutschen Kolonien, Leipzig, Comissions-Verlag, 1891; J. Unold, Das Deutschtum in Chile, München, J.F. Lehmann, 1900; Die deutsche Arbeit in Chile, Deutscher Wissenschaftlicher Verein zu Santiago, Santiago de Chile 1910 et 1913; K. Bauer, Das Gewissen der Stadt, 1925 ou Helden der Arbeit, Concepción, Verlag des Wissenschaftlichen Archiv von Chile, 1929; 75 Jahre Deutschtum in Llanquihue, Deutsch-chilenisches Bund, Santiago de Chile, 1927 ou 75 Jahre Deutsche Schule Valdivia, Valdivia, Imprenta Borneck, 1934.

${ }^{2}$ Par exemple : E.Held Winkler, H. Schuenemann, C. von Plate (dir.), 100 Jahre deutsche Siedlung in der Provinz Llanquihue, Santiago, Verlag Condor, 1952 et plus récemment, Pioneros del Llanquihue, Edición Conmemorativa, 1852-2002, Liga Chileno-alemana, Santiago, 2002, 310 p. On observera le glissement de l'allemand au castillan entre les deux éditions, sans doute pour toucher un public plus large, étant donné le recul de l'allemand comme langue maternelle au sein de la communauté germano-chilienne.

${ }^{3}$ Sa collection a été en grande partie léguée à la Biblioteca e Archivo Emilio Held Winkler du DCB pour constituer l'Archivo genealógico Ingeborg Schwarzenberg de Schmalz. Le fichier de notices généalogiques a été entièrement digitalisé pour être converti en un catalogue électronique.

${ }^{4}$ Entre autres : Plano catastral del norte y oeste de la Colonia de Llanquihue (1930), Plano general con subdivisión de tierras desde Puerto Montt a Osorno (1933), 100 Jahre Deutsche Siedlungin der Provinz Llanquihue (1952), Documentos sobre la colonización del sur de Chile (1970), Cien años de navegación en el lago Llanquihue (1981), Ensayo histórico de Puerto Octay (1986), Crónica de las primeras escuelas fundadas en la colonia de Llanquihue, Cementerios de la colonia de Llanquihue (1988), Antecedentes históricos de la familia Held (1993) et plusieurs Arboles genealógicos.
} 
compilation d'Emilio Held Winkler est aujourd'hui d'une richesse inestimable, mais ses analyses sont le fruit d'un historien amateur, qui n'est pas toujours très fiable dans ses affirmations, inventant parfois des faits, ce que lui reprochait Ingeborg Schwarzenberg ${ }^{1}$. Ainsi, entre éditions commémoratives et publications de sources, jusqu'aux années 1970, la thématique des Allemands au Chili a fait l'objet d'un traitement interne, peu historicisé. Il s'avère que les premières thèses ont été réalisées par des historiens qui n'étaient ni Chiliens, ni Allemands. Le sujet méritait peut être en effet une prise de distance radicale.

\subsubsection{Les premières thèses d'historiens}

La première grande thèse entreprise par un historien de métier est celle du Français Jean-Pierre Blancpain, héritier de l'Ecole des Annales $^{2}$. Réalisée sur sept années, elle recouvre une bibliographie quasi-exhaustive, avec une analyse minutieuse des archives nationales et privées ${ }^{3}$. Blancpain semble avoir tout lu et abordé tous les aspects de la question: quantitatifs, démographiques, sociaux, culturels et politiques. Maîtriser le français s'avère donc être un avantage considérable pour travailler sur les Allemands au Chili, d'autant plus que la traduction castillane en réduit considérablement la portée ${ }^{4}$. Le travail de Blancpain prétend couvrir une période de 1816 à 1945, débutant donc bien avant les projets d'émigration organisés au Sud du pays, qu'il intègre à la suite des voyages scientifiques, des missions religieuses et des relations économiques entre l'Allemagne et le Chili. Blancpain ne consacre cependant que vingt-cinq pages à la période de l'entre-deux-guerres, évitant soigneusement la question du lien entre les colonies germano-chiliennes et le national-socialisme, traité en une vingtaine de lignes. La période 19181945 est exclusivement consacrée à la fondation des dernières colonies allemandes, Peñaflor en 1929, La Serena en 1956. On peut regretter en outre l'intégration, dans le récit, de la création dans les années 1960 de la Colonia Dignidad, dépassant ainsi largement le cadre chronologique fixé pour traiter un tout autre type d'émigration, dont la spécificité n'est pas nettement dégagée. Blancpain évite en réalité dans son récit toute polémique, cherchant à démontrer le caractère avant tout socioculturel de la minorité allemande au Chili, marquée par une «sensibilité originale». Il

\footnotetext{
${ }^{1}$ Malgré l'enthousiasme de la dédicace de son ouvrage ( $«$ A Monsieur Emile Held, qui joint à l'énergie du pionnier la patience et la passion du savant [...] »), Jean-Pierre Blancpain lui adresse également une critique impitoyable au sujet de sa liste des passagers. Cf. J.-P. Blancpain, Les Allemands au Chili, Op. Cit. p. 203, note de bas de page 62 .

${ }^{2}$ Ibid. La préface est de Pierre Chaunu.

${ }^{3}$ Comme d'autres latino-américanistes, tel François Chevalier ou Jean-Pierre Berthe au Brésil, Blancpain a passé de nombreuses années au Chili comme professeur d'histoire-géographie, au lycée de l'Alliance française de Santiago. Il a consulté la bibliothèque privée d'Emilio Held, dont le livre de visite mentionne ses quatre séjours : février 1967, septembre 1967, février 1968 et juillet 1968. Held précise que Blancpain a toujours été accompagné de son épouse Anne, qui lui traduisait de l'allemand les documents et prenait les notes sur sa machine à écrire, à l'image de ces femmes d'historiens de l'ombre (Bear, Braudel, Chaunu) qu'évoque F. Thébaud dans Écrire l'histoire des femmes et du genre, Paris, ENS Éditions, 2007, p. 39.

${ }^{4}$ J.-P. Blancpain, Los Alemanes en Chile (1816-1945), traduction de Luis Enrique Jara. Santiago, Ediciones Pedagogicas Chilenas y Editorial Universitaria, 1985. L'ouvrage français de 1200 pages est réduit à quelques 200 pages castillanes.
} 
explique la réticence à l'assimilation et la persévérance de la culture, particulièrement à Valdivia et Llanquihue, comme résultat de l'isolement géographique des colonies, un isolement de double dimension : au niveau national d'abord, par rapport à la région centrale du Chili dominée par Santiago et Valparaiso, mais aussi au niveau local, par la distance au bourg qui reste importante dans des régions australes chiliennes où, jusqu'à la fin du XIX ${ }^{\mathrm{e}}$ siècle, les communications locales sont inexistantes ou impraticables l'hiver. Dans ce contexte, le souvenir de la vieille patrie et de ses coutumes constitue un lien fort pour ces néo-arrivants. Ainsi, selon Blancpain, le Deutschtum relèverait finalement davantage d'un sentiment strictement culturel et non politique ou séparatiste, liée à l'essence spirituelle et nationale des colons qui s'exprime dans la langue, la foi, et à travers l'éducation et les associations. C'est là une vision consensuelle, voire conservatrice du phénomène de l'immigration, qui présente notamment le caractère familial et religieux comme fondamental, vision qui sera largement critiquée par les publications postérieures ${ }^{1}$.

La seconde thèse importante sur les Allemands au Chili est celle de l'Américain Georg Young, publiée la même année que celle de Blancpain, et portant le même titre ${ }^{2}$. L'intérêt du travail de Young est de dégager des lignes de rupture, là où justement Blancpain cherche à homogénéiser. Il insiste particulièrement sur les divergences, nées directement de la diversité du courant migratoire, tandis que Blancpain entretient le mythe d'une unification autour de la langue et des traditions, peut être parce qu'il évite trop facilement dans sa thèse, qui se veut pourtant globale, de traiter des Allemands de Valparaiso, manque non mineur. A la différence de statut entre Chile-Deutsche et Deutschchilenen se greffe une fracture sociale évidente entre «d'une part, les gens d'affaires et de profession, nés en Allemagne, issus d'une classe moyenne voire élevée, bien éduqués, vivant en ville et de l'autre, des gens du petit commerce, de l'artisanat ou de l'agriculture, nés au Chili, issus d'une classe ouvrière ou moyenne, moins bien éduqués, et vivant en province ${ }^{3}$, explique Young. La différence religieuse du groupe n'est pas non plus à négliger. Le clivage religieux est notable autour du lac de Llanquihue, où cohabitent les protestants et leurs descendants de Hesse, du Wurtemberg, de Saxe et les Catholiques de Westphalie, Silésie et Bohême, et leurs deux systèmes scolaires parallèles. Sur ce clivage social et religieux, se greffent des divergences d'orientation politique, composant trois groupes : les Chile-Deutsche libéraux, qui nourrissent leurs intérêts dans le commerce extérieur et la prospérité économique, les Deutschchilenen protestants radicaux et anticléricaux, qui embrassent les intérêts de classe moyenne des affaires et les Deutschchilenen catholiques et conservateurs. Enfin, remarque Young, il est incontestable que les clivages religieux,

\footnotetext{
${ }^{1}$ Voir la sévère critique de J. Ojeda Ebert, Deutsche Einwanderung und Herausbildung der chilenischen Nation (1846-1920), Nürnberg, Fink Verlag München, 1984, pp. XII-XIII, qui reproche à Blancpain une «fuite dans le culturel» («Fucht ins Kulturelle») pour éviter soigneusement les questions politiques sensibles.

${ }^{2}$ G. Young, The Germans in Chile, Op. Cit. Curieusement, il semblerait que Blancpain et Young aient réalisé leur thèse sur le même sujet et à la même époque, sans jamais se connaître. D'ailleurs, ils ne se citent pas.

${ }^{3}$ Ibid., p. 165: «between urban well educated middle-class/upper middle-class German born business and professional people, on the one hand, and provincial less well educated middle-class/working-class Chileanborn small business, artisan or farming people, on the other hand »
} 
politiques et sociaux ont déterminé les modalités du processus d'assimilation. Pour les artisans et travailleurs des villes provinciales et des grandes villes, l'assimilation était plus fréquente. Parmi les catholiques de ces classes sociales, et en réalité de toutes les classes sociales, elle était rapide, plus rapide que pour les protestants ${ }^{1}$. Enfin, parmi les classes hautes et moyennes qui s'allient avec la haute société chilienne, l'assimilation était complète et rapide. Dans le cas de mariage entre protestant et catholique, le protestant se convertit au catholicisme pour intégrer l'éthique de la haute classe sociale chilienne. Finalement, cette étude permet à Young d'identifier le groupe rural protestant des régions australes comme «le cœur réel du Deutschtum chilien $»^{2}$, formant «une communauté ethnique autonome et consciente d'elle même », ce qui motive par ailleurs le choix méthodologique de notre étude ${ }^{3}$. Cette vitalité explique la persistance de la langue allemande à Valdivia, Osorno, Puerto Mont et l'influence allemande qui y est perceptible, notamment dans l'architecture, le système scolaire et les communautés paroissiales évangéliques. Young et Blancpain s'accordent en revanche sur deux facteurs qui ont contribué à la préservation de la culture allemande : l'isolement de la région et sa faible densité démographique à l'arrivée des colons ainsi que leur niveau supérieur d'éducation et d'alphabétisation par rapport à leur environnement. «L'effet de ces deux facteurs, à savoir l'isolement et la supériorité culturelle, a fortement renforcé la propension naturelle d'un groupe d'immigrant à perpétuer son identité culturelle et ethnique » estime Young ${ }^{4}$. Les associations sont le biais privilégié qu'utilise l'auteur pour sonder cette «germanité $»^{5}$. Les communautés germano-chiliennes ont en effet mis en place toute une série d'associations, au premier titre, les Deutscher Verein ou Clubes alemanes, dont certains sont encore actifs aujourd'hui.

\subsubsection{En Allemagne : la redécouverte du national.}

En Allemagne, l'étude historique des communautés germanophones «hors frontières » fut longtemps proscrite par le grand tabou d'après-guerre qui toucha tous les concepts renvoyant à la définition du national ${ }^{6}$. Depuis la fin du XIX ${ }^{\mathrm{e}}$ siècle et jusque dans les années 1930, les ouvrages

\footnotetext{
${ }^{1}$ Sur la différence d'intégration entre Catholiques et Protestants, voir P. Bernedo, « Las Iglesias alemana », $O p$. Cit., p. 80. Un des biais d'intégration souvent évoqué pour les catholiques est le suivi de la messe en latin, langue universelle.

${ }^{2}$ G. Young, The Germans in Chile, Op. Cit., p. 168 : "the very core of Chilean Deutschtum"

${ }^{3}$ Ibid., p. 153: "a self-sufficient and self-conscious ethnic community".

${ }^{4}$ Ibid., p. 154: "The effect of these two factors, i.e. isolation and cultural superiority, was strongly to reinforce the natural proclivity of an immigrant group to perpetuate its cultural and ethnic identity".

${ }_{5}^{5}$ Parmi ces associations, le Bund Chilenischer Buschenschaft (BCB), Deutsch-Chilenische Bund (DCB), Deutsch-Chilenische Industrie- und Handelskammer, Deutsch Schulen und Schulverbände (VdLiCH), les institutions paroissiales, culturelles, sportives, les maisons de retraites, les hôpitaux, la presse germanophone et les nombreuses Deutsche Vereine locales déclinées en associations de pompiers, de femmes, de chant, d'assistance et charité.

${ }^{6}$ Des appellations telles que «Auslandeutscher », «Volksdeutscher $», ~ «$ deutscher Volksgruppen $»$ ou encore «deutsche Minderheiten » sont devenues taboues après 1945. Leur définition a en effet fait l'objet de grandes préoccupations à l'époque national-socialiste et ces termes ont ainsi été puissamment «nazifiés », au point de les rendre inutilisables dans la seconde moitié du $\mathrm{XX}^{\mathrm{e}}$ siècle. $C f$. K. Schobert, Soziale und kulturelle
} 
sur les Allemands au Chili s'appuyaient largement sur ces concepts nationalistes ${ }^{1}$. Cette littérature a alors été considérée comme pré-nazie. Pourtant, si l'émigration allemande au Chili peut en effet s'assimiler à une «colonisation », c'est au sens premier du terme, c'est-à-dire, une mise en valeur de territoires incultivés qu'il faut l'entendre. Jean Roche, étudiant les colonies allemandes du Brésil, rappelle en effet à ce propos :

«Pendant tout le XIX ${ }^{\mathrm{e}}$, coloniser c'est d'une part introduire avec de nouveaux habitants une main d'œuvre introuvable sur place et d'autre part l'employer dans les établissements agricoles où on l'installe [...] En parlant de colonisation allemande, on entend la mise en valeur d'une région $»^{2}$.

Ainsi, en allemand, le Kolonist désigne l'homme qui défriche et cultive la terre. Que l'émigration allemande au Chili ait pu ensuite inspirer des projets pangermanistes de «colonisation», au sens d'expansion territoriale, chose à laquelle se livraient alors les puissances européennes en Asie et en Afrique, est à prendre en compte. Il faut bien souligner cependant que, en ce qui concerne les colonies latino-américaines, de tels projets n'en sont restés qu'au stade du fantasme dans l'imaginaire de nationalistes allemands du XIX ${ }^{\mathrm{e}}$ siècle $^{3}$. Il y a toujours débat sur l'influence de la politique pangermaniste du Reich dans les colonies chiliennes. Patricio Bernedo s'interroge sur la portée des sentiments nationalistes des immigrés allemands, dès les premiers temps de la colonisation ${ }^{4}$. Stefan Rinke soutient qu'un sentiment nationaliste serait né dans les colonies allemandes seulement après l'unification, du fait de la fascination qu'aurait provoquée la puissante patrie dans une sorte de «re-germanisation» a posteriori ${ }^{5}$. Sur ce point le rejoint Jorge OjedaEbert, qui évoque un «patriotisme rétrospectif » suite à 1871 qui favorise le développement dans les colonies de l'idée de nation culturelle qui inclurait tous les germanophones, suisses et autrichiens compris, mais sans réel lien politique étatique ${ }^{6}$. Jean-Pierre Blancpain, quant à lui, a toujours défendu, le caractère uniquement culturel de cette identité allemande, tout comme George Young. Schobert rappelle enfin que les objectifs premiers de l'émigration allemande sont économiques, et non pangermanistes ${ }^{7}$. Cependant, sont apparus au Chili, dans les années 1930, des réseaux, organisations, écrits et journaux, liés directement au parti national-socialiste allemand, le

Intergration am Beispiel der deustchen Einwanderung und Deutschchilenen in Südchile, München, 1983,, p. 191.

${ }^{1}$ Parmi ces concepts, le «Volkstum », qui renverrait aux caractères qui font un peuple (dans ce cas, le «Volkstum » allemand, c'est le «Deutschtum»), ou encore la «Blutverwandschaft», la parenté par le sang, la seule à déterminer l'accès à la nationalité allemande (jus sanginis). Cf. H. Fröschle, Die Deutschen in Lateinamerika, Schiksal und Leistung, Darmstadt, Horts Erdmann Verlag, Tübingen, 1979, p. 15.

2 J. Roche, La colonisation allemande et le Rio Grande do Sul, Paris, Institut des Hautes Etudes de l'Amérique Latine, 1959, p. 3.

${ }^{3}$ J.-P. Blancpain, Les Allemands au Chili, Op. Cit., pp. 178-179.

${ }^{4}$ P. Bernedo, "Impactos económicos y sociales de la inmigración alemana en Valdivia en el siglo XIX" [en ligne], entretien avec Lisette Winkler (1:08:16), réalisé le 20 décembre 2007 à Santiago du Chili. Accessible à l'URL : http://www.archivesaudiovisuelles.fr/1509/introduction.asp?id=1509 [consulté le 14 août 2008].

${ }^{5}$ S. Rinke, « Las relaciones germano-chilenas, 1918-1933», Historia 31/1998, pp. 217-308.

${ }^{6}$ G. J. Ojeda-Ebert, Op. Cit., p. 100.

${ }^{7}$ K. Schobert, Op. Cit., p. 1 : «Deutsche Einwanderung in Chile war in ihrer Zielausrichtung nicht von Nationalismus und Deutschtümelei geprägt. Sie war in vieler Hinsicht denen, die nach Chile aufbrachen, existenznotwendiger Neuanfang - soweit sie bewusst als Einwanderung vollzogen wurde“". 
NSDAP, et qui ne peuvent faire oublier la fascination que le nazisme a exercé sur certains Germano-chiliens, qui devaient donc déjà être sensibles à l'idéologie avant les années 1930. Patricio Bernedo appelle à un travail de fond et d'ampleur sur le sujet ${ }^{1}$.

Publiée en 1979, la synthèse monumentale de Harmut Fröschle sur les Allemands en Amérique latine prétend rompre avec les «tabous» pour restaurer certains concepts sous un jour ethnographique. Le chapitre de Christel Converse sur le Chili vise à donner un aperçu du développement du Deutschtum depuis les débuts de la colonisation ${ }^{2}$. Les références constantes aux ouvrages de Blancpain et Young ne cachent pas qu'il s'agit de rendre accessible à un public germanophone la production historique antérieure, même si Converse peut proposer une étude originale des écoles allemandes, de la langue et du bilinguisme. Son texte souffre cependant d'une tendance téléologique, s'attachant à décrire un processus historique comme inévitable, construit sur l'esprit pionnier des Allemands. Sa chronologie proposée en fin d'ouvrage est, de ce point de vue, éloquente puisqu'elle reconstruit une continuité de l'immigration allemande des conquistadores du $\mathrm{XVI}^{\mathrm{e}}$ siècle aux ouvriers du salpêtre du XIX ${ }^{\mathrm{e}}$, en passant par les fondateurs de brasseries, tanneries et distilleries et les colons du Sud. Les deux Allemands qui ont participé à la conquête du Chili dans les années 1640 au côté de Pedro de Valdivia, associés aux Jésuites allemands chargés ensuite d'évangéliser le pays, se transforment en précurseurs d'une émigration qui les suit de plus de trois siècles ${ }^{3}$.

Relativement éloigné de ce corpus bibliographique, se situe un ensemble d'écrits ethnographiques édités en Allemagne qui s'intéressent à cette «curiosité » que représente les communautés germanophones hors d'Allemagne, à l'image de l'étude de Karl Ilg qui retrace l'évolution différenciée des colonies grâce à une étude doublement comparative, avec l'Allemagne mais aussi entre les différents pays latino-américains récepteurs, comme le Brésil, le Paraguay, l'Argentine, le

\footnotetext{
${ }^{1}$ Sur ce sujet, on renverra à une littérature abondante mais éparse, notamment : C. Gödde, ,„Mit begreiflicher Spannung lauschten wir auf die Echos in der Welt... “Die Perzeption des „Dritten Reiches" in der deutschsprachigen Presse Chiles (thèse), Chemnitz, Allemagne, 2002; C. Converse, The rise and fall of Nazi infuence among the German-Chileans (thèse de doctorat), Ann Arbor, 1990, 2 v; M. Klein, „The Chilean Movimiento Nacional Socialista, The German-Chilean Community, and the Third Reich, 1932-1939”, The Americas, 60-4/2004, pp. 589-616 et "The making of an unlikely chilean fascist: reflections on the intellectual development and political work of Carlos Keller Rueff', Historia, 35/2002, pp. 187-209; O. Gaudig et P. Veit, „El Partido Alemán Nacionalsocialista en Argentina, Brasil y Chile frente a las comunidades alemanas: 1933-1939“ [en ligne], EIAL, 6-2/1995. Accessible à l'URL : http://www.tau.ac.il/eial/VI_2/gaudig_veit.htm [consulté le 31 juillet 2008].

${ }^{2}$ C. Converse, « Die Deutschen in Chile » dans Harmut Fröschle (Hrsg.), Op. Cit., pp. 301-372.

${ }^{3}$ Il s'agit de Bartolomé Blümen, procurateur du territoire chilien, et Peter Leisperberg, alcade de Santiago et plusieurs fois regidor, plus tard Bartolomé Flores et Pedro Lisperguer. Flores s'est consacré à la vitiviniculture et de ses domaines naquit la ville de «Viña del Mar ». Quant aux descendants de Leisperberg, ils sont connus au Chili comme fonctionnaires, capitaines, conseillers, maires et deux ont été Président de la République au XIX ${ }^{\mathrm{e}}$ siècle. $C f$. C. Converse, «Die Deutschen in Chile », Op. Cit., p. 303, K. Götz, Brüder über Land und Meer, Bodensee, Hohenstaufen Verlag, 1967, pp. 325-326 et A. Krebs (dir), Los alemanes y la comunidad chileno-alemana en la historia de Chile, Santiago, Deutsch-chilenischer Bund, 2002, 256 p. [cet ouvrage de vulgarisation, publié par la Liga Chileno-Alemana, en espagnol et en allemand, reprend la même chronologie que Converse]. Sur les jésuites, voir W. Hanisch, Historia de la Compañia de Jesus en Chile. Buenos Aires, Santiago de Chile, Ed. Francisco de Aguirre, 1974.
} 
Venezuela et le Chili, qu'il connaît bien pour les avoir parcouru au cours de cinq expéditions de 1965 à $1977^{1}$. L'ouvrage revêt un aspect largement socioculturel qui échappe à la critique historiographique, adoptant un point de vue proche du monde des valeurs des colons. La première partie recrée de manière vivante leur environnement, leurs comportements, leur monde professionnel et leurs problèmes, mais souffre d'un manque cruel de rigueur, allant jusqu'aux fautes répétées sur les noms d'auteurs ${ }^{2}$, et dérivant dans des formulations lyriques, relatant l'émigration telle une épopée. L'auteur fait part d'une série d'expériences personnelles, décrivant en réalité au lecteur son propre voyage qu'il reconstitue dans un parallèle narratif à l'arrivée des colons. La seconde partie est plus intéressante, se consacrant à analyser l'ethnologie des colons germanophones. Elle expose les modes de vie perpétués par les immigrants, constitutifs de leur identité, à travers la description des formes d'installation, d'alimentation, les costumes et habits, les fêtes nationales, religieuses ou familiales et la situation linguistique.

L'intérêt principal des publications allemandes postérieures porte sur les phénomènes d'intégration sociale $^{3}$. De nombreuses études tentent en effet d'expliquer comment ont pu se maintenir les traditions et la langue allemandes au sein de la communauté germano-chilienne. En 1983, Kurt Schobert publie une thèse de sociologie sur l'intégration sociale et culturelle, en s'appuyant sur l'exemple de l'émigration allemande au Chili ${ }^{4}$. La première partie de l'analyse développe les aspects théoriques s'attachant à définir les concepts tels que assimilation, acculturation et intégration, à dégager les formes et facteurs de l'intégration sociale et culturelle pour proposer en conclusion un modèle schématique des processus d'intégration. La seconde partie consiste en la mise en pratique du schéma théorique proposé à l'exemple germano-chilien. Schobert privilégie l'analyse des associations telles que le Bund Chilenischer Burschenschaften (BCB), les associations juvéniles et les écoles allemandes, du rôle des églises ou encore des stratégies familiales. Il s'agit d'une analyse sociologique qui adopte une perspective historique, dans l'objectif de dégager une «théorie de l'intégration sociale $»^{5}$.

\subsubsection{L'école historique chilienne entre tradition et révision.}

L'intérêt de l'école historique chilienne pour la question des Allemands au Chili est plus tardif et ne se manifeste pendant longtemps encore que dans le milieu germano-chilien. Le thème a peu intéressé l'historiographie nationale, qui se contente de recopier les derniers chapitres des mémoires de Vicente Pérez Rosales, se réduisant à une série de lieux communs répétés sans aucun sens

\footnotetext{
${ }^{1}$ K. Ilg, Pioniere in Argentinien, Chile, Paraguay und Venezuela, Tyrolia-Verlag, Innsbruck, 1976.

2 «Plancpain » pour Blancpain, «Subercaseauos » pour Subercaseaux.

${ }^{3}$ Processus théorisé par P. Waldmann, «Conflicto cultural y adaptacion paulatina. La évolucion de las colonias de inmigrantes alemanes en el sur de Chile », Jahrbuch für Geschichte von Staat, Wirtschaft und Gesellschaft Lateinamerikas 25, 1988, pp. 437-453.

${ }^{4}$ K. Schobert, Op. Cit.

${ }^{5}$ Ibid., p. 3 : ,Theorie der sozialen Integration ,
} 
critique, comme le constate Gabriel Guarda ${ }^{1}$. En 1984, l'historien chilien Gerardo Jorge OjedaEbert publie une thèse qui vise à démontrer, dans une perspective politique et économique, comment l'immigration allemande participa à la construction de l'Etat-Nation chilien ${ }^{2}$. A la faveur des conditions d'isolement, mises en évidence par Blancpain, le maintien parmi les colons de la culture, de la langue, des coutumes et des valeurs allemandes les aurait dotés de différentes «fonctions » qui en auraient fait des instruments efficaces dans la création d'une nouvelle société régionale ${ }^{3}$. Ojeda-Ebert met en évidence que l'émigration allemande signifie un apport en capital, en technologie et en force productive qui met un terme à la vie autarcique du Sud, par la mise en place d'une agriculture moderne et d'une industrie agro-alimentaire ayant motivé l'intégration du territoire grâce au chemin de fer sous la présidence de Balmaceda (1886-1891). D’un point de vue social, la venue de l'Allemand aurait introduit une nouvelle classe sociale alors inconnue au Chili, la classe moyenne, grâce au processus d'ascension sociale et l'emploi de chiliens dans l'agriculture et l'industrie allemande. Enfin, d'un point de vue politique, l'Allemand aurait assuré la défense de la souveraineté chilienne contre l'Argentine, la pacification de la frontière indienne, le soutien d'une classe capitaliste à un pouvoir exécutif fort contre les mouvements conservateurs et cléricaux. L'auteur conclue que, grâce à leur héritage « démocratique, libéral y humaniste » les Allemands auraient participé au renforcement de la démocratie, notamment à travers le développement d'une société civile par le biais des associations comme les Deutsche Verein ${ }^{4}$. Il est indéniable que l'œuvre d'Ojeda-Ebert, pour aussi intéressante qu'elle soit, perpétue en un sens cette tradition élogieuse qui s'attache à mettre en avant les « effets positifs de la colonisation». Surtout, elle est fortement idéologisée, fait à mettre sans doute en rapport avec la trajectoire personnelle de l'auteur. Le lecteur s'étonnera en effet de voir débuter l'introduction de l'ouvrage par une longue description tragique des événements de septembre 1973, qui auraient peut-être décidé Ojeda-Ebert à réaliser sa thèse en l'Allemagne, tout juste au début des années Pinochet ${ }^{5}$. S'agirait-il d'un exil déguisé ? Son texte est en tout cas une critique à peine voilée du régime du général auquel il oppose avec tant d'insistance la figure du libéral Allemand démocratique de 1848 exilé au Chili. Sans cette grille de lecture, le texte peut apparaître complexe voire confus, liant des données très éloignées.

Dans l'ensemble, l'historiographie chilienne récente tente de réinsérer l'immigration allemande dans le processus de construction nationale et l'histoire locale, plutôt que de l'identifier comme un accident externe. Elle rappelle ainsi que l'arrivée des Allemands au Chili est d'abord une volonté du gouvernement chilien. Elle a aussi le mérite de rompre avec une tradition historique chilienne

\footnotetext{
${ }^{1}$ G. Guarda, Nueva Historia de Valdivia, Op. Cit., p. 518.

${ }^{2}$ G. J. Ojeda-Ebert, Op. Cit.

${ }^{3}$ Ibid., pp. 145-147.

${ }^{4}$ Ibid., p. 97.

${ }^{5}$ L'auteur, de nationalité chilienne, regrette ainsi dans son introduction qu'un séjour d'étude au Chili n'ait pas pu être réalisé, sans en donner la raison, $C f$. Ibid., p. X.
} 
« centraliste et aristocratique $»^{1}$, c'est à dire traditionnellement orientée vers la capitale et la région centrale ainsi que sur ses élites, étudiant les diverses régions du pays dans un rapport de subordination à ces dernières. L'histoire des frontières et des marges a contribué à remettre en cause ce paradigme tenace de l'historiographie chilienne, donnant lieu à des études tant de la région australe chez Mario Gongora ou Sergio Villalobos ${ }^{2}$, que du «Norte Chico » minier, les régions d'Atacama et de Coquimbo, chez Marcelo Carmagnani, María Angélica Illanes ou Jorge Pinto ${ }^{3}$. A partir de l'œuvre de ces historiens s'est développée une vaste série d'études régionales sur l'histoire des régions australes. Parmi elles, les travaux de Gabriel Guarda, qui mêle les variables de modernisation, immigration et ethnicité à l'échelle locale de Valdivia ${ }^{4}$. Son histoire de la ville consacre un chapitre à la «colonisation allemande », qui met en avant les apports économiques, culturels et sociaux de la présence allemande, tant dans l'architecture ou la musique que dans les formes de sociabilité, puis intègre la présence allemande dans l'histoire de la ville, faisait des germano-chiliens des citoyens à part entière qui lui donnent sa touche originale. Il met ainsi largement l'accent sur l'impact «positif» de la colonisation allemande dans les terres australes. Les immigrants, provenant d'un pays à la «culture supérieure », selon le religieux bénédictin, ont transformé définitivement l'histoire de la ville et de ses habitants. Auparavant, on n'y trouvait que terrains improductifs et citoyens délaissées par le pouvoir central. L'émergence d'une élite germano-chilienne au tempérament d'entrepreneur ainsi que le travail acharné des paysans colons à vocation d'exportation ont fait de la région un bastion du développement économique du sud chilien pendant presque quatre-vingt ans, jusqu'à la crise de $1929^{5}$. Guarda étudie la société valdivienne selon une perspective élitiste, confrontant les mentalités de deux groupes ethniques, l'élément chilien étant absorbé par l'allemand, plus résistant par ses caractéristiques de travail, d'épargne et son esprit d'entreprise.

\footnotetext{
${ }^{1}$ R. Araya, Chilenos, Huilliches e Inmigrantes. Arcaísmo y modernidad en Valdivia. 1896-1926, Tesis para optar al grado de Magíster en Historia de $\mathrm{Chile}^{1}$, Universidad de Chile, Facultad de Filosofía y Humanidades, 2006, p. 2.

${ }^{2}$ M. Góngora, "Vagabundaje y sociedad fronteriza en Chile (siglos XVI a XIX)", Cuadernos del Centro de Estudios Socioeconómicos 2, Universidad de Chile, Santiago, 1966. L'œuvre de Sergio Villalobos sur le thème des frontières est importante, $C f$. S. Villalobos, Relaciones fronterizas en la Araucanía, Santiago, Ediciones Universidad Católica de Chile, 1982; Araucanía. Temas de historia fronteriza, Temuco, Universidad de la Frontera, 1985; Vida fronteriza en la Araucanía. El mito de la guerra de Arauco, Barcelona, Andrés Bello,1995.

${ }^{3}$ Entre autres : M. Carmagnani, El salariado minero en Chile colonial: su desarrollo en una sociedad provincial; el Norte Chico 1690-1800, Santiago, Universidad de Chile, Centro de Historia Colonial, 1963 ; M. A. Illanes, La dominación silenciosa: productores y prestamistas en la minería de Atacama Chile, 1830 1860, Instituto Profesional de Estudios Superiores Blas Cañas, Santiago, 1992 ; J. Pinto, La población del Norte Chico en el siglo XVIII, crecimiento y distribución en una región minero-agrícola de Chile, La Serena, Talleres Gráficos U. del Norte, 1980, La Serena Colonial: la ciudad y sus valles hace dos siglos, Valparaíso, Eds. Universidad Católica de Chile, 1983.

${ }^{4}$ G. Guarda, Nueva Historia de Valdivia, Op. Cit., réedition de la Historia de Valdivia 1552-1952, Santiago, Cultura, 1953 publiée sous son nom de laïc, Fernando Guarda Geywitz; La Sociedad en Chile austral antes de la colonización alemana 1645-1850, Santiago, Ed. Andrés Bello, 1979.

${ }^{5}$ G. Guarda, Nueva Historia de Valdivia, Op. Cit., p. 670 et suivantes.
} 
A la suite des travaux de Guarda est apparue une série d'études sur les aspects économiques du développement de la ville et ses relations avec l'influence allemande. Fabián Almonacid, Patricio Bernedo et Luis Carreño ont décrit les activités des colons et de leurs descendants, soulignant la spécificité du complexe industriel valdivien au sein de l'économie chilienne ${ }^{1}$. En 2000, Patricio Bernedo s'intéresse de manière novatrice aux dimensions culturelles de la communauté germanochilienne de Valdivia, dans son analyse du Valdivia's Deutsche Zeitung, principal hebdomadaire en langue allemande de la communauté, publié de 1884 à 1912. Il étudie les causes des succès et échecs de la stratégie éditoriale des différentes directions auprès des lecteurs, en rapport avec le contexte social, politique et économique dans lequel s'insère la publication ${ }^{2}$. Les stratégies devaient être capables de nourrir cette «essence allemande », le Deutschtum, qui fonctionnait parmi les lecteurs comme sentiment d'identification, pour créer l'adhésion de la communauté à l'hebdomadaire. L'historien connaît bien le contexte social dans lequel s'insère son étude, puisqu'il l'a préalablement analysé dans sa thèse de doctorat sur le processus de modernisation qu'ont connu Valdivia et la région de «La Frontera » pendant la période de l'immigration allemande ${ }^{3}$.

Plus récemment encore sont apparus quelques travaux qui ont recomposé l'histoire d'autres localités de la province. Dans cet ensemble se détache l'apport de Patricio Bernedo qui élabore une histoire de la petite localité de Panguipulli combinant histoire locale et aspects économiques, mettant en avant le travail des familles fondatrices de la localité. Bernedo affirme ainsi : «L'arrivée des colonisateurs n'a pas signifié seulement abus et destruction: au contraire. Beaucoup d'entre eux se sont installées pacifiquement dans la zone, donnant son origine à l'établissement d'une petite bourgade qui aujourd'hui constitue le village de Panguipulli ${ }^{4}$.

L'arrivée des Allemands au Chili est en effet souvent contée en termes de progrès et de civilisation. Contre cette idée est apparu un courant historiographique « révisionniste » qui prétend corriger les lieux communs d'une « littérature de vulgarisation » antérieure ${ }^{5}$. Gilberto Harris remet en question à juste titre l'expression de «Sud allemand », argumentant que les Allemands n'ont jamais dépassé le nombre de résidents chiliens. "Mais bien plus, dans l'une des "sagas" de Jean-Pierre Blancpain, on prétend nous faire croire que tous avaient une situation économique aisée » critique l'auteur ${ }^{6}$. Il

\footnotetext{
${ }^{1}$ F. Almonacid, Valdivia, 1870-1935 Imágenes e Historias, Valdivia, U. Austral de Chile, 1995 ; P. Bernedo, "Los industriales alemanes de Valdivia, 1850-1914", Historia 29, Santiago, Pontificia U. Católica de Chile, 1999 ; L. Carreño, "La industria de la cerveza en la región de los Lagos", Boletín de Historia y Geografía 16, U. Católica Cardenal Raúl Silva Henríquez, Santiago, 2002.

${ }^{2}$ P. Bernerdo, «Las estrategias periodísticas del periódico Valdivia's Deutsche Zeitung, 1886-1912 », Historia 33/2000, pp. 5-61.

${ }^{3} \mathrm{P}$. Bernedo, Bürgertum und Moderniesierungansätze, Op. Cit.

${ }^{4}$ P. Bernedo, Panguipulli: historia de cuatro tiempos, Panguipulli, 1994, p. 12 : "la llegada de los colonizadores no significó únicamente abusos y destrucción: por el contrario. Muchos de ellos se instalaron pacíficamente en la zona, dando origen al establecimiento de una pequeña población en lo que actualmente constituye el pueblo de Panguipulli"

${ }^{5}$ G. Harris Bucher, Inmigración y emigración en Chile durante el siglo XIX: estudios y documentos, Valparaíso, Universidad de Playa Ancha, 1997, p. 25 : "literatura de divulgación".

${ }^{6}$ Ibid., p. 25 : «Es mas, en una de las "sagas" de Jean-Pierre Blancpain se nos pretende hacer creer que todos tenían una holgada situación económica ».
} 
rappelle que le courant migratoire fut composé aussi de «prolétaires, aventuriers, déserteurs et débiteurs ", composant une frange de misère prompte à saisir toute opportunité d'émigration ${ }^{1}$. Or, après plusieurs années ils sont toujours charpentier, cordonnier, forgeron, domestique et commerçant, constate t-il, ce qui sonne comme le reproche de ne pas avoir connu de mobilité professionnelle ${ }^{2}$. C'est là un commentaire qui fait preuve de peu de jugement historique, car une étude du contexte allemand permettrait de comprendre que pouvoir exercer librement un métier d'artisanat est en soi-même une ascension économique voire sociale pour ces émigrés, qui en outre profitent d'une large clientèle, dans une région qui, rappelons-le, au milieu du XIX ${ }^{\mathrm{e}}$ siècle en est totalement dépourvu de services et artisanat. Les correspondances attestent, nous le verrons, que les artisans et commerçants croulaient sous les commandes, imposaient leurs prix et leurs délais et gagnaient très bien leur vie. Il n'y a donc aucun déshonneur à être « resté » artisan dans de telles conditions. En réalité, c'est bien un « livre noir» de la colonisation allemande que propose Harris. Entre 85 et $90 \%$ des Allemands arrivées entre 1857 et 1861 étaient sous contrat et les colons de Llanquihue auraient vécu de l'aide de l'Etat chilien, se faisant soigner et nourrir gratuitement dans les hôpitaux, plusieurs années après leur arrivée encore ${ }^{3}$. On ne sait pas bien quels sont ces hôpitaux qu'évoque l'auteur, qui, pour sûr, n'existaient pas à Llanquihue, tandis que ceux de Valdivia et de Puerto Montt étaient à plusieurs jours de voyage... Bien plus, les émigrés sont présentés comme des criminels : «Dans notre sud, les chiliens reçurent les étrangers avec un crucifix dans une main et un poignard dans l'autre, ce qui en réalité ne correspondait par à une calomnie gratuite; et pour cause, à Valdivia par exemple, vers 1895, 27 Européens purgeaient des peines de prison pour différents délits, parmi eux 7 Allemands, 6 Autrichiens, 1 Belge et 13 Italiens » ${ }^{4}$, explique t'il, sans même fournir les chiffres globaux d'incarcération pour rendre compte de la part relative des «étrangers ${ }^{5}$. Enfin, non seulement l'ouvrage présente les émigrés comme de véritables «assistés » de l'État chilien, mais également comme des profiteurs conscients :

«Le gros des Allemands qui entrèrent dans le pays fut recrutés par l'Etat et savait très bien que notre administration couvrirait les frais que générait leur transport, qu'elle leur offrirait généreusement, à titre de prêt, des terres [...], des outils de labour, des animaux, des semences, tout le nécessaire pour élever une demeure et, fait encore plus important, qu'elle les aiderait à se maintenir grâce à des sommes d'argent quotidiennes pendant une année, outre d'importantes franchises fiscales $»^{6}$.

\footnotetext{
${ }^{1}$ G. Harris Bucher, Op. Cit., p. 12 : "proletarios, aventureros, desertores y deudores".

${ }^{2}$ Ibid., p. 25.

${ }^{3}$ Ibid., p. 26.

${ }^{4}$ Ibid.: « en nuestro sur los chilenos recibían a los extranjeros con un crucifijo en una mano y un puñal en la otra, cuestión que en verdad no correspondía a una gratuita calumnia ; mas, en Valdivia por ejemplo, hacia 189527 europeos cumplían condena en la cárcel por diferentes delitos, contándose entre ellos 7 alemanes, 6 austriacos, 1 belga y 13 italianos »

5 «D'un chiffre seul, on ne peut rien induire », dit Donald Mc Kloskey dans Donald M. McCloskey, The Rhetoric of Economics, Madison, University of Wisconsin Press, 1985, p. 143.

${ }^{6}$ G. Harris Bucher, Op. Cit., p. 27. : "el grueso de los alemanes que ingresaron al país fueron contratados por el Estado, y estaban perfectamente interiorizados de que nuestras administraciones correrían con los gastos que demandaba su traslado, que graciosamente les otorgaría en calidad de préstamo tierras - no precisamente
} 
Harris établit alors un compte des sommes consacrées à l'immigration par l'administration Montt, démontrant que la grande majorité des Allemands n'ont rien remboursé, consacrant ainsi une dizaine de pages à l'inventaire de leurs dettes envers le gouvernement chilien de 1852 à $1868^{1}$. Laissons la critique finale à Olivier Compagnon :

«Concluons sur deux nuances qui ternissent l'impression générale que laisse la lecture de cet ouvrage : d'une part, l'absence de toute perspective comparatiste avec d'autres pays latino-américains, qui aurait pu donner à penser sur une éventuelle spécificité chilienne en matière de flux migratoires au XIX ${ }^{\mathrm{e}}$ siècle ; d'autre part le ton volontiers péremptoire et parfois naïf d'un auteur oubliant parfois que ses travaux n'auraient pas existé sans ceux de ses prédécesseurs (qui ne sont pas tous des pseudo historiadores), et que l'écriture de l'histoire relève d'une sédimentation de connaissances et de problématiques jamais achevée $»^{2}$.

Les différentes publications historiques produites sur le thème des Allemands au Chili depuis les années 1970 sont donc de valeurs inégales, et issues de divers milieux et disciplines, l'apport de l'ethnologie ayant été important pour expliquer le maintien des traditions et celui de la sociologie pour dégager les modalités du processus d'intégration. Elles ont permis l'élaboration d'un corpus bibliographique relativement important dont se sont nourris divers travaux universitaires. Depuis 1995 en effet se sont multipliés les recherches sur l'immigration et la présence allemande au Chili, chez les jeunes chercheurs allemands comme chiliens, soucieux de décrire l'histoire et les traditions des émigrés allemands et de documenter l'histoire de la « communauté culturelle » des Germanochiliens $^{3}$. Il manquait cependant de traiter la question des procédés de construction de cette communauté culturelle chez les migrants et de leurs représentations identitaires. Le travail d'Alexandra Lübke répond précisément à cette question ${ }^{4}$. Oscillant entre littérature et histoire, son travail constitue un apport notable à la recherche sur l'identité nationale et culturelle dans le contexte de la migration. Son ouvrage porte un titre plutôt long et complexe, qui traduit une approche poststructuraliste complexe. Lübke s'interroge sur les modes de construction d'une

muladares - , útiles de labranza, animales, semillas, todo lo necesario para levantar una vivienda, y más importante aún, que los auxiliara en sus mantención con un diario en dinero durante un año, amén de importantes franquicias tributarias".

${ }^{1}$ G. Harris Bucher, Op. Cit., pp. 31-40.

${ }^{2}$ O. Compagnon, «Gilberto Harris Bucher, Emigrantes e inmigrantes en Chile, 1810-1915. Nuevos aportes y notas revisionistas, Valparaíso, Universidad de Playa Ancha Editorial, $2001 »$ [en ligne], Nuevo Mundo Mundos Nuevos, Reseñas de libros y CD roms, 2005. Accessible à l'URL : http://nuevomundo.revues.org//index262.html. [Consulté le $1^{\mathrm{er}}$ août 2008].

${ }^{3}$ Quelques unes de ces thèses, de niveaux académiques divers, figurent dans la bibliographie. Les travaux de Kerscher et Singer s'attachent, dans la lignée de Schobert, à rendre compte des formes et conditions de maintien de la culture allemande au Chili, dont l'histoire semble cependant assez méconnue des auteurs. La thèse de Gödde est en revanche d'excellente facture et a le mérite de traiter d'une question longuement éludée, celle de l'influence du national-socialisme dans les communautés germano-chiliennes, à travers l'analyse de la presse des années 1930. Au Chili, Gleisner s'est attachée à décrire les formes de maintien de la culture allemande au sud du Chili tandis que Rodrigo Araya, se fondant sur des sources hispanophones (presse, archives notariales, etc.), redéfinit l'immigré d'origine allemande comme acteur dans les conflits de terres et propriétés qui marquent la région et par conséquent dans l'histoire locale du Chili.

${ }^{4}$ A. Lübke, Op. Cit. Le titre pourrait se traduire par : «Que de différences entre l'Europe et ici ... ». Analyse, à l'appui de la théorie du discours, des notions de nation, émigration et identité culturelle de genre, à partir des lettres d'Allemandes émigrées au Chili au XIX siècle. 
identité nationale et culturelle chez les émigrées allemandes au Chili, une identité toujours genrée. Insérant sa recherche dans un corpus de textes emblématiques du linguistic turn et des théories de la déconstruction et du discours, elle envisage la nation comme une communauté imaginée (Anderson), développant le concept culturel de nation comme narration (H. Bhabha), ou comme système culturel de représentations et de pratiques (S. Hall), pour ainsi reconstruire les notions qui sont au cour de la construction du discours de la Nation, comme l'ethnicité, le genre, la nationalité et la citoyenneté, en rapport avec le discours contemporain sur l'émigration. Cette construction discursive est illustrée par les correspondances de femmes allemandes émigrées au Chili au XIX siècle. La lettre, «narration d'un moi culturel », est lue en effet comme le lieu de l'articulation de l'identité culturelle, apparaissant comme le lieu de rencontre des discours sur la nation, l'émigration et le genre. En ce sens, Alexandra Lübke est la première à mentionner une réalité autre, jusque là éludée par l'historiographie des Allemands au Chili : la présence des femmes. Cependant, la position postmoderniste radicale de l'auteur, proche de Hayden Whyte, empêche clairement de voir une expérience féminine concrète. Les tenants du linguistic turn ne font pas de distinction en effet entre les pratiques discursives et les réalités sociales et postulent que les intérêts sociaux n'auraient aucune visibilité en dehors des discours qui les énoncent. L'historien ne serait ainsi confronté qu'à des jeux de langage ou à des conflits de représentations. Roger Chartier avertit des risques d'une telle posture, identifiant «dans les formulations radicales du linguistic turn à l'américaine, la dangereuse réduction du monde social à une pure construction discursive, à de purs enjeux de langage $»^{1}$. Michel de Certeau rappelle aussi très concrètement que, si l'on peut faire de l'Histoire, c'est parce qu'il existe des hommes, qui ont vécu. Ainsi, « l'objet, la réalité, le monde sensible» doivent être saisis en tant qu' «activité humaine concrète », en tant que «pratique ». De Certeau propose ainsi un «retour au fondamental »: «pour vivre il faut avant tout boire, manger, se loger, s'habiller et quelques autres choses encore. Le premier fait historique est donc la production des moyens permettant de satisfaire ces besoins, la production de la vie matérielle ellemême $»^{2}$. Il restait donc à historiciser l'expérience, bien réelle, des Allemandes au Chili.

\subsection{Femmes et genre en migration}

«Un émigré et une émigrée, ça n’est pas la même chose », rappelle Monica Raisa Schpun². C'est là un constat qui a bien tardé à être pris en considération dans le champ des études historiques des migrations. «La plupart des histoires de l'immigration aux Etats-Unis commencent comme des

\footnotetext{
${ }^{1}$ R. Chartier, Au bord de la falaise. L'histoire entre certitudes et inquiétude, Paris, Albin Michel, 1998, p. 11.

${ }^{2}$ M. de Certeau, Op. Cit., p. 21.

${ }^{3}$ M. R. Schpun, «Histoire, culture et genre dans le contexte des migrations internationales [en ligne], entretien (01:28:18). Accessible à l'URL : http://www.archivesaudiovisuelles.fr/FR/video.asp?id=926\&ress=2976\&video=65092\&format=23\#0 [consulté le 17décembre 2007]
} 
expériences de migrants déguisés en humains asexués » constate l'historienne américaine Donna Gabaccia dans une affirmation qui peut sans aucun être étendue à d'autres espaces ${ }^{1}$.

\subsubsection{Des études migratoires longtemps androcentrées.}

Les études historiques des processus migratoires ont en effet longtemps peiné à concevoir la femme comme actrice à part entière des processus migratoires contemporains, ces derniers étant longtemps lus comme liés à l'industrialisation, l'urbanisation et la modernisation, donc à des processus économiques, par conséquent à des figures masculines ${ }^{2}$. L'économie s'est en effet précocement intéressée à l'étude des migrations. Les migrations internationales contemporaines s'expliquent principalement par le développement d'une économie mondiale capitaliste, génératrice d'inégalités entre pays, mais aussi de mobilité, selon la loi de l'offre et de la demande. Les migrants sont des travailleurs, puisque par la migration, l'individu cherche à assurer sa survie matérielle et celle de sa famille, qu'elle le suive ou qu'elle reste sur place ${ }^{3}$. Marx avait déjà lié mobilités et problèmes démographiques, dans le cadre de la théorie de la nécessaire accumulation du capital. Produisant, grâce à leur travail, cette accumulation, les ouvriers générèrent un surplus relatif de population, c'est à dire une suroffre relative, génératrice de mobilité. Le déséquilibre au niveau du pays de départ crée un excédent structurel de main d'œuvre rendant l'émigration possible, tandis que les besoins de main d'œuvre de la part du pays d'immigration déterminent l'existence et l'importance des flux migratoires ${ }^{4}$. Les migrations seraient donc un phénomène structurel du capitalisme contemporain, une sorte de soupape de sécurité à «la pression qu'une population exerce sur un minimum vital limité » ${ }^{5}$. Ainsi, la première grande synthèse sur le sujet de l'émigration allemande, de Wilhelm Mönckmeier, définit l'immigration comme « un mouvement du marché international du travail », « un flux de va-et-vient de main d'œuvre des régions à la conjoncture économique en baisse vers celle en hausse $»^{6}$. Fondamentalement, l'émigration des Allemands au Chili s'explique par, d'un côté, le surplus d'une main d'œuvre essentiellement agricole, et de l'autre, une demande de cette même main d'œuvre dans l'objectif de mettre en valeur les territoires fertiles du Sud. Cette réalité correspond à la dichotomie traditionnelle du push and pull, le «couple fameux des études

1 D. Gabaccia, From the Other Side: Women, Gender and Immigrant Life in the US. 1820-1990, Bloomington, Indiana University Press, 1996, p. XI : "most histories of immigrants in the United States begins with the experiences of migratory men disguised as genderless humans"

${ }^{2}$ N. L Green., Repenser les migrations, Op. Cit.

${ }^{3}$ Ibid., p. 78.

${ }^{4}$ K. Marx, Le Capital. Édition populaire, Paris, PUF, 1965, p. 134.

5 W. Köllmann et P. Marschalck, «German oversea emigration since 1815 » dans Les migrations internationales, Op. Cit., p. 448 : « the pressure of a population against a limited level of subsistance ».

6 W. Mönckmeier, Die deutsche überseeische Auswanderung, Jena, 1912. Cité dans H. Bickelmann, Deutsche überseeauswanderung in der Weimarer Zeit, Wiesbaden, Franz Steiner Verlag, 1980, p. 2 : « eine Bewegung des internationalen Arbeitsmarktes », « ein Hin- und Herfluten von Arbeitskräften aus Gebieten mit sinkender Wirtschaftskonjonktur in solche mit aufsteigender ».

${ }^{7}$ G. Dupeux, Op. Cit., p. 14. 
migratoires » selon Nancy Green ${ }^{1}$, en français, les facteurs de répulsion et d'attraction des mouvements migratoires. Alors, dans cette histoire, dont le protagoniste est l'homme travailleur et civilisateur, la femme n'avait pas sa place.

Janine Dahinden et al résument ainsi le chemin parcouru par l'historiographie des migrations, mettant au jour trois phases dans la manière $d$ 'aborder la situation des migrantes :

«De l'invisibilité des femmes, on est passé à une vision familialiste, puis à la conception des migrantes comme actrices économiques et sociales à part entière [...] Sortir les femmes de l'invisibilité devint, dans ce champ d'études comme dans d'autres, l'objectif premier de celles qui souhaitaient rompre avec l'image androcentrée des migrations, où seuls les hommes pouvaient être protagonistes des processus migratoires $»^{2}$.

\subsubsection{Les femmes en migration}

Retracer l'histoire de l'historiographie d'un thème développé aussi récemment que «genre et migration » n'est pas une tache aisée, vu sa nouveauté ${ }^{3}$. L'histoire des femmes migrantes se situe au point de rencontre de trois domaines historiques ayant finalement eux-mêmes émergés récemment: l'histoire des pauvres, l'histoire de l'immigration et l'histoire des femmes. Par conséquent à l'intersection de l'histoire de classe, de genre et de race ${ }^{4}$. Aux Etats-Unis comme en Europe, l'histoire des femmes en migration est relativement tardive par rapport à d'autres disciplines comme la sociologie, la médecine, la psychologie, qui se sont intéressées dès la première moitié du $\mathrm{XX}^{\mathrm{e}}$ siècle au cas des immigrantes. L'analyse de l'historiographie de l'immigration féminine aux États-Unis, relève ainsi une série de publications dès les années 1910, issues de groupes de femmes spécialistes de la question sociale qui intervenaient dans les campements ou quartiers d'immigrés ${ }^{5}$. Ces études n'avaient pas de perspective historique mais ethnographique et sociologique. Elizabeth Ewen analyse pour le New York de début de siècle ce mouvement réformateur, constitué de femmes, sorte d'activistes de l'assistance sociale, en majorité protestantes et issues des classes moyennes, dont les missions visaient à promouvoir l'intégration des immigrés. Elles donnaient lieu à des rapports témoignant notamment de relations privilégiées

\footnotetext{
${ }^{1}$ N. L. Green, Repenser les migrations, Op. Cit., p. 88

${ }^{2}$ J. Dahinden, M. Rosende, N. Benello (et al.), «Édito. Migrations : genre et frontières - frontières de genre », Nouvelles Questions Féministes, 26-1/2007, Migrations : genre et frontières - frontières de genre, p. 6.

${ }^{3}$ Je tiens à remercier ici particulièrement les Pr. Philippe Rygiel, Nancy Green et Mônica Raisa Schpun pour leurs précieuses indications.

${ }^{4}$ A. Morelli, « Jalons pour une histoire des femmes migrantes en Europe », Rapport du colloque Histoire/Genre/Migration, Paris, mars 2006. Accessible en ligne à l'URL : http://barthes.ens.fr/clio/dos/genre/resumpan1a3.html [consulté le 17 janvier 2008] et S. Pedraza, «Women and Migration. The social consequences of gender », Annual Review of Sociology, 17/1991, pp. 304.

${ }^{5}$ K. M. Donato, D. Gabaccia, J. Holdaway (et al.), "A Glass Half Full? Gender in Migration Studies", International Migration Review, 40-1/2006, Center of Migration Studies, New York, s. p. et Dorothée Schneider, "L'immigration féminine aux Etats-Unis : un essai historiographique », Actes de l'Histoire de l'Immigration, 3/2003. Accessible à l'URL : http://barthes.ens.fr/clio/revues/AHI/articles/volumes/wo.html [consulté le 23 avril 2008].
} 
de femme à femme ${ }^{1}$. La sociologie s'est dans l'ensemble précocement préoccupée de la question de l'immigration féminine et de son intégration. En 1979 est publiée en France Femmes et immigrées, une enquête sociologique sur les femmes d'Afrique du Nord immigrées en France, tandis qu'aux États-Unis paraît le recueil de témoignages de migrantes transatlantiques édité par Maxine Seller, Immigrant Women ${ }^{2}$. En 1984, l'International Migration review consacre un numéro spécial multidisciplinaire à la question, où Mirjana Morokvasic rappelle, en référence à l'ouvrage de Michael Piore ${ }^{3}$, que «les oiseaux de passage sont aussi des femmes » ${ }^{4}$. L'ouvrage de Hasia Diner sur les migrantes irlandaises illustre encore la difficulté d'envisager une problématique claire, indépendante de la question des enfants et de la famille, pour porter sur la femme ${ }^{5}$. Ainsi, jusque dans les années 1980, les écrits sur l'histoire femmes immigrées restent encore minoritaires, alors que le champ des études migratoires lui-même est en pleine expansion. Plusieurs enquêtes bibliographiques témoignent de cette contradiction, comme celle de Louis Taravella en France en 1984, de Marie Poirier au Québec en 1985 ou de Donna Gabaccia aux États-Unis en $1989^{6}$.

C'est d'abord aux États-Unis que l'intérêt pour l'histoire des migrations féminines se manifeste, une fois mise en évidence la féminisation des flux migratoires. A partir de 1930 en effet, la part relative entre hommes et femmes s'inversent et les femmes qui immigrent aux États-Unis deviennent plus nombreuses que les hommes, fait mis en lumière seulement en 1974 ${ }^{7}$. Suzanne Singe identifie plusieurs traditions anglo-saxonnes ayant débouché sur un intérêt pour les questions de genre et migration ${ }^{8}$. Une première tradition est celle des Migrations studies qu'incarne entre autres le Center of Migrations Studies of New-York, qui publie la International Migration Review et dont est issue par exemple Donna Gabbacia. Une deuxième tradition est celle de l'histoire sociale, et notamment des élèves de Tilly, qui porte souvent un intérêt aux questions françaises. L'ouvrage

\footnotetext{
${ }^{1}$ E. Ewen, Immigrant women in the land of dollars. Life and culture on the lower east side, 1890-1925, New York, Wayne Monthly Review Press, 1985. Ces relations féminines visaient à initier les mères de famille à un modèle de ménagère alors en vogue aux Etats-Unis, centrée sur l'espace domestique, responsable, rationnelle dans l'organisation de ses tâches ... modèle en réalité peu accessible à des femmes vivant dans les logements précaires et qui n'était pas celui que représentaient ces jeunes-femmes célibataires qui passaient leurs journées à travailler.

2 I. Tabaoda, F. Lévy, Femmes et immigrées : l'insertion des femmes immigrées en France, Paris, La Documentation française, 1979 et M. Schwartz Seller, Immigrant Women, Philadelphie, Temple University Press, 1981.

${ }^{3}$ M. Piore, Birds of passage. Migrant Labor and Industrial Societies, New Yors, Cambridge, University Press, 1979 .

${ }^{4}$ M. Morokvasic, "Birds of passage are also women", International Migration Review, 18-4/1984, pp. 886907.

${ }^{5}$ H. Diner, Erin's Daughter in America : Irish Immigrant Women in the Nineteenth Century, Baltimore, John Hopkins University Press, 1983.

${ }^{6}$ L. Taravella, Les femmes migrantes, bibliographie analytique internationale (1965-1953), Paris, l'Harmattan, 1984, Marie Poirier, Les femmes immigrées au Québec. Bibliographie annotée, Gouvernement du Québec, Ministère des Communautés culturelles et de l'Immigration, 1985, et D. Gabaccia, Immigrant women in the United States: a selectively annotated multidisciplinary bibliography, New York, Greenwood Press, 1989.

${ }^{7}$ S. Pedraza, Op. Cit., p. 304.

${ }^{8}$ S. Sinke, "Gender and Migration: Historical Perspective", International Migration Review, 40-1/2006, Center of Migration Studies, New York, pp. 82-103.
} 
de Louise Tilly et Joan Scott, Women, Work and Family, couple un modèle économique marxiste et des théories anthropologiques sur la division des sphères publiques et privées de la vie ${ }^{1}$. Tilly, Scott et leurs étudiants analysent les migrations féminines des régions rurales européennes orientées vers l'économie de subsistance vers les communes industrialisées et urbaines d'Europe et des EtatsUnis $^{2}$. Une troisième tradition, enfin, est issue des Family studies, une forme de démographie historique qui conjugue méthode quantitative à histoire orale, où s'illustre par exemple Tamara Hareven avec son étude des migrants franco-canadiens installés en nouvelle Angleterre, qui prête attention à l'économie familiale et par là, aux femmes ${ }^{3}$. Au Canada, les travaux de Franca Iacovetta méritent également d'être cités, notamment sa collaboration avec Donna Gabaccia ${ }^{4}$.

Dans l'historiographie de langue française, la recherche sur genre et migration est encore très peu développée. En général, les spécialistes des migrations connaissent peu l'histoire du genre et inversement. Pourtant, les travaux sur les migrations ont peu à peu porté leur attention sur les migrantes et le genre en migration et c'est le cas de Janine Ponty qui fait une très large place dans sa thèse aux migrantes polonaises et à leurs travaux ${ }^{5}$, comme de son élève Philippe Rygiel qui pose la question du travail des migrantes et de leurs filles ${ }^{6}$.

Il restait cependant à problématiser la thématique, à démontrer que le fait que les migrants avaient un genre n'était pas un détail mais devait avoir pour effet la mise en discussion d'un certain nombre de thèmes, pour pouvoir réellement produire des thèses qui osent mettre en relation genre et migration. La première tâche était bien de convaincre de la légitimité d'une lecture genrée des processus migratoires historiques. «Croiser genre et migration était légitime parce que scientifiquement pertinent et efficace » affirme Philippe Rygiel ${ }^{7}$, qui, conjointement à Natacha Lillo en résume les enjeux :

«L'expérience immigrée, dans ses différents moments, est en effet structurée par le genre en ce qu'elle ne prend pas les mêmes formes pour les hommes et pour les femmes. De même, images et représentations des populations en migration sont genrées, tant parce que le regard porté sur les migrants distingue entre eux en fonction du genre que parce que

\footnotetext{
${ }^{1}$ En français : L. A. Tilly, J. W. Scott, Les femmes, le travail et la famille, Paris, Payot et Rivages, 2002 (1978), $389 \mathrm{p}$.

${ }^{2}$ De cette école provient notamment Leslie Page Moch, qui porte attention aux relations entre migration, mariages et économie familiale. Cf. L. Page Moch, Moving Europeans: Migration in Western Europe since 1650, Indiana University Press, 1992.

${ }^{3}$ T. K. Hareven, Family time and industrial time : the relationship between the family and work in a New England industrial community, Cambridge, New York, Cambridge University Press, 1982.

${ }^{4}$ F. Iacovetta, Such Hardworking People: Italian Immigrants in Post-war Toronto, Montreal, McGillQueen's University Press, 1992; Women, Gender and Transnational Lives: Italian Worker of the World (avec Donna Gabaccia), Toronto, University of Toronto Press ou encore Sisters or Strangers? Immigrant Women and the Racialized "Other" in Canadian History, Toronto, University of Toronto Press, 2004.

${ }^{5}$ J. Ponty, Polonais Méconnus histoire des travailleurs immigrés en France dans l'entre-deux-guerres, Paris, PUS, 1988 (la thèse date de 1981).

${ }^{6}$ P. Rygiel, Destins immigrés. Cher 1920-1980 : trajectoires d'immigrés en Europe, Besançon, Presses universitaires franc-comtoises, 2001 (la thèse est de 1996)

${ }^{7}$ P. Rygiel, « Des mondes genrés et mobiles. Introduction au colloque Histoire/Genre/Migration, Paris, mars 2006 » [en ligne]. Accessible à l'URL : http://barthes.ens.fr/clio/dos/genre/com/intro.pdf [consulté le 27 mars 2008].
} 
migrants et migrantes ne proposent pas les mêmes récits, ou ne portent pas la même mémoire de l'expérience migratoire $»^{1}$.

En France, l'année 2002 voit l'ouverture d'un cycle de recherche, autour du séminaire de l'Ecole Normale Supérieure, animé par Philippe Rygiel depuis $1996^{2}$. Signe que les thématiques de genre et migration étaient dans l'air du temps, cette même année, Nancy L. Green publie Repenser les migrations où elle consacre son dernier chapitre au glissement de paradigme «de l'immigré à l'immigrée $»^{3}$. Elle est la première invitée du séminaire de Philippe Rygiel, qui trouve sa conclusion dans un colloque final en 2006, intitulé « Histoire/Genre/Migration » ${ }^{4}$. L'un des enjeux consistait, selon Rygiel, à faire connaître en France les recherches étrangères, d'où les traductions systématiques de l'anglais et de l'allemand, d'éveiller des vocations chez les jeunes chercheurs français, particulièrement chez les historiens, encore largement absents et d'affiner le vocabulaire, certains chercheurs s'inscrivant dans le cadre de l'histoire des femmes quand d'autres préfèrent se définir comme historiens et historiennes du genre. Il s'agissait enfin et surtout de définir les problématiques et enjeux spécifiques de l'histoire des femmes et du genre en migration.

\subsubsection{Genre en migration, migration de genre}

Femmes et genre ne sont pas synonymes, en histoire des migrations comme en histoire générale : «La migration en elle-même est un phénomène genré qui requière des outils théoriques et analytiques plus sophistiqués que l'étude des rôles sexuels et du sexe comme variable dichotomique du passé », remarquent les chercheuses américaines ${ }^{5}$. Rappelons que l'histoire des femmes, en tant que groupe social, est née dans les années 1970 sous l'influence étroite des luttes féministes. Dans les pays pionniers tels que la France, les Etats-Unis et le Royaume-Uni, elle a connu trois phases distinctes que résume Asunción Lavrin ${ }^{6}$ : la première étape consistait à rendre visible la femme comme acteur social dans l'Histoire, la seconde à identifier l'expérience féminine comme originale et digne d'études pour elle-même, tandis que la troisième se soucia de théoriser le champ de recherche et d'insérer les études de la femme dans une dimension relationnelle, c'est à dire en lien avec l'expérience masculine, débouchant ainsi sur l'élaboration du genre, tel que le

\footnotetext{
${ }^{1}$ N. Lillo, P. Rygiel (dir.), «Avant-propos » dans N. Lillo, P. Rygiel (dir.), Rapports sociaux de sexe et immigration. Actes de l'Histoire de l'Immigration, 6/2006, Paris, Publibook Université, 2007, p. 12.

${ }^{2}$ Le séminaire s'intitulait «Femmes en migrations » en 2002-2003 et « Genre en migration » en 2003-2004.

${ }^{3}$ N. L. Green, Repenser les migrations, Op. Cit.

${ }^{4}$ Les actes du colloque furent publiés successivement dans N. Fouché, S. Weber (dir.), Construction des sexualités et migration. Migrance 27/1er semestre 2006, 104 p. ; N. Lillo, P. Rygiel (dir.), Rapports sociaux de sexe et immigration (Actes de l'Histoire de l'Immigration, 6/2006), Paris, Publibook Université, 2007 et $\mathrm{N}$. Lillo, P. Rygiel (dir.), Images et représentations du genre en migration (Actes de l'Histoire de l'Immigration, 7/2007), Paris, Publibook Université, 2007.

${ }^{5}$ K. M. Donato, D. Gabaccia, J. Holdaway (et al.), Op. Cit., s. p.

${ }^{6}$ A. Lavrín, "Género e Historia: Una conjunción a finales del siglo XX" dans Nomadías, Santiago, Univ. de Chile, PGAL, 1999, p. 15-16.
} 
définit Joan Scott comme catégorie d'analyse historique ${ }^{1}$. Françoise Thébaud identifie exactement la même évolution lorsqu'elle distingue dans son ouvrage une phase d' "émergence de l'histoire des femmes », une «phase d'accumulation » et enfin, un «temps du gender » pleinement reconnu en France dans les années 1990-2000². Ainsi, il est vrai que l'histoire du genre en migration n'a pu se faire qu'une fois la femme rendue visible. L'analyse des rapports de genre et migration n'est pas toujours distincte d'une exploration de l'expérience des femmes migrantes. Or, «à trop vouloir focaliser le regard sur les femmes, à trop chercher à rendre visible la face cachée de la migration, cette littérature a oublié les hommes. L'occasion de saisir le genre, la différence entre les sexes a été délaissée » constatent Christine Catarino et Mirjana Morokvasic ${ }^{3}$. L'expérience migratoire des hommes, comme expérience de genre, est peu pris en compte. Néanmoins, s'il y a eu renouvellement des approches avec l'invention du genre, cela n'invalide par l'histoire des femmes en elle-même. Ses premières militantes en rappellent aujourd'hui la nécessité. Tout en invitant à user du genre, Michelle Perrot a rappelé qu'il ne faut pas abandonner « l'histoire dite 'des femmes' toute simple », et Gerda Lerner, mère de l'histoire des femmes aux États-Unis, est plus explicite encore lorsqu'elle à remplir tous les blancs de la carte de l'histoire des femmes ${ }^{4}$. Il est donc possible et légitime, suivant le thème et le sujet, de faire de l'histoire des femmes et de l'histoire du genre et de fait, la plupart des recherches mêlent les deux approches. Christine Catarino et Mirjana Morokvasic résument ainsi le débat entre histoire des femmes et histoire du genre dans le champ des études migratoires :

«À regarder les travaux consacrés au couple genre et migration, il apparaît pourtant que certains se limitent à une étude des femmes tout en défendant qu'une telle approche n'est pas incompatible avec la prise en compte des rapports de domination entre les sexes (Parreñas, 2001). Il est vrai que pour certain(e)s tant que les traités de sociologie des migrations, les états des lieux ou rapports d'envergure ayant prétention à englober l'ensemble des phénomènes migratoires (Commissariat Général du Plan, 2002) continuent d'ignorer les femmes et a fortiori le genre, la phase compensatrice s'avèrera nécessaire (Morokvasic, 2003). D'autres auteurs proposent une comparaison de l'expérience migratoire des hommes et des femmes en migration (Pessar, 1999 ; Yeoh et Huang, 2003). Le débat reste entier ... $»^{5}$.

\subsection{Ecrits de migrantes}

Les sources représentent le principal nœud problématique de l'histoire des femmes migrantes comme celle de l'histoire des femmes en général.

\footnotetext{
${ }^{1}$ J. Scott, « Genre : Une catégorie utile d'analyse historique », Les Cahiers du GRIF, 37-38,/1998, Le genre de l'Histoire, p. 141: «Le genre est un élément constitutif des rapports sociaux fondés sur des différences perçues entre les sexes, et le genre est une façon première de signifier des rapports de pouvoir ».

${ }^{2}$ F. Thébaud, Op. Cit.

${ }^{3}$ C. Catarino et M. Morokvasic, Op. Cit.

${ }^{4}$ Citées dans F. Thébaud, Op. Cit., p. 208.

${ }^{5}$ C. Catarino et M. Morokvasic, Op. Cit.
} 


\subsubsection{Les sources de l'histoire des femmes migrantes}

Les sources posent en effet un double problème: elles sont rares, et celles qui existent sont biaisées.

«Parce que [les femmes] apparaissent moins dans l'espace public, objet majeur de l'observation et du récit, on parle peu d'elles, constate Michelle Perrot, et ce, d'autant moins que le récitant est un homme qui s'accommode d'une coutumière absence, use d'un masculin universel, de stéréotypes globalisants ou de l'université supposée d'un genre : LA FEMME. Le manque d'informations concrètes et circonstanciées contraste avec l'abondance des discours et la prolifération des images. Les femmes sont imaginées beaucoup plus que décrites ou racontées, et faire leur histoire, c'est d'abord, inévitablement, se heurter à se bloc de représentations ${ }^{1}$.

En outre, pendant des siècles, les femmes n'étaient pas considérées comme sujets de l'histoire, mais comme des objets ${ }^{2}$. Outre des figures telles que Mary Wollstonecraft ou Olympe de Gouges qui relèvent davantage de l'exceptionnalité, la femme du peuple n'est que rarement « représentée », si ce n'est dans des actes de procédés judiciaires qui la mettent en cause pour participation à une rébellion collective, adultère, sorcellerie et autres accusations. De plus, ces sources sont toutes produites par des hommes, ce qui constitue le second problème méthodologique. Notre connaissance des femmes est largement limitée par la vision qu'en ont les hommes, qu'ils soient médecins, juristes, clercs ou théologiens, force est de constater que ce point de vue masculin nous donne accès à une réalité qui n'est peut-être pas toujours celle que vivent les femmes ${ }^{3}$. Ainsi, les sources qui nous informent sur les migrations de célibataires sont toutes traversées par la suspicion puisqu'une femme qui émigre seule, sans famille et sans référent masculin, est forcément une femme «publique », par conséquent mal vue. A ce sujet, Pierre Bourdieu, s'appuyant sur son concept de la «violence symbolique », définit la femme comme un esse percipi, un « être perçu ${ }^{4}$. Il met en évidence un pouvoir masculin discursif, celui de nommer, de définir la femme, dans ses propriétés corporelles, mentales, etc. qui la place dans une position fragile et incertaine de « dépendance symbolique », puisque condamnée à être «vue à travers des catégories dominantes, c'est à dire masculines, à exister « d'abord par et pour le regard des autres » 5 .

Trouver trace des femmes migrantes n'est donc pas chose aisée. «Les pauvres, les femmes et les oiseaux de passage laissent souvent peu de traces» poétise Philippe Rygiel ${ }^{6}$. Pour palier ses difficultés de méthode, l'histoire orale apparaît comme la plus valable dans la mesure où elle

\footnotetext{
${ }^{1}$ M. Perrot, Les femmes ou les silences de l'Histoire, Champs Flammarion, Paris, 1998, p. III.

${ }^{2}$ M. Riot-Sarcey, «Les sources du pouvoir, l'événement en question » dans F. Collin (dir.), Le genre de l'Histoire. Les Cahiers du GRIF 37/38, Paris, Editions Tierce, 1988, p. 26.

${ }^{3}$ Ainsi, Hugo voyait, sans doute comme tous ses contemporains, dans les femmes des barricades de 1848, des «filles publiques », incapable de concevoir qu'elles puissent être de bonnes mères de famille. Cf. : Ibid., p. 31 .

${ }^{4}$ P. Bourdieu, La domination masculine, Paris, Seuil, 1998, p. 70.

${ }^{5}$ Ibid., p. 73.

${ }^{6} \mathrm{P}$. Rygiel, « Des mondes genrés et mobiles », Op. Cit.
} 
permet de rendre compte de la manière la plus authentique de ces «voix» féminines ${ }^{1}$. Elle est cependant impossible pour des époques les plus reculées qui n'ont plus de témoins en vie, et c'est le cas de cette étude. Les premiers entretiens réalisés auprès de générations bien postérieures à celles de l'immigration ne se sont pas révélés très concluants. Les descendants d'immigrés allemands au Chili sont toujours très enthousiastes à l'idée de partager le passé familial, mais il est difficile pour le chercheur de retrouver, dans cet exercice de mémoire collective, des éléments d'authenticité. On observe une tendance à réciter une histoire très proche de celle rencontrée dans les ouvrages commémoratifs, qui sont bien connus de la communauté, et une vision finalement très stéréotypée de l'expérience des aïeules, figées dans des rôles d'accompagnatrices dignes et fidèles. Il y a bien réinvention et redéfinition de l'expérience féminine par le travail de mémoire, fait en soi-même intéressant, mais qui ne constitue pas l'objet de cette étude.

L'histoire des femmes migrantes invite donc l'historien(ne) à faire preuve d'innovation dans sa méthodologie et à donner visibilité à des documents considérés comme n'étant pas des documents d'archives. «Les femmes ont toujours participé aux migrations mais elles sont absentes d'un grand nombre de sources «classiques », ce qui oblige donc à en « pressurer " d'autres pour les rendre visibles » résume Anne Morelli ${ }^{2}$. On aura donc recours aux sources parlementaires, notariales, judiciaires, aux recensements, aux archives d'association d'émigrés, aux documents d'entreprise ou de missions religieuses, à la littérature, aux témoignages et journaux intimes, aux correspondances privées enfin. «Siècle de familles, d'armoires et d'écritures personnelles, le XIX ${ }^{\mathrm{e}}$ siècle est un immense réservoir. Correspondances, journaux intimes, autobiographies ont été exhumés et analysés comme mode de communication et d'expression » note Michelle Perrot ${ }^{3}$. En effet, la prise en compte croissante de la vie privée et familiale a modifié le regard que l'on portait sur ce type d'écrits.

La recherche sur les Allemandes émigrées au Chili au XIX ${ }^{\mathrm{e}}$ siècle est largement facilitée par le fait que ces femmes, alphabétisées, savaient et aimaient écrire. La thèse d'Alexandra Lübke s'appuie sur la correspondance de sept femmes, qui ont constitué le point de départ de la recherche, bientôt enrichis par d'autres correspondances, des mémoires et des journaux intimes conservés aux archives Emilio Held Winkler du DCB/Liga chileno-alemana. Le cœur des sources est constitué par un ensemble d'écrits de femmes, à savoir huit correspondances à destination de l'Allemagne, deux journaux intimes de voyage et sept mémoires et souvenirs. Il est complété par des récits de voyageurs et de scientifiques tels que Paul Treutler, José Alfonso, Kurt Bauer, Otto Bürger, Fritz Gädicke et Hugo Kunz, des archives de l'intendance de Valdivia et de Llanquihue du Ministère de

\footnotetext{
${ }^{1}$ Sur l'histoire orale, $C f$. F. Descamps, L'historien, l'archiviste et le magnétophone. De la constitution de la source orale à son exploitation, Comité pour l'histoire économique et financière de la France, 2001 ; P. Joutard, Ces voix qui nous viennent du passé, Paris, Hachette, 1983 et « Histoire orale et histoire des femme » Table ronde du 16 octobre 1981, dans Bulletin de l'histoire du temps présent, supplément n $3,1982$. ${ }^{2}$ A. Morelli, Op. cit.

${ }^{3}$ M. Perrot, Les femmes, Op. Cit., p. 9
} 
l'intérieur, des correspondances et des mémoires d'administrateurs comme Vincente Pérez Rosales, quelques titres de périodiques et des sources statistiques telles que les recensements décennaux chiliens. Des sources produites exclusivement par des hommes.

Au sein du corpus principal se dégage trois temporalités. Le premier ensemble de textes, constitué de correspondances et de journaux intimes, est daté des premiers temps de l'émigration, autour de 1850 et donc produit par les pionnières du processus de colonisation. Le second ensemble est postérieur d'une génération, écrit autour de 1890-1900. Il s'agit principalement de mémoires ou souvenirs de femmes d'âge mûr qui font part de leur expérience de l'émigration en tant qu'enfants et de leur expérience de descendantes d'immigré(e)s ${ }^{1}$. Enfin, un dernier texte, plus tardif, de 1940, permet d'introduire une triple temporalité dans l'expérience migratoire féminine. Dans l'ensemble, les écrits des générations postérieures à la première sont plus rares, ce qui invite à avancer deux hypothèses : soit les femmes de deuxième ou troisième génération éprouvaient moins le besoin d'écrire à la vieille patrie ou à elles-mêmes, sous la force naturelle de l'intégration, soit leurs écrits n'ont pas dépassé la sphère de diffusion familiale ou encore ont été perdus, et par conséquent, dans les deux cas, restent difficilement accessibles pour la recherche. Il faut en effet préciser que les écrits de la première génération, ont été non seulement nombreux, mais également souvent publiés, sans doute parce qu'ils décrivent l'époque héroïques des premiers temps, topos fondamental de la culture germano-chilienne, ce qui facilite grandement leur consultation et analyse.

\subsubsection{Des epistolières et diaristes}

Dix femmes représentent la première génération. Klara Anwandter (1820-1919) émigre au Chili en 1850 avec son père, Karl Anwandter, alors apothicaire de profession, maire de Calau et député du Landtag de Prusse en 1847, ainsi qu'avec son fiancé, Theodor Körner. La famille fuit la répression antilibérale qui suit l'échec de la révolution de 1848 et choisit le Chili comme terre de refuge à l'invitation de Kindermann. Klara a écrit une lettre, sur le bateau, au moment du départ, à ses belles-sœurs Körner ${ }^{2}$. Sophie von Bischhoffshausen (1815-1892), née von Eschwege, émigre en 1854 avec son mari Gustave et leurs six enfants. Elle met au monde deux autres filles au Chili. La famille, originaire de Neuenrode en Hesse, loge quelques mois à Valdivia avant d'acheter le domaine du Roble, où elle se consacre aux activités agricoles. Sophie a laissé une correspondance d'une dizaine d'années (1854-1865) qui relate son expérience de la migration depuis le départ du bateau, à destination de ses parents puis de ses frères et sœurs ${ }^{3}$. Antonie Exss (1794-1882), née

\footnotetext{
${ }^{1}$ Dans l'historiographie des migrations, les enfants arrivés en bas âge, en général avant l'âge de dix ans, dans le pays d'accueil, sont considérés comme de la deuxième génération, au même titre que leurs frères et sœurs nés après la migration, parce que l'ont considère que leurs souvenirs d'enfant sont relatifs au pays d'immigration.

${ }^{2}$ Lettre de Klara Anwandter dans I. Schwarzenberg (éd.), Dokumente zur Geschichte der deutschen Einwanderung, III, Santiago, Talls. Gráfs. Claus von Plate, 1973, pp. 7-8.

${ }^{3}$ Lettre de Sophie von Bischhoffshausen dans I. Schwarzenberg (éd.), Dokumente zur Geschichte der deutschen Einwanderung, VI, Santiago, Talls. Gráfs. Claus von Plate, 1973.
} 
Wiegand, et sa fille Anna (1826- ?) ont émigré au Chili en 1850-1851, avec le père, Heinrich et une sœur plus jeune. Fille et mère écrivent à la famille, notamment aux autres enfants, restés en Allemagne auprès de leur propre famille. Les lettres publiées datent de 1852 et $1868^{1}$. Clémentine Gleisner (1838-1897) a effectué le voyage pour le Chili en 1865 avec son frère Victor, pour y retrouver un autre frère, Moritz, entrepreneur installé à Nacimiento, près de Concepción et fondateur de la lignée des Gleisner au Chili ${ }^{2}$. Elle a écrit un journal intime relatant le voyage de Hambourg à Nacimiento et les premiers temps de son existence au Chili, document conservé dans la famille de son époux, Carl Aichel et légué aux Archives Emilio Held Winkler ${ }^{3}$. Adelheid Kindermann (1817- ?) est la mère d'une famille paysanne émigrée au Chili à une date inconnue. A la date des correspondances publiées, en février 1853, la famille est en tout cas installée depuis plusieurs mois, puisque les cultures ont déjà donné leurs fruits ${ }^{4}$. En réalité, leur fils aîné, Franz, est l'un des principaux artisans de l'immigration privée au Chili. On peut donc supposer que l'émigration est précoce, sans doute autour de 1850. Marie Konrad (1828-1906), née Püschel, est arrivée au Chili en 1856 avec son mari Julius mais aussi avec ses parents, ce qui explique peut être qu'elle n'ait pas eu la nécessité d'écrire au moment de son arrivée. Sa correspondance est donc plus tardive, des années 1888-1891, et est déclenchée par le départ de ses propres enfants, une fois mariés et installés sur leurs propres terres ${ }^{5}$. Elle donne donc davantage de renseignements sur la deuxième génération. Magdalena Barbara Aichele (1830-1857) fait partie de l'émigration souabe et plus précisément du village de Nellingen (Würtemberg) vers le Chili, où elle a émigré à bord de l'«Australia » en 1852. Elle arrive célibataire mais avec ses frères, Gottlieb et Christian. Elle écrit à ses parents en 1855, et ceux-ci la rejoignent au Chili en 1856 avec les plus jeunes frères et soeurs $^{6}$. Elle épouse à Cabulco, le 8 juin 1855, David Herz, passager du même bateau, mais meurt en couche en 1857. Pauline Metzdorf (ou Metzdorff) est arrivée à Valdivia le 13 novembre 1850 à bord du «Hermann », en compagnie de son mari Auguste, agriculteur de Frankfurt-sur-Oder, de leurs trois enfants dont un nourrisson, et de son beau-frère Louis. Elle écrit à ses parents depuis le bateau, puis une fois arrivée au Chili, jusque $1852^{7}$. Enfin, Fanny Zöhrer (1825-1873), de son vrai prénom Fransisca, est arrivée à Valdivia avec le «Fortunata » en 1854 en compagnie de son époux

1 Lettres de Antonie et Anna Exss dans G. Schwarzenberg (éd.), Geschichtliche Monatsblätter. Quellensammlung und Beiträge zur Geschichte der Deutschen Einwanderung, XII, Valdivia, 1918, pp. 3-22.

${ }^{2}$ Sur les Gleisner, voir C. Converse, « Die Deutschen in Chile », Op. Cit., p. 320.

${ }^{3}$ C. Gleisner, Tagebuch, transcription dactylographiée, s. d, s.p., Archivo Emilio Held Winkler, Fonds général, Santiago de Chile, (PER 100 GLE)

${ }^{4}$ Lettres de Adelheid Kindermann dans G. Schwarzenberg (éd.), Geschichtliche Monatsblätter, Op. Cit, XII, Valdivia, 1918, pp. 39-51.

${ }^{5}$ Lettres de Marie Konrad dans Kurt Konrad (ed.), Familia Konrad, Julius Konrad y Marie Püschel, 150 años, 1856-2006, Santiago, Impr. Gráfica Escorpio, 2007 et Festschrift : 75 Jahre Deutschtum in Llanquihue, Op. Cit., p. 138.

${ }^{6}$ Lettre de Magdalena Barbara Aichele du 28.02.1855, transcription dactylographiée et document original, Biblioteca e Archivo Emilio Held Winkler, Santiago de Chile, 3 p.

${ }^{7}$ Pauline Metzdorf et Klara Awandter ont voyagé sur le même bateau. Lettres de Pauline et Louis Metzdorf dans G. Böhm (éd.), Dokumente sur Geschichte der deutschen Einwanderung, V, Santiago, Talls. Gráfs. Claus von Plate, 1974, pp. 23-43. 
Franz Fonck, le premier et seul médecin jusque 1869 de la colonie de Llanquihue. Au cours des cent-vingt jours de voyage, elle rédige un journal de bord ${ }^{1}$.

Toutes ces femmes sont des Deutsch-chilenen qui vivent en majorité à la campagne. Le cas de Fanny et de Clémentine est peu particulier. Toutes deux sont épouses de médecins allemands recrutés par le gouvernement chilien pour une durée fixe plusieurs fois prolongée. Leurs familles gardent des liens très étroits avec l'Allemagne, où elles voyagent à plusieurs reprises et envoient les enfants pour s'y former. Fanny meurt d'ailleurs en Allemagne.

Les femmes représentant la deuxième génération sont au nombre de sept. Rosine Held (18401908), née Schönherr, a émigré au Chili à 20 ans, avec ses parents et ses quatre autres frères et sœurs. Elle a épousé en septembre 1861 Julius Held avec lequel elle a eu cinq enfants. Ont été conservé des lettres à son amie Marie Rummler et à son cousin Johann, datées de 1890-1891, dans lesquelles elle relate ses souvenirs de l'émigration et donne de riches indices de leur situation au début des années $1890^{2}$. Gertrud Muñoz est, en quelque sorte, un fruit de la politique de « germanisation » de l'éducation chilienne. Son père, José Muñoz, fut envoyé en Allemagne par le gouvernement chilien afin de devenir formateur de professeurs du primaire et secondaire. Quelques années plus tard, sa mère, de nationalité autrichienne, fut recrutée pour un contrat de professeure à Valparaiso. José fut son professeur d'espagnol. Le couple s'est installé avec ses deux premiers enfants à Valdivia, où José avait été nommé formateur. Gertrud, l'ainée, a laissé des souvenirs de son enfance à Valdivia et en particulier de l'école allemande. Son récit donne des indications sur la vie de la communauté germanique de Valdivia au tournant du siècle ${ }^{3}$. Pauline Renz (1857-1956), née Hube, est née au Chili de deux parents germano-allemands, émigrés jeunes au Chili : sa mère en 1852 avec la famille Geisse, où elle servait comme couturière, et son père en 1855 avec l'intention de monter un commerce. Pauline évoque le parcours de ses parents et ses souvenirs d'enfance. Elle a épousé en 1875 le pasteur Renz, dont elle a eu 6 enfants, et le couple a effectué plusieurs voyage en Allemagne ${ }^{4}$. Berta Robert (1838-1920), née Schöbitz, a laissé quelques souvenirs d'enfance de la Union, où sa famille, originaire de Silésie, s'est installée après avoir émigré au Chili en 1850-1851 à bord du «Sankt Pauly » ${ }^{5}$. Berta avait alors 14 ans. Elle a épousé en 1862 Franz Robert, dont elle a eu 7 enfants. Anna Schmidt (1836-1917), née Bittner,

\footnotetext{
${ }^{1}$ Journal de Fanny Fonck, née Zöhrer, manuscrit, Biblioteca e Archivo Emilio Held Winkler, Santiago de Chile. Publié dans G. Schwarzenberg (éd.), Geschichtliche Monatsblätter, Op. Cit., IX, Valdivia, 1917, pp. 156-170.

${ }^{2}$ Lettres de Rosine Held, née Schönherr, dans Briefwechsel Schubert-Held-Aurich und andere (PER 906 $\mathrm{EH})$, documents originaux et transcriptions dactylographiées, Biblioteca e Archivo Emilio Held Winkler, Santiago de Chile, pp. 127-144.

${ }^{3}$ G. Muñoz, Kindheitserinnerungen aus Valdivia, transcription dactylographiée (1984), Biblioteca e Archivo Emilio Held Winkler, Santiago de Chile.

4 Errinerungen von Pauline Renz, geb. Hube (PER $966 \mathrm{EH}$ ), document original et transcription dactylographiée, Biblioteca e Archivo Emilio Held Winkler, Santiago de Chile.

${ }^{5}$ Berta Robert, née Schöbitz, «Erinerungen aus La Union»dans Berichte, Erinnerungen und Briefe der Anfangszeit der Kolonisation im Süden Chiles, Tome V (PER 953 EH), documents originaux et transcriptions dactylographiées, Biblioteca e Archivo Emilio Held Winkler, Santiago de Chile, pp. 85-89.
} 
est arrivée au Chili en 1852 avec son père et ses cinq frères et sœurs, comme en atteste ses souvenirs ${ }^{1}$. La famille s'est installée à la Fabrica, sur les rives du lac Llanquihue. Son mariage avec Franz Schmidt en 1855 est le premier enregistré à la paroisse de Puerto Montt ${ }^{2}$. Berta von Schwarzenberg (1829-1926), née Klix, originaire de Francfort-sur-l'Oder, en Prusse orientale, est arrivée au Chili en 1849, son père ayant été convaincu par Franz Kindermann de s'installer sur ses terres. Elle a épousé Adolf Emile Schwarzenberg, fut la fondatrice et la première présidente de la Société de Secours des Dames d'Osorno, la Sociedad de Socorros de Señoras de Osorno. Elle a laissé des souvenirs d'enfance de son voyage au Chili - elle avait alors $10 \mathrm{ans}^{3}$.

Enfin, Hélène Scheel, (1883-1960), née Biel Linke, représente les générations postérieures. Née au Chili, de parents allemands émigrés depuis une et deux générations, elle écrit en 1940, à la demande de l'un de ses fils, l'histoire de sa famille et partage également ses mémoires d'enfant ${ }^{4}$.

Les textes étudiés sont donc produits par des femmes qui ne sont en aucun cas des écrivains expérimentés. Roger Chartier souligne qu'il y a corrélation évidente entre alphabétisme et pratique épistolaire, mais, précise t'il, «une compétence n'entraîne pas nécessairement une pratique $»^{5}$. C'est bien l'émigration qui semble générer la pratique épistolaire. En effet, «le besoin de recourir à la communication écrite dépend à priori de la distance qui sépare les interlocuteurs » rappellent Cécile Dauphin, Pierrette Lebrun-Pezerat et Danièle Poublan ${ }^{6}$. L'importance des relations épistolaires en milieu d'émigration a été maintes fois soulignée. La situation d'éloignement pousse un grand nombre à apprendre à écrire sur le tas. Ainsi, la lettre peut devenir instrument d'acculturation écrite, dans une perspective dynamique de l'alphabétisation où l'usage motive l'apprentissage. «Les migrations, qui portent la nécessité de communiquer à distance, jouent le rôle de catalyseur $»$, conclut les auteures ${ }^{7}$.

Lettres et journaux intimes couvrent des périodes très diverses. Sophie von Bischhoffshausen écrit sur une dizaine d'années, tandis que Magdalena Barbara Aichele et Klara Anwandter n'ont laissé qu'une seule lettre ${ }^{8}$. L'écriture d'une même lettre peut être filée dans le temps ou ponctuelle.

\footnotetext{
${ }^{1}$ Souvenirs de Anna Schmidt dans Berichte, Op. Cit., pp. 247-251.

2 Matrimonios Puerto Montt (1855-1884) (EH 5000 PM), Biblioteca e Archivo Emilio Held Winkler, Santiago de Chile.

${ }^{3}$ Souvenirs de Berta Klix dans Berichte, Op. Cit., pp. 79-84

${ }^{4}$ Histoire familiale et mémoires de Hélène Scheel née Biel Linke, document original et dactylographié conservé par la famille Scheel. Nous remercions Gisela Scheel d'avoir mis à disposition les mémoires de sa grand-mère.

${ }^{5}$ R. Chartier, «Introduction» R. Chatier (dir.), La correspondance, les usages de la lettre au XIX ${ }^{e}$ siècle, Fayard, Paris, 1991, p. 18-19.

${ }^{6}$ C. Dauphin, P. Lebrun-Pezerat et D. Poublan, «L'enquête postale de 1847 » dans Ibid., p. 46.

${ }^{7}$ Ibid., p. 75-76.

${ }^{8}$ En réalité, ces lettres uniques sont sans doute les derniers témoins d'un échange plus vaste, perdu ou détruit ou bien, les seules publiées. L'état des sources dépend en effet très largement des «politiques » familiales, conscientes ou non, de préservation des objets de mémoire. Certaines familles entreprennent la démarche de déposer les lettres de leurs aïeux dans un centre d'archive ou un musée, qui peuvent offrir des conditions optimales de conservation après avoir entrepris sa transcription, ce qui a l'avantage de rendre les documents accessibles et lisibles. Le déchiffrement de l'écriture gothique du XIX ${ }^{\mathrm{e}}$ siècle est une difficulté non négligeable en effet, et le travail de transcription des descendants des familles comme Emilio Held Winkler,
} 
Sophie écrit ses lettres progressivement, à trois ou quatre dates différentes, au cours des huit semaines qui séparent chaque relève postale, et cette pratique s'apparente presque à l'écriture d'un journal intime. Journaux et correspondances sont en effet des genres d'écritures intimes différents mais étroitement liés. Le journal intime, pratique qui se diffuse au XIX ${ }^{\mathrm{e}}$ siècle comme «hygiène intime » privilégiée des femmes, possède des caractéristiques qui le différencient nettement de la correspondance, rappelle Martine Ried : d'abord, il est écrit au jour le jour, ensuite, le contenu de son écriture est principalement d'ordre privé, l'auteur ne s'adresse qu'à lui, troisièmement, le texte n'est pas destiné à la publication, et enfin, il s'étend en général sur une longue période de temps ${ }^{1}$. Elle montre cependant que l'opacité entre les deux genres n'est pas si nette, puisque les épistoliers sont presque tous des diaristes - on écrit à l'autre pour « se connaître » - tandis que le journal intime tend sans cesse à inventer un autre, à s'adresser à une deuxième personne du singulier : un « tu » qui permet de rendre visible par contraste le « je » afin de produire un effet d'écho et de dialogue avec un journal qui sert de «confident» ou de confrontation avec un lecteur hostile «qui ne comprendra pas $» .^{2}$ La présence de cet autre peut suffire à elle-seule à déclencher l'écriture intime. Le journal de bord de Fanny est adressé à une amie de Prague, personnage constamment présent dans l'écriture : dans ses entrées régulières, elle interpelle son amie lectrice, la tutoie, l'interroge. A travers l'écriture intime sous forme de journal ou de lettre, c'est donc d'abord une écriture du «soi » qui se dégage.

Analysant les journaux de religieuses françaises au Chili, Sol Serrano affirme que « les journaux de vie se constituent en eux-mêmes comme littérature et comme sources pour l'histoire $»^{3}$. Quant à la lettre, constate José Luis Diaz, elle constitue une sorte de «littérature à l'état sauvage » ou «en réserve » qui permet d'observer les processus de construction identitaire des personnes d'une époque, une identité tendue entre la réalisation du moi et les contingences collectives ${ }^{4}$. Mireille Bossis démontre qu'elle est bien un document d'histoire en tant qu' « objet d'étude qui réfracte et condense notre manière d'être au monde, de façon différente, à chaque époque $»^{5}$.

les éditeurs de correspondances comme Ingeborg Schwarzenberg et plus récemment, le personnel des archives Emilio Held Winkler de la Liga chileno-alemana est de ce point de vue de grande valeur.

${ }^{1}$ M. Ried, «Écriture intime et destinataire » dans M. Bossis, C. A. Porter (dir.), L'épistolarité à travers les siècles: geste de communication et/ou d'écriture, Stuttgart, F. Steiner, 1990, p. 21.

${ }^{2}$ Ibid., p. 22

${ }^{3}$ S. Serrano, Vírgenes viajeras: diarios de religiosas francesas en su ruta a Chile, 1837-1874. Santiago de Chile, Ediciones Universidad Católica de Chile, 2000, p. 16.

${ }^{4}$ J.-L. Diaz, «La féminité de la lettre dans l'imaginaire critique au XIX ${ }^{\mathrm{e}}$ siècle » dans C. Planté, L'épistolaire, un genre féminin?, Honoré Champion, Paris, 1998, p. 160-161.

${ }^{5}$ M. Bossis, «Une correspondance paysanne en Normandie (1860-1866) : quelle approche ? » dans A. M. Sohn, La correspondance, un document pour l'histoire, Publications de l'Université de Rouen, 2002, p. 90. 
Les premières études sur l'immigration allemande au Chili ne disposaient pas des outils d'analyse historiographique des femmes et du genre, développés postérieurement. Ce sont là deux catégories qui permettent aujourd'hui de compléter voire de réorienter les premières observations. Reconsidérer la femme et le genre dans les processus de migration permet d'ouvrir plusieurs pistes de réflexion. Il ne s'agit pas de se contenter de constater la présence des femmes en migration, mais de proposer une redéfinition du champ d'étude à travers une réflexion à la fois sur le statut de la femme comme mobile et sédentaire et sur la mobilité elle-même. De plus, les lettres, journaux de vie et mémoires des Allemandes immigrées au Chili au XIX ${ }^{\mathrm{e}}$ siècle sont autant de sources qui permettent d'entrevoir comment se construit l'identité de la communauté germano-chilienne, une identité originale qui se meut entre les catégories de nation, émigration et genre. 


\section{CONTOURS D'UN GROUPE SOCIAL : LES IMMIGRÉES ALLEMANDES AU CHILI}

Avant de retracer l'expérience des immigrées allemandes au Chili et d'analyser leur texte, il convient de dresser les contours du groupe social en question, et en premier lieu, ses contours numériques. Les dénombrements de population ont longtemps reposé sur les chefs de famille et seules les veuves étaient recensées comme tel. Les épouses et parentes apparaissaient, parfois sans nom, ni indications, à la suite du chef de feu. «En somme, les femmes ne comptent pas », résume Michelle Perrot ${ }^{1}$. Par conséquent, il est impossible de fournir un chiffre précis des Allemandes émigrées au Chili au XIX ${ }^{\mathrm{e}}$ siècle - les historiens s'accordent déjà difficilement sur un chiffre pour la population allemande totale ${ }^{2}$. Déterminer un ordre de grandeur de la taille du groupe permet cependant d'en comprendre les caractéristiques. Le recours à la quantification permet en effet, souligne Philippe Rygiel, d'établir un travail en série, enrichit la comparaison et contraint à préciser le vocabulaire ${ }^{3}$. Dans ce cas, il laisse apparaître une réalité jusqu'alors peu soulignée et pourtant digne d'intérêt : la présence d'un contingent important de femmes seules, célibataires ou veuves, jeunes ou moins jeunes, parmi celles qui émigrent. D'autre part, la prise en compte de l'origine socio-économique et culturelle de ces femmes, célibataires ou mariées, permet de comprendre les raisons qui ont motivé leur migration. Dans cette décision, la part de l'individu ne doit pas être négligée. Comment expliquer en effet que, à conditions égales, certaines émigrent et d'autres restent?

\subsection{Compter pour comprendre}

\subsubsection{Les statistiques allemandes}

Les sources qui renseignent sur l'émigration allemande au Chili sont les listes de passagers des bateaux reliant Hambourg à Valdivia ou Valparaíso, tenues par les capitaines des navires et remises normalement aux autorités à leur arrivée ${ }^{4}$. Celles de 1851 enregistrent tous les émigrants sans lacune, et à partir de 1855 y figure chaque passager ${ }^{5}$. Elles indiquent pour chacun ses dates de naissance et d'arrivée au Chili, son âge, son origine, et le cercle qui l'accompagne : épouse,

\footnotetext{
${ }^{1}$ M. Perrot, Les femmes, Op. Cit., p. III.

${ }^{2}$ Le nombre des Allemands émigrés au Chili a fait l'objet de nombreux calculs, certains complètement fantaisistes, oscillant globalement entre 10000 et 37 000. Kurt Schobert les expose en détail les calculs de divers auteurs, $C f$. K. Schobert, $O p$. Cit., p. 194 et suivantes.

${ }^{3}$ P. Rygiel, «Les traces de la mobilité géographique» Actes de l'Histoire de l'Immigration, 0/ 2000. Accessible en ligne à l'URL : http://barthes.ens.fr/clio/revues/AHI/articles/volumes/mobgeo.html [consulté le 17 janvier 2008].

${ }^{4}$ G. Dupeux, Op. Cit., p. 5.

${ }^{5}$ J.-P. Blancpain, Les Allemands au Chili, Op. Cit., p. 195 et A. Clasen, «Deustsche Auswanderung nach Chile, 1850-1852 » dans Zeitschrift für Niedersächsiche Familienkunde, 32. Jahrgang, Heft 2, mars 1957, p. 47.
} 
enfants, parents et personnel éventuel. Mais elles ne distinguent pas les vrais émigrants des simples voyageurs ou résidents de retour au Chili après un séjour en Allemagne. Elles permettent néanmoins d'établir des estimations presque complètes, concernant l'émigration directe depuis Hambourg mais aussi indirecte par l'Angleterre, depuis Liverpool ou Southampton ${ }^{1}$. Il a sans doute existé également des listes d'arrivées, dressées par les intendants chiliens, de Pérez Rosales en 1852 à Prieto en 1883, mais elles ont disparu dans l'incendie des archives de l'Intendance de Valdivia en $1909^{2}$. Les seuls vestiges sont quelques listes transmises à l'époque aux ministères de l'intérieur et des relations étrangères, mais de manière irrégulière ${ }^{3}$.

\subsubsection{Les statistiques chiliennes}

$\mathrm{Au}$ Chili, les statistiques de l'immigration n'ont jamais fait l'objet d'un travail spécifique et systématique au XIX ${ }^{\mathrm{e}}$ siècle, si ce n'est, de manière indirecte, pour la période 1882-1914, lorsque fonctionnait l'Agencia General de Colonización e Inmigración en Europa qui fournissait les chiffres des émigrés européens recrutés. Les recensements chiliens, décennaux à partir de 1854, sont ainsi les seuls documents qui renseignent sur les populations étrangères résidant au Chili ${ }^{4}$. Ils ont en effet l'avantage de distinguer par sexe, dès 1854, les «étrangers » des «nationaux ». En 1865, sont distingués, parmi les «étrangers », les «naturalisés » (nacionalizados), en 1875, les «naturalisés » et les «résidents et de passage»(residentes y transeúntes). Enfin en 1885, les étrangers « de passage », « résidents » et «naturalisés » forment trois catégories distinctes. En ce qui concerne la population allemande au Chili, qu'elle soit résidente, de passage ou naturalisée, l'évolution dégagée de 1854 à 1895 révèle une augmentation générale, de 1822 individus à 7560 (figure 1).

\footnotetext{
${ }^{1}$ A. Clasen, «Die Schiffe der Chile-Auswanderung über Hamburg 1850-1875 und die Schiffbauerfamilie von Somm », Zeitschrift für Niedersächsiche Familienkunde, 38. Jahrgang, 1/1963 p. 1. Il resterait à prendre en compte les autres voies d'émigration, directement depuis l'Angleterre à bord d'une compagnie anglaise, comme l'a fait la famille Claude, ou encore, comme le repère Sol Serrano, chez les religieuses missionnaires françaises dont elle étudie les journaux, les routes de New-York et l'isthme de Panama et celle de Buenos Aires et Mendoza. $C f$. S. Serrano, Virgenes viajeras, Op. Cit., p. 16.

${ }^{2}$ E. Held Winkler, Documentos sobre la colonización del Sur de Chile, Santiago, Talleres Grafico Claus Von Plate, 1970, p. 17 et J.-P. Blancpain, Les Allemands au Chili, Op. Cit., p. 197.

${ }^{3}$ Par exemple : Liste du «Susanna », du « Adolph » et du «Victoria » de 1852, ANH, MINT, Colonización Alemana (1849-1852), vol. 273, p. 193, 246, 307 ; Lettre de F. Geisse du 12.4.1857, ANH, MINT, Colonización de Llanquihue (1857-1859), vol. 389, s. p ; Liste des de 1' «Iserbrook », arrivé le 2.11.1860, ANH, MINT, Oficios recibidos de la Intendencia de Llanquihue (1859-1863), vol. 403, s. p. [Distingue émigration subventionnée et émigration volontaire (emigrados subvencionados, emigrados salidos por su propia cuenta), celle à destination de Valdivia ou de Valparaiso] ; Rapport du 20.6.1883, $\mathrm{n}^{\circ} 242$, annexe 1, ANH, MREL, Oficios recibidos de la Intendencia de Llanquihue (1883 - 1884), vol. 280 [mémoire de l'intendance, de 1852 à 1883, où Prieto recense 13 voiliers arrivés à Puerto Montt depuis 1852, $C f$. La critique de J.-P. Blancpain, Les Allemands au Chili, Op. Cit., p. 196 (note de bas de page 44)].

${ }^{4}$ Censo general de la República de Chile: levantado en abril de 1854, Santiago de Chile, Imp. Del Ferrocarril, 1858, Censo general de la República de Chile levantado el 19 de abril de 1865, Santiago, Impr. Nacional, 1866; Quinto Censo general de la Población de Chile: levantado el 19 de abril de 1875, Valparaíso, Impr. del Mercurio, 1876; Sesto Censo general de la Población de Chile: levantado el 26 de noviembre de 1885, Valparaíso, La Patria, 1889-1890; Sétimo Censo general de la Población de Chile: levantado el 28 de noviembre de 1895, Santiago, La Oficina, 1900-1904.
} 


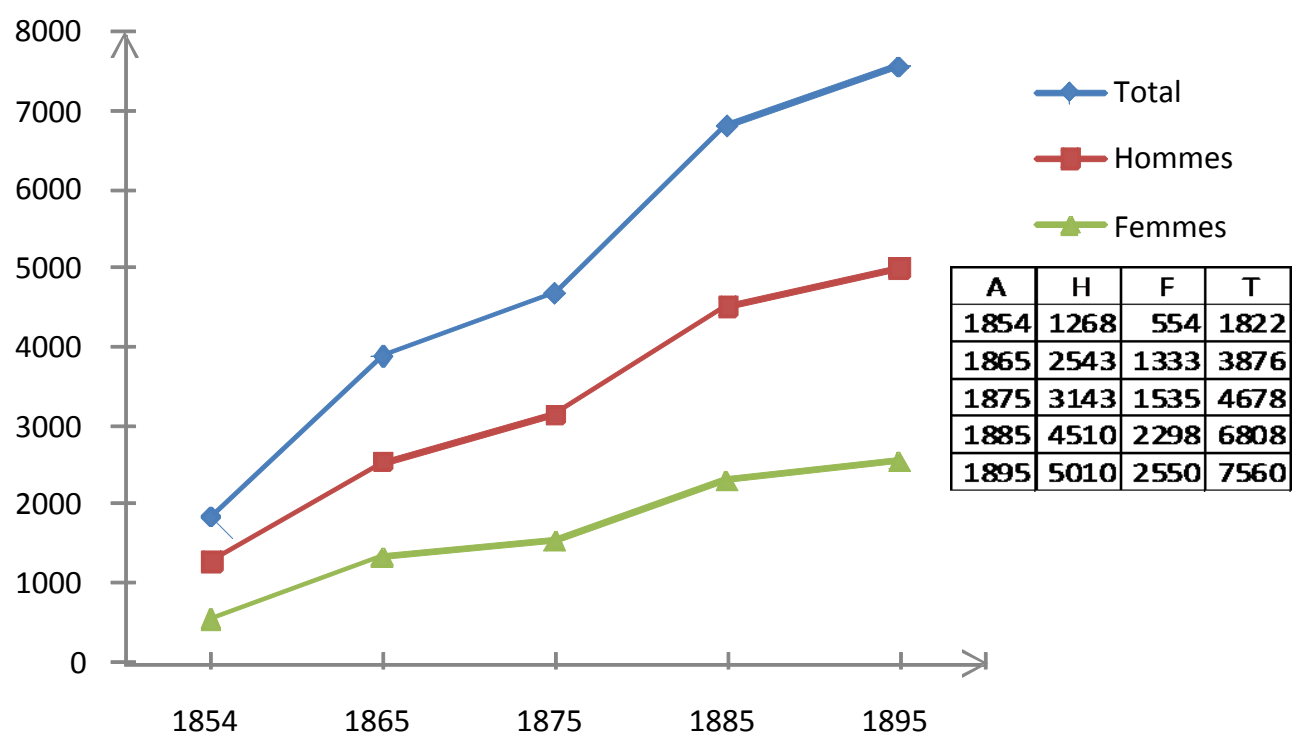

Figure 1. Évolution de la population allemande au Chili d'après les recensements chiliens (1854-1895).

Cependant à l'échelle provinciale, notamment dans les régions de forte émigration allemande, comme Valdivia ou Llanquihue, on observe, après une forte augmentation, une diminution, temporaire ou générale, de la population allemande. L'incongruité est particulièrement frappante pour Llanquihue (figures 2 et 3).

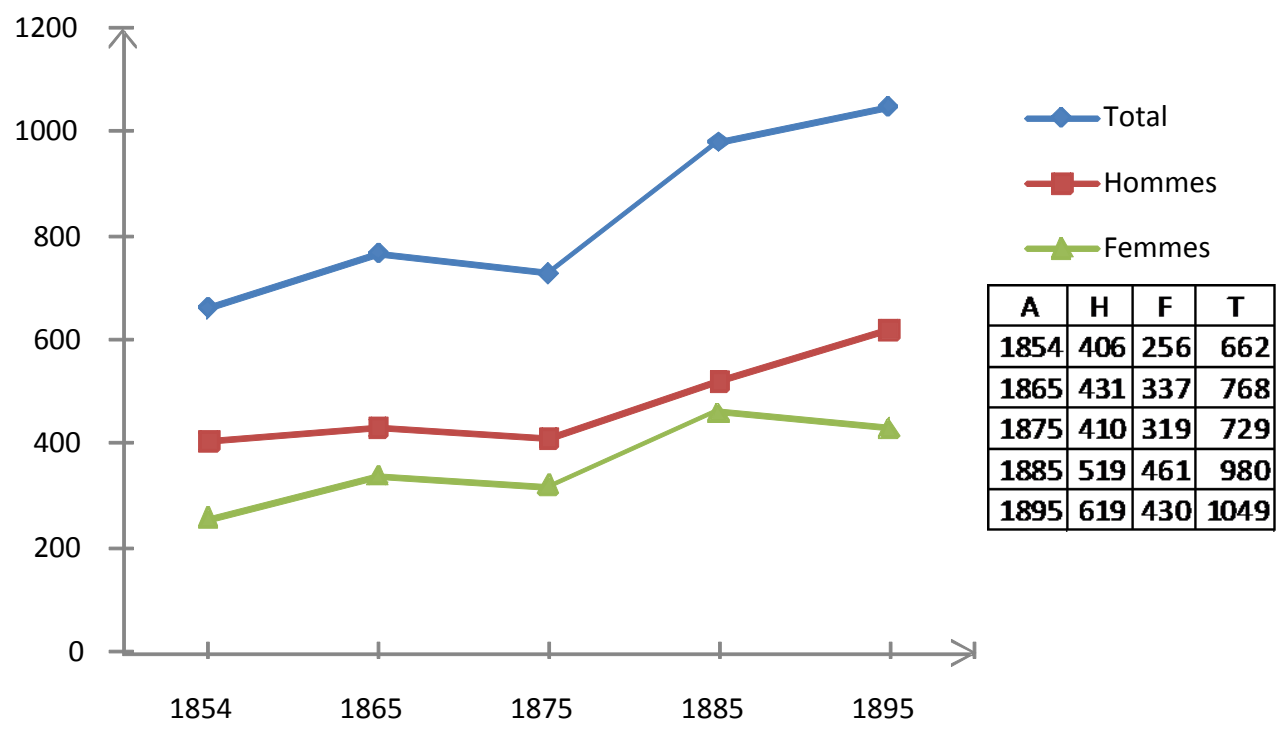

Figure 2. Évolution de la population allemande à Valdivia d'après les recensements chiliens (1854-1895). 


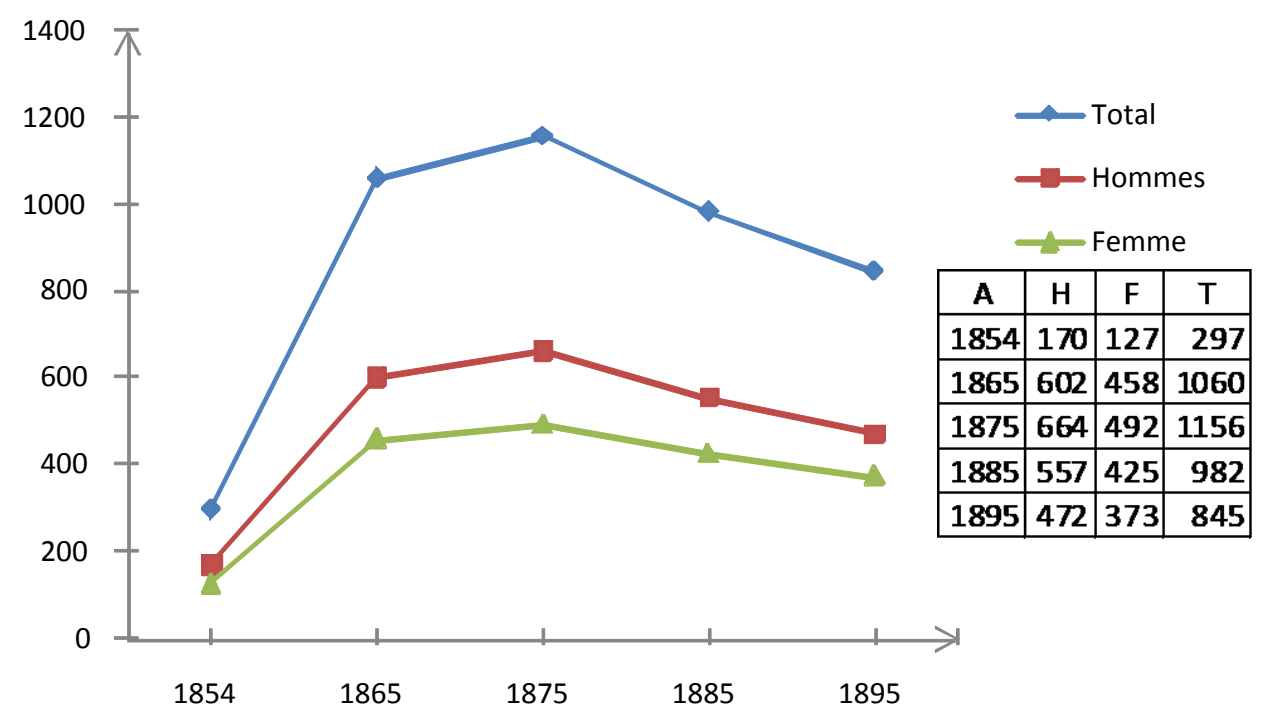

Figure 3. Évolution de la population allemande à Llanquihue d'après les recensements chiliens (1854-1895).

Plusieurs hypothèses peuvent expliquer cette diminution de population à l'échelle locale. L'hypothèse démographique, celle d'un solde migratoire négatif ou d'un taux de fécondité qui n'assurerait pas le renouvellement des générations, est à éliminer d'emblée. Elle est en effet peu probable étant donné le taux de fertilité des ménages ${ }^{1}$ et le peu de départs signalés ${ }^{2}$. L'hypothèse juridique l'emporte plutôt. La nationalisation des Allemands émigrés au Chili était fréquente, même automatique dans le cas des émigrés recrutés par l'Etat chilien. Les dispositions de la loi de 1845 prévoyaient que tout étranger pouvait acquérir la nationalité après un an de résidence sur simple demande au conseil municipal de son lieu de résidence ${ }^{3}$. Ainsi, de 1850 à 1880, les immigrés demandèrent systématiquement la nationalité et l'administration adopta une position généreuse. Il est possible que les agents chargés des recensements de la fin du XIX ${ }^{\mathrm{e}}$ siècle considéraient qu'un Allemand arrivé vingt ou trente ans plus tôt, naturalisé ou non, n'avait plus à être considéré comme «étranger» mais comme «national». Surtout, les enfants des couples allemands nés sur le sol chilien acquéraient automatiquement la nationalité chilienne. Ainsi, la première génération «allemande» des années 1850 était remplacée par une génération «chilienne » au cours des décennies suivantes et c'est là l'explication principale. En somme, dans

\footnotetext{
${ }^{1}$ Sur les taux de fécondité de la population allemande émigrée au Chili, $C f$. J.-P. Blancpain, Les Allemands au Chili, Op. Cit., p. 304-315. Cet aspect est traité au chapitre suivant.

2 Le solde migratoire de la population allemande une fois installée au Chili est en effet minime. Pour les populations les plus modestes, un retour en Allemagne, après un voyage aussi long et coûteux, est difficilement envisageable. Sur les colons destinés à Llanquihue et Puerto Montt, 1526 personnes de 1850 à 1875 , seuls 31 ont déserté, qu'il s'agisse de retour en Allemagne ou de poursuite au Pérou. $C f$. E. Held Winkler, H. Schuenemann, C. von Plate (dir.), Op. Cit., pp. 45-85.

${ }^{3}$ J.-P. Blancpain, Francia y los franceses en Chile (1700-1980), Santiago, Ediciones Pedagógicas Chilenas y Editorial Universitaria, 1987, p. 191. Cependant, certains colons ont du réclamer la nationalité chilienne pendant plusieurs années. Cf. J.-P. Blancpain, Les Allemands au Chili, Op. Cit, p. 150, pp. 619-620.
} 
les régions où l'apport allemand se tarit dans le dernier quart du XIX ${ }^{\mathrm{e}}$ siècle, comme Valdivia et Llanquihue, la population «allemande » diminue donc. Ces recensements témoignent donc de la volonté des autorités chiliennes d'assimiler l'immigration allemande. Elles rendent également compte des arrivées les plus récentes d'Allemands et donc permettent d'avancer un chiffre minimum de la présence allemande au Chili pour chaque époque, soit en ce qui concerne les femmes : 554 en 1854, 1333 en 1865, 1535 en 1875, 2298 en 1885 et 2550 en 1895.

\subsubsection{Comptes de chercheurs}

Jean-Pierre Blancpain et Georg Young sont les premiers chercheurs qui ont établi un ordre de grandeur de l'immigration allemande au Chili. S'ils n'ont jamais travaillé ensemble, leurs résultats sont pourtant proches. En croisant les listes de passagers, les recensements chiliens, les travaux généalogiques, les registres des Eglises dissidentes, des cimetières « allemands » et les archives des écoles allemandes, Blancpain établit un chiffre d'environ 8500 Allemands émigrés depuis 1846 à Valdivia ou Valparaíso, dont plus de la moitié avant 1874 , avec les pointes suivantes (figure 4) ${ }^{1}$.

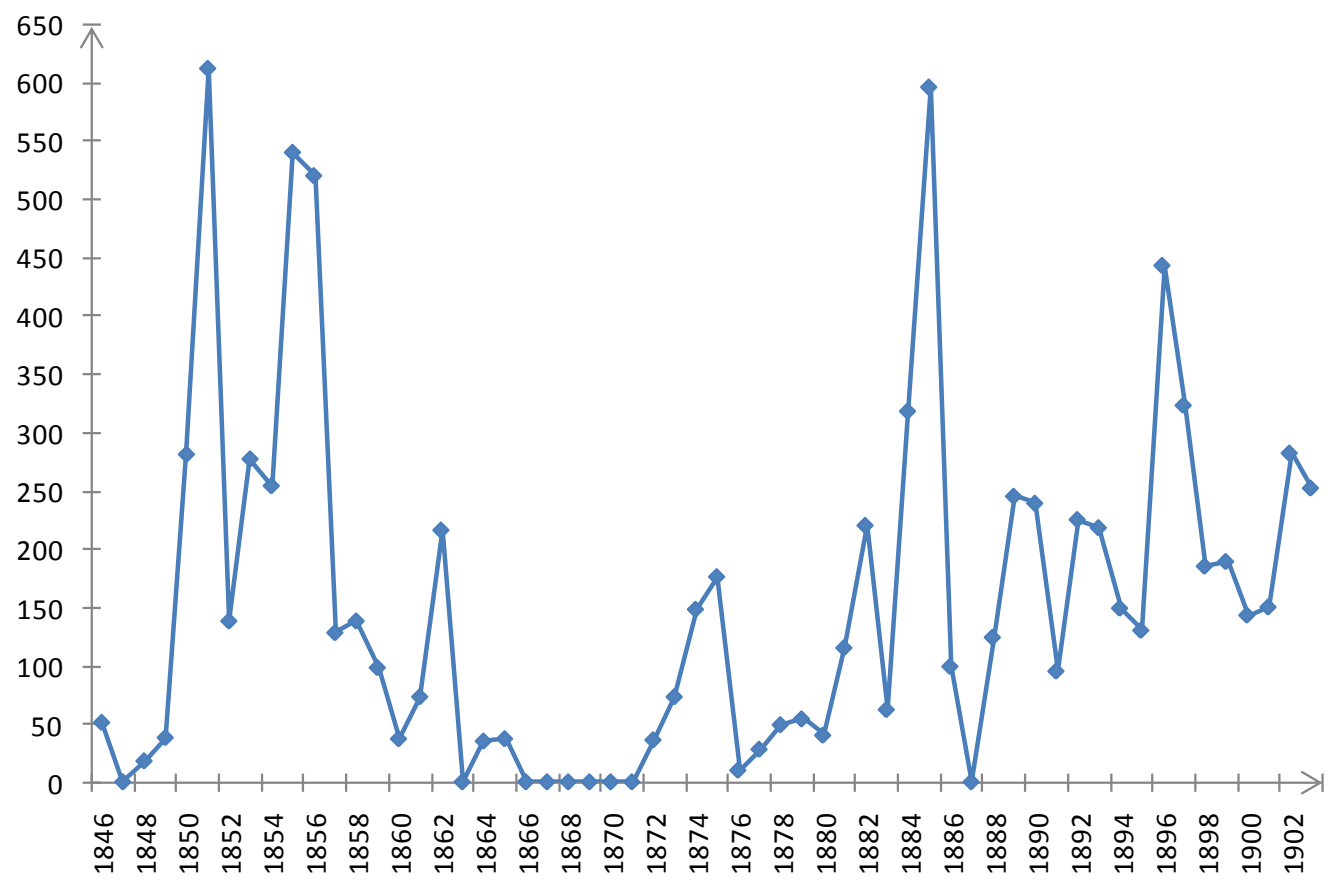

Figure 4. Émigration allemande au Chili, selon Jean-Pierre Blancpain (1846-1903) ${ }^{2}$

Young estime de son côté l'immigration allemande au Chili à 11000 personnes de 1850 à 1914, soit $14 \%$ de l'immigration totale au Chili'. Il recense 5600 colons ruraux jusque 1920, en cinq étapes : 3500 colons de 1846 à 1866, installés à Valdivia et Llanquihue essentiellement, 400 de plus à Llanquihue de 1872 à 1875, 1100 à la Frontera de 1882 à 1889, 500 à Chiloé de 1895 à

\footnotetext{
1 J.-P. Blancpain, Migrations et mémoire germaniques en Amérique latine à l'époque contemporaine, contribution à l'étude de l'expansion allemande outre-mer, Presse Universitaire de Strasbourg, 1994, p. 28. ${ }^{2}$ J.-P. Blancpain, Les Allemands au Chili, Op. Cit., pp. 197 et 486.

${ }^{3}$ G. Young, The Germans in Chile, Op. Cit., p. 15.
} 
1897 et enfin 90 à 100 supplémentaires à la Frontera, de 1900 à 1902. Patricio Bernedo conclut à un chiffre de 6000 Allemands dans la région du Sud chilien, dont 2000 à Valdivia et ses environs ${ }^{1}$.

L'accroissement naturel amplifie rapidement ces chiffres, surtout dans les colonies rurales. Blancpain établit ainsi un chiffre de 30000 germanophones présents au Chili en 1914, «chiffre invariable depuis lors $»^{2}$. En réalité, en 1916-1917, une enquête du Deutsch-chilenischer Bund (DCB) prétend identifier les germanophones du Chili et donne un total de 21039 personnes : 15 912 nées chiliennes, soit "germano-chiliennes », descendant des émigrés du XIX ${ }^{\mathrm{e}}$ siècle et 5127 de nationalité allemande, soit une proportion de deux-tiers pour un tiers, constante déjà mise en évidence par Young ${ }^{3}$. La répartition par sexe est de 6745 hommes, 4133 femmes, 5113 garçons et 5028 filles. Cependant, le recensement du D.C.B. prend en compte toute la population germanophone du Chili, ce qui peut concerner des Suisses, des Autrichiens, etc. On peut donc estimer les Allemands à 20000 , soit $0,6 \%$ de la population chilienne ${ }^{4}$.

Pour la seconde moitié du XIX ${ }^{\mathrm{e}}$ siècle, il faut donc considérer quelques 11000 Allemands émigrés au Chili. L'immense majorité vient en famille. Mais puisqu'il existe d'avantage de célibataires hommes que femmes, il faut arrondir le nombre des femmes à un peu moins de la moitié de la population allemande totale, soit autour de 4000 ou 5000 personnes. C'est donc un groupe numériquement peu important.

\subsection{Les origines géographiques, religieuses et sociales du groupe}

\subsubsection{Des origines géographiques communes}

Les quelques milliers de femmes allemandes émigrées au Chili ont des origines géographiques différentes, comme le suggèrent les listes de passagers. L'origine des femmes n'y est cependant pas toujours indiquée, contrairement à celle des hommes. On peut estimer que les Allemandes du Chili proviennent en majorité, à l'image de la population totale, de la Hesse (18,6\%), du Württemberg (12,8\%), de la Saxe, du Brandebourg et de la Silésie (13,6\%), de la Westphalie et de la Bohême (10\%), et minoritairement des régions orientales de la Poméranie et de la Prusse orientale ${ }^{5}$. Il existe des régions d'Allemagne qui n'ont donné que très peu d'émigrantes, principalement les régions du sud et de l'ouest : la Bavière, la Rhénanie, la plaine saxonne. J.-P. Blancpain révèle ainsi que plus de la moitié des colons de Llanquihue proviennent des massifs hercyniens de l'Allemagne moyenne (Saxe, Hesse, Silésie et Bohême), donc des régions forestières et montagneuses, « régions frontières, elles-mêmes créatrices de pionniers », ce qui les prédisposait

\footnotetext{
${ }^{1} \mathrm{P}$. Bernedo, «Las estrategias periodísticas », Op. Cit.

2 J.-P. Blancpain, Migrations et mémoire germaniques, Op. Cit., p. 28.

${ }^{3}$ Censo de familias alemanas y familias chilenas de origen alemán, 1916/1917, 2 vol., Deutsch-chilenischer Bund/Liga chileno-alemana, Archives Emilio Held, Santiago de Chile.

${ }^{4}$ C. Converse, « Die deutschen in Chile », Op. Cit., p. 301.

${ }^{5}$ E. Held Winkler, Documentos, Op. Cit, p. 22. $C f$. carte des Etats allemands en annexe.
} 
sans doute à leur tâche au Chili ${ }^{1}$. A titre d'exemple, sont originaires du Brandebourg, dans le royaume de Prusse, Adelheid Kindermann, Pauline Metzdorff et Berta Klix, toutes trois de Francfort-sur-l'Oder, Klara Anwandter, Antonie Exss et Anna Exss, originaires de Kalau ou de ses environs - Ullersorf, terre royale, pour les Exss. Sophie von Bischhoffshausen est quant à elle de la Hesse, près de Cassel $^{2}$. Enfin, sont de Silésie, dans le royaume de Prusse également, Rosine Schönherr, originaire d'Erdmannsdorf, Berta Robert, de Breslau et Anna Schmidt, de Reinerz, trois localités situées aujourd'hui en Pologne.

\subsubsection{Des catégories sociales diverses mais une alphabétisation généralisée}

Ces femmes appartiennent à des catégories sociales diverses. Elles sont épouses ou filles de régisseurs de domaines, de commerçants, d'artisans de village, de pasteurs, de professeurs, de médecins, d'agriculteurs. Sophie von Eschwege, épouse de Gustav von Bischhoffshausen, est baronne de Neuenrode. Pauline Metzdorf, a épousé un maître d'école rurale. Fanny Zöhrer émigre avec son mari, le médecin Franz Fonck. Magdalena Barbara Aichele est une fille d'agriculteurs, Klara Anwandter d'un bourgeois pharmacien et bourgmestre de Kalau. La diversité sociale de ce courant d'émigration a beaucoup été soulignée, et elle est réelle ${ }^{3}$.

Le point commun de ces femmes est qu'elles sont toutes alphabétisées. Il faut rappeler que la mobilité et l'émigration résultent d'un processus de lecture : il faut pouvoir lire et s'informer pour prendre la décision du départ ${ }^{4}$. Même si leur niveau de formation peut être différent, les émigrées allemandes savent lire, écrire et compter. Les recensements chiliens donnent des chiffres d'alphabétisation de $100 \%$ au delà de 13 ans d'âge, pour les femmes comme pour les hommes. Le recensement de 1854 donne par exemple 1599 Allemands et Allemandes qui savent lire dont 1567 qui savent écrire, sur un total de $1822^{5}$. Par conséquent, 255 ne sachant pas écrire, dont 223 ne sachant pas lire ${ }^{6}$. Or, ce chiffre ne recouvre même pas celui des enfants âgés de 1 à 13 ans, qui sont 329 au total. Ainsi, certains enfants, sans doute les plus âgés, sont déjà alphabétisés : 74 d'entre eux sauraient déjà écrire et 42 supplémentaires sauraient lire ${ }^{7}$.

Rapportés à l'ensemble de la population féminine allemande au Chili, les chiffres laissent apparaître un contraste important avec les femmes chiliennes (figure 5$)^{8}$. Les femmes allemandes

\footnotetext{
${ }^{1}$ J.-P. Blancpain, Les Allemands au Chili, Op. Cit., p. 209.

${ }^{2}$ I. Schwarzenberg (éd.), Dokumente, Op. Cit., VI, p. 108.

${ }^{3}$ J.-P. Blancpain, Les Allemands au Chili, Op. Cit., p. 214.

${ }^{4}$ K. Schobert, Op. Cit., p. 281.

${ }^{5}$ On suppose en effet que ceux qui écrivent lisent aussi, alors que ceux qui lisent ne savent pas forcément écrire.

${ }_{7}^{6}$ Censo general, 1854, Op. Cit., s. p., tableau n ${ }^{\circ} 2$.

${ }^{7}$ Emmanuel Todd estime que l'apprentissage de la lecture se fait en Europe entre 6 et 12 ans, et celui de l'écriture à partir vers 13 ans. $C f$. E. Todd, L'invention de l'Europe, Paris, Seuil, 1990, p. 143.

${ }^{8}$ Censo general, 1854, Op. Cit., s. p., tableau n ${ }^{\circ} 2$; Censo general, 1865, Op. Cit., pp. 371 et 338 ; Censo general, 1875, Op. Cit., p. 625 et 604-605 et Censo general, 1885, Op. Cit., pp. 459 et 862 et Censo general, 1895, Op. Cit., pp. 461 et 502.
} 
sont proportionnellement plus alphabétisées que les Chiliennes et creusent donc moins l'écart avec les hommes

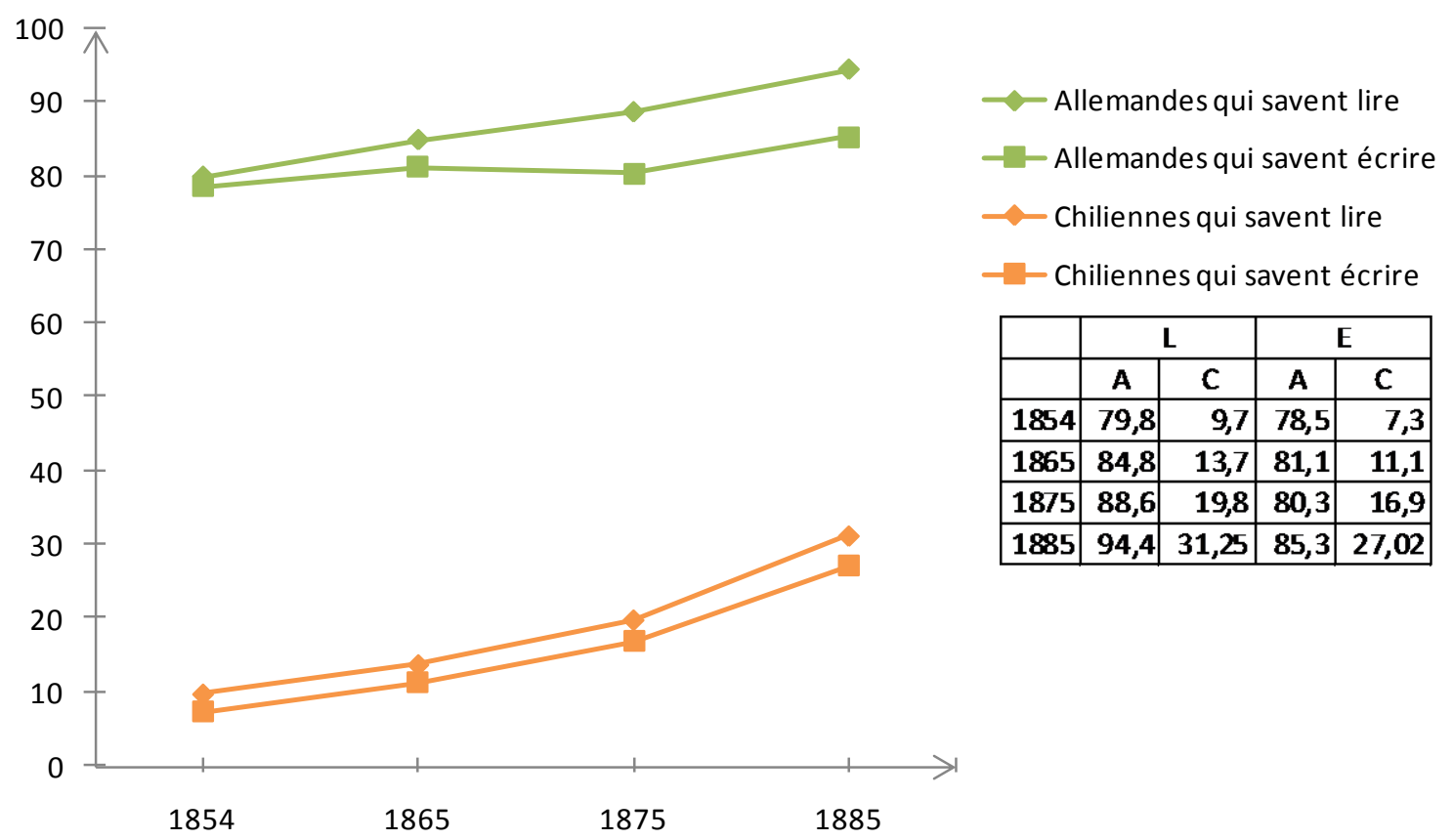

Figure 5. Pourcentages d'alphabétisation chez les Chiliennes et les Allemandes d'après les recensements chiliens (1854-1895).

Christel Converse a souligné que l'alphabétisation des immigrés allemands leur permet de se démarquer d'une population locale majoritairement analphabète et de constituer ainsi une classe moyenne jusqu'alors relativement absente au Chili ${ }^{1}$. Dans son rapport au ministère de l'intérieur, l'intendant Vincente Pérez Rosales souligne les contrastes culturels locaux entre Chiliens et Allemands, au Nord du territoire de Llanquihue :

«Le profond retard ou plutôt l'absence totale d'instruction et le manque total de toute industrie destinée à satisfaire les besoins premiers de l'homme sautent à la vue. Sur 1650 habitants, seuls savent lire et écrire 131 d'entre eux, dont 62 allemands, sur les 71 des deux sexes et de tous âges qu'ils sont $»^{2}$.

Plus loin, il constate le taux d'alphabétisation général de la colonie de Llanquihue :

«Sur 247 colons de tous âges et sexes que compte la population totale allemande de la colonie de Llanquihue, 181 savent lire et écrire. Sur les 66 restants, 45 ont entre quelques mois et 5 ans, 20 entre 5 et dix ans, déjà scolarisés, et une seule femme de 23 ans $»^{3}$.

\footnotetext{
${ }^{1}$ C. Converse, "Die deutschen in Chile", Op. Cit., p. 323.

${ }^{2}$ Lettre de V. Pérez Rosales au ministre de l'intérieur du 11.08.1854 dans AHN, MINT, vol. 328, Oficios recibidos de la Intendencia de Valdivia (1854 - 1855), p. 114 recto/verso : "El profundo atraso o mas bien la ignorancia completa en instrucción y la carencia total de aquellas sencillas industrias que tienden a satisfacer las primeras necesidades del hombre resaltan desde luego a la vista. Sobre 1650 vecinos solo saben leer y escribir 131 incluso 62 alemanes que leen y escriben, de los 71 de todos sexos y edades que se encuentran entre ellos."

${ }^{3}$ Ibid., p. 115 verso : "Sobre 247 colonos de todas edades y sexo de que consta la población alemana total en la Colonia de Llanquihue, 181 saben leer y escribir. De los 66 restantes 45 se cuentan entre la edad de meses y la de cinco años, 20 entre la de 5 y la de diez, ya en la escuela, y una sola mujer de 23 años".
} 
L'intendant révèle ainsi que pour les Allemandes, savoir lire et écrire est la condition minimum de la respectabilité. Il se remémore l'anecdote d'une jeune fille pauvre de Puerto Montt, qui refusa le mariage avec un jeune commerçant aisé, parce qu'elle constata, au moment de s'engager, qu'il ne savait pas lire ${ }^{1}$.

L'alphabétisation massive des Allemandes s'explique par des politiques scolaires précoces dans les États allemands, en particulier du Nord, où les taux de scolarisation féminine peuvent atteindre 86,5\% dès 1750, constate Marie-Claire Hoock-Demarle ${ }^{2}$. Ainsi dans l'Oldenburg, dès 1750, 1,5\% des femmes est analphabète ${ }^{3}$. Cette chronologie différenciée suggère l'influence du facteur religieux. Les États d'obédience protestante montreraient, par l'ingérence directe du prince sur son territoire, une nette avance sur les pays catholiques, qui réservent longtemps l'éducation aux garçons, et le couvent aux filles. Emmanuel Todd explique à ce sujet :

«L'importance du facteur religieux dans la dissociation culturelle du continent européen est une évidence. Le progressisme protestant était d'ailleurs conscient, l'alphabétisation des chrétiens constituant un aspect fondamental du programme réformé. Le freinage subi par les régions catholiques ne fut pas moins voulu, l'Église de Rome n'acceptant pas l'accès de tous, c'est-à-dire des laïcs, aux Écritures Saintes, et donc à la lecture »",

Les foyers de diffusion de l'alphabétisation sont ainsi les pays de réforme luthérienne et par «contagion», celle-ci se fait ensuite en terres catholiques, des plus proches aux plus éloignées 5 . C'est donc une lente diffusion du Nord-est vers le Sud-ouest de l'Europe que Todd dégage, proposant une cartographie de l'alphabétisation en «couronnes ». A l'échelle allemande, le modèle s'applique également ${ }^{6}$. La scolarisation, des filles comme des garçons, est obligatoire en Prusse dès 1717, en Bavière en 1802. Marie-Claire Hoock-Demarle souligne le caractère général de l'alphabétisation féminine, au XIX ${ }^{\mathrm{e}}$ siècle, en Allemagne : «L'alphabétisation, par la scolarisation obligatoire, est à la portée de toutes les filles : lire, écrire ou compter, dans une moindre mesure, est parfaitement accessible aux filles des villes comme des campagnes, des couches aisées comme des milieux moins favorisés ${ }^{7}$. L'alphabétisation de ces femmes, en majorité protestantes, n'est pas une donnée mineure pour notre recherche. Le fait que les Allemandes émigrées au Chili savent écrire permet évidemment d'accéder aujourd'hui à divers récits de leur expérience.

Un autre facteur de différenciation au sein de cette population féminine est leur état civil. La grande majorité part mariée, en famille, mais une analyse statistique montre qu'il existe une part non négligeable de femmes seules, célibataires ou veuves, qui sont candidates à l'émigration.

\footnotetext{
${ }^{1}$ V. Pérez Rosales, Recuerdos, Op. Cit., pp. 424-425.

2 M.-C. Hoock-Demarle, «Lire et écrire en Allemagne », dans G. Duby, M. Perrot (dir.), Histoire des Femmes en Occident. 4. Le XIX $X^{e}$ siècle, Paris, 2002, p. 178.

${ }^{3}$ Ibid.

${ }^{4}$ E. Todd, Op. Cit., p. 135.

${ }^{5}$ Ibid., p. 130. Carte 25. L'alphabétisation en 1900.

${ }^{6}$ Ibid., p. 134. Carte 26. Allemagne : l'alphabétisation vers 1875.

${ }^{7}$ M.-C. Hoock-Demarle, Op. Cit., p. 181.
} 


\subsection{Un groupe particulier : les femmes seules}

Outre les femmes mariées, les difficultés que traverse l'Allemagne au milieu du XIX ${ }^{\mathrm{e}}$ siècle ont également poussé à l'émigration de nombreuses femmes seules, qui n'avaient d'autres perspectives en Allemagne que la survie par le travail, de plus en plus rare dans les campagnes. Il s'agit de «femmes sans mari, veuves ou célibataires, avec ou sans enfant » comme les décrit Cécile Dauphin ${ }^{1}$. Leur migration ne revêt pas la même signification que pour une femme mariée ${ }^{2}$. Nancy L. Green constate à ce sujet : «Les départs de femmes seules sont plus nombreux au XIX ${ }^{\mathrm{e}}$ siècle que l'on a souvent pu le croire. Si la majorité part, en effet, pour rejoindre maris et parents, d'autres partent à l'aventure, pour quitter leurs maris... ou en trouver un ${ }^{3}$. En effet, à travers l'émigration, elles cherchent aussi à gagner certaines formes d'émancipation.

\subsubsection{Une estimation difficile}

La situation des Allemandes célibataires qui ont émigré au Chili est très variée et leur estimation difficile. Les listes de passagers rassemblées par Emilio Held permettent de donner un ordre de grandeur ${ }^{4}$. Elles concernent 69 bateaux connus, qui ont transporté, de Hambourg à Valdivia et Valparaiso, de 1840 à 1875, 6373 passagers, dont 1441 femmes. Les femmes seules y sont citées indépendamment, c'est-à-dire sans père, référent masculin privilégié 5 . La seconde est une liste alphabétique de 1425 autres passagers, dont 476 femmes, dont on ne connaît pas le bateau. Ces listes doivent être manipulées avec précaution, puisque Held y commet de multiples erreurs ${ }^{6}$ dont la plus fréquente, concernant les femmes, est de recenser des femmes arrivées célibataires la suite d'un homme qu'elles n'ont épousé en réalité qu'au Chili. Il mentionne ainsi, dans la liste de l' «Alfred» en 1851, les sœurs Auguste Joséphine Pauer de Pausenberger et Thérèse Pauer de Pausenberger à la suite de Theodor Pausenberger, comme si de dernier était venu avec deux épouses. En réalité, selon Ingeborg Schwarzenberg, Auguste Joséphine a émigré avec ses parents sur le «Grasbrook » en 1856, et elle n'a épousé Theodor Pausenberger qu'en 1859, à Valdivia. Sa sœur, Thérèse, est arrivée avec le «Reiherstieg » en 1857, accompagnée d'une autre sœur, Emilie,

\footnotetext{
${ }^{1}$ C. Dauphin, «Femmes seules » dans G. Duby, M. Perrot (dir.), Op. Cit., p. 514.

${ }^{2}$ S. Pedraza, Op. Cit., p. 314.

${ }^{3}$ N. L. Green, Repenser les migrations, Op. Cit., p. 112.

${ }^{4}$ E. Held Winkler, "La Lista de los Barcos (1840-1875). Numero de pasajeros, su procedencia y profesiones" dans Documentos, Op. Cit., pp. 17- 214.

${ }^{5}$ Une jeune fille qui voyage avec sa famille est recensée en général dans les enfants à la suite de son père. Si les employés de la compagnie estimaient qu'elle était déjà trop âgée pour être qualifiée d'enfant, elle était répertoriée seule, à la suite et avec le nom du père. Dans ce cas le lien de parenté est évident voire explicitement spécifié.

${ }^{6}$ Voir la critique de J.-P. Blancpain dans Les Allemands au Chili, Op. Cit., p. 203, note de bas de page 62 : «Confusion de noms de famille ou de localités homographes, dernier domicile pris pour la véritable origine géographique, retours d'Europe vus comme une première arrivée, compte non tenu des retours immédiats ou des séjours temporaires, fantaisies concernant le lieu de naissance, la parenté, le mariage ou la progéniture [...] Vétilles, certes, mais qui fourvoient un compilateur qui se targue précisément de compléter et rectifier ».
} 
décédée pendant la traversée. Thérèse a épousé le même Theodor en 1863, deux ans après la mort d'Auguste Joséphine. Ceci n'empêche pas Held de faire réapparaître les deux femmes dans les bonnes listes quelques pages plus loin ${ }^{1}$. De même, Barbara Nobis, passagère du «Victoria » en 1851 avec sa fille Maria de 4 ans, figure aussi dans la liste des passagers de bateaux inconnus, étant pas conséquent comptée deux fois ${ }^{2}$. L'exemple le plus absurde reste celui de Pauline Fuchslocher, recensée trois fois: dans liste de l' «Australia» de 1852, à la suite de son père Johann Fuchslocher, dans la liste de l' «Alfred » de 1852, à la suite de Friedrich Demmerer, qu'elle n'a épousé qu'en 1854 au Chili, et dans la liste des passagers de bateaux inconnus ${ }^{3}$.

Nous proposons de dresser une étude statistique des célibataires, à partir de l'échantillon des 69 bateaux connus, en croisant, pour chacune d'entre elles, les différentes sources - les listes de passagers et les documents généalogiques - mais également en ajoutant les «fausses » femmes mariées, afin d'écarter les erreurs possibles ${ }^{4}$. Sur les 1141 femmes recensées, 316 sont sans aucun doute seules, célibataires ou veuves. Elles représentent ainsi $22 \%$ des femmes de cette liste d'émigration au Chili, soit un peu plus que leur proportion au sein de la population allemande, estimée par Cécile Dauphin à 10\% dans les Etats du Nord de l'Allemagne et à plus de $15 \%$ dans ceux du Sud'. Dans l'ensemble, il s'agit de jeunes femmes, d'une moyenne d'âge de 28,1 ans. Elles viennent avec des enfants, à savoir 2,15 en moyenne par femme. Si toutes sont célibataires, elles ne viennent pas toutes en solitaire. Il est possible en effet d'identifier quatre groupes qui correspondraient à autant de situations différentes.

\subsubsection{Des situations diverses}

Un premier groupe est constitué par les célibataires qui effectuent le voyage avec un ou des membres de la famille (68 personnes exactement). Dans ce cas, les couples voire les trios de sœurs sont fréquents. A titre d'exemples, à bord du « Marbs » en 1853, les sœurs Meyer, Marie et Emilie, voyagent ensemble, comme les Reiche, Rosalie et Antonie et les trois sœurs Schramm, Regina, Dorotea et Eva. Sur le « Nicoline » en 1855 voyagent Mathilde et Emma Merzrath, âgées de 16 et 17 ans, ainsi que les trois sœurs Schmidt, Johanna, Wilhelmine et Amalie, âgées quant à elles de 14, 15 et 18 ans. Marie et Ernestine Bopp, 22 et 23 ans, font le voyage sur le «Vesta » en 1857,

\footnotetext{
${ }^{1}$ Sur ce cas, voir E. Held Winkler, Documentos, Op. Cit., pp. 33, 90 et 106 et Notices Liga 15026 Pauer et Liga 15072 Pausenberger dans Archivo genealógico Ingeborg Schwarzenberg, Biblioteca e Archivo Emilio Held Winkler, Santiago (par la suite AGS).

${ }^{2}$ E. Held Winkler, Documentos, Op. Cit., pp. 38 et 161 ; Schiffslisten, 1850-1854, Fondo Held, Biblioteca e Archivo Emilio Held Winkler, Santiago, p. 88 et notice Liga14454 dans AGS, Op. Cit.

${ }^{3}$ E. Held Winkler, Documentos, Op. Cit., p. 43, 47, 148; Schiffslisten, Op. Cit, p. 111.

${ }^{4}$ La liste des bateaux inconnus est inexploitable pour notre recherche, puisqu'il est impossible de reconstituer les éventuels liens de parenté ou d'alliance entre passagers d'un même bateau et surtout d'identifier les célibataires. Held recense en effet pratiquement toutes les femmes sous leur nom d'épouse alors que nous avons constaté que certaines arrivaient bien célibataires.

${ }^{5}$ C. Dauphin, «Femmes seules », Op. Cit., p. 516.
} 
Friederike et Catharina Mödinger, 21 et 23 ans, sur le « August » en 1864. ${ }^{1}$ Il existe également des couples de frères et sœurs, comme Christine Friedrich, âgée de 17 ans, qui émigre avec son frère Johann, plus âgé, à bord du «Alfred» en 1852, à bord duquel voyagent également Genoveva Klotz, 18 ans, et son frère. Il s'agit souvent de contingents familiaux détachés comme « éclaireurs » dans la perspective d'une émigration familiale plus ample, avec les plus jeunes enfants. En 1852 émigrent à bord de 1'« Australia », les six cousins Aichele-Mautz- par la branche maternelle - tous âgés de la vingtaine : du côté des Aichele, Magdalena Barbara, l'auteure de la lettre de 1855, ses frères Gottlieb et Christian (accompagné de son épouse Magdalena) et du côté Mautz, Marie Magdalena, Christiane et Georg Adam. Les Aichele-Mautz migrent tous définitivement en 1855$1856^{2}$. Autre cas, celui des Schwenke, dont les quatre enfants, Hélène, 23 ans, Martin, 22 ans, Johann, 19 ans et Martha, 14 ans, émigrent ensemble sur le « Grasbrook» en $1856^{3}$.

Quand il s'agit d'une veuve âgée, elle suit souvent un fils ou une fille, qui peut être accompagné(e) de sa propre famille. Par exemple, Caroline Lerche, passagère du « Middleton » en 1850, âgée de 69 ans, est citée seule et considérée comme veuve, mais elle accompagne en réalité sa fille, répertoriée à la suite de l'époux Karl Numers, quelques lignes plus bas. Sophie von Bischhoffshausen confirme dans une lettre qu'elle s'est liée d'amitié, à Valdivia, avec une Marie Numers, qui est venue avec sa « vieille mère " ${ }^{4}$. De même, Margaretha Hospes, répertoriée seule et sans âge, voyage avec son gendre, le pasteur Karl von Manns. Dans la généalogie des Manns, Ingeborg Schwarzenberg indique en effet que la mère de l'épouse du pasteur, nommée Hospes, est décédée en 1854 à Chorocomayo, là où la famille Manns s'est installée 5 . Enfin, Johanna Rosina Diesner, originaire de Saxe, près de Rupersdorf, émigre en tant que veuve de Carl Biebrach, avec ses quatre enfants, âgés de 4 à 21 ans, dont Karl, l'ainé, est déjà père et accompagné de sa propre famille $^{6}$. Nombreux sont les exemples de trois générations d'une même famille qui émigrent ensemble au Chili.

Un deuxième groupe réunit les célibataires qui viennent avec une famille dans laquelle elles servent comme domestiques ou plus rarement professeurs particulières. Berta Klix se souvient ainsi que lorsque sa famille émigre au Chili, ils sont onze, «douze avec la bonne » ${ }^{7}$. Les Geisse emmènent avec eux la mère de Pauline Hube, épouse Renz, Elisabeth Marie Reuter Schäfer, orpheline née à

\footnotetext{
${ }^{1}$ E. Held Winkler, Documentos, Op. Cit., pp. 36, 37, 62-63, 69, 77-78, 107, 125 et notices Liga16459, Ribbeck, Liga27557 Bopp et Liga13548 Moedinger dans AGS, Op. Cit.

${ }^{2}$ E. Held Winkler, Documentos, Op. Cit., p. 43 ; notices Liga01796 Aichele, Liga13023 Mautz, Liga27836 Bräuning, Liga08816 Hermann dans AGS, Op. Cit. ; Schiffslisten, Op. Cit., p. 113 et lettre du 28.02.1855 dans M. B. Aichele, Op. Cit.

${ }^{3}$ E. Held Winkler, Documentos, Op. Cit., p. 90 et notice Liga19639 Schwenke dans AGS, Op. Cit.

${ }^{4}$ E. Held Winkler, Documentos, Op. Cit., p. 26, notice Liga14528 Numers dans AGS, Op. Cit. et lettre du 9.11.1854 dans I. Schwarzenberg, Dokumente, Op. Cit., VI, p. 12.

${ }^{5}$ E. Held, Winkler Documentos, Op. Cit., p. 58 ; notices Liga12767 Manns et Liga12768 Manns, dans AGS, Op. Cit. et I. Schwarzenberg, «Origen de algunas familias alemanas radicadas en Chile », dans Revista de Estudios Históricos, $\mathrm{n}^{\circ}$ 14, 1969, p. 58.

${ }^{6}$ E. Held Winkler, Documentos, Op. Cit., p. 51 et notice Liga27000 Biebrach dans AGS, Op. Cit.

${ }^{7}$ Souvenirs de Berta Klix dans Berichte, Op. Cit., p. 80 : „Zwölf mit dem Mädchen“.
} 
Rothenburg-sur-Fulda en 1831, employée comme couturière ${ }^{1}$. Au XIX ${ }^{\mathrm{e}}$ siècle, la domesticité, jusqu'alors réservée aux aristocrates, se démocratise, devenant un signe de la distinction bourgeoise, en même temps qu'elle se féminise et se dévalorise. "Toutes les grandes villes et les bourgs d'Europe drainent les filles des campagnes sans autre qualification que leurs forces et leur jeunesse » écrit Cécile Dauphin, qui estime qu'en Prusse, en 1882, 96\% des domestiques sont célibataires ${ }^{2}$. Leur nombre à bord est difficile à estimer, parce que n'est pas toujours mentionné un lien de ce type entre une célibataire et une famille du même bateau. La famille von Bischhoffshausen voyage ainsi, sur le «Grasbrook» de 1854, avec trois domestiques : Johanna Lindenkohl, Margaretha Kahlmeyer Köhler et Friederike Auguste Kayser, soit Hannchen, Gretchen et Riekchen comme les surnomme Sophie dans sa correspondance ${ }^{3}$. De même, Teresa Wagner, âgée de 19 ans, accompagne les Eisene dans le «Cäsar und Helene » en 1856, un gros bateau constitué de 38 familles, où l'on trouve en conséquence peu de célibataires, sauf, peut-on supposer, les employées de celles-ci ${ }^{4}$.

Le troisième groupe caractérise les célibataires qui font le voyage seules, mais dans la perspective de retrouver des proches qui ont déjà émigré au Chili. Là encore, il est difficile de savoir combien ont déjà des attaches au Chili si ce n'est pas explicitement indiqué. Par exemple, Eléonore Dittrich Holz de Kretschmar est une veuve de 37 ans qui rejoint avec ses 2 enfants, Ernst et Pauline, âgés de 6 et 12 ans, à bord du «Wandrahm» de 1872, son père et sa famille émigrés vingt ans plus tôt ${ }^{5}$. Johanna Byhain apparaît comme célibataire sur la liste des passagers du «Susanne » de 1852. On pourrait la penser veuve, puisqu'elle émigre ave 5 enfants qui ont entre 3 mois et 8 ans. En réalité, elle rejoint son mari qui a déjà émigré au Chili quelques mois plus tôt ${ }^{6}$. Enfin, la veuve Christiane Kayser qui voyage à bord du «Wandrahm » en 1856 vient au Chili, à 50 ans, pour y retrouver sa fille, Friedrike Auguste, l'une des trois bonnes de Sophie ${ }^{7}$.

Enfin, un quatrième ensemble correspond aux célibataires qui voyagent seules. Il est difficile d'en donner un chiffre exact. On sait qu'elles existent, des textes l'attestent. Il est sûr par exemple que Louise Blüffert, répertoriée dans la liste du «Hermann » en 1850, âgée de 31 ans et accompagnée d'un enfant de 8 ans, Karl, est venue seule. Elle a épousé sur le bateau même, selon divers récits, et notamment une lettre de Pauline Metzdorff, le docteur juif Franz Kaskel, âgé de 50 ou 54 ans, cinq

\footnotetext{
${ }^{1}$ Cette dernière s'est alors mariée et a ouvert un atelier de couture qui recevait des commandes de toute la région. $C f$. P. Renz, Errinerungen, Op. Cit.

${ }^{2}$ C. Dauphin, «Femmes seules », Op. Cit., p. 520.

${ }^{3}$ Les diminutifs (-chen en allemand) sont formés sur la terminaison de leur prénom (-hanna, -g'rethe et rike). Gretchen est faussement appelée Holmbach dans la liste dans passagers et Riekchen n'y apparaît pas. $C f$ E. Held Winkler, Documento., Op. Cit., pp. 70-71; Liga12403 Lindenkohl, dans AGS, Op. Cit. et lettre du 18.6.1854, dans I. Schwarzenberg (éd.), Dokumente, Op. Cit., VI, p. 7.

${ }_{5}^{4}$ E. Held Winkler, Documentos, Op. Cit., p. 87 et notice Liga20692 Wagner dans AGS, Op. Cit.

5 Notices Liga10637 Kretschmar, Liga03590 Dittrich, et Liga03591 Dittrich dans AGS, Op. Cit. et généalogie de la famille «Dittrich» dans Patricio Legarraga, Frutillar, genealogías de Familias alemanas, Santiago, 1998, pp. 401-402.

${ }^{6}$ E. Held Winkler, Documentos, Op. Cit., p. 51 et notice Liga26408 Byhain dans AGS, Op. Cit.

7 E. Held Winkler, Documentos, Op. Cit., p. 98 et lettre du 16.10.1857 dans I. Schwarzenberg (éd.), Dokumente., Op. Cit., VI, p. 45.
} 
jours avant l'arrivée ${ }^{1}$. Plus de deux cents femmes sont répertoriées sans indications autres que le nom et prénom, parfois l'âge et plus rarement l'origine, sans qu'on puisse les lier directement avec un autre passager du même bateau. Ainsi sur le «Nicoline» voyagent en 1856 une quinzaine de jeunes femmes vraisemblablement seules, sans enfant, âgées de 17 à 36 ans, et pour qui seule est mentionnée l'origine géographique ${ }^{2}$. Autant de noms muets qui peuvent pourtant avoir des liens familiaux ou d'ordre économique avec des familles voyageant sur le même bateau. Il est sûr qu'elles ne voyagent pas avec un membre de leur famille, mais il est possible qu'elles accompagnent une famille où elles servent, ou encore des familiers qui n'ont pas le même nom de famille. L'immense majorité de ces célibataires, si elles voyagent seules, ne vient cependant sans doute pas sans un projet au Chili. L'idée que des jeunes femmes célibataires s'embarquent, certaines avec leurs enfants illégitimes, sur un bateau dans la perspective de voir ce qui peut bien advenir d'elles et de leur progéniture est séduisante, mais peu tenable. On peut supposer qu'elles s'y rendent pour avoir été recrutées par des familles déjà installées au Chili pour y être bonnes, professeurs ou gouvernantes. Certaines de ces passagères se rendent notamment à Valparaiso où la demande en personnel est importante au sein des familles allemandes du grand commerce.

\subsubsection{Un projet commun : le mariage et l'autonomisation.}

Un fait semble commun à toutes ces femmes seules : une fois arrivées au Chili, elles se marient rapidement, qu'elles soient célibataires ou veuves, avec ou sans enfant. En réalité, au sein de la communauté allemande, où règne l'endogamie, elles sont très recherchées par les hommes seuls ${ }^{3}$. Les recensements chiliens, de 1854 à 1895, montrent en effet que les Allemands célibataires ou veufs, sont, au Chili, en moyenne 2,5 fois plus nombreux environ que les Allemandes célibataires ou veuves (figure 6).

\footnotetext{
${ }^{1}$ E. Held Winkler, Documentos, Op. Cit., p. 27 ; notice liga27265 Blüfert dans AGS, Op. Cit. et lettre du 12.11.1850 dans G. Böhm (éd.), Dokumente, Op. Cit., V, p. 25.

${ }^{2}$ E. Held Winkler, Documentos, Op. Cit., pp. 76-78.

${ }^{3}$ Sur l'endogamie de la communauté germano-chilienne, voir J.-P. Blancpain, Les Allemands au Chili, Op. Cit., p. 303. Il suffit de consulter les registres civils et les généalogies pour constater que les Allemands du Chili se marient presque exclusivement entre eux : Matrimonios Puerto Montt (1855-1884) et Matrimonios Osorno, Fondo Held, Biblioteca e Archivo Emilio Held Winkler, Santiago. En 1883, le rayon dans lequel le mariage se réalisait était de 12 km, contre 200 en 1972, Cf. Kurt Schobert, Op. Cit., p. 282. «On épouse son semblable aussi parce qu'on le rencontre » rappelle fondamentalement Michelle Perrot dans «Figures et rôles » dans P. Ariès, G. Duby (dir.), Histoire de la vie privée. 4. De la Révolution à la Grande Guerre, Points Seuil, Paris, 1999 (1987), p. 122.
} 


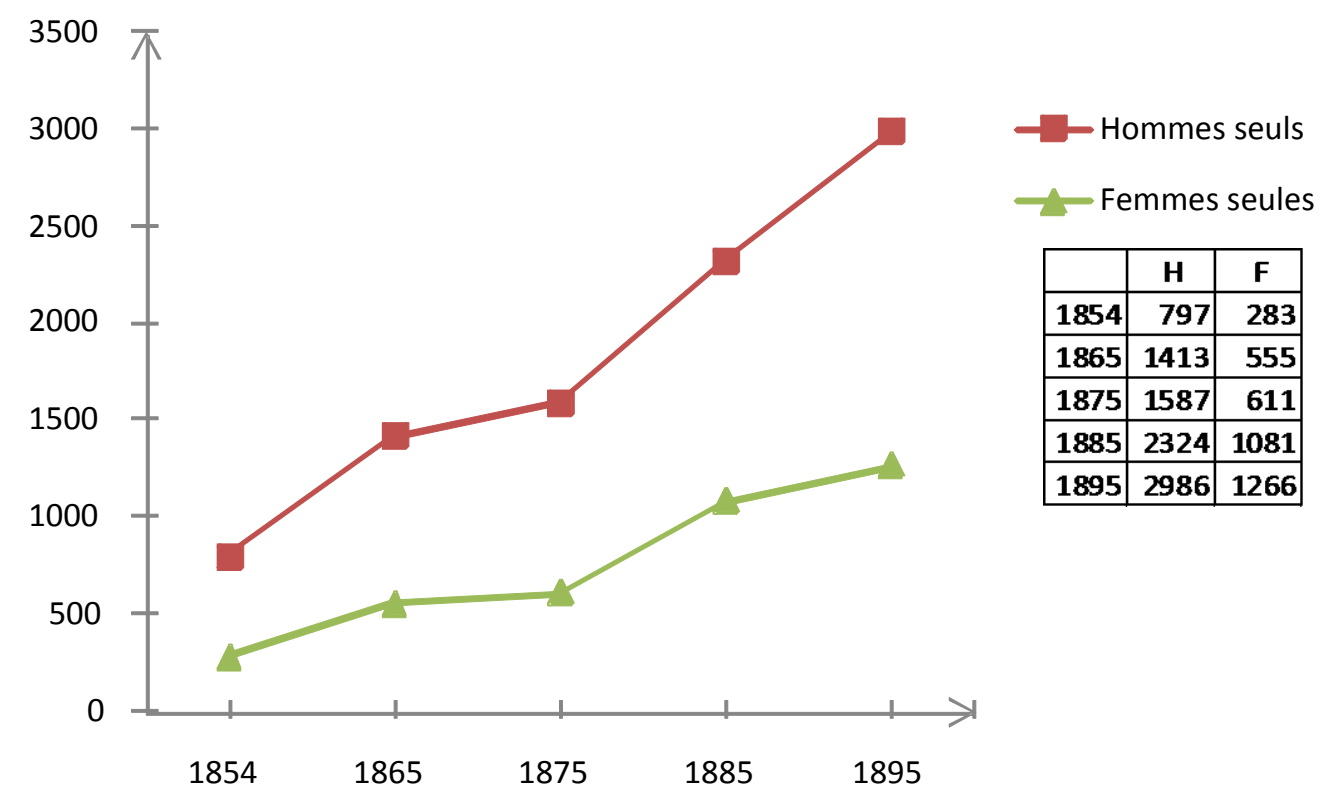

Figure 6. Allemands et Allemandes célibataires ou veufs au Chili d'après les recensements chiliens (1854-1895) ${ }^{1}$.

Il faut cependant considérer que le nombre des Allemands célibataires est gonflé au niveau national par l'important contingent résidant dans les régions minières du Nord ${ }^{2}$. A l'échelle des provinces du Sud, les plus peuplées en Allemands, le rapport est moindre, mais néanmoins présent (figures 7 et 8).

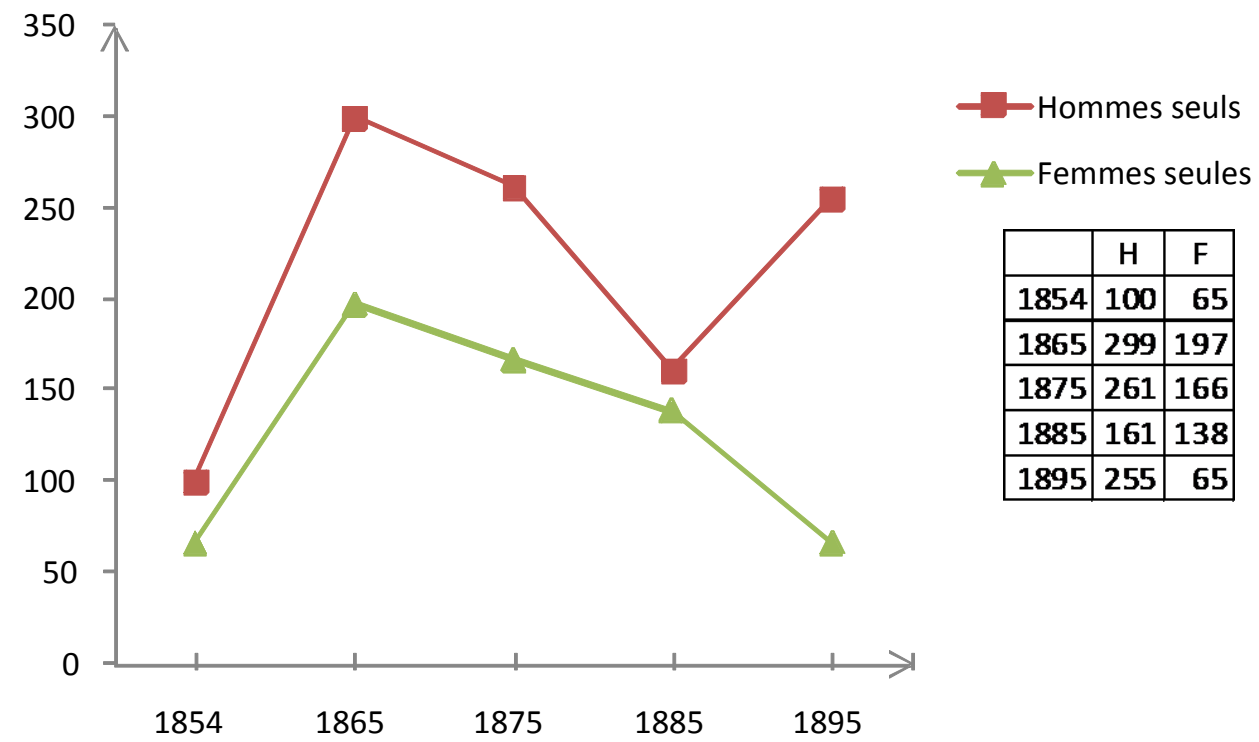

Figure 7. Allemands et Allemandes célibataires ou veufs à Llanquihue d'après les recensements chiliens (1854-1895).

\footnotetext{
${ }^{1}$ Pour les données au niveau du Chili et des trois provinces, Cf. Censo general, 1854, Op. Cit., s. p., tableau $\mathrm{n}^{\circ} 1$ et 2 ; Censo general, 1865, Op. Cit., p. 26, 29, 182 et 371 ; Censo general, 1875, Op. Cit., p. 60, 80, 550, 625 ; Censo general, 1885, Op. Cit., p. 31, 48, 271, 459 et Censo general, 1895, Op. Cit., tome 1, p. 301, tome 2 p. 202 et 302. Notons qu'avec la stabilisation de la population allemande au Chili vers la fin du XIX ${ }^{\mathrm{e}}$ siècle, le veuvage féminin reprend ses droits, sous l'effet naturel d'une espérance de vie structurellement différenciée entre hommes et femmes. Le nombre des «célibataires» femmes augmentent donc et l'écart se réduit avec les hommes. Il ne s'agit plus cependant de femmes qui peuvent prétendre au remariage.

${ }_{2}^{2}$ Par exemple, en 1854, la région d'Atacama compte 77 Allemands célibataires contre 7 Allemandes. $C f$. Censo General, 1854, Op. Cit., s. p., tableau ${ }^{\circ}{ }^{\circ}$.
} 


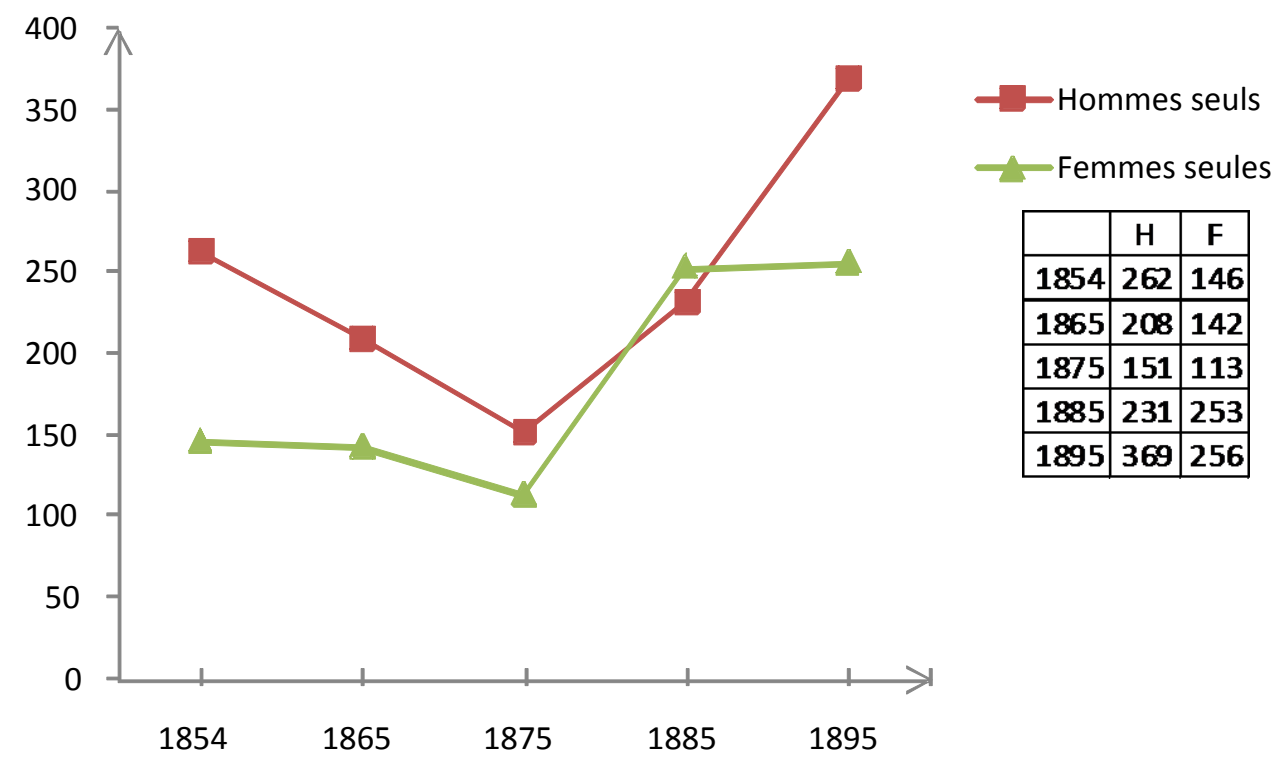

Figure 8. Allemands et Allemandes célibataires ou veufs à Valdivia d'après les recensements chiliens (1854-1895) ${ }^{1}$.

Si ces femmes célibataires étaient tant recherchées, c'est parce que, dans le projet de colonisation du Sud mis en place par le gouvernement chilien, les familles étaient privilégiées. Une lecture genrée des phénomènes migratoires permet ainsi de mettre en évidence des pratiques législatives des Etats elles-mêmes genrées ${ }^{2}$. " De la colonisation du sud, le célibataire et l'homme seul étaient, par principe, exclus. L'attribution d'une chacra leur était refusée. L'arrivée impromptue d'un contingent de cette nature est jugée avec réprobation par l'administration » rappelle Jean-Pierre Blancpain ${ }^{3}$. Dans une lettre au ministre de l'Intérieur, l'intendant Vincente Pérez Rosales rappelle en effet l'inutilité des célibataires. «Un hommes sans famille est inutile, dans un tel état de solitude $»^{4}$. En mars 1855 , dans des instructions adressées à son successeur, il conseille :

«Dans le choix des colons qui se présenteront successivement, en plus des conditions requises signalées dans les articles 6 et 7, vous devrez, Monsieur, respecter comme point capital qu'ils appartiennent à notre religion, et qu'ils soient mariés. L'homme seul n'est pas un colon. Vous

\footnotetext{
${ }^{1}$ Pour les données au niveau du Chili et des trois provinces, Cf. Censo general, 1854, Op. Cit., s. p., tableau $\mathrm{n}^{\circ} 1$ et 2 ; Censo general, 1865, Op. Cit., p. 26, 29, 182 et 371; Censo general, 1875, Op. Cit., p. 60, 80, 550, 625 ; Censo general, 1885, Op. Cit., p. 31, 48, 271, 459 et Censo general, 1895, Op. Cit., tome 1, p. 301, tome 2 p. 202 et 302.

${ }^{2}$ Les réglementations de séjour, d'accès au marché du travail et de naturalisation ne sont pas insensibles au sexe du prétendant, et celles-ci varient en fonction des besoins et intérêts de la société d'accueil, voir à ce sujet Kitty Calavita, "Gender, Migration, and Law: Crossing Borders and Bridging Disciplines », International Migration Review, 40-1/2006, Center of Migration Studies, New York, pp. 104-132 et Nicola Piper, « Gendering the politics of migration », Ibid., pp. 133-164.

${ }^{3}$ J.-P. Blancpain, Les Allemands au Chili, Op. Cit., p. 304. La chacra est une parcelle.

${ }^{4}$ Lettre du 2.03.1853 dans AHN, MINT, vol. 308, Colonización de Llanquihue (1852-1854) : "Un hombre sin familia es en aquellas soledades inútil”.
} 
n'admettrez que le célibataire qui vient au service d'une famille ou celui qui est artisan. Mais aucun des deux ne pourra accéder à la propriété tant qu'il ne sera pas marié ${ }^{1}$.

Pérez Rosales rappelle ici en réalité un point fondamental de la loi de colonisation de 1845 : les terres de la République ne sont attribuées qu'à des familles, donc à des hommes mariés, et, pour chaque enfant de plus de dix ans, leur taille augmente. On notera en revanche que jamais n'est exclue, dans ces propos, la femme célibataire. Par conséquent, « avant de se rendre sur une chacra, la première chose à faire est de prendre femme », résume le colon Karl Seidler ${ }^{2}$. Dicton que semble avoir assimilé le colon Franz Kaskel qui n'attend même pas de débarquer au Chili pour épouser sa promise, Luise Blüffert. Ainsi, au sein de la communauté germano-chilienne, dans la logique de l'économie des échanges symboliques mise en évidence par Pierre Bourdieu, la femme acquière un «statut social d'objet d'échange », parce qu'elle assure à l'homme une terre et une descendance. Bourdieu dégage la valeur symbolique de cette réalité économique :

«Le principe de l'infériorité et de l'exclusion de la femme [...] n'est autre chose que la dissymétrie fondamentale, celle $d u$ sujet et de l'objet, de l'agent et de l'instrument, qui s'instaure entre l'homme et la femme sur le terrain des échanges symboliques, des rapports de production et de reproduction du capital symbolique, dont le dispositif central est le marché matrimonial, et qui sont au fondement de tout l'ordre social: les femmes ne peuvent apparaître qu'en tant qu'objets, ou mieux, en tant que symboles, dont le sens est constitué en dehors d'elles et dont la fonction est de contribuer à la perpétuation ou à l'augmentation du capital symbolique détenu par les hommes. ${ }^{3}$

La majorité des femmes seules trouve donc un prétendant rapidement dans les années qui suivent leur arrivée au Chili. Parmi les célibataires arrivées en 1852 à bord des quatre bateaux «Australia », «Alfred», «Susanna » et «Hermann », nombreuses sont celles qui se marient dès 1853-1854. Parmi elles, les trois filles Aichele-Mautz ${ }^{4}$, Adelaïde Kapf ${ }^{5}$, Marie Betz ${ }^{6}$, Henriette Hartmann $^{7}$. Les recrues de 1856, arrivées à bord du «Cäsar und Helene », du « Grasbrook », de l' «Alfred» ou du «Wandrahm», se marient tout aussi rapidement, comme Teresa Wagner, la

\footnotetext{
1 "Instrucciones que se dejan al Jefe que debe subrogarme en la dirección de la Colonia de Llanquihue", mars 1855 dans AHN, MINT, vol. 308, Op. Cit.: "En la elección de los pobladores que sucesivamente se presentaren, á mas de los requisitos que se señalan en los art. 6 i 7, VS. deberá observar como punto capital el que pertenezcan a nuestra religión y que sean casados. El hombre soltero no es colono. Solo admitirá V.S. al soltero que venga al servicio de alguna familia i al que sea artesano; pero ninguno de los dos podrá ser propietario de terrenos mientras no contraiga matrimonio."

${ }^{2}$ Cité dans J.-P. Blancpain, Les Allemands au Chili, Op. Cit., p. 304.

${ }^{3}$ P. Bourdieu, Op. Cit., p. 49.

${ }^{4}$ Lettre du 28.03.1855 dans M. B. Aichele, Op. Cit., p. 2 et notices Liga01796 Aichele, Liga13023 Mautz, Liga27836 Bräuning et Liga08816 Hermann dans AGS, Op. Cit. Magdalena Barbara épouse David Herz, passager du même bateau, Maria Magdalena, Santiago Bräuning et Christiane, Auguste Hermann.

${ }^{5}$ Notices Liga11278 Kapf, Liga27355 Boeck et Liga27357 Boeck dans AGS, Op. Cit. Elle épouse Eugene de Boeck, professeur ayant voyagé sur le même bateau qu'elle, futur directeur du lycée de garçons à Valdivia.

${ }^{6}$ Notices Liga26964 Betz dans AGS, Op. Cit. Elle a épousé, à Valdivia en 1853, Gottlieb Breckle, menuisier et compagnon de voyage.

${ }^{7}$ Notices Liga07452 Hartmann et Liga11619 Lang dans AGS, Op. Cit., et Schiffslisten, Op. cit., p. 161. Arrivée par le «Susanne » de 1852 avec un enfant de 8 ans, elle a épousé en 1854, à Concepción, Friedrich Lang.
} 
bonne des Eisele ${ }^{1}$, Teresa Feh ${ }^{2}$, Dorothea Kunze, qui épouse en 1857 David Herz, déjà veuf de Magdalena Barbara Aichele ${ }^{3}$. Des familles se recomposent aussi, les maris adoptant les éventuels enfants de leur épouse. Wilhelmine Schleifer, 30 ans, épouse en 1856 Johannes Kehl, qui semble avoir adopté son fils Friedrich, âgé de 5 ans, puisque celui ci prend son nom ${ }^{4}$. Certaines choisissent en revanche de se placer au service d'une famille pour constituer des économies suffisantes et établir ensuite leur propre foyer. Marie Louise Schönewolf, originaire de la Hesse, arrivée au Chili avec l'« Alfred » de 1852, se marie en 1868 avec Auguste Schuster, agriculteur installé à Cutigo en $1852^{5}$. La liste des passagers la dit «cuisinière », ce qui laisse penser qu'elle est arrivée avec une famille dans laquelle elle servait et qu'elle y a gardé sa place plusieurs années au Chili, ou bien qu'elle s'est placée à son arrivée dans une famille allemande émigrée, jusqu'à la date de son mariage.

De manière générale, l'émigration permet donc de mettre fin ou d'éviter une situation de célibat ${ }^{6}$. Le célibat est le symptôme d'un modèle démographique européen classique, où prévalent les mariages tardifs ${ }^{7}$, la « grande arme contraceptive », selon le mot de Pierre Chaunu. Mais la solitude féminine est aussi une constante démographique depuis le Moyen-âge. «Les 'mécanismes' qui la produisent sont multiples. Les stratégies matrimoniales d'abord, qui créent un ordre de mariage et des exclues ; l'assistance aux vieux parents, souvent confiée aux filles cadettes, le veuvage surtout, lié à la longévité féminine et à la rareté des remariages », explique Michelle Perrot ${ }^{8}$. Au Chili, le «marché matrimonial », comme l'entend Bourdieu, présente des caractéristiques différentes. Une famille qui arrive au Chili accompagnée de son personnel de service le perd ainsi en quelques mois : toutes se marient. Il faut rappeler que c'est là une situation impossible en Allemagne, où les jeunes filles de milieux modestes doivent servir de longues années pour accumuler un pécule, une formation ménagère, quelques rudiments d'instruction et ainsi pouvoir prétendre au mariage ; certaines ne se marient même jamais ${ }^{9}$. De plus, dans certains États allemands, en particulier à l'Est de l'Elbe, c'est-à-dire en Prusse orientale et occidentale, Silésie, Poméranie, Mecklembourg et Brandebourg, la domination de la seigneurie domaniale (Gutsherrschaft) est totale jusqu'au début des années $1860^{10}$. Elle s'étend non seulement aux maisons et aux terres mais également aux personnes, qui ont à payer des redevances supplémentaires pour se marier, hériter ou quitter leur terre Quant aux paysans «libres» des pays de l'Ouest de l'Elbe, sous le régime de la seigneurie

\footnotetext{
${ }^{1}$ Notices Liga20692 Wagner dans AGS, Op. Cit. Elle épouse Gerhard Dicke Hansen, à Puerto Montt, en 1857.

${ }^{2}$ Notices Liga 24672 Feh dans AGS, Op. Cit. Elle se marie, dès son arrivée, à 23 ans, à Carl Christian Strauss.

${ }^{3}$ Notices Liga1 1002 Kunze et Liga08998 Hoerz dans AGS, Op. Cit.

${ }^{4}$ Liga18577 Schleifer dans AGS, Op. Cit.

${ }^{5}$ Liga19098 Schönewolf et Liga19463 Schuchster dans AGS, Op. Cit.

${ }^{6}$ S. Sinke, Op. Cit., s.p.

${ }^{7}$ C. Dauphin, «Femmes seules », Op. Cit., p. 515.

${ }^{8}$ M. Perrot, «En marge : célibataires et solitaires » dans P. Ariès, G. Duby (dir.), Op. Cit., p. 274.

${ }^{9}$ C. Dauphin, «Femmes seules », Op. Cit., p. 520.

${ }^{10}$ S. Kott, L'Allemagne au XIX $X^{e}$ siècle, Hachette, carré Histoire, Paris, 1999, p. 34.
} 
foncière (Grundherrschaft), ils sont tous soumis à l'autorité politique, sociale et morale du seigneur, chef de la vie locale, détenteur du pouvoir de basse justice, de contrôle des mœurs, des écoles, de la vie religieuse, et représentant du gouvernement ${ }^{1}$. Finalement, les multiples obstacles mis au mariage génèrent mariages tardifs... et émigration, comme le démontrent Peter Marschalck, Jacques Dupâquier ou Hans-Ulrich Wehler ${ }^{2}$.

Une fois au Chili, le modèle démographique s'inverse radicalement. Sophie von Bischhoffshausen rend compte, peu après son arrivée, de la situation matrimoniale au sein de la communauté allemande de Valdivia. Il lui est difficile de trouver du personnel de maison qui compléterait celui qu'elle a emmené d'Allemagne, parce que toutes se marient pour être rapidement maîtresses de leur propre maison. "Qui veut trouver mari n'a qu'à venir par ici. Les filles sont des produits affreusement demandées ici », dit- t'elle ${ }^{3}$. Une fois installée sur son domaine du Roble, elle souhaite faire venir du personnel d'Allemagne, n'en trouvant pas sur place ${ }^{4}$. Riekchen a préféré rester à Valdivia pour s'installer avec un couturier ${ }^{5}$ et Gretchen, sa bonne favorite, la quitte en 1856 pour un charpentier, venu construire le moulin du domaine l'été ${ }^{6}$. Sophie espère alors pouvoir compter sur un recrutement par contact : Gretchen voudrait en effet faire venir sa sœur et Riekchen une jeune fille de Berge ${ }^{7}$. Se crée en effet un réseau d'information et de recrutement au sein des domestiques, qui signalent les postes libres à leurs amies en Allemagne, comme le décrit Mareike König pour les domestiques allemandes de Paris ${ }^{8}$. Elles savaient bien en effet que leurs amies ou parentes y trouveraient, comme elles, des possibilités d'avenir meilleur. Souvent, les familles en demande de personnel offraient ou avançaient le voyage pour le Chili, comme le propose Sophie9 Voilà qui garantissait donc à la jeune fille, une fois sur place, une autonomie certaine, après avoir rempli un certain temps ses engagements de service. Sophie espère alors pouvoir embaucher une de ces jeunes filles pour alléger un peu la charge de travail qui l'accable depuis le départ de Gretchen ${ }^{10}$. Elle doit gérer des conflits avec un personnel «insupportable et rebelle», qui n'hésite plus à imposer ses conditions ${ }^{11}$. Après la naissance d'Elizabeth en juin 1855, Hannchen refuse de

\footnotetext{
${ }^{1}$ S. Kott, Op. Cit., p. 35.

2 P. Marschalck, J. Dupâquier, Op. Cit., pp. 181-200.

${ }^{3}$ Lettre du 10.12.1854 dans I. Schwarzenberg (éd.), Dokumente, Op. Cit., VI, p. 14 : „Wer gern einen Mann haben will kann nur herkommen. Mädchen ist hier eine schreklich gesuchte Ware ».

${ }^{4}$ Lettre du 16.10.1855 dans Ibid., p. 49.

5 Elle épouse finalement un riche menuisier en 1856. Sur le parcours de Riekchen, voir les Lettres du 30.03.1855, du 20.02 et du 11.9.1856, 10.11.1857 dans Ibid, p. 26, 56, 63 et 90.

${ }^{6}$ Lettre du 24.03.1856 dans Ibid., p. 57.

${ }^{7}$ Lettre du 24.03.1856 dans Ibid., p. 58.

${ }^{8}$ Mareike König, «Les domestiques allemandes à Paris au XIX ${ }^{\mathrm{e}}$ siècle » [en ligne], Actes de l'Histoire de l'immigration, 2003. URL : http://barthes.ens.fr/clio/revues/AHI/articles/preprints/koenig.html [consulté le 17 janvier 2008].

${ }^{9}$ Lettre du 30.03.1855 dans I. Schwarzenberg (éd.), Dokumente, Op. Cit., VI, p. 26.

${ }^{10}$ Lettre sans date (vers début juin 1856) dans Ibid., p. 60.

${ }^{11}$ Lettre du 12.7.1855 dans Ibid. p. 36.
} 
s'occuper des enfants, et n'accepte plus que de faire la cuisine, dont elle fait sa chasse gardée ${ }^{1}$. Elle devient grincheuse et mesquine : «ils ne pensaient plus avoir d'enfant, et bien voilà qu'ils en ont eu encore un, et un chilien en plus !», dit-elle au sujet de la petite dernière, ce à quoi rétorque son frère Georg qu' «on voit très bien qu'elle est allemande, même si elle est née chez les Chiliens ! »². Sophie rapporte qu'elle se plaint « du matin au soir de choses qui ne peuvent pas changer comme la pluie, la poussière, le vent », mais doit pourtant bien reconnaitre que c'est la seule domestique qui lui reste « fidèle et honnête » ${ }^{3}$.

Il faut donc conclure que l'émigration au Chili permet aux célibataires de s'assurer la perspective d'une émancipation, d'ordre économique, à travers le mariage. Tenir sa propre maison est un luxe auquel beaucoup de femmes aspirent, parce que le statut d'épouse entraîne immédiatement des garanties économiques, comme le sanctionne le code napoléonien, inspirateur des codes européens ${ }^{4}$. «Le déplacement à la fois géographique, social et culturel, constitue un phénomène essentiel pour l'histoire des femmes et leur conquête de l'autonomie économique. Hors du mariage, point de salut !», rappelle Cécile Dauphin ${ }^{5}$. Les Allemandes qui débarquent ainsi à Valdivia ont une relative liberté dans leur choix de vie. Ce n'est pas le cas par exemple de celles qui vivent à Valparaiso pour servir dans les familles du commerce international. Le cas de Marie Bülling, célibataire de Valparaiso, illustre clairement ces différences. Marie est bien consciente de cette vérité et des possibilités d'émancipation que lui offre l'émigration ${ }^{6}$. Elle est la cadette d'une famille de la bourgeoisie élevée, qui a vécu de graves difficultés suite au décès de la mère et à la démission forcée du père, fonctionnaire de l'administration royale de l'Oldenbourg, accusé, en 1848, de violations de ses devoirs administratifs et poursuivi par des rumeurs d'homosexualité ${ }^{7}$. Dans ces conditions, disparaît la perspective d'un bon parti pour Marie, et même plus, surgit la nécessité de subvenir seule à ses besoins. Pour une telle demoiselle, le choix des emplois est limité, du fait de sa position sociale : gouvernante, dame de compagnie ou institutrice de niveau primaire, dans le cercle privé d'une famille, activités auxquelles Marie se consacre déjà en Allemagne ${ }^{8}$. Il s'agit là d'un phénomène croissant au $\mathrm{XIX}^{\mathrm{e}}$ siècle :

\footnotetext{
${ }^{1}$ Lettre du 20.8.1855 dans I. Schwarzenberg (éd.), Dokumente, Op. Cit., VI, p. 37 : „da werde ich sehr oft nicht gefragt was gekocht werden soll, sondern $\mathrm{H}$. sagt das muss gekocht werden, ich lasse sie gewären und schweige still"“

${ }^{2}$ Lettre du 28.9.1855 dans Ibid., p. 44 : ,“Nicht war da dachten sie schon sie kriegten keine Kinder mehr? und nun haben sie doch noch eins! Und noch dazu ein Chilenisches!“ antwortet Hannchen, worauf [Georg] denn ganz klugt mint : "das es ein Deutsches ist, das sieht man ja wohl; wenn's auch bei den Chilenen jung geworden ist"“."

${ }^{3}$ Lettre du 21.6.1856 dans Ibid., p. 62 : ,Hannchen ist noch ein's von den schlimmsten, d.h. es arbeitet wie ein Pferd, klagt aber von Morgen bis Abend's über alles was sich nicht änder lässt, über Regen, Schmutz, Wind [...] doch muss ich wieder froh sein dass ich es habe, so treu und redlich giebt es wenig Menschen"

${ }^{4}$ Cécile Dauphin, « Femmes seules », Op. Cit., p. 518.

${ }^{5}$ Ibid.

${ }^{6}$ E. von Loe (éd.), Marie Bülling: Una institutriz Alemana en Valparaíso. Diario de vida, 1850-1861, Trad. del alemán: Rosemarie Kempf Titze. Valparaíso, Universidad de Playa Ancha, 2004, 324 p.

${ }^{7}$ Le parcours familial des Bülling a été reconstitué dans E. von Loe, Marie Bülling, Op. Cit., pp. 151-156.

${ }^{8}$ Ibid., p. 13.
} 
« Les préceptrices ou gouvernantes, «mamzelles » ou « Miss » [sont] souvent recrutées dans des familles bourgeoises modestes, filles de pasteurs ou de petits fonctionnaires, orphelines ou encore issues de familles nombreuses, explique Cécile Dauphin. [...] La misère des travailleuses ou des domestiques était perçue comme une fatalité sociale. Mais que des femmes bourgeoises soient contraintes de travailler dans des conditions difficiles, ou de chercher un emploi pour la première fois à quarante ou cinquante ans, après la mort des parents, apparaissait plus pitoyable encore, trop visible à la conscience des classes supérieures. »

Considérant cet ensemble de données, le départ de Marie vers le Chili paraît motivé par un profond désir d'indépendance et de liberté. Mais chez les Müller, une famille de classe moyenne ascendante, l'épouse se consacre exclusivement à ses loisirs et revêt surtout un rôle de représentation. Bientôt, elle demande à Marie de s'occuper des enfants à plein temps, ce qui n'était pas prévu dans le contrat initial ${ }^{2}$. Marie y voit une limitation de ses libertés, habituée qu'elle est à consacrer ses demi-journées à ses visites amicales. C'est qu'elle a un statut social ambigu, qu'il lui est difficile d'accepter : elle conserve son statut de demoiselle, et peut apparaître en public comme telle, mais son activité rémunérée la relègue bien au bas de l'échelle sociale. Cécile Dauphin dresse ainsi le portrait sans appel de l'institutrice du XIX ${ }^{\mathrm{e}}$ siècle : «Frappée par le destin (mort d'un père, ruine familiale...), c'est une bourgeoise dans le besoin dont le travail devient 'prostitution' de son éducation $»^{3}$. Marie est bien consciente de sa situation et elle associe clairement sa condition économique à sa condition de femme. Elle montre ainsi une nette conscience des discriminations de genre, qui lui provoquent un sentiment de rage, toujours latent dans son texte, par exemple lorsqu'elle s'indigne :

« Vraiment, notre vie à nous, les institutrices, n'est pas facile, et ce qui me fait encore plus rager c'est qu'on nous exige bien plus qu'aux hommes dans ce domaine. Eux, ils donnent leurs cours, touchent le double du salaire que nous nous touchons, pauvres femmes, et bientôt ils sont libres comme des oiseaux dans l'air. Combien de fois ai-je souhaité être un homme, pour être libre et entrevoir un avenir. Et comme je le souhaite de nouveau maintenant! Mais nous, les pauvres femmes, nous sommes seules au monde, créatures misérables, et c'est bien pour cela que toutes désirent se marier $»^{4}$.

La seule vraie liberté d'une femme, pour Marie, c'est en effet d'être épouse et d'avoir son propre foyer ${ }^{5}$. Elle écrit en effet à ce sujet :

\footnotetext{
${ }^{1}$ C. Dauphin, «Femmes seules », Op. Cit., pp. 520-521.

${ }^{2}$ Entrée du 15.01.1851 et 3.05.1851 dans E. von Loe, Marie Bülling, Op. Cit., pp. 38 et 63.

${ }^{3}$ Ibid. p. 521. La mort du père, en 1854, attache Marie encore davantage à sa condition de gouvernante et la condamne à poursuivre les cours privés, une fois son contrat achevé chez les Müller, repoussant indéfiniment le retour en Allemagne. Dès son arrivée, elle pense rentrer et économise dans cette perspective. Mais les aléas de la vie, notamment les soucis de santé, ne lui permettent jamais de rassembler la somme suffisante. Peu à peu, elle se fait à l'idée de prolonger son séjour au Chili.

${ }^{4}$ Entrée du 3.05.1851 dans Ibid., pp. 63-64: «Realmente, no es fácil la existencia de nosotras las institutrices, y lo que mas rabia es que a nosotras se nos exija tanto más que a los hombres en este rubro; Ellos dan sus clases, reciben el doble del sueldo de lo que recibimos nosotras las pobres mujeres, y luego están libres como pájaros volando por los aires. Cuantas veces he deseado ser hombre, para restar libre y en condiciones de seguir adelante [...] Pero nosotras, pobres mujeres, estamos solas en el mundo, criaturas miserables, y esa es la razón por la cual todas desean casarse ».

${ }^{5}$ Entrée du 4.02.1851 dans Ibid., p. 43.
} 
«Liberté, Liberté ! C'est bien ce que mon cœur regrette et demande avec fougue. La liberté et autre chose. Sans liberté, sans amour, il n'y a que de tristesse ! L'un des deux m'est-il réservé ? Ou vais-je devoir rester toute la vie sans amour? Maintenant que j'ai le temps de penser à cela, je crois bien que Marie Thölken avait raison quand elle me conseillait de me marier, quand bien même le parti qui s'offrait n'était pas bien brillant ${ }^{1}$.

Pourtant, dès son arrivée, Marie est très courtisée ${ }^{2}$. Mais elle est une jeune fille romantique et exigeante et estime avoir eu raison de repousser les propositions. Elle ne voulait pas s'engager dans « une union pour toute la vie», si le prétendant ne lui inspirait pas de sentiments ${ }^{3}$. Toutes les propositions qu'elle a reçues jusqu'à présent ne lui conviennent pas : «L'homme parfait ne viendra jamais ! » se désespère-t-elle au retour d'un bal ${ }^{4}$.

Le principal obstacle aux projets de Marie vient en réalité de ses employeurs, et du fort contrôle social auquel elle est soumise en tant qu'employée de maison. Progressivement, le rythme de vie de Marie se heurte à la désapprobation des Müller qui critiquent ses visites répétées chez ses différentes amies allemandes ${ }^{5}$. Le 13 juillet, Mr Müller exprime clairement ce que Marie pressentait :

«Non, quand c'est trop, c'est trop! Aujourd'hui, j'ai appris, et je me suis vraiment énervée, mais je le craignais depuis un certains temps, que Mr Müller n'aime pas qu'on vienne m'inviter à midi. C'est ce qu'il a dit à Mrs U. et S. [Uhde et Sebikoh]. Les deux étaient venus pour m'inviter au nom de leur épouse pour ce dimanche. Pourquoi ? Le motif est si ridicule que je ne veux même pas le mentionner, ou plutôt, si égoïste, qu'il est horrible : ils ont peur que je veuille me mar... Comme si quelqu'un s'était intéressé à moi, ou comme si moi j'allais accepter le premier venu qui croise mon chemin! Non, je suis vraiment en rage et je me rends compte que mes craintes, à savoir qu'ils sont jaloux de mes bonnes relations avec les Allemands, sont parfaitement fondées. Oh égoïsme, ton règne est immense ! Quand serai-je libre des velléités des autres ? ${ }^{6}$

\footnotetext{
${ }^{1}$ Entrée du 4.02.1851, dans E. von Loe, Marie Bülling, Op. Cit., p. 43 : "Libertad, Libertad, es lo que mi corazón añora y piede con ímpetu. Libertas y algo más. Sin libertad, sin amor, ¡sólo hay tristeza! ¿me estará reservado lo uno o lo otro, o tendré que andar por la vida sin amor? Ahora tengo tiempo para para estas reflexiones, y creo que Marie Thölken tenía razón cuando me aconsejó que me casara, incluso si el partido que se me ofreciera no fuera brillante".

${ }^{2}$ Notamment par Mr. Burdry, passager du Gustav : "Parece que rompí algunos corazones en el viaje. Elle pobre me da mucha pena, ¡Pero! ¡No!”dit-elle à son sujet. Bientôt c'est un mystérieux Mr H. qui lui laisse quotidiennement des cartes de visite. Entrées du 7, 10 et 13.10.1850 dans Ibid., p. 23-24.

${ }^{3}$ Entrée du 4.02.1851 dans Ibid., p. 43.

${ }^{4}$ Entrée du 1.03.18151 dans Ibid., p. 47 : «¡Nunca vendré el hombre adecuado!». Les nombreux divertissements sont, pour elle, autant d'occasion d'espérer trouver son promis. Chaque entrée qui suit une soirée est un bilan des hommes qui lui ont plu, ou non. Au retour d'un bal, elle écrit, désabusée : «El calor fue horrible, y la mayoría de los que bailaron conmigo no me gustaron ». Entrée du 7.02.1851 dans Ibid., p. 44.

${ }^{5}$ Entrée du 3.07.1851 dans Ibid., p. 73.

${ }^{6}$ Entrée du 13.07.1851 dans Ibid., pp. 74-75: "No, ¡Lo que es demasiado es demasiado ! Hoy me informé y me enojé mucho, pero había temido hace tiempo. Y es que al Sr. Müller no le agrada que me inviten al mediodía; así le dijo a los señores U. y S.; los dos habían venido para invitarme en nombre de sus esposas para este domingo. ¿Y porque no? El motivo es tan ridículo que ni lo quisiera mencionar, o, más bien, tan egoísta, que es horrible: temen que pretendo cas... ¡Como si alguien se hubiese fijado en mi, o como si yo aceptara al primero que se me cruzara por el camino! No, me da mucha rabia y me doy cuenta de que mis temores de que sienten envidia por mi trato con los alemanes no carecen de fundamento. ¡Oh egoísmo, tu reinado es inmenso! ¿Cuándo estaré libre de las veleidades de otras personas?”.
} 
Pendant un mois, Marie est littéralement privée de sortie par ses employeurs, «par peur qu' [elle] y rencontre quelqu'un et [se] marie » ${ }^{1}$, et ces derniers sabotent même toute entreprise de séduction, déroutant systématiquement les prétendants, au point d'en faire une célibataire intouchable ${ }^{2}$. Finalement, à l'âge de 37 ans et dont onze ans de vie à Valparaíso, après avoir souffert d'amours non réciproques ${ }^{3}$, elle se résout à accepter l'offre d'un prétendant qu'elle connait à peine - c'est à peine si elle se souvient de lui quand elle reçoit la proposition de mariage ${ }^{4}$. Son journal s'arrête abruptement, le 21 octobre 1861, sans qu'elle ne dise mot du prétendant. Dans les dernières entrées, elle analyse très froidement son avenir à ses côtés, qu'elle envisage principalement en termes matériels, ce qui étonne de la part d'une Marie connue pour ses envolées romantiques ${ }^{5}$. Elle y voit en réalité la possibilité d'accéder enfin à cette liberté qu'elle associe au statut d'épouse et de maîtresse de maison, ce dont elle rêvait depuis toujours. C'est donc bien un mariage de raison, et non d'amour ${ }^{6}$. Incontestablement, l'expérience migratoire de Marie Bülling lui a permis de gagner en maturité et en auto-estime féminine. Les pages de son journal montrent qu'elle se sent plus sûre d'elle, plus indépendante, osant exprimer des idées sur le rôle de la femme peu conventionnelle pour son époque. Son désir d'émancipation est cependant fortement limité par le contrôle social qu'exercent ses « patrons », personnalités importantes du commerce international.

C'est donc dans un vent de liberté et avec des espoirs d'ascension économique que les célibataires s'embarquent à bord des voiliers pour le Chili. Comme les femmes mariées, elles décident de mettre fin à une situation économique délicate à laquelle elles sont confrontées et provoquée par les troubles économiques et politiques qui touchent l'Allemagne au milieu du XIX ${ }^{\mathrm{e}}$ siècle.

\footnotetext{
${ }^{1}$ Entrée du 17.07.1851 dans E. von Loe, Marie Bülling, Op. Cit., p. 76 : “ ¿No quieren que vaya por temor a que me dé a conocer y me case?".

${ }^{2}$ Entrée du 19.07.1851 dans Ibid : "Nuevamente el egoísmo de los M.; molestaron y se burlaron del pobre Hallmann, a quien no le quedo mas remedio que ignorarme. Claro que no se me va a acercar nunca más, y de esta manera he perdido un amigo que había creído tener. ¿Cómo la gente puede ser tan egoísta y mezquina, impidiendo nuestra felicidad en vez de fomentarla? Confieso que estoy algo molesta con los Müller y que no los habría creído capaces de tan mezquinas intrigas. Al final uno pierde su fe en la gente".

${ }^{3}$ Marie a longtemps soupiré pour Bluhm, précepteur puis fondateur de l'école de commerce du « Séminaire anglais et allemand», plus connue sous le nom «Goldfinch\&Bluhm». Ce dernier lui témoigne cependant une sorte d'agressivité et de mépris (dans la limite de la courtoisie de l'époque), qui l'affecte beaucoup. Elle le remplace par Hallmann qui a beaucoup de sympathie pour elle, mais ne prend aucune initiative, vu la pression exercée par Mr. Müller. Puis vient Poppe... qui épouse une autre institutrice. Cf. Ibid., pp. 199-200. ${ }_{5}^{4}$ Entrée du 27.03.1861 dans Ibid., p. 268.

${ }^{5}$ Il semblerait qu'elle ait posé comme condition au mariage une augmentation future des revenus de son prétendant, Richard Schumacher, astronome de l'Observatoire de Santiago. Cf. F.W. Ristenpart, « Deutsche Astronomen en Chile » dans Die deutsche Arbeit, Op. Cit., vol. I, p. 176.

${ }^{6}$ Le mariage a été de courte durée et stérile. Selon E. von Loe, Richard retourna en Allemagne en 1869, seul, et travailla à l'Observatoire de Kiel jusqu'à sa mort en 1902. Marie est restée à Valparaíso, s'employant toujours comme professeure de piano et de langue. Elle est retournée en Allemagne en 1874 en compagnie d'une amie, mais ayant passé la moitié de sa vie au Chili, elle est retournée y vivre et y mourir, le 18 décembre 1914, à 90 ans. Cf. E. von Loe, Marie Bülling, Op. Cit., pp. 283-289.
} 


\subsection{Choisir l'émigration}

Les motivations des femmes allemandes qui émigrent au Sud du Chili relèvent souvent de nécessités immédiates. La première vague d'immigration allemande, de 1846 à 1875, dont font partie en majorité les femmes dont les écrits sont étudiés dans ce travail, est faite de bourgeois, artisans, professeurs, médecins et paysans. Fondamentalement, ils sont poussés par la grande crise du milieu de siècle, ou vaincus politiquement. Cependant, dissocier l'émigration politique des contraintes de la vie matérielle est souvent illusoire. Il faut rappeler le contexte de l'Allemagne au milieu du XIXe pour comprendre pourquoi ces femmes la fuient, avec leur famille ou seules.

\subsubsection{Fuir la répression politique}

La vague de répression qui suit la révolution manquée de 1848 n'est pas étrangère au mouvement migratoire allemand. Les idées libérales et démocratiques ont en effet gagné du terrain dans les années 1830, jusqu'à emporter la majorité dans de nombreux parlements d'État, y compris au Landtag de Prusse en $1847^{1}$. Les révolutions allemandes de 1848-1849, étendues sur dix-sept mois, contiennent trois phases bien distinctes ${ }^{2}$. De mars à septembre 1848 , se structurent les mouvements révolutionnaires, animant les premières insurrections et aboutissant à l'élection du Parlement de Francfort. De septembre 1848 à mars 1849, le mouvement gagne en hétérogénéité mais aussi en vulnérabilité. Les revendications populaires, culminant dans les révolutions de septembre 1848 à Vienne, Berlin ou Francfort, dépassent largement les projets politiques, entraînant la paralysie du parlement de Francfort et un premier triomphe de la contre-révolution en Autriche et en Prusse. Enfin, les mois de mars à juillet 1849 marquent la phase de reflux des idées révolutionnaires, avec l'échec de la campagne constitutionnelle ${ }^{3}$. C'est à ce moment précis que de nombreux notables influents décident de quitter le pays, entrainant avec eux parenté et concitoyens. Quelques jours avant le départ du bateau, Klara Anwandter évoque les problèmes politiques du moment qui ont poussé sa famille à l'exil ${ }^{4}$. Son père, Karl Anwandter, pharmacien de profession, est un notable influant de Kalau connu pour ses convictions démocratiques radicales ${ }^{5}$. Élu au Landtag prussien en 1847, comme représentant démocrate du district de Kalau, il siège un an plus tard à l'Assemblée nationale prussienne et est élu bourgmestre de la ville. Mais face à l'opposition constante du gouvernement prussien, il doit démissionner cinq mois plus tard et l'émigration s'offre alors comme sa seule chance de survie. Il embarque en juin 1850 à bord du "Hermann », le

\footnotetext{
${ }^{1}$ S. Kott, Op. Cit., p. 55.

${ }^{2}$ Ibid, pp. 50-75.

${ }^{3}$ F. Roth, L'Allemagne de 1815 à 1918, Paris, Armand Colin, 2002, pp. 34-35.

${ }^{4}$ Lettre du 25.6.1850 dans I. Schwarzenberg (éd.), Dokumente, Op. Cit., III, p. 7.

${ }^{5}$ Sur Karl Anwandter, Cf. G Grossbach, Carl Anwandter, Valdivia, Instituto Alemán Carl Anwandter, 2005, 347 p. et R. Krebs, «Carl Anwandter y la Colonia Alemana de Valdivia» dans Desde Hamburgo a Corral: diario de viaje de Carl Anwandter a bordo del velero Hermann, Valdivia, Santiago, Pehuén, 2001, pp. 13-27.
} 
«Mayflower» de l'émigration allemande au Chili ${ }^{1}$. « Cela nous fait de la peine de quitter tous nos chers amis, dit la jeune fille, mais d'un autre côté, on est heureux de pouvoir partir de ce pays de misère. Notre chère Kalau va maintenant trouver ce qu'elle mérite $»^{2}$. Fanny Zöhrer accompagne quant à elle un époux médecin, Franz Fonck, également inquiété pour ses opinions démocrates. En 1848, il avait pris les armes avec ses compagnons de l'université de médecine ${ }^{3}$.

Ainsi, dans un contexte politique fragile, les ambitions familiales se voient rapidement compliquées et la situation économique peut se dégrader. Les Exss fuient ainsi la pauvreté de leurs terres d'Ullersdorf, domaine royal qu'ils louent, et les événements de $1848^{4}$. En Hesse, c'est le régime de terreur entretenu par les armées contre-révolutionnaires qui fait fuir les populations. L'occupation de Cassel par la Bundesexekutions Armee, jusque juillet 1851, ruine l'Électorat ${ }^{5}$. Les Schwarzenberg doivent ainsi loger quelques 1100 soldats en 1850-1851 ${ }^{6}$. Jean-Pierre Blancpain décrit une situation dramatique induite par un véritable régime policier :

«Mutations, condamnations, révocations des fonctionnaires hessois se multiplient à partir de décembre 1850 [...]. Les fonctionnaires refusant la levée d'impôts nouveaux sont révoqués et emprisonnés [...]. Toutes les villes de l'Électorat sont traitées de même : Hanau, Fulda, Münden, Marburg, Rotenburg-an-der-Fulda enfin, dont les juges trop cléments sont emprisonnés huit mois. La petite ville fournira à l'émigration vers le Chili un contingent de plus de 200 individus entre 1852 et $1857 »^{7}$.

\subsubsection{Echapper à la crise économique}

Aux événements politiques de 1848 et leurs conséquences se greffent des difficultés économiques sérieuses depuis la crise de 1846-1847. Dans les années 1840, la société allemande compte 50 à $60 \%$ de «pauvres $»^{8}$. Du fait de la croissance démographique, le nombre de paysans sans terre

\footnotetext{
${ }^{1}$ G. Guarda, Nueva Historia de Valdivia, Op. Cit., p. 535.

${ }^{2}$ Lettre du 25.6.1850 dans I. Schwarzenberg (éd.), Dokumente, Op. Cit., III, p. 7: „Es tut uns wehe von so lieben Freunden zu gehen, aber andererseits ist man froh aus diesem elenden Lande gehen zu können, unser liebes Kalau wird jetzt so gemassregelt wie nur irgend möglich“.

${ }^{3}$ J.-P. Blancpain, Les Allemands au Chili, Op. Cit., p. 189.

${ }^{4}$ I. Schwarzenberg, «Soziale Herkunft und Entwicklung einiger deutschstämmiger Familien in Chile », Sonderdruck aus Genealogisches Jahrbuch, Bd. 5, 1965, p. 60.

${ }^{5}$ Le gouvernement de la cour hessoise (notamment le très conservateur ministre de l'Intérieur et de la Justice Hassenpflug) persécute durement les mouvements libéraux au milieu du XIXe siècle. Face aux protestations des forces libérales de l'assemblée des États, le prince Friedrich Wilhelm I ${ }^{\mathrm{er}}$ dissout cette dernière, le 12 juin 1850. Décrétant l'état de guerre, il impose une modification de la constitution dans un sens encore plus conservateur mais se heurte à une «grève générale» des officiers hessois en octobre 1850. Le prince fait alors appel à l'assemblée fédérale, la Bundesversammlung, organe supérieur de la Confédération germanique, pour imposer la contre-révolution. Le 16 octobre 1850, celle-ci déclare la Hesse en état d'occupation et y envoie des troupes bavaroises et autrichiennes. Sur la Hesse au milieu du XIX ${ }^{\mathrm{e}}$ siècle, voir : K. E. Demandt, Geschichte des Landes Hessen, 2. Auflage, Bärenreiter Verlag Kassel und Basel, 1972; Historische Kommission für Hessen, Das Werden Hessens, Hrsg. W. Heinemeyer, N.G. Elwert Verlag Marburg, 1986 et sur l'émigration hessoise: I. Auerbach, Auswanderung aus Kurhessen : nach Osten oder Westen?, Hessisches Staatsarchiv Marburg, 1993.

${ }^{6}$ U. Steenbuck, «Inmigrantes alemanes rumbo a Chile en el siglo XIX » dans Desde Hamburgo a Corral, Op. Cit., p. 32.

7 J.-P. Blancpain, Les Allemands au Chili, Op. Cit., pp. 190-191.

${ }^{8}$ S. Kott, Op. Cit., p. 52.
} 
s'accroît, premiers touchés lors des grandes disettes de 1817,1831 et $1846^{1}$. Michel Hau note que, sur toute la première moitié du $\mathrm{XIX}^{\mathrm{e}}$ siècle, la croissance de la production agricole ne suffit pas à compenser celle de la population. Au contraire, l'expansion démographique suit une courbe presque parallèle à celle de la croissance agricole, de telle sorte que le nombre des habitants rattrape sans cesse les accroissements de la production des denrées alimentaires. De plus, la «libération des paysans» a produit un effet presque inverse dans les catégories les plus vulnérables, cette unterbaüerliche Schicht, la «couche infra-paysanne», qui doit chercher dans l'industrie à domicile un moyen de compenser les pertes de revenus engendrées d'une part, par le partage des communaux et d'autre part, par l'obligation du rachat des terres, c'est à dire des tenures des seigneurs qu'ils exploitaient, ce à quoi bien souvent ils ne peuvent prétendre, faute de moyens ${ }^{2}$. Cette crise structurelle est alors aggravée par une crise conjoncturelle en 1846-1847, une crise de subsistance caractéristique de l'Ancien régime économique. Les mauvaises récoltes de pommes-de-terre en 1845-1846 entraînent un doublement des prix ${ }^{3}$. Cette hausse affecte bientôt d'autres produits comme la viande et le seigle, principale céréale cultivée en Allemagne, puisqu'elle réussit bien sur ses sols pauvres, majoritaires ${ }^{4}$. Cette année marque, pour une partie de la population, le passage de la pauvreté au dénuement absolu ${ }^{5}$.

L'un des symptômes du bas niveau de vie de la population allemande est l'augmentation des mouvements migratoires, d'abord vers la ville, puis Outre-Atlantique. A partir du milieu du XIX', l'émigration se fait directement du village vers l'Amérique. Avant 1830, émigrent quelques 4000 individus par an. La «manie d'émigrer » est déjà signalée par le gouvernement du district de Trêves en $1827^{6}$. Vers 1840, ils sont 20000 par an et à partir de la crise agricole de 1846, plus de $100000^{7}$. On compte ainsi 433000 départs de 1846 à 1851, 566000 de 1852 à 1854 et 430000 de 1855 à 1860 . Au total, 2,723 millions de 1816 à $1870^{8}$. De 1880 à 1885 , une nouvelle vague emporte 975000 Allemands et le flux annuel se maintient à près de 100000 pour ne baisser qu'à partir de 1894-1913. Au total, de 1871 à 1914 ont émigré 2,85 millions d'Allemands supplémentaires ${ }^{9}$. Dans toutes les grandes villes d'Allemagne sont fondés des bureaux, des sociétés et des agences spécialisées dans le conseil et l'orientation des candidats à l'émigration.

\footnotetext{
${ }^{1}$ M. Hau, Op. Cit., p. 9.

${ }^{2}$ H.-U. Wehler, Essai sur l'histoire de la société allemande (1870-1914), Paris, Maison des Sciences de l'Homme, 2003pp. 185-186.

${ }^{3} \mathrm{Si}$ l'on considère que les céréales provenaient de plus en plus de l'importation, mais que les pommes-deterre étaient produites sur place, ces dernières constituent alors l'indicateur approprié de la santé de l'agriculture allemande à cette époque. $C f$. C. Zimmermann, « La modernisation des campagnes allemandes (XIX ${ }^{\mathrm{e}}-\mathrm{XX}^{\mathrm{e}}$ siècles). Les apports de l'historiographie récente en Allemagne », Histoire et sociétés rurales, $11 / 1^{\mathrm{er}}$ semestre 1999 , pp. 87-108.

${ }^{4}$ M. Hau, Op. Cit., p. 8.

${ }^{5}$ S. Kott, Op. Cit., p. 53.

${ }^{6} \mathrm{~K}$. Obermann, "Les grands mouvements de l'émigration allemande vers les Etats-Unis d'Amérique au XIXe siècle » dans Les migrations internationales, Op. Cit., p. 409.

${ }^{7}$ M. Hau, Op. Cit., p. 10.

${ }^{8}$ P. Marschalck, J. Dupâquier, Op. Cit., p. 409.

${ }^{9}$ Ibid., p. 420.
} 
Elles dispensent des informations sur les itinéraires, les ports, les conditions de transport et les possibilités concrètes d'établissement en Amérique, diffusent une presse spécialisée et soutiennent des publications diverses, des récits de voyage aux conseils d'un émigré ${ }^{1}$. A la faveur des échanges d'information naît une véritable mystique de l'émigration et jusqu'au fond des campagnes, l'Amérique apparaît « comme une sorte de terre promise ruisselant du lait de la liberté et du miel de l'opulence » ${ }^{2}$. L'émigration devient même un topos des poèmes et chants populaires ${ }^{3}$.

Rosine Schönherr fait partie par exemple de l'émigration des Zillerthaler du Riesengebirge. Le groupe a envoyé des «éclaireurs » à bord du « Cäsar und Helene » en 1856 avant de se déplacer en masse à bord de l'«Inca » fin 1856 et de l'«Iserbrook» en $1857^{4}$. Il s'agit de fils et filles de Tyroliens protestants, de la vallée du Ziller, mal intégrés à une société catholique sous l'emprise de l'évêque de Salzbourg 5 . En 1837, Frédéric-Guillaume III de Prusse leur propose le domaine d'Erdmannsdorf en Silésie. Ils s'y déplacent par centaines l'année suivante et rebaptisent le lieu Zillerthaler-Erdmannsdorf. Cependant, malgré la protection de la baronne Reeden, ils ne s'adaptent pas à la Silésie, et leur extrême pauvreté les incite à émigrer, aux Etats-Unis, en Australie, tandis qu'un groupe choisit le Chili : les familles Schönherr, Kröll, Kolcker, Heim, Fleidl et Hechenleiter, soit une centaine de personnes. Hesse, Souabe, Lusace, Brandebourg, Bohême sont des régions également touchées à la fois par la pauvreté conjoncturelle, la crise de 1847 et les débuts de mutations industrielles, qui portent gravement préjudice à l'activité des artisans. La proto-industrie ou Verlagsystem de la rubanerie est alors importante en Saxe, celle du lin ou de la laine dans la vallée de la Wupper, du coton dans le Wurtemberg, en Saxe ou en Silésie, tandis que l'on travaille le bois dans le Sauerland et le fer en Haute Silésie, dans le Harz ou les Monts Métallifères ${ }^{6}$. A la crise du Verlagsystem à partir de 1848, répond l'ouverture de la «soupape de sécurité » de l'émigration ${ }^{7}$. Les tisserands de Haute-Lusace, de Gross-Schönau près de Zittau, quittent ainsi leurs terres en deux convois pour le Chili, en avril 1850 et en juillet 1852, poussés à l'émigration par la brutale introduction des métiers mécaniques et l'échec de leurs deux grandes révoltes de 1844 et $1848^{8}$. Parmi leurs descendants, Hélène Biel Linke, épouse Scheel, qui témoigne combien l'expérience de cette émigration artisane reste vive dans la mémoire de la communauté germanochilienne. Dans ses mémoires, en 1940, elle raconte ainsi, que ses grands- parents paternels, tisserands, sont arrivés parmi les premiers émigrés en décembre 1850 sur le voilier «Susanne », en

\footnotetext{
1 Sur les associations d'émigration, voir H. Bickelmann, A. Bretting, Auswanderungsagenturen und Auswanderungsvereine im 19. und 20. Jahrhundert, Stuttgart, Franz Steiner, 1991, 288 p.

${ }^{2}$ P. Marschalck, J. Dupâquier, Op. Cit., p. 410.

${ }^{3}$ A. Lübke, Op. Cit. pp. 37-38.

${ }^{4}$ J.-P. Blancpain, Les Allemands au Chili, Op. Cit., pp. 206-207.

${ }^{5}$ Sur les Zillerthaler, Cf. Eckart Sauser, Die Zillertaler Inklinanten und ihre Ausweisung im Jahre 1837, Innsbruck, Üniversitätsverlag Wagner, 1959.

${ }^{6}$ S. Kott, Op. Cit., pp. 39-41.

${ }^{7}$ M. Hau, Op. Cit., p. 262.

${ }^{8}$ Sur le mouvement des tisserands silésiens, voir J.-P. Blancpain, Les Allemands au Chili, Op. Cit., p. 192193 ; S. Kott, Op. Cit., p 53. et A. Optiz, «Situación socio-economica y politica en Silesia de los anos 30 del siglo XIX y la emigración » dans K. Konrad (éd.), Familia Konrad, Op. Cit., pp. 7-9.
} 
compagnie d'autres familles apparentées : les Heitmann, Biel, Michaelis, Oemick, Griebel, Scheel, Jonas, Adler, Holland. " La révolte des tisserands en Allemagne a causé l'émigration de beaucoup de familles », explique-t-elle. Jean-Pierre Blancpain de conclure alors que « les crises européennes de $1848-1851,1857$ et 1873-1875 correspondent bien à trois pulsations de cette première émigration allemande vers le Chili, malgré sa modestie quantitative. » ${ }^{1}$

Ainsi, face aux menaces de déchéance sociale et économique, à la pression quotidienne des troupes d'occupation ou à la répression politique, la décision familiale est forcée en faveur de l'émigration. Il faut se représenter concrètement des foyers, par exemple en Hesse, où des dizaines de soldats occupent le logis tandis que la famille est réduite à occuper la grange, avec les animaux. Pauline Beyrodt de Geisse écrit, désespérée, en 1851 :

« Nous avons supporté l'horrible fardeau des Prussiens, des Bavarois et des Autrichiens de décembre 1850 à juillet 1851. Père était au bureau, moi au milieu des soldats. Nos revenus se réduisent à rien, tout est hors de prix et nous sommes dans la pire situation financière $»^{2}$.

C'est alors un réflexe de protection des enfants qui se manifeste chez les femmes. Concrètement, dans de telles conditions, l'unique objectif est de leur trouver un endroit plus sûr. Les Allemands et Allemandes qui émigrent au Chili au milieu du XIXe siècle ne le font pas tant par misère - sinon ils ne pourraient pas s'offrir le voyage ni émigrer avec leur personnel - que pour en échapper ${ }^{3}$. Il s'agit en effet d'éviter une déchéance certaine, qui touchera cette génération ou la suivante. L'émigration se fait bien "pour les enfants », comme le dit Sophie, la veille de son départ de Hambourg ${ }^{4}$.

\subsubsection{Les femmes et la décision de migration}

Dans ce contexte, la migration apparaît bien comme «le fruit de la négociation entre plusieurs personnes », le résultat d'une décision pensée et partagée entre les différents membres de la famille, dans le cadre d'une stratégie de survie ${ }^{5}$. Les femmes mariées émigrantes sont souvent représentées comme des «suiveuses passives » inconsolables qu'on arrache à leur patrie et leur famille tant aimées. Or, le cas des Allemandes au Chili contribue à mettre sérieusement en doute cette image. Les femmes participent pleinement de la décision de migration. L'émigration des célibataires s'inscrit également dans des stratégies familiales de survie économique, ce qui ne signifie pas que les jeunes filles n'aient pas de part à la décision qui les concerne. A ce sujet, Philippe Rygiel rappelle que :

\footnotetext{
${ }^{1}$ J.-P. Blancpain, Les Allemands au Chili, Op. Cit., p. 193.

${ }^{2}$ Citée dans I. Schwarzenberg, «Soziale Herkunft und Entwicklung », Op. Cit., p. 34.

3 Sur ce point, il est à noter que l'isolement du Chili - il s'agit du pays de l'Amérique latine géographiquement situé le plus loin de l'Europe - se convertit en avantage puisqu'il lui permet de «trier», d'un point de vue socio-économique, ses immigrants, vu la cherté du voyage. Cf. R. Krebs, „Carl Anwandter", Op. Cit., p. 14.

${ }^{4}$ Lettre du 14.6.1854 dans I. Schwarzenberg (éd.), Dokumente, Op. Cit., tome VI., p. 5.

${ }^{5}$ J. Dahinden, M. Rosende, N. Benello (et al.), Op. Cit., p. 7.
} 
«La prise en compte de ce que l'économie familiale met aux prises des hommes et des femmes incite à ouvrir la boîte noire des stratégies familiales et à lire les décisions prises comme provenant de négociations, éventuellement conflictuelles, entre des agents dont les positions sont pour partie structurées par le genre et l'âge $»^{1}$.

Berta Klix raconte ainsi que son père a été convaincu d'émigrer en 1850 par une amie de son épouse, ce qui laisse entendre plusieurs sessions de discussion entre les conjoints ${ }^{2}$. Certaines femmes provoquent aussi clairement la décision. C'est le cas de la mère de Julius Held, époux de Rosine Schönherr, émigré avec sa famille en 1852, qui relate :

«Feu mon père n'avait pas grande envie d'émigrer, alors que ma mère y pensait depuis toujours, même avant ma naissance. Si mon père s'était laissé faire, ce n'est pas au Chili que nous serions maintenant, mais en Amérique du Nord, pays qui attirait ma mère.

Mon père tenta, quelques années encore, d'améliorer sa situation, mais il finit par perdre patience, céda à ma mère et émigra. Et par combien de mauvais jours, et même d'années, avons-nous dû passer, avant de retrouver une situation à peu près correcte ! Bien que ma mère fût l'instigatrice de tout ceci, je n'ai jamais entendu le moindre reproche de la bouche de mon père... » ${ }^{3}$.

Le bilan statistique et l'identification géographique et sociale du groupe permettent donc d'en cerner les caractéristiques et de réviser l'image traditionnelle de l'émigration allemande au Chili, une image souvent masculinisée. Ce premier travail rend visible l'expérience migratoire de jeunes-filles célibataires ou veuves, accompagnées parfois d'enfants, qui espèrent trouver au Chili un emploi, un mari ou les deux. Les femmes mariées quant à elles participent pleinement à la prise de décision de la migration. Toutes fuyaient l'Allemagne pour trouver au Chili des perspectives d'avenir meilleures, pour elles et leur progéniture. Dans cette prise de décision, l'élément décisif est bien le caractère propre de ces femmes, laissant émerger une réalité individuelle qui mériterait d'être réhabilitée dans le champ des études migratoires. L'économique à lui seul n'explique pas tout. Les individus sont également capables de décider de leur sort et de construire ainsi l'Histoire. A une époque où les limites du village, du bourg, de la ville ou de la région sont encore souvent les seuls horizons explorés, songer à l'émigration témoigne, sans nul doute, d'une conscience de soi clairement achevée, d'un caractère affirmé et d'une détermination sans faille. Joue également, dans ce processus de décision, dans le cas des femmes mariées, le degré de cohérence et de complicité au sein du couple. Il s'agit concrètement d'un homme et d'une femme qui se projettent ensemble,

\footnotetext{
${ }^{1} \mathrm{P}$. Rygiel, « Des mondes genrés et mobiles », Op. Cit.

2 B. Klix, Op. Cit., p. 86.

${ }^{3}$ Lettre de juin 1888 à son ami Julius Aurich dans Berichte, Op. Cit., p. 55-56 : „Mein seliger Vater hatte nicht eigentlich die meiste Lust zum Auswandern, wo hingegen meine mutter schon immer, schon vor meiner Zeit, ans Anwandern gedacht hatte. Hätte der Vater nachgegeben, wären wir jetzt nicht in Chile, sondern in Nordamerika, wohin es meine Muetter zog. Nachdem sich nun mein Vater eine Reihe von Jahren bemüht hatte, um vorwärts zu kommen, riss ihm doch endlich die Geduld, gab nach und wanderte aus. Und wieviel schlechte Tage und Jahre haben wir durchzumachen gehabt, ehe wir einigermassen wieder eingerichtet waren. Obwohl die Mutter der Urheber war, hab ich doch nie etwas wie einen Vorwurf aus seinem Mund gehört.".
} 
avec leurs enfants, au bout du monde, dans un pays inconnu. Sans doute font-ils confiance à la solidité de leur relation et à la bonne marche de leur maisonnée pour améliorer le destin de leur famille. Les lettres de Sophie von Bischhoffshausen, d'Adelheid Kindermann ou encore d'Antonie Exss, témoignent constamment de l'assurance qu'elles ont de la légitimité de leur choix, de l'affection qu'elles portent à leur époux et à leurs enfants, de la certitude que leur couple, cette «association» matrimoniale d'intérêts, parviendra à bout de toutes les difficultés. En ce sens, les Allemandes du Chili sont bien des figures exceptionnelles, tant numériquement que qualitativement, et en ce sens, des curiosités de l'histoire qui méritent une meilleure visibilité. 


\section{VIES DE MIGRANTES}

L'adieu à la patrie, aux parents et aux proches était vécu comme une déchirure par les émigrantes. «Le départ de la patrie natale perdure généralement dans la mémoire féminine comme une punition et un éloignement douloureux », constate Paula Zaldivar au terme d'une enquête menée sur dix Italiennes émigrées au Chili au $\mathrm{XX}^{\mathrm{e}}$ siècle $^{1}$. Une fois arrivées au Chili, les immigrées doivent s'adapter à des conditions de vie particulièrement difficiles, dans une région dépeuplée et sans structure d'accueil. Cependant, dans de telles conditions, elles s'obstinent à reconstituer un foyer «à l'allemande ». Le soin apporté à la maison et à la vie domestique témoigne ainsi du souci de recréer des repères de l'identité. Dans la littérature germano-chilienne, c'est bien la seule sphère dans laquelle interviennent les femmes. Pourtant, leur participation au marché du travail, souvent imposée par le contexte de migration, et l'organisation de diverses structures de sociabilité et de solidarité, semblent également dignes d'intérêt pour les possibilités d'émancipation qu'elles génèrent. Leur rôle dans l'éducation des enfants et la transmission de la foi atteste par exemple d'un réaménagement des rôles masculins et féminins au sein du couple, de la famille et de la communauté immigrée.

\subsection{Des femmes sur un bateau}

La traversée était une réelle épreuve, comme l'attestent les journaux de bord. Un mois après l'arrivée, Sophie von Bischhoffshausen se la remémore avec horreur : « Je ne conseillerais à personne le voyage, parce qu'il cause des peines infinies [...] si l'on avait su, on ne l'aurait pas fait » écrit-elle ${ }^{2}$. De même, Pauline Metzdorf peine à croire que sa famille ait pu résister aux privations et s'en sortir échapper saine et sauve, en particulier les enfants ${ }^{3}$. Comme le rappelle Susanne Sinke, le transport transatlantique en lui-même, et surtout à ses débuts, lorsqu'il est encore mal organisé et non réglementé, présente une «accessibilité genrée » dans la mesure où il ne représente pas le même risque pour un homme que pour une femme ${ }^{4}$. De fait, sur les bateaux allemands à destination du Chili, les victimes des privations, épidémies et intempéries sont majoritairement les femmes et les enfants.

\footnotetext{
${ }^{1}$ P. Zaldivar, Op. Cit., p. 77 : "La partida desde la patria natal perdura en la memoria femenina, generalmente, como castigo y doloroso distanciamiento"

${ }^{2}$ Lettre du 9.11.1854 dans I. Schwarzenberg (éd.), Dokumente, Op. Cit., VI, p. 11 : „,aber zu einer Reise will ich niemand zurathen, denn sie hat unendliche Beschwerlichkeiten [...] Hätte man das so gewusst, es wäre nicht unternommen".

${ }^{3}$ Lettre du 12.11 .1850 dans G. Böhm (éd.), Dokumente, Op. Cit., V, p. 24.

4 "To what degree transportation options and risks operated as filters not only of age but of gender remains an area for exploration" suggère-t-elle d'ailleurs, $C f$. S. Sinke, $O p$. Cit., s.p.
} 


\subsubsection{Les drames et difficultés d'une longue traversée}

La route traditionnelle pour le Chili était celle du Cap Horn. Soixante six bateaux sont venus de Hambourg à Valdivia et Valparaiso entre 1846 et 1875, la majorité de la compagnie Godeffroy \& Fils, certains effectuant plusieurs voyages ${ }^{1}$. Ce sont des navires en bois de chêne, construits par la famille Somm, de tailles, entre 60 et 282 tonnes, de la taille du brick à celle de la frégate, filant en moyenne à 8 nœuds. Le plus rapide des voiliers fut le « Carl et Auguste» en 1856 avec 87 jours de voyage et le plus long le «Peter» de 1854 avec 163 jours $^{2}$. Il existait une autre route plus rapide par Panamá, d'une durée de deux mois ${ }^{3}$. Cependant, vu le nombre d'embarquements et de débarquements ${ }^{4}$, des trajets par voie de terre ou ferrée, des nuits d'hébergement à assurer dans les escales, mais aussi de la rapidité du voyage, la route était plus chère que celle du cap Horn ${ }^{5}$, et donc réservée à l'élite commerçante de Valparaíso.

$\mathrm{Si}$, dans la propagande de la Godeffroy\&Fils, la traversée était présentée comme une croisière de plaisance avec navires neufs, nourriture copieuse, saine et variée, cabines spacieuses, la réalité était tout autre. Jean-Pierre Blancpain croque en ces termes l'ambiance à bord des voiliers :

«Le règlement du bord, draconien, eût été supportable quelques jours entre Hambourg et New York; il tournait à la persécution au terme des 110, 120 parfois 145 jours qui séparaient l'Allemagne du Chili. Assorti de considérations paternalistes, il soumettait le «chargement» à la dictature du capitaine. Le navire est un casernement : l'émigrant est tenu de se lever aux aurores pour laver le pont ; après avoir fait son lit, il se met à la disposition du maître d'équipage. Il fournit sa literie, sa gamelle, son couvert. Caisses et bagages tiennent lieu de tables pour déjeuner. On est divisé en équipe de 10 à 12 émigrants sous la responsabilité d'un «Schaffner » qui perçoit le pain, la farine et les légumes secs pour la semaine, le café et le thé pour le lendemain. Un responsable général, le «Vorstand », est désigné par le capitaine : c'est par l'intermédiaire de celui-là qu'on peut demander le rapport de celui-ci. Il est interdit de parler à l'équipage, de fumer sur

\footnotetext{
1 Le «Hermann» réalisa cinq voyages, le «Susanna» quatre, l' «Alfred», le «Victoria» et le «Grasbrook» trois, le «Adolph» et le «Australia» deux. Chargés d'émigrants à l'aller, les voiliers revenaient avec des cargaisons de cuivre, de salpêtre, de guano péruvien, de peaux, de laine, de miel et de cire. Sur la compagnie Godeffroy, fondée en 1766, et ses voiliers, voir J.-P. Blancpain, Les Allemands au Chili, Op. Cit., p. 227-228, G. Guarda, Nueva Historia de Valdivia, Op. Cit., p. 534, A. Clasen, « Die Schiffe der Chile-Auswanderung », Op. Cit., pp. 1-3, K. Bauer, Das Gewissen der Stadt, Op. Cit., p. 38, H. Kunz, Op. Cit., p. 578. $C f$. illustrations des voiliers en annexe.

${ }^{2}$ Le «Schonerbrigg Anita », en 1857-1858, est quant à lui hors course, avec 343 jours de voyage ! $C f$. A. Clasen, «Deustsche Auswanderung nach Chile, 1853-1856», Op. Cit., p. 89.

${ }^{3}$ Minna Claude, qui a voyagé à destination de Valparaíso par le cap Horn en 1840, annonce à sa famille que s'ouvrira « une nouvelle route par Panamá et qu'on ne mettrait que 50 jours depuis l'Angleterre ». Lettre du 8.09.1841 dans I. Schwarzenberg (éd.), « Aus Granny's Nachlass, Briefe und Tagebuch aus den Jahren 18401849 », Sonderabdruck der Geschichtlichen Monatshefte des Deutsch-chilenischen Bundes, Santiago de Chile, DCB, 1933, p. 50. La voie ferrée transisthmique de Panama est en effet inaugurée le 28 janvier 1855. Longue de 77 km, la ligne relie Colón, sur la côte Atlantique, à Panamá, sur le Pacifique. De là, on empruntait les navires de la Pacific Steman Navegation Company, qui assurait la liaison Panamá-Le CallaoValparaíso et fut fondée par l'entrepreneur nord-américain Wheelwright, résident à Valparaíso. $C f$. N. Cruz, P. Whipple (coord.), Nueva historia de Chile: desde los orígenes hasta nuestros días, Santiago de Chile, ZigZag , 2000, p. 276.

${ }^{4}$ Les journaux de bords de Laura Grisar en 1855 et Clémentine Gleisner en 1865 l'attestent. Cf. C. F. Gleisner, Tagebuch, Op. Cit. et L. Hoestrey, ép. Grisar, Tagebuch und Briefe von Laura Hoesterey 18541855, Édition privée, Imprenta Victoria-Valparaíso, 1938.

${ }^{5}$ Minna Claude atteste qu'elle l'était pour les lettres, donc à plus forte raison pour les émigrants. Lettre du 8.05.1846 dans I. Schwarzenberg (éd.), « Aus Granny's Nachlass », Op. Cit., p. 95.
} 
l'entrepont ou dans les cabines, de conserver sur soi des armes. Le capitaine répartit les corvées et entend que l'on soit de bonne humeur dans l'exécution. 'Les passagers, dit le règlement, doivent s'attendre à être malades : ils devront réagir, endurer la maladie sans se plaindre. Calme, ordre et discipline sont nécessaires. La place de chacun est réduite, il n'y en a pas pour l'ennui et l'oisiveté aux conséquences toujours funestes. Patience et indulgence sont, avec la propreté, la règle d'or de l'émigrant' »'.

L'un des maux à bord du bateau était l'angoisse d'être entouré pendants des semaines d'eau, dans un voyage sans escale. Fanny Fonck confie ainsi que la terre lui manque terriblement et qu'elle rêve de pouvoir la toucher ${ }^{2}$. La vue de la terre, à l'approche des côtes argentines, est toujours un vrai événement à bord ${ }^{3}$. En outre, le manque d'aération, de nourriture, d'hygiène et l'entassement reviennent régulièrement parmi les plaintes des émigrantes. Certaines passent des semaines entières alitées, sans pouvoir dormir, affectées par le mal de mer. Fanny Fonck vit trois jours insupportables, sans pouvoir manger ni se lever ${ }^{4}$. A l'approche de l'Équateur, elle ne sait plus où se réfugier dans le bateau, partout, la chaleur, lui «transperce les semelles ${ }^{5}$. Bientôt, les pluies tropicales pénètrent les cabines, souillant les couches, le linge et les vêtements. Les changements de climat sont extrêmes, les bateaux passant d'un hémisphère à l'autre. Aux chaleurs insupportables de l'Équateur succède ainsi le froid glacial, une fois passées les Malouines ${ }^{6}$.

La nourriture est une préoccupation constante à bord. On embarque du bétail vivant que l'on abat au cours du voyage ${ }^{7}$. On charge aussi des rations d'œufs, de sucre, de café, de thé, et surtout d'eau potable. Mais l'eau fraîche se gâte et devient imbuvable ${ }^{8}$. Alors on boit l'eau de pluie bouillie et refroidie $^{9}$. La nourriture et les rations sont servies en fonction du type de réservation, à l'entrepont ou en cabine, mais dans les deux cas, elles se font aussi de plus en plus rares ${ }^{10}$. Fanny Fonck raconte qu'un mois après le départ, elle a faim, et qu'elle n'a jamais autant pensé à la nourriture. Il n'y a plus de pain, et les biscottes qui restent sont tellement dures qu'elles lui abîment les dents ${ }^{11}$. Sur le «Hermann » de 1850, les réserves de haricots, de sucre et de café sont consommées au bout

\footnotetext{
${ }_{1}^{1}$ J.-P. Blancpain, Les Allemands au Chili, Op. Cit., p. 228-229.

${ }^{2}$ Entrées du 23, 26.05.1854 dans G. Schwarzenberg (éd.), Geschichtliche Monatsblätter, Op. Cit., IX, p. 162.

${ }^{3}$ Entrée du 9.11.1840 dans I. Schwarzenberg (éd.), « Aus Granny's Nachlass », Op. Cit., p. 18 : „Land! Das ist Land!" crie alors le capitaine.

${ }^{4}$ Entrée du 4.05.1854 dans G. Schwarzenberg (éd.), Geschichtliche Monatsblätter, Op. Cit., IX,, p. 159.

${ }^{5}$ Entrée du 5 et 6.06.1854 dans Ibid., pp. 163-164.

${ }^{6}$ Entrées du 18.10.1840 et 12.11.1840 dans I. Schwarzenberg (éd.), « Aus Granny's Nachlass », Op. Cit., pp. 10,18 .

${ }^{7}$ Entrées du 25. 10.1840, 3.11.1840, 8.11.1840 dans I. Schwarzenberg (éd.), « Aus Granny's Nachlass», Op. Cit., p. 11, 15, 17 et lettre du 30.05.1850 dans I. Schwarzenberg (éd.), Dokumente, Op. Cit., III, p. 7.

${ }^{8}$ Entrée du 10.08.1854 dans G. Schwarzenberg (éd.), Geschichtliche Monatsblätter, Op. Cit., IX, p. 167 et lettre du 17.08.1890 dans R. Held, Op. Cit., p. 127.

${ }^{9}$ Entrée du 6.05.1854 dans G. Schwarzenberg (éd.), Geschichtliche Monatsblätter, Op. Cit., IX, p. 163.

${ }^{10}$ Karl Anwandter évoque les différences de traitement entre l'entrepont et les cabines, notamment en ce qui concerne la viande et l'eau. Cf. K. Anwandter, Desde Hamburgo a Corral, Op. Cit., pp. 78-79 et 114-115. Minna Claude décrit quant à elle le régime à bord du bateau, $C f$. Entrée du 31. 10.1840 dans I. Schwarzenberg (éd.), « Aus Granny's Nachlass », Op. Cit., p. 14.

${ }^{11}$ Entrées du 27.05.1854 et 7.06.1854 dans G. Schwarzenberg (éd.), Geschichtliche Monatsblätter, Op. Cit., IX, p. 163.
} 
de 29 jours ${ }^{1}$. Dans ces conditions, les tensions apparaissent. Controverses, méfiances, jalousies, vols de nourriture font partie également du quotidien, pouvant dégénérer en affrontements verbaux voire physiques, avec un duel sur le « Middleton $»^{2}$.

L'hygiène pose également problème. A bord, Rosine Schönherr, se souvient qu'il n'y avait pas d'eau chaude. On leur attribuait de l'eau de pluie pour faire la lessive, mais il était interdit de la faire bouillir, la cuisine étant exclusivement réservée à la préparation des nombreux repas, et en période de sécheresse, elle était sévèrement rationnée ${ }^{3}$. Fanny Fonck reçoit, après de fortes tempêtes à hauteur de l'Équateur, un seau d'eau de pluie avec lequel elle parvient à faire une lessive entière ${ }^{4}$. Dans ces conditions, on imagine que le problème de la toilette, notamment menstruelle, devait être préoccupant pour ces femmes. Elle est réduite au minimum. Elles n'ont pas vraiment la possibilité non plus de se soigner. Le vent, le soleil, le sel abîment la peau et les cheveux ${ }^{5}$.

De plus, le manque d'hygiène et de nourriture est propice aux épidémies, qui déciment parfois des bateaux entiers. En 1850, tout l'équipage du « New Ed» arrive à Valparaiso souffrant de scorbut, tandis que le «Henriette» arrive en 1854 avec le choléra. Parmi les victimes, le vannier Kehl, qui laisse seules femme et fille. Le « Reiherstieg » déplore quant à lui 14 victimes en 1857. A son bord, Georg et Dorothea Haverbeck, de Göttingen, perdent six de leurs douze enfants, tous victimes d'une intoxication alimentaire. Le cadet, Edmund, né à hauteur du Cap d'Horn, est nourri de biscuits prémâchés, faute d'aliment pour nourrisson ${ }^{6}$. Julius Held se souvient encore en 1888 de la mort de deux jeunes-filles et d'un enfant à bord du « Susanna ${ }^{7}$. La mort est en effet une constante du voyage. La tradition veut alors que les défunts soient rendus à la mer, pour éviter qu'ils ne choisissent le bateau comme cercueil et décident de le faire couler. En réalité la raison principale était d'éviter le risque d'épidémie que représenterait un cadavre en décomposition, surtout lors de tels trajets sans escale. En tant qu'épouse du médecin du bateau, Fanny Fonck est bien placée pour voir défiler blessures et drames qu'elle décrit de manière crue. Elle assiste notamment à la cérémonie funéraire d'un marin ${ }^{8}$.

Le pire moment du voyage restait cependant la traversée du cap Horn. Il marque l'étape finale, mais tant redoutée par des passagers déjà très fatigués et affaiblis. La force des courants est telle

\footnotetext{
${ }^{1}$ K. Götz, Op. Cit., p. 330.

${ }^{2}$ U. Steenbuck, «Inmigrantes alemanes rumbo a Chile en el siglo XIX » dans Desde Hamburgo a Corral, Op. Cit., p. 41.

${ }^{3}$ Lettre du 17.08.1890 dans R. Held, Op. Cit., p. 127.

${ }^{4}$ Entrée du 6.05.1854 dans G. Schwarzenberg (éd.), Geschichtliche Monatsblätter, Op. Cit., IX, p. 164.

${ }^{5}$ En janvier 1851, trois mois après son arrivée au Chili, Marie Bülling note que ses cheveux commencent à se remettre enfin de l'épreuve du voyage, $C f$. Entrée du 8.01.1851 dans E. von Loe, Marie Bülling, Op. Cit., Op. Cit., p. 37.

${ }^{6}$ A. Clasen, «Deustsche Auswanderung nach Chile, 1853-1856», Op. Cit., p. 89 et U. Steenbuck, Op. Cit., p. 40.

${ }^{7}$ Lettre de juin 1888 dans J. Held, Op. Cit., p. 56.

${ }^{8}$ Entrée du 19.05.1854 dans G. Schwarzenberg (éd.), Geschichtliche Monatsblätter, Op. Cit., IX, pp. 160161.
} 
qu'en 1846, le «Catalina » est repoussé par une tempête jusqu'à un point atteint 13 jours plus tôt. Jakob Keller se remémore même qu'après un mois d'efforts infructueux, le capitaine du «Hermann » avait songé à faire demi-tour pour débarquer ses passagers au Brésil ${ }^{1}$. A bord du «Fortunata », on allume, pour survivre au froid glacial, un feu dans la cabine avec les morceaux de bois décrochés par la tempête, mais il fait tellement de fumée que tous ont la migraine et la nausée ${ }^{2}$. Fanny Fonck, qui a bien cru mourir lors des 26 jours de traversée du cap, raconte qu'il fallut attacher le pilote à la barre pour ne pas que les vagues ou le vent ne l'emportent, mais qu'un matelot à tout de même succombé à une chute depuis le mât ${ }^{3}$.

Après le passage du Cap Horn et du détroit de Magellan, le temps s'adoucit, le soleil réchauffe les âmes, la mer se calme, les esprits aussi. On se repose, et l'on commence à préparer les bagages pour l'arrivée ${ }^{4}$. Ce sont bien des gens affamés et épuisés qui débarquent au Chili. Fanny Fonck est gravement malade au cours des six dernières semaines de navigation, souffrant d'une hémorragie intestinale qu'elle soigne tant bien que mal avec des huiles et de l'opium ${ }^{5}$. L'équipage comme les passagers sont pétris de froid et de fatigue. Au terme d'un long voyage de quatre mois, elle rend hommage aux marins :

«L'idée que les matelots sont des gens incultes et grossiers est complètement fausse. Il n'y a pas d'hommes plus honorables, zélés et pieux. Ils travaillent jusqu'à la limite de leurs forces et supportent patiemment la fatalité. J'éprouve pour ces gens un immense respect, et je souffre de les voir si mal nourris, pour faire du riche propriétaire du bateau un homme encore plus riche $»^{6}$.

Peu à peu, elle reprend ses esprits. Même si le voyage a été épouvantable, elle est «infiniment heureuse », parce que cette épreuve l'a rapprochée de son époux, Franck, qu'elle connaît désormais mieux comme médecin. Elle en est sûre, c'est le meilleur et le plus noble de tous les hommes qu'elle a connu? ${ }^{7}$.

\subsubsection{La sociabilité du voyage}

A bord du bateau, il faut lutter aussi contre l'ennui. Les jours se ressemblent et il faut sans cesse trouver des occupations pour les enfants : travaux manuels, jeux, classes également pour garder l'esprit vif, quand le mal de mer ne l'empêche pas $^{8}$. Rosine Schonherr se remémore, en 1890, les

\footnotetext{
${ }^{1}$ J.-P. Blancpain, Les Allemands au Chili, Op. Cit., p. 231.

${ }^{2}$ Entrée du 10.10.1854 dans G. Schwarzenberg (éd.), Geschichtliche Monatsblätter, Op. Cit., IX, p. 167.

${ }^{3}$ Entrée du 24 et 26.06.1854 dans Ibid., pp. 166-167.

${ }^{4}$ Entrées des 30.11.1840, 1, 2, 4 et 5.12.1840 dans I. Schwarzenberg (éd.), « Aus Granny's Nachlass », $O p$. Cit., pp. 23-24.

${ }^{5}$ Entrée du 14.08.1854 dans G. Schwarzenberg (éd.), Geschichtliche Monatsblätter, Op. Cit., IX, p. 169-170.

${ }^{6}$ Ibid.: „Der Wahn, dass die Matrosen ungebildete, rohe Menschen sind, ist ganz falsch; es kann keine besseren, fleissigeren und frommeren Menschen geben. Sie arbeiten, so lange es ihre Kräfte zulassen, und ertragen jedes Schiksal mit Geduld. Ich habe für diese Leute alle Achtung, und mein Herz blutet, wenn ich sehe, wie schlecht sie beköstigt werden, und damit der reiche Schiffsinhaber um so reicher wird.“

${ }^{7}$ Entrée du 10.08.1854 dans Ibid., p. 168.

${ }^{8}$ Entrées du 18. 10.1840 et 7.11.1840 dans I. Schwarzenberg (éd.), « Aus Granny's Nachlass», Op. Cit., pp. 10 et 16 .
} 
longues heures à patienter sur le pont, moment propice pour le tricot, mais beaucoup moins pour la couture, à cause du tangage qui empêche de viser le chat ${ }^{1}$. On lit également, en particulier des ouvrages de sciences naturelles et d'histoire sur le Chili. On apprend un peu d'espagnol. Le ballet de la faune maritime est une distraction en lui même : défilent des baleines, des oiseaux de mer, des manchots de Magellan et de Humboldt, des dauphins et même des poissons volants qui tombent sur le pont et sont aussitôt mangés par les cochons ${ }^{2}$. Fanny Fonck décrit le charme de la nuit, des étoiles, qui se reflètent dans la mer et semblent y mettre le feu ${ }^{3}$. Une fois passé l'Équateur, on observe la Croix du Sud. Pauline Metzdorf se rappelle ainsi les soirées passées sur le pont, à jouer de la musique, danser, jouer aux cartes et écouter les contes du capitaine, qui en est à sa dixième traversée et parle du Chili ${ }^{4}$. On boit aussi, beaucoup de vin, notamment pour dormir ${ }^{5}$. Le 23 mai 1854, le capitaine du «Fortunata » veut célébrer la première partie du voyage. On sert du ponch sur le pont. Fanny y goûte, apprécie et arrive ivre au repas du soir ${ }^{6}$.

$\mathrm{La}$ « vie sur le bateau » est en effet faite également de rencontres, de joies et de moments uniques de solidarité que racontent les émigrées. La sociabilité du voyage, qui naît sur des trajets avec de telles distances et d'un tel enjeu que l'émigration, mériterait à elle seule une étude. Sophie évoque cette «société un peu folle et si variée du bateau » et les liens qu'elle noue avec certains passagers, dont elle est déjà très amie à l'approche des côtes brésiliennes ${ }^{7}$. Les listes de passagers permettent ainsi d'associer les passagers d'un même bateau, et comprendre les liens de solidarité qui ont pu se créer au Chili et qui prolongent souvent les liens nés sur le bateau pendant la traversée. A l'arrivée, les mariages entre jeunes gens compagnons de voyage sont fréquents. Les fiançailles ont parfois lieu sur le bateau, comme entre Berta Buschmann et Karl Seidler à bord du Middleton, le 12 novembre $1849^{8}$, et même des mariages, comme celui de Luise Blüffert et de Franz Kaskel, cinq jours avant l'arrivée, évoqué par Pauline Metzdorf ${ }^{9}$. Sans oublier les naissances, autant de petits Middleton, Alfred, Susanne, Helene ou Etienne qui gardent en eux la mémoire du voyage.

Sur le bateau, on a également du temps pour penser. Le voyage est un moment propice à l'écriture intime, en dépit des difficultés matérielles. Sophie von Bischhoffshausen raconte sa peine à trouver un espace et un moment à elle pour poser quelques lignes. L'anniversaire de sa mère la rend particulièrement triste et lui rappelle comme elle s'éloigne ${ }^{10}$. Il est difficile aussi de se concentrer

\footnotetext{
${ }^{1}$ Lettre du 17.08.1890 dans R. Held, Op. Cit., p. 127.

${ }^{2}$ Entrée du 19.09.1840 dans I. Schwarzenberg (éd.), « Aus Granny's Nachlass », Op. Cit., p. 9.

${ }^{3}$ Entrée du 23.05.1854 dans G. Schwarzenberg (éd.), Geschichtliche Monatsblätter, Op. Cit., IX, p. 162.

${ }^{4}$ Lettre du 12.11.1850 dans G. Böhm (éd.), Dokumente, Op. Cit., V, p. 24.

${ }^{5}$ Entrée du 24.06.1854 dans G. Schwarzenberg (éd.), Geschichtliche Monatsblätter, Op. Cit., IX, p. 166.

${ }^{6}$ Entrée du 23.05.1854 dans Ibid., p. 162.

${ }^{7}$ Laissant d'ailleurs apparaître des émigrants et émigrantes qui ne figurent même pas sur la liste des passagers. Lettre du 15.08.1854 dans I. Schwarzenberg (éd.), Dokumente, Op. Cit., VI, p. 9 : „das ist eine närrische bunte Gesellschaft auf dem Schiffe“.

${ }^{8}$ J.-P. Blancpain, Les Allemands au Chili, Op. Cit., p. 232.

${ }^{9}$ Lettre du 12.11.1850 dans G. Böhm (éd.), Dokumente, Op. Cit., V, p. 25.

${ }^{10}$ Lettre du 11.07.1854 dans I. Schwarzenberg (éd.), Dokumente, Op. Cit., VI, p. 8.
} 
sur l'écriture, à cause du mal de mer et du tangage permanent du voilier ${ }^{1}$. Et puis, l'encre ne suffit plus bientôt. Le journal de Fanny Fonck passe, le 16 juillet 1854, d'une écriture à l'encre à celle du crayon-mine ${ }^{2}$. Unificateur entre un avant et un après, le voyage est propice à la narration. Evoquant l'expérience de voyages d'immigrées italiennes au Chili au $\mathrm{XX}^{\mathrm{e}}$ siècle, Paula Zaldivar démontre que c'est là une vérité intemporelle :

«Le mélange de sentiments que chacune emmenait dans ses bagages - d'un côté, l'anxiété, l'incertitude, la tristesse et la douleur, et de l'autre, les espérances et les illusions - les accompagnait pendant toute la traversée sur le bateau et également pendant la première étape du séjour dans la 'nouvelle patrie' »"

\subsection{Reconstruire un foyer en terre d'immigration}

L'arrivée au Chili et le retour à la terre est un grand soulagement. Après son entrée dans le port de Corral le 25 octobre 1854, «entre 13h et 14h », Sophie von Bischhoffshausen s'exclame : «Pour l'amour de Dieu, nous y sommes !» ${ }^{4}$. Pauline Metzdorf raconte tout aussi précisément : «Aujourd'hui, mardi 12 novembre, nous sommes finalement entrés dans le port de Valdivia. Quelle joie, après tant de temps, de revoir la terre ! ${ }^{5}$.

\subsubsection{L'arrivée au Chili}

Rares sont ceux qui, les premières années d'émigration, ont un proche, un parent ou une connaissance qui les attende et les accueille à l'arrivée. La banqueroute de Kindermann en 1850 laisse dans le désœuvrement plusieurs familles. Pauline Metzdorf témoigne :

« Nous sommes venus ici avec de grands espoirs, mais nous sommes très vite heurtés à la réalité. Aussitôt après notre arrivée dans le port, nous avons appris la malheureuse histoire de la banqueroute de Franz Kindermann. Vous imaginez bien le choc que cela m'a fait ${ }^{6}$.

Lorsque débarquent les premiers émigrés à Valdivia en novembre 1850, rien n'est prêt. Pérez Rosales est dépêché en urgence comme «agent de colonisation» pour recevoir et installer les étrangers, et surtout, les aider dans la recherche de terres ${ }^{7}$. Or, depuis l'arrivée des Allemands, les

\footnotetext{
${ }^{1}$ Entrées du 8.09.1840 et 25.10.1840 dans I. Schwarzenberg (éd.), « Aus Granny’s Nachlass », Op. Cit., pp. 8 et 10 et entrée du 19.05.1854 dans G. Schwarzenberg (éd.), Geschichtliche Monatsblätter, Op. Cit., IX, pp. 160 et 161 .

${ }^{2}$ Manuscrit du journal de bord de Fanny Zöhrer, 1854, Fondo Fonck, Biblioteca e Archivo Emilio Held Winkler, Santiago de Chile.

${ }^{3}$ P. Zaldivar, Op. Cit, p. 82 : “[...] La mezcla de sentimientos que cada una cargaba en sus maletas - por un lado, ansiedad, incertidumbre, tristeza y dolor y, por otro, expectativas e ilusiones - las acompañaba durante toda la travesía en el barco y también durante la primera etapa de estadía en la "nueva patria"”

${ }^{4}$ Lettre du 27.10.1854 dans I. Schwarzenberg (éd.), Dokumente, Op. Cit., VI, p. 9 : „Gott lob sind wir da !!!“

${ }^{5}$ Lettre du 12.11.1850 dans G. Böhm (éd.), Dokumente, Op. Cit., V, p. 25 : „Heute Dienstag, den 12. November, sind wir glücklich im Hafen von Valdivia, eingelaufen. Welche Freude, nach so langer Zeit wieder Land zu sehen!“”.

${ }^{6}$ Lettre du 12.11.1850 dans Ibid., p. 24 : ,Wir gingen zwar mit grossen Hoffnung hierher, wurden aber nur zu bald eines Anderen belehrt; bald nach unserer Ankunft im Hafen erfuhren wir die saubere Geschichte von Fr. K's Bankerott; was für einen Eindruck auf mich machte, könnt Ihr euch wohl denken.“

${ }^{7}$ J.-P. Blancpain, Les Allemands au Chili, Op. Cit., p. 235-236.
} 
terres prennent de la valeur, beaucoup de valeur: «loi de l'offre et de la demande », explique Guarda, «opportunisme de l'aristocratie valdivienne», rétorque Blancpain ${ }^{1}$. Ainsi, l'arrivée à Valdivia des Linke, Carl et Augusta, les grands parents maternels d'Hélène Biel, épouse Scheel, marque le début de nouvelles difficultés. Le voyage a été douloureusement vécu par la famille suite à la perte d'une tante sur le bateau. Or, les difficultés semblent se prolonger sur terre, où les émigrés n'ont tout simplement pas de logement. Les autorités dressent des campements de fortune. Helene raconte ainsi que, « dans la mesure où rien n'avait été préparé pour leur arrivée, les émigrés durent camper un long moment sous les tentes de l'armée sur les plages de Valdivia, souvent sous une pluie torrentielle $»^{2}$. Arrivée avec son père, Karl Bittner, par le «Victoria », le 13 décembre 1852, Ana Schmidt se souvient combien la déception fut grande. Rien n'était prévu pour les accueillir, et « pourtant tous ceux qui déjà étaient arrivés auparavant se rendirent sur les quais, pour saluer les nouveaux arrivants $»^{3}$. Il n’y avait plus de place dans la «casa grande », un baraquement construit pour accueillir les immigrés, et la famille a dû loger sous des tentes, ce qui compliquait fortement la garde de tous les bagages, caisses et meubles transportés par bateau. Leur transfert de Valdivia à Ancud, sur l'île de Chiloé, puis à Melipulli, future Puerto Montt, se fait par le bateau de guerre, l'«Infatigable », pour éviter les assauts des indigènes ${ }^{4}$. A ce sujet, Berta Klix se souvient qu'il leur avait été en effet déconseillé de partir en voilier, et à juste raison puisque ce dernier fut attaqué par les Araucans. Tous les passagers furent assassinés, sauf une, Elisa Bravo, qui vit mourir son enfant et son mari et aurait disparu par la suite ${ }^{5}$.

Rapidement se met en place un premier réseau d'entraide au sein de la communauté allemande. Les nouveaux arrivés sont pris en charge par les familles, le temps de trouver leur propre logis ou un domaine à mettre en culture. Pauline Renz relate ainsi que lorsque son père, Hermann Hube, est arrivé au Chili, à bord du «Reiherstieg» en 1857, il s'est retrouvé sans terre, les projets de

\footnotetext{
${ }^{1}$ L'accueil des Allemands par les Valdiviens est sujet à de vives controverses. Pérez Rosales s'insurge à l'époque contre «l'égoïsme, [...] l'intérêt mal compris, l'âpreté au gain » de l'aristocratie locale qui n'a pas tardé à tirer profit de cette émigration désorientée et déracinée mais non désargentée, vendant à des prix d'or des terres qu'elle considérait auparavant comme incultivables et sans valeur, «comme si, recevant mal les premiers, ont eût pu raisonnablement s'attendre à ce qu'il en arrivât d'autres...» Rapport de mai $1851, E l$ Araucano, 17.6.1851, cité dans J.-P. Blancpain, Les Allemands au Chili, Op. Cit., p. 241. Voir également G. Guarda, Nueva Historia de Valdivia, Op. Cit., p. 545.

${ }^{2}$ H. Biel Linke, Op. Cit., p. 13: „Es war für die Einwanderer so gut wie keine Vorbereitung getroffen worden, sie mussten daher eine zeitlang in Soldatenzelten auf der Playa Valdivias bei oft strömenden Regen kampieren."

${ }^{3}$ A. Schmidt, Op. Cit., p. 248 : „Doch alle schon früher Angekommenen [...] kamen freudig ans Ufer, um die Neulinge zu begrüssen." L'attroupement s'explique aussi par les nouvelles des familles, sous forme de lettre et de colis, que sont susceptibles d'apporter les nouveaux arrivants.

${ }^{4}$ Ibid., pp. 248-249.

${ }^{5}$ B. Klix, Op. Cit., p. 81. En juillet 1849, le voilier chilien « Joven Daniel» fit naufrage entre Valdivia et Valparaiso, au niveau de l'embouchure du Tolten, sur la page de Puancho. Les cadavres des passagers furent retrouvés sur la plage au milieu des restes de la cargaison. Les rumeurs prétendirent à une attaque des mapuches qui auraient sauvé puis assassiné les naufragés, préservant la vie de la jeune Elisa Bravo, une valdivienne, qui serait restée captive en Araucanie. Le gouvernement envoya une expédition militaire punitive qui fit plusieurs détenus indigènes. Jamais Elisa Bravo ne réapparut, devenant un véritable mythe symbolisant la sauvagerie des indigènes au Chili.
} 
colonisation privée des messieurs Mas et Mohr ayant échoué. Les Allemands de Valdivia l'ont cependant secouru, le temps qu'il décide de s'installer à Osorno, où il a ouvert un magasin, une distillerie puis un moulin ${ }^{1}$. Sophie von Bischhoffshausen raconte comment sa famille a été accueillie en 1854 par des parents émigrés deux années plus tôt ${ }^{2}$. Elle apprécie très vite la vie à Valdivia. Elle s'y sent bien, parce qu'entourée de nombreux Allemands, avec qui elle a des contacts quotidiens ${ }^{3}$. Dans les jours suivants leur arrivée se succèdent les visites de bienvenue, qui leur permettent de s'intégrer rapidement dans le cercle de sociabilité allemande. La tradition veut en effet que les nouveaux arrivants soient accueillis par les résidents, qui se présentent spontanément chez lui, contrairement à l'Allemagne, où c'est à la personne récemment arrivée de prendre l'initiative de saluer ses nouveaux voisins ${ }^{4}$.

Cependant, les von Bischhoffshausen occupent un logement provisoire et Sophie ne se sent pas encore à la maison. Elle doit partager un logis exigu et rudimentaire avec une quinzaine de personnes : outre la famille, le professeur particulier des enfants, l'administrateur, le pâtre, le valet de ferme et les trois bonnes, qui ont aussi émigrés pour reprendre leurs fonctions sur le nouveau domaine de la famille. Ce domaine, Sophie et son époux Gustav le cherchent activement. Sophie apprend même à monter à cheval ${ }^{5}$, réalise des chevauchées de plusieurs jours, s'habitue à dormir à la belle étoile, utilise, pour se protéger de la pluie, orageuse à cette saison, le «ponscho » : «cet énorme manteau constitué d'une épaisse couverture de laine avec au milieu un trou pour passer la tête », explique-t-elle à ses parents ${ }^{6}$. Elle se plaît à raconter les anecdotes des chevauchées et rapporte fièrement que, hormis l'épouse du Dr. Schneider ${ }^{7}$, aucune femme avant elle n'avait fait encore cette chevauchée périlleuse. «Les Allemandes ici me considèrent comme une sorte de cavalière talentueuse, dit-elle. Elles envient mon adresse $»^{8}$. Elle s'imagine déjà sur son domaine, chevauchant pour visiter voisins et amis ${ }^{9}$. «Contrairement à ce que l'on entend toujours, ce n'est vraiment pas facile pour un nouvel arrivant de trouver une propriété, rappelle Sophie. Il y a une grande part de mensonges dans la propagande. Seulement, ce qui est vrai, c'est que la terre est

\footnotetext{
${ }^{1}$ P. Renz, Op. Cit., p. 1.

${ }^{2}$ Il s'agit du père de Gustav, son époux, qui a émigré en 1852 à bord de l' " Alfred » avec sa seconde épouse et ses cinq enfants. Cf. I. Schwarzenberg (éd.), Dokumente, Op. Cit., VI, p. 108.

${ }^{3}$ Lettre du 9.11.1854 dans I. Schwarzenberg (éd.), Dokumente, Op. Cit., VI, p. 11.

${ }^{4}$ E. von Loe, «Esparcimiento, sociabilidad y vida comunitaria en la colectividad alemana de Valparaíso durante el siglo XIX », Mapocho, 45/1999, p. 189.

${ }^{5}$ Lettre du 10.12.1854 dans I. Schwarzenberg (éd.), Dokumente, Op. Cit., VI, p. 13.

${ }^{6}$ On aura reconnu le poncho chilien. Cf. Lettre du 27.12.1854 dans Ibid., p. 16: „die hisigen Mäntel bestehend aus einer wollnen Decke die in der Mitte einen Riss ha taus dem der Kopf komme „.

${ }^{7}$ Katharina Mundt, émigrée avec son époux Hermann Schneider, médecin, à bord du « Hermann » en 1851, Cf. Ibid., p. 111.

${ }^{8}$ Lettre du 27.12.1854 dans Ibid., pp. 18-19 : „Die Deutschen hier betrachten mir wie eine art Kunstreiterin und beneiden mich und meine Geschicklichkeit".

${ }^{9}$ Lettre du 27.12.1854 dans Ibid, p. 17.
} 
belle et fertile et que le gouvernement fait beaucoup d'efforts pour promouvoir l'immigration et développer les communications intérieures $»^{1}$.

Sophie visite donc elle-même les domaines pour les évaluer, ce qui prouve qu'elle s'implique entièrement dans les affaires économiques du ménage. Elle ébauche des projets de mise en valeur, démontrant une capacité d'analyse économique poussée. Elle envisage de consacrer une bonne partie de l'activité à l'élevage, estimant que le bétail est un outil important dans la mise en valeur de la région. Elle remarque que l'industrie laitière est quasiment absente et pense donc monter une laiterie, ébauchant quelques comptes rapides. Elle veut cultiver un potager, parce qu'elle a noté que les légumes sont chers et qu'elle pourrait donc produire pour la consommation familiale, mais aussi pour la vente. Sophie compte ainsi tirer partie des lacunes du marché local et de la loi de l'offre et de la demande pour vendre à prix fort.

Pour échapper aux incertitudes des premiers temps, elle rêve de sa future maison. "La maison à soi » constitue un point de référence fondamental des premières lettres des Allemandes émigrées au Chili $^{2}$. Sans elle, la nouvelle vie ne peut pas commencer. «Tant que nous n'aurons pas notre propriété et que je resterai assise là à ne rien faire, j'aurai toujours le mal du pays » ${ }^{3}$ analyse Sophie. Les premiers mois d'incertitude et de transition sont vécus comme une mise en suspens de leur vie, une prolongation d'un voyage qu'on voudrait pourtant vite oublier. Dans l'attente de leur foyer à elles, ces femmes sont toujours sur la mer, dans le bateau, entre deux continents. De plus, Paula Zaldivar démontre que l'adaptation à une nouvelle temporalité est difficile pour les femmes issues du monde rural. Le temps rural est fondamentalement «cyclique », lié au rythme naturel, polarisé par le temps de la naissance et de la mort, et c'est un temps collectif, qui se partage. Or, à l'arrivée, cette conception du temps change. Le temps devient un moment «linéaire ${ }^{4}$. Avec l'acquisition d'un domaine ou d'une terre, c'est une nouvelle étape biographique qui s'ouvre pour ces femmes, mais aussi la possibilité d'entrevoir un avenir heureux pour la famille. En février 1855, Sophie annonce avec un grand soulagement qu'ils ont enfin acquis le domaine du Roble. Voilà un an que, entre le voyage et le séjour à Valdivia, elle n'a plus sa maison à elle. Elle se réjouit d'avoir bientôt «un nouveau Heimat». A cette nouvelle maison est associée en effet la possibilité de pouvoir envisager, enfin, « un futur paisible en toute sérénité et assurer en même temps un avenir à nos enfants » 5 .

\footnotetext{
${ }^{1}$ Lettre du 27.12.1854 dans I. Schwarzenberg (éd.), Dokumente, Op. Cit., VI, p. 20 : „Es ist überhaupt für einen neuen ankommenden gar nicht so leicht ein Unterkommen zu finden wie das immer beschrieben wird, überhaupt sind in der Büchelerchen gar viele Lügen, nur das es ist wirklich wahr dass das Land schön und fruchtbar ist, und die Regierung unendlich viel thut um die Einwanderung zu begünstigen, und die Communication in's Innere zu beförden“.

${ }^{2}$ A. Lübke, Op. Cit., pp. 211-213.

${ }^{3}$ Lettre du 27.12.1854 dans I. Schwarzenberg (éd.), Dokumente, Op. Cit., VI, p. 20 : „So lange wir noch kein Eigenthum haben und ich sitze und so wenig zu thun wie jetzt werde ich das Heimweh wohl nicht verlieren“. ${ }^{4}$ P. Zaldivar, Op. Cit., pp. 92-93.

${ }^{5}$ Lettre du 6.02.1855 dans I. Schwarzenberg (éd.), Dokumente, Op. Cit., VI, p. 22 : «mit völliger Ruhe einer sorgenfreien Zukunft entgegen und für unsre Kinder ihre Zukunft ebenfalls zu sorgen zu können“.
} 


\subsubsection{L'installation du ménage}

Avant d'investir un domaine ou une terre, les colons devaient d'abord pouvoir y accéder et se frayer un chemin parmi l'épaisse forêt, précédant les initiatives gouvernementales ${ }^{1}$. La colonisation du Sud chilien se fait sur trois fronts, en commençant par les territoires plus proches de Valdivia. En premier lieu, l'île de la Teja, prise entre le Calle-Calle, le Cruces et le Cau-Cau, sorte de quartier insulaire, forestier et marécageux, de Valdivia, proposée par Vicente Pérez Rosales aux premiers émigrés Allemands arrivés en $1850^{2}$. Par la suite, le front progresse en direction des Llanos, région de forêt et d'étendues herbeuses autour des localités d'Osorno et de La Unión, atteinte en 1851. On y accède en remontant le fleuve Futa jusqu'au point de rupture de charge, à partir duquel il faut chevaucher une dizaine d'heures, itinéraire précisément décris par Sophie ${ }^{3}$. Enfin, Llanquihue est déclaré « territoire de colonisation » par une série de lois promulguées entre 1851 et 1853 . Le front est conquis à partir de Melipulli qu'on gagne par bateau depuis Valdivia puis $\mathrm{Ancud}^{4}$. Si la colonisation a été prévue sur les bords du lac, la parcellisation n'est pas réalisée, et les chemins d'accès sont inexistants. Le règlement lui-même de la colonie ne sera fixé qu'en $1858^{5}$. Nombreux sont les chefs de famille qui périssent dans cette conquête pionnière, happés par la forêt, laissant autant de veuves et d'orphelins ${ }^{6}$. La veuve Siebald, émigrée avec ses parents en 1856, se souvient que, dans une forêt qui laissait à peine passer les rayons du soleil, sa famille tenta, au cours d'une expédition de deux jours - itinéraire qui prend quatre heures à pied actuellement - de se frayer un chemin pour atteindre le bord du lac Llanquihue et prendre possession de sa chacra à Punta Larga. Sa mère était alors enceinte de six mois ${ }^{7}$. Face au front presque impénétrable que représente la forêt, beaucoup aussi ont renoncé tout simplement à l'agriculture pionnière pour reprendre leur ancien métier d'artisans et s'installer en ville. Valdivia, Osorno, La Union, Puerto Mont après sa fondation, ont ainsi repris vie.

\footnotetext{
${ }^{1}$ Les archives des intendances de Valdivia et Llanquihue postérieures à 1855 abondent de rapports sur la construction des chemins, avec salaires et traitements des ingénieurs et ouvriers. $C f$. "Informes sobre obras de apertura y reparación de caminos", ANH, MINT, vol. 389, Op. Cit., s.p.

${ }^{2}$ L'arpenteur Santiago Reuter la divisa en 48 lots allongés dit hijuelas. Les Anwandter y reçurent d'emblée une quarantaine de cuadras. Aujourd'hui, l'île est entièrement intégrée au tissu urbain de Valdivia. On y visite encore la précieuse maison des Anwandter (aujourd'hui Museo historico e antropologico Maurice van der Maele) ainsi que les installation et bâtiments de l'industriel. Cf. J.-P. Blancpain, Les Allemands au Chili, Op. Cit., p. 248.

${ }^{3}$ C'est là que sont situés les domaines de Bellavista des commerçants de Valparaíso et le domaine du Roble des von Bischhoffshausen. Lettre du 27.12.1854 dans I. Schwarzenberg (éd.), Dokumente, Op. Cit., VI, pp. 16-18.

${ }^{4}$ Ancud, fondée en 1768 comme port international et escale majeure de la route du Cap Horn, fut la capitale de Chiloé de 1788 à 1982, date à laquelle le siège revient à Castro.

5 «Reglamento de la Colonia de Llanquihue (1858)», ANH, MINT, vol. 389, Op. Cit., s.p et B. Vicuña Mackenna, Op. Cit., pp. 110-117.

${ }^{6} \mathrm{~V}$. Pérez Rosales mentionne au ministre de l'intérieur le cas de deux hommes, pères de famille, perdus dans la forêt, dont les orphelins ont été pris en charge par les autorités tandis que les mères ont continué à affronter la forêt. Lettre du 2.3.1953 dans AHN, MINT, vol. 308, Op. Cit., s.p.

${ }^{7}$ I. Siebald, "Colonización y asentamiento alemán en el lago Llanquihue" [en ligne]. Entretien avec Lisette Winkler (42:43), réalisé le 12 décembre 2007 à Frutillar. Accessible à l'URL : http://www.archivesaudiovisuelles.fr/FR/_video.asp?id=1528\&ress=4611\&video $=105799 \&$ format $=68$ [consulté le 14 août 2008]
} 
Une fois leur domaine trouvé, Sophie et Gustav planifient un déménagement sur plusieurs semaines, plusieurs fois repoussé à cause du climat ${ }^{1}$. Sophie a la chance, en réalité, d'avoir acquis un domaine cultivable avec maison habitable, sans doute les barons von Bischhoffshausen en avaient-ils les moyens. Ce n'est pas le lot de tous les colons qui achètent des terrains privés ou des terres gouvernementales, terrains vierges couverts d'une épaisse forêt qu'ils doivent d'abord défricher. La veuve Robert se remémore ainsi le difficile voyage par Futa avec trente mules chargées de leurs bagages et une charrue. A l'arrivée son père commence à construire leur maison, grâce au bois qu'il abat progressivement dans la forêt environnante ${ }^{2}$. Anna Schmidt raconte comment les hommes explorent progressivement le chemin jusqu'au lac pour trouver des terres à La Fabrica, avant de planifier un déménagement, des hommes et des jeunes-filles les plus fortes d'abord, tandis que les femmes et les enfants restent à Puerto Montt, le temps que le logis se construise ${ }^{3}$. Le défrichage est en lui même une rude épreuve, les outils manquent et le risque de régénération de la flore est permanent ${ }^{4}$. Sophie révèle ainsi qu'à partir d'avril commence la saison pluvieuse et qu'il ne sert à rien de défricher ni de construire 5 .

Une fois le brûlis constitué, on pouvait commencer à planter les semailles en mars et construire une première cabane plus élaborée. Le processus de construction du logement est similaire à celui décrit par Jean Roche pour les Allemands du Rio Grande ${ }^{6}$. Les différentes formes de maisons correspondent à différentes étapes de prospérité. Au début, on se contente d'une simple cabane, avec un toit de branchages, mal protégée de la pluie, du vent et du froid. Dans plus d'un cas, il arrivait que l'édification s'écroule entièrement ${ }^{7}$. Puis vient la phase de consolidation de la cabane, avec l'avancée du défrichement qui dégage des poteaux plus résistants, toujours avec toit de branches et feuillages, ou un lacis de baguettes servant de support à de la terre pétrie. Enfin, vient la phase du colombage. La maison se dote de murs de pierre ou de brique et d'une toiture de bois puis de tuiles ou de zinc. Les fermes sont construites de manière isolée, dans un habitat dispersé ${ }^{8}$. Ce dernier se densifie avec l'apparition de Seehaufendörfer, de «villages-tas lacustres », à

\footnotetext{
${ }^{1}$ Lettre du 6.02.1855 dans I. Schwarzenberg (éd.), Dokumente, Op. Cit., VI, pp. 21-23

${ }^{2}$ B. Schöbert, Op. Cit., p. 87.

${ }^{3}$ A. Schmidt, Op. Cit., p. 250.

${ }^{4}$ Les premiers colons n'avaient pas emmené d'outils puisque la compagnie Godeffroy avait assuré qu'on pouvait en faire venir bon marché des Etats-Unis, ce qui s'est révélé faux. Anwandter conseille aux futurs émigrants d'emmener tout ce qu'ils peuvent (meubles, outils, ustensiles domestiques, instruments de musique) pour l'usage personnel ou pour la revente à bien meilleur un prix qu'en Allemagne puisque tout manque. Cf. K. Anwandter, „Meine Übersiedlung nach der Provinz Valdivia in Chile“ Op. Cit., pp. 156-157.

${ }^{5}$ Lettre du 6.02.1855 dans I. Schwarzenberg (éd.), Dokumente, Op. Cit., VI, p. 23

${ }^{6}$ J. Roche, Op. Cit., p. 166. $C f$. Les formes d'habitat en annexe.

${ }^{7}$ E. Kinzel, B. Horn, Puerto Varas, 130 años de historia, 1852-1983, Puerto Varas, Imprenta y Liberia Horn y Cía., Ldta., 1983p. 98.

${ }^{8}$ En effet, au lac, l'habitat rural est dispersé. C'est un paysage quadrillé par la limite des lots et qui donne une impression de bocage. Les autorités n'ont pas conçu en effet un plan d'occupation centré avec rayonnement de chemins. Elles ont distribué mécaniquement des parcelles, sans créer d'espace pour un village groupé. Pour une comparaison avec les colonies germano-brésiliennes voir J. Roche, Op. Cit., p. 175.
} 
Llanquihue, avec l'émergence d'un centre postérieur à un carrefour ou proche de l'église ou de l'école, comme à Frutillar' ${ }^{1}$.

La demeure aménagée à l'allemande est le témoin d'années de grandes difficultés surmontées. Tous les témoignages concordent dans la description de ces premières années de désolation. Berta, veuve de Schwarzenberg, se souvient de la misère de sa famille. Après quatorze jours de résidence à Valdivia, elle voyagea en direction de l'intérieur pour s'installer sur le domaine tant promis de Bellavista, propriété de Kindermann. «A l'époque, se remémore-t-elle, il était difficile de se procurer des aliments. Une fois, nous sommes restés huit jours sans pain, ni pomme de terre, nous n'avions que de la viande $»^{2}$. Devant les difficultés, son père a vite décidé de quitter les rives du Bio Bio pour s'installer comme industriel à Valdivia. Les rapports de Vincente Pérez Rosales attestent de situations de misère profonde sur les rives du Llanquihue. En 1853, les premiers colons sont réduits à consommer les semences et à abattre le bétail mis à disposition par le gouvernement ${ }^{3}$. Deux années plus tard, la situation se répète sur un nouveau front, à Maullin, où les colons, saxons et silésiens, vivent dans une misère déplorable : «Il y en a un par exemple qui, pendant six semaines, s'est nourri, lui, sa femme et ses six enfants, uniquement de choux.», rapporte l'Intendant ${ }^{4}$. La veuve Siedbald Michael se souvient que pour s'assurer des ressources financières supplémentaires, les parents envoyaient leurs filles à Puerto Montt ou Osorno comme domestiques.

«Les filles partaient avec leur lit sur le dos, à pied dans la forêt, seules, sans compagnie, puisque personne n'avait le temps de les accompagner, parce que le temps, c'était de l'argent, c'est-à-dire du pain. La peur que nous avons dû supporter est indescriptible. Dans plus d'un cas, elles se sont faites violer ou assassiner par des vagabonds $»^{5}$.

Les malheurs existent aussi en effet. L'année 1856 est marquée par l'assassinat de la famille Martin, les deux époux et les quatre enfants. Le meurtrier fut retrouvé en possession des vêtements, d'outils et d'une somme non négligeable ( 800 pesos) apportée un an plus tôt par la famille ${ }^{6}$.

Cette première phase de grande difficulté est fondamentale dans la mémoire collective et familiale de la communauté germano-chilienne. Nohelia Westermeier explique en effet qu'à chaque génération, se manifesta le souci de raconter les difficultés des premiers temps pour «apprendre aux enfants la valeur du travail ». Sa belle-mère, une Niklitscheck, famille de Bohême installée à Frutillar dans les années 1850, racontait souvent comment les femmes pleuraient sous les arbres et

\footnotetext{
${ }^{1}$ K. Ilg, Pioniere, Op. Cit., p. 234-235.

${ }^{2}$ B. Klix, Op. Cit., p. 83 : „,Damals war es sehr schwer, Lebensmittel zu bekommen. Einmal waren wir acht Tage ohre Brot und Kartoffeln und hatten nur Fleisch".

${ }^{3}$ Rapport du 1.12.1853 dans ANH, MINT, vol. 308, Op. Cit. s.p.

${ }^{4}$ Rapport du 26.09.1855 dans Ibid., s.p. : " hay uno por ejemplo que durante seis semanas se ha mantenido con su mujer i seis hijitos solo de coles".

${ }^{5}$ Citée dans E. Kinzel, B. Horn, Op. Cit., p. 98 : "Las niñas llevaban su cama a sus espaldas, y se iban de a pié por la selva, solas, sin compañía, ya que nadie tenía tiempo de acompañarlas, porque el tiempo valía más que el dinero, lo que significaba pan. Cuanto miedo tuvimos que soportar es indescriptible. Sucedió más de una vez, que niñas fueron violadas y muertas por vagabundos".

${ }^{6}$ Le cas est rapporté par l'Intendant le 11.9.1857 dans ANH, MINT, vol. 389, Op. Cit., s.p. et evoqué dans le souvenirs de B. Schöbitz, Op. Cit., p. 87.
} 
sous la pluie, parce qu'elles n'avaient pas encore de maison ${ }^{1}$. Une fois les deux premières années surmontées, la situation des colons s'améliorait. Adelheid Kindermann écrit à ce sujet: «Pour tout débutant, la première année est très difficile. A la deuxième, on se sent plus à l'aise, à la troisième, bien et à la quatrième, du moins je l'espère, on se sent vraiment très bien $»^{2}$.

\subsection{Les travaux et les jours au féminin}

Le travail des femmes était fondamental dans ses premières années de difficulté. La veuve Siebald de Michael en témoigne «Pendant plus d'une dizaine d'années, les colons travaillèrent durement, que les mères durent allaiter ou non, elles devaient aller travailler aux champs ou à la forêt, pour que la famille ne meurt pas de faim $»^{3}$.

\subsubsection{Le travail féminin}

La ferme est au centre de la vie rurale, et la maison en constitue le cœur, autour duquel s'organise le travail ${ }^{4}$. Dans une répartition traditionnelle des tâches,

«les hommes travaillaient aux champs tandis que les femmes tenaient la maison, cousaient les vêtements, soignaient les vaches, les cochons et la volaille, s'occupaient du potager et vendaient au marché les surplus de lait, de légumes, de poulets et d'œufs $»^{5}$.

Suivant le rythme des saisons et les périodes de travail intensif, notamment les premières années de mise en culture, la femme peut être appelée également au champ pour semer, moissonner et glaner. La fermière germano-chilienne respecte un emploi du temps précis, tant dans la journée que dans la saison, avec des tâches régulées : la crème et le beurre sont faits deux fois par semaine, le pain tous les samedis pour la semaine ${ }^{6}$, la grande lessive toute les deux semaines, la choucroute à la fin de l'automne pour affronter l'hiver etc. ${ }^{7}$

En tant que mère de famille et maitresse de maison, la femme participe activement à l'économie familiale ${ }^{8}$. Plusieurs correspondances attestent qu'elles sont chargées de la vente des produits. Sophie von Bischhoffshausen vend sur le marché local ou directement auprès des voisins, tandis

\footnotetext{
${ }^{1}$ Entretien avec Nohelia Clara Westermeier Birke, en espagnol, le 7 février 08, Frutillar (0:40:35)

${ }^{2}$ Lettre du 23.02.1853 dans G. Schwarzenberg (éd), Geschichtliche Monatsblätter, Op. Cit., XII, Op. Cit., p. 49 : „Für jeden Anfänger ist das erste Jahr ein sehr schweres jahr ; im zweiten fühlt man sich behaglicher, im 3ten wohl und im 4ten, hoffe ich, fühlt man sich recht wohl“".

${ }^{3}$ Citée dans E. Kinzel, B. Horn, Op. Cit., p. 98: "Por mas de una década los colonos trabajaron duramente, sea que las madres tenían que amamantar o no, ellas tenían que ir al campo o al bosque a trabajar para que la familia no padeciera hambre".

${ }_{5}^{4}$ L. A. Tilly, J. W. Scott, Op. Cit., p. 36.

${ }^{5}$ Ibid., p. 91.

${ }^{6}$ La préparation du pain est décrite par Gertrud Muñoz dans Kindheitserinnerungen, Op. Cit., pp. 32-33 : La veille, de la pâte constituée de farine de blé, de seigle, d'eau, de sel, de levain et parfois de lait, on formait des miches d'environ 40 centimètres de long, dessinées de traits au couteau et recouvertes d'un linge. Le lendemain, le pain levé était enfourné. Il se conservait une semaine dans un linge et était consommé sous forme de tranches découpées au fur et à mesure

${ }^{7}$ J.-P. Blancpain, Les Allemands au Chili, Op. Cit., p. 353-354.

${ }^{8}$ L. A. Tilly, J. W. Scott, Op. Cit., p. 89.
} 
que son époux réalise des trajets de plus grande ampleur, notamment à Valdivia ${ }^{1}$. En 1857, elle se réjouit de voir que «les affaires sont bonnes", notamment avec le beurre, que lui achètent les Valdiviens de passage ${ }^{2}$. Adleheid Kindermann s'assure un revenu hebdomadaire pour le beurre, les œufs, les légumes et la chicha ou Apfelwein qu'elle vend. Elle engraisse également des porcs et des poulets pour la vente ${ }^{3}$. A ce sujet, Louise Tilly et Joan Scott expliquent que « la participation des femmes au marché local assurait la subsistance de la famille, et elles pouvaient utiliser la somme pour acheter aliments et fournitures pour la maisonnée ${ }^{4}$. Ces femmes sont capables de négocier les prix, qu'elles manient parfaitement ${ }^{5}$. Leur fluctuation est précisément décrite, notamment les prix bon marché du bétail ou au contraire ceux élevés du lait et du beurre, conséquence d'un élevage exclusivement destiné à l'abattage et à la production de viande, expliquent Pauline Metzdorf et Sophie von Bischhoffshausen ${ }^{6}$. Par conséquent, les femmes contribuent à l'intégration de la famille, conçue comme unité de production, dans le marché économique local. De plus, le fait qu'elles tirent de leur travail des revenus contribue à valoriser ce dernier. Pierre Bourdieu rappelle en effet que

« le fait que le travail domestique de la femme n'a pas d'équivalent en argent contribue en effet à le dévaluer, à ses yeux mêmes, comme si ce temps sans valeur marchande était sans importante et pouvait être donné sans contrepartie, et sans limites, d'abord aux membres de la famille, et surtout aux enfants (on a ainsi observé que le temps maternel peut plus facilement être interrompu), mais aussi à l'extérieur, pour les tâches bénévoles, à l'Église, dans des institutions charitables $[\ldots] »^{7}$.

Au Sud du Chili, étant donnée la dureté du travail, surtout les premières années, celui réalisé par la femme est partie entière de l'économie familiale, au même titre que celui de l'homme, et il est reconnu comme tel, en premier lieu par la femme elle-même. C'est elle en outre qui gère les finances de la famille. C'est beaucoup moins vrai dans les familles de Valparaíso, où les épouses de commerçants ne travaillent pas, consacrant leur temps à leur loisirs et rôle social, délaissant l'éducation des enfants au professeur ou à l'institutrice, leurs soins à la nourrice, et le maintien de la maison au personnel ${ }^{8}$. Là, « souvent cantonnées dans des activités non rémunérées et peu portées de ce fait à penser en termes d'équivalence du travail en argent, les femmes sont, beaucoup plus

\footnotetext{
${ }^{1}$ Lettre du 14.03.1857 dans I. Schwarzenberg (éd.), Dokumente, Op. Cit., VI, p. 74

${ }^{2}$ Lettre du 10.11.1857 dans Ibid. : „,das sind gute Geschäfte!“”

${ }^{3}$ Lettres du 18.02.1853 et 23.02.1853 dans G. Schwarzenberg (éd.), Geschichtliche Monatsblätter, Op, Cit., XII, pp. 41 et 45.

${ }^{4}$ L. A. Tilly, J. W. Scott, Op. Cit., p. 90.

${ }_{6}^{5}$ Lettre du 25.05.1855 dans M.B. Aichele, Op. Cit., p. 2.

${ }^{6}$ Lettre du 10.05.1851 dans G. Böhm (éd.), Dokumente, Op. Cit., V, p. 27 et lettres du 9.11.1854, 37.12.1854, 25.03.1855, 28.05.1855 et 1.09.1857 dans I. Schwarzenberg (éd.), Dokumente, Op. Cit., VI, pp. $12,17,26,33$ et 85 .

${ }^{7}$ P. Bourdieu, Op. Cit., p. 105.

${ }^{8}$ C'est le cas de Mme Müller, la patronne de Marie Bülling, ou encore de Laura Grisar et Minna Claude. Aucune de ces femmes ne travaille, comme toutes les autres épouses de commerçants qui sont évoquées dans ses trois journaux et correspondances. Cf. E. von Loe, Marie Bülling, Op. Cit, L. Hoesterey, Op. Cit et G. Schwarzenberg (éd.), « Aus Grannys's Nachlass », Op. Cit.
} 
souvent que les hommes, disposées au bénévolat, religieux ou caritatif notamment ${ }^{1}$. Leur fonction est de manifester "par tout ce qui concourt à leur apparence - cosmétique, vêtement, maintien, etc. - le capital symbolique du groupe domestique : de ce fait, elles sont rangées du côté du paraitre, du plaire $»^{2}$.

En revanche, au Sud du Chili, les immigrées travaillent. La laiterie est par exemple une activité spécifiquement allemande et féminine dans la seconde moitié du XIX ${ }^{\mathrm{e}}$ siècle, productrice de lait, de beurre, de formage et de crème, les produits d'exportation principaux de la colonie allemande. Certaines femmes sont installées à leur compte. Sophie von Bischhoffshausen relate l'expérience d'une Allemande, Madame C., " la cocue du fils d'un meunier de Beesenhausen », qui, s'arrêtant sur le chemin du voyage à Hambourg pour soigner un enfant gravement malade, a rejoint ensuite son mari au Chili, et l'a retrouvé légalement marié avec une autre ${ }^{3}$. Elle s'est alors installée à Osorno comme couturière, et loin d'être miséreuse, s'est assurée de bons revenus, l'artisanat étant particulièrement bien payé. En effet, les familles de colons sont très demandeuses en services et, dans une région qui en est totalement dépourvue, sous la loi de l'offre et de la demande, les rares couturières, blanchisseuses, tailleuses demandent cher, sujet de plainte constant des épistolières ${ }^{4}$. Les recensements chiliens révèlent également cette réalité féminine. En 1865, on compte par exemple une agricultrice, une aubergiste, sept commerçantes, seize cuisinières, vingt-six couturières, neuf blanchisseuses, sept tailleuses ${ }^{5}$. En 1875, huit agricultrices, une brodeuse, deux brasseuses, une vendeuse de tabac, vingt-et-une cuisinières, vingt-quatre commerçantes, deux fileuses et tisseuses, deux hôtelières, onze sages-femmes, trois stylistes, une meunière, deux boulangères, huit professeures, trente religieuses, trente tailleuses, trente-quatre domestiques, une teinturière ${ }^{6}$. On imagine que la grande majorité du reste des femmes, bien que non recensées comme actives, travaillent aussi comme agricultrice ou artisane, mais au côté d'un mari, dans une organisation de l'atelier ou de la ferme traditionnelle. Les professions d'artisanat féminin sont davantage représentées en milieu urbain, dans les villes et bourgs comme Valdivia, Osorno ou La Unión ${ }^{7}$. Il s'agit souvent de métiers qui prolongent les fonctions domestiques de la femme et qui leur assurent une autonomie financière incontestable. Or, à l'émancipation économique est liée l'émancipation de genre. Asunción Lavrin affirme en effet la nécessité d'insérer fondamentalement l'histoire de la femme dans l'histoire sociale et économique ${ }^{8}$. L'oubli qui touche

\footnotetext{
${ }^{1}$ P. Bourdieu, Op. Cit., p. 105.

${ }^{2}$ Ibid.

${ }^{3}$ Lettre du 12.07.1854 dans I. Schwarzenberg (éd.), Dokumente, Op. Cit., VI, p. 35-36 : „Die ungetraute Frau von einem müllersonh aus Beesenhausen“.

${ }^{4}$ Sophie se plaint souvent de la cherté des travaux d'artisanat en général, de la charpenterie et menuiserie en particulier. Cf. Lettre du 12.12.1856 dans Ibid., p. 68.

${ }^{5}$ Censo general, 1865, Op. Cit., p. 372.

${ }^{6}$ Censo general, 1875, Op. Cit., p. 626.

${ }^{7}$ Censo general, 1865, Op. Cit., p. 27, 42 et Censo general, 1875, Op. Cit., p. 64 et 83.

8 A. Lavrín, "Género e Historia: Una conjunción a finales del siglo XX" dans Nomadías, Santiago, Univ. de Chile, PGAL, 1999, pp. 15-48
} 
les activités de la femme, souvent domestiques, ne doit pas masquer sa participation au marché du travail, par laquelle elle accède à une autonomie croissante :

«[La] culture des genres affecte le marché du travail, produisant une ségrégation professionnelle tenace et par conséquent la situation d'infériorité économique et d'autorité dans laquelle se trouve les femmes en général. [...] L'inclusion de la femme dans l'étude de la main-d'œuvre, d'un point de vue historique, sociologique, économique ou même de l'anthropologie sociale, contribue à changer notre perception de cet important secteur de l'économie » conclut l'auteur'.

La migration pose ainsi nécessairement la question du réaménagement des rôles féminins et masculins, au sein du couple comme de la communauté. Elle s'affirme «comme une expérience qui déstructure et restructure l'ordre du genre à l'intérieur du couple et de la famille », selon Monica Raisa Schpun ${ }^{2}$, Ainsi, la migration, tend à dévoiler les implicites qui fondent les relations de genre en même temps qu'elle constitue un puissant facteur de leur transformation ${ }^{3}$. Les diverses expériences croisées d'Allemandes émigrées au Chili permettent de conclure à des cas d'émancipation, outre le cas des célibataires. Croiser genre et migration est donc efficient parce que l'émigration par définition modifie les conditions dans lesquelles se sont élaborées les relations hommes/femmes. Fanny Fonck rapporte que lorsqu'elle réalise sur le bateau une lessive complète avec un unique sceau d'eau, elle suscite l'admiration de son mari ${ }^{4}$. Ce dernier lui dit alors qu'elle pourrait toujours gagner de l'argent au Chili en se faisant blanchisseuse, proposition qui n'aurait jamais été formulée hors du contexte de migration, si le couple était resté en Allemagne par exemple.

«En somme, le rapport de genre subsiste après la migration comme forme sociale [...] tout en recevant des contenus différents, dont la valence et les formes s'apprécient et se comprennent en contexte et en référence aux autres inscriptions sociales des agents » résume Philippe Rygiel ${ }^{5}$.

Au Sud du Chili, les femmes immigrées, surtout celles porteuses d'un savoir-faire, profitent d'un marché du travail libre et ouvert à la concurrence, contrairement au marché de l'artisanat, saturé en Allemagne. Elles peuvent même faire concurrence aux hommes. Ainsi, l'installation à leur compte des célibataires mais aussi des femmes mariées est fondamentale dans ce processus d'émancipation. Paradoxalement, le travail des femmes a été peu pris en compte comme réalité

\footnotetext{
${ }^{1}$ Ibid., pp. 27-28 : "La misma cultura de géneros afecta el mercado de trabajo, produciendo una segregación ocupacional persistente y la consecuente situación de inferioridad económica y de autoridad en que se encuentran las mujeres en general [...] La inclusión de la mujer en el análisis de la fuerza laboral, sea desde el punto de vista histórico, sociológico, económico o aun de la antropología social, esta contribuyendo a cambiar nuestra percepción de ese importante sector de la economía"

${ }^{2}$ M. R. Schpun, «Immigration, genre et projet familial » [en ligne] dans Migrations internationales : études de cas et débats historiographiques (diasporas et sociétés d'accueil, XIXe-XXe siècles), enregistrement vidéo $\mathrm{du}$ séminaire de l'EHESS $(2: 04: 07)$, 2007-2008. Accessible à l'URL: http://www.archivesaudiovisuelles.fr/FR/video.asp?id=1203\&ress $=4127 \&$ video $=77193 \&$ format $=22 \# 16970$ [consulté le 13 mai 2008]

${ }^{3}$ N. Lillo, P. Rygiel, « Avant-propos », Op. Cit., p. 13.

${ }^{4}$ Entrée du 6.06.1854 dans G. Schwarzenberg (éd.), Geschichtliche Monatsblätter, Op. Cit., IX, p. 164.

${ }^{5}$ P. Rygiel, «Le genre de l'émigrante et ses transformations », dans N. Lillo, P. Rygiel, Rapports sociaux de sexe et immigration, Op. Cit., p. 26.
} 
dans la littérature germano-chilienne. Or, le marché du travail est souvent conçu comme la voie de l'intégration à la société locale dans les études migratoires. Par conséquent, les germano-chiliennes, à l'image des femmes immigrées en général, sont souvent représentées comme en repli, physique et culturel, sur le foyer.

\subsubsection{Le maintien des traditions}

Il est vrai que la première préoccupation de l'immigrée allemande était bien de recréer un environnement chaleureux pour la famille, pour se sentir «à la maison», comme le révèle le témoignage de Pauline Metzdorf : «Je crois que lorsque nous aurons notre petite maison à nous à la campagne et que nous pourrons l'aménager à l'allemande, ce sera bien » espère-t-elle ${ }^{1}$. Selon Pierre Bourdieu, les femmes auraient une inclination sociale à prolonger leur fonction d'« objet esthétique » à leur environnement. Par conséquent, « ce sont elles [...] qui assument le soin et le souci du décor de la vie quotidienne, de la maison et de sa décoration intérieure» ${ }^{2}$.

La reproduction fidèle du foyer allemand est visible de la construction de la maison aux détails de décoration ${ }^{3}$. Les styles de foyer qui prévalent dans la colonie allemande du Chili étaient le Biedermeier puis le Jungendstil, maintenus jusqu'à la fin du siècle ${ }^{4}$. Les formes de vie de la bourgeoisie allemande se reconstituent même autour du lac Llanquihue. Là, le corps de ferme se compose de la maison, de la grange, de l'atelier, des étables et parfois d'un moulin ${ }^{5}$. Le jardin et le potager devant la maison sont une nouveauté qui contraste avec les demeures locales, comme le souligne Vicente Pérez Rosales ${ }^{6}$. La demande importante en graines et semences génère un négoce féminin très rentable ${ }^{7}$. Sophie von Bischhoffshausen fait ainsi affaire avec cette Madame C. spécialisée également dans l'importation de semences ${ }^{8}$. La décoration intérieure respecte également les traditions allemandes. A la demande des maîtresses de maison, les magasin de Valdivia, Waschmann, Prochelle ou Springmüller, vendent tout type de vaisselle, des meubles, des articles

\footnotetext{
${ }^{1}$ Lettre du 10.05.1850 dans G. Böhm (éd.), Dokumente, Op. Cit., V, p. 26 : "Ich denke, wenn wir erst ein Häuschen auf unserm Lande haben, und es nach deutscher Art einrichten können, dann wird es ganz gut sein".

${ }^{2}$ P. Bourdieu, Op. Cit., p. 107.

${ }^{3}$ L'arrivée de professionnel et d'artisans introduit une réelle révolution architecturale à Valdivia, avec surgissement en un temps record de demeures néoclassiques avec piliers et moulures. A Puerto Montt, Osorno et Coral, l'évolution est similaire Cf.: P. Treutler, Andanzas de un alemán en Chile (1851-1863), Santiago de Chile, Editorial del Pacifico S.A., Traducción de Carlos Keller, p. 279 et G. Guarda, Nueva Historia de Valdivia, Op. Cit., p. 571.

${ }^{4}$ J. Ojeda-Ebert, Op. Cit., p. 125 et 140 et J. Unold, Op. Cit., p. 53.

${ }^{5}$ V. Pérez Rosales, Recuerdos, Op. Cit., p. 413. Sophie von Bischhoffshausen décrit précisément sa maison dans la lettre du 8.07.1857 dans I. Schwarzenberg (éd.), Dokumente, Op. Cit., VI, p. 82.

${ }^{6}$ L'intendant décrit le paysage suite à l'immigration allemande,: "En Puerto Montt no se comprende que pueda nadie edificar sin designar antes que nada el lugar que puede ocupar el jardín; En todos ellos, alternando con las flores y las legumbres tempranas, se ven árboles cargados de frutos cuya posibilidad de cultivo solo ahora comienzan a creer realizables los envejecidos moradores de los contornos", $C f$. V. Pérez Rosales, Recuerdos, Op. Cit., p. 414.

${ }^{7}$ C. Gleisner, La conservación de la germanidad, Op. Cit., p. 99.

${ }^{8}$ Lettre du 10.08.1855 dans I. Schwarzenberg (éd.), Dokumente, Op. Cit., VI, p. 37.
} 
de décoration, des machines à coudre et des articles de couture, de la tapisserie, des outils de bureau, de papeterie, indispensables pour la correspondance, et des instruments de musique. Le piano de prestigieuse marque allemande est indispensable dans la maison bourgeoise ${ }^{1}$. Les femmes confectionnent elles-mêmes des rideaux, des nappes, des broderies de décoration, qu'elles peuvent d'ailleurs vendre pour avoir un complément de revenus ${ }^{2}$. Certaines peignent également, composant des panneaux de bois, décorés de fleurs et de lettres réalisés avec patrons à objectif moralisateur, composant un extrait de la Bible, une citation d'un penseur allemand ou un refrain populaire sur les valeurs du Deutschtum ${ }^{3}$. Hugo Kunz résume, dans la dernière décennie du XIX ${ }^{\mathrm{e}}$ siècle, la délicatesse d'une demeure allemande de Valdivia :

«Les jacinthes en fleur, les tulipes, les violettes et les myosotis exhalent leur parfum à travers les rideaux blancs comme neige des fenêtres impeccablement propres En leur centre, d'un luminaire grimpe un lierre vert, tandis que derrière l'appui-fenêtre blanc se chauffent au soleil les pensionnaires d'un bocal à poissons rouges posé sur une petite table à fleurs » ${ }^{4}$.

Tandis qu'en ville les familles les plus aisées perpétuaient le style bourgeois le plus raffiné, à la campagne, les demeures reproduisaient la tradition paysanne, que décrit Johannes Unold :

«La solidité et la propreté de la maison, dotée de nombreux édifices annexes, la bonne tenue du jardin et du potager annonçaient de loin déjà le propriétaire allemand... Tout rappelait la maison d'un paysan allemand aisé : la large table de bois massif, d'où ressortait un bouquet coloré de fleurs d'automne, les chaises de bois à haut dossier, l'imposant poêle de céramique, les huiles sur les murs - témoignages de la fidélité du sentiment patriotique des habitants - et la série de pots de fleurs devant les fenêtres $»^{5}$.

En outre, les immigrées entretiennent des liens bien spécifiques avec la nourriture, comme lieu de rattachement à la patrie d'origine ${ }^{6}$. Le maintien des traditions culinaires allemandes dans les familles du Sud du Chili est, de ce point de vue, exceptionnel et a fait l'objet d'une étude spécifique par Christine Gleisner ${ }^{7}$. La cuisine joue un rôle déterminant en effet dans l'évocation des saveurs de la mère patrie mais aussi par les rencontres qu'elle génère et la sociabilité qu'elle crée. La nourriture y est même plus riche que dans le pays d'origine, comme pour chasser la nostalgie et

\footnotetext{
${ }^{1}$ C. Gleisner, La conservación de la germanidad, Op. Cit., p. 102.

${ }^{2}$ C'est le cas d'Elise Hantelmann qui fait de la publicité dans le Valdivia's Deutsche Zeitung les 18.10.1890, 3. 10.1895 et 19.10 .1895 .

${ }^{3}$ C. Gleisner, La conservación de la germanidad, Op. Cit., p. 106.

${ }^{4}$ H. Kunz, Op. Cit., p. 587 : „Blühende Hyazinthen und Tulpen, Veilchen und Vergissmeinnicht duften zwischen den schneeweissen Vorhängen der spiegelblank geputzten Fenster, in deren Mitte aus einer Ampel der grüne Epheu rankt, während hinter der weissgemalten Fensterbank die Insassen eines im Blumentische aufgestellten Goldfischhafens dem Sönnenblicke ausgesetzt sind“.

5 J. Unold, Op. Cit., p. 53 : „Das solide, saubere Wohnhaus mit zahlreichen Nebengebaüden, der wohlgepflegte Blumen- und Gemüsegarten, kündigten schon von ferne den deutschen Besitzer an. Die Familie kam eben von den Erntearbeiten nachhause. Sie führten uns sofort in das freundliche ganz von naturbraunem holze getäfelte Wohnzimmer. Der massive breite Holztisch, auf dem ein Strauss der buntesten Herbstblumen prangete, die hochlehnigen Holzstühle, der mächtige Kachelofen, die Oeldruckbilder an den Wändern, die von dem patriotischen wie dem frommen Sinne der Bewohner zeugten, endlich die Reihen von Blümentöpfen vor den Fenstern erinnerten an ein wohlhabendes deutsches Bauernhauses“.

${ }^{6}$ A. Morelli, Op. cit.

${ }^{7}$ Pour un exposé détaillé des traditions culinaires allemandes au Chili, on consultera C. Gleisner, El Kuchen, Op. Cit. et C. Gleisner, La conservación de la germanidad, Op. Cit., pp. 135-160.
} 
soulager le déracinement, remarque $\operatorname{Karl} \operatorname{Ilg}^{1}$. Les livres de cuisine les plus populaires étaient ceux de Mary Hahn et Henriette Davidis, avec plus d'une trentaine d'éditions de la moitié du XIX ${ }^{\mathrm{e}}$ au début du $\mathrm{XX}^{\mathrm{e}}$ siècle $^{2}$. Ils sont emmenés, importés ou commandés à des parentes et amies. On notera la grande variété de plats, majoritairement composés autour de la pomme de terre, aliment de base, de différentes variétés et cuisinés selon de multiples recettes ${ }^{3}$, ou du choux, décliné sous toutes ses formes et indispensable pour la choucroute. $\mathrm{L}$ a pomme est cuisinée de mille façons, utilisée dans la préparation de la compote, de la chicha, comme accompagnement, dans les farces des volailles avec des poires et des marrons, et à l'heure du thé dans l'incontournable Kuchen de manzanas, produit phare des traditions culinaires chiliennes actuelles ${ }^{4}$. De même, l'importation des produits allemands est directement générée par la demande des maitresses de maison, de la campagne comme de la ville ${ }^{5}$. La période privilégiée reste Noël et la Nouvelle année où la femme mettait un point d'honneur à cuisiner comme en Allemagne, confectionnant de copieux plats hivernaux, malgré l'inversion des saisons. Ainsi, parmi les biscuits indispensables à Noël, les gaufrettes, pralinés, spécialités allemandes comme les Freiburger Bretzeln, les Friedrichsdorfer Zwieback et surtout le marzipan. Afin de préparer toutes ces recettes, l'importation d'ustensiles de cuisine est impérative, surtout lors des premiers temps de la colonisation où ils ne sont pas fabriqués localement. Font ainsi leur entrée au Sud du Chili tout type de moules et de machines - à beurre, à pâte, à glace, pour hacher la viande, presser les fruits ou fourrer les saucisses - qui constituent la batterie de cuisine idéale de la ménagère germano-chilienne ${ }^{6}$. La table reçoit également tous les soins. Sur les nappes brodées sont disposé des tasses et théières fleuries, des cuillères délicates, des plats à gâteaux et des plateaux peints de fleurs d'après le style champêtre, accompagnés d'un gâteau aromatisé et d'un vase de fleurs fraîches du jardin ${ }^{7}$.

La nourriture est fondamentale dans la sociabilité allemande. L'heure du thé est un moment privilégiée de partage familial, vicinal ou amical. Tous les dimanches, à la campagne comme à la ville, on reçoit à tour de rôle pour le fameux Kaffeeklatsch pour lequel Madame a préparé toute une série de gâteaux et biscuits. Pour l'anniversaire des enfants, on invite tous les camarades et les mères rivalisent pour servir les meilleures pâtisseries. La mère de Gertrud Muñoz était ainsi réputée pour être la meilleure pâtissière de l'école allemande de Valdivia, notamment pour la fête de fin

\footnotetext{
${ }^{1}$ K. Ilg, Op. Cit., p. 242.

${ }^{2}$ Les archives Emilio Held Winkler conservent plusieurs numéros de ces livres de recettes. Quelques exemplaires figurent en annexes.

${ }^{3}$ Adelheid énumère fièrement les différentes espèces qu'elle cultive : la bleue, la blanche avec point bleus, la rouge et également la «pomme-de-terre-œuf », parce qu'aussi jaune que le jaune d'œuf et de même texture une fois cuite (farineuse dehors, coulante à l'intérieur), consommée comme met délicat pour son rendement inférieur aux autres. Lettre du 18.02.1853 dans G. Schwarzenberg (éd.), Geschichtliche Monatsblätter, Op. Cit., XII, pp. 40-41.

${ }^{4}$ K. Ilg, Op. Cit., p. 242-243. Un des faits qui prouve qu'il s'agit d'une alimentation « allemande » et que ce régime est trictement similiaire à celui de la colonie teuto-brésilienne. Cf.: J. Roche, Op. Cit., p. 477.

${ }^{5}$ C. Gleisner, La conservación de la germanidad, Op. Cit., p. 143-144.

${ }^{6}$ C. Gleisner, Ibid., p. 150.

${ }^{7}$ G. Ojeda-Ebert, Op. Cit., p. 142.
} 
d'année ${ }^{1}$. Pâques et Noël étaient également des moments privilégiés pour confectionner des sucreries à partager. Les associations allemandes avaient également leurs propres petits-déjeuners, déjeuners, repas ou soupers, proposés aux familles des membres. Les manifestations allaient du déjeuner au majestueux buffet en passant par le pique-nique. Lors des sorties en plein air se produisait un curieux mélange entre cuisine allemande et chilienne : café, bière et Kuchen se mélangeaient aux empanadas, asado, cazuela et curanto. Christine Gleisner de remarquer finalement que les hommes intègrent plus facilement, dans leurs sorties, des éléments culinaires chiliens, tandis que les femmes se font un honneur à conserver intactes les traditions allemandes à la maison ${ }^{2}$.

\subsubsection{L'intégration de la femme immigrée}

Du fait de ce repli sur le foyer, les immigrées représenteraient alors les tenantes de la tradition et les immigrés, qui s'intègrent par le marché du travail, la modernité. La conception de l'assimilation est ainsi elle-même profondément genrée. Dans la littérature germano-chilienne, la femme comme gardienne des traditions est un topos:

«La femme, explique Christine Gleisner, occupe une place fondamentale dans la famille comme gardienne des traditions. C'était elle qui enseignait la langue aux petits, leur inculquait les valeurs et cuisinait suivant les recettes ancestrales. Par sa position de maîtresse de maison, elle restait plutôt éloignée du monde extérieur, raison pour laquelle elle n'apprenait pas la langue ni les coutumes du nouveau pays $»^{3}$.

Le rapport des femmes allemandes à la langue espagnole est de ce point de vue éloquent. En 1960, l'enquête de Grandjot et Schmidt sur le bilinguisme de la communauté germano-chilienne démontre que les femmes, encore à la cinquième génération, parlent beaucoup moins espagnol que les hommes.

«Presque sans exception, les hommes, chez qui influe constamment la vie hors de la maison, en public, au sein d'une population de langue castillane, se distinguent pas des valeurs plus importantes de S [Sprachneigung, tendance linguistique], c'est-à-dire une inclinaison plus prononcée vers le castillan, que les femmes, qui, à la maison, parmi leurs enfants, sont les conservatrices des coutumes et de la langue allemande $»^{4}$.

\footnotetext{
${ }^{1}$ G. Muñoz, Op. Cit. p. 23.

${ }^{2}$ C. Gleisner, La conservación de la germanidad, Op. Cit., p. 160.

${ }^{3}$ C. Gleisner, El kuchen, Op. Cit., p. 11 : "La mujer ocupaba un lugar fundamental en la familia como guardiana de las tradiciones, era ella quien ensenaba a los pequeños el idioma, inculcaba los valores y cocinaba según las recetas ancestrales. Por su situación de amas de hogar, quedaban bastante mas ajenas al mundo exterior, razón por la cual muchas veces no aprendían la lengua ni las costumbres de la nueva tierra".

${ }^{4}$ C. Grandjot, E. Schmidt, El Bilingüismo de los chilenos de ascendencia alemana, resultado de una encuesta estadística, Santiago de Chile, Liga Chileno-Alemana, 1960, pp. 30-31 : "Casi sin excepción los hombres, cuya vida fuera de la casa, en público, en medio de una población de habla castellana no deja de hacer sentir su influencia - se diferencian por valores mayores de S [Sprachneigung, tendencia lingüística], vale decir, más pronunciada inclinación al castellano, de las mujeres - que, en sus casa, entre sus niños son conservadoras de las costumbres y del habla alemanas".
} 
L'apprentissage de la langue est un deuxième facteur fondamental d'intégration avec le travail. Or, après plusieurs années voire décennies de vie au Chili, certaines ne parlent pas espagnol ${ }^{1}$. Les femmes de la première génération ont en effet peiné dans l'apprentissage de la langue. Déjà sur le bateau, elles essaient bien de s'y mettre, mais sont souvent vite découragées, vues les conditions de navigation $^{2}$. Une fois au Chili, toutes disent leurs efforts pour apprendre la langue, et leurs difficultés dans le processus. Sophie von Bischhoffshausen raconte à ce sujet, à son arrivée : “Avec la langue, c'est toujours difficile, mon français élémentaire m'aide beaucoup, les achats de provisions comme le lait, les œufs, les légumes et tout ce qui est nécessaire à la maison, je peux les faires toute seule $»^{3}$. Les années passent et elle confesse qu'il lui est toujours difficile de tenir une conversation avec ses voisins. Néanmoins, les mots castillans, voire des phrases entières, ne sont pas absentes des correspondances. Chaque lettre est une «mosaïque de citations ${ }^{4}$. L'introduction de termes étrangers germanisés est également remarquable chez Antonie Exss et Marie Konrad qui évoquent la «Schakra» ${ }^{5}$, chez Adelheid Kindermann et Pauline Metzdorff qui parlent de la Chich ${ }^{6}$. Enfin, Magdalena Barbara Aichele décrit l' «Indident [...] Wisende Peres Rosales » dans une lettre de «Puerta Mond ${ }^{7}$. Cette intertextualité linguistique se rencontre fréquemment dans les lettres de Sophie von Bischhoffshausen, qui semble presque inventer une nouvelle langue tant abonde l'utilisation des termes «Schitscha (en espagnol Chicha, une boisson à base de pomme), «Mula » et «Packmula » (mules), «Pastören » (esp. pastores - bergers), «Vackero/Waguero » (esp. vaquero - vacher), «Karretha ( (esp. carreta - charrette), «Zirko» (esp. cerco - enclos), «Fannega » (esp. Fanega, une unité de mesure), «Baril» (esp. barril - baril), « Cavalliero » (esp. caballero - cavalier), « contracte » (esp. contratos - contrats), ces deux derniers termes révélant une touche de français dont Sophie a dit avoir quelques rudiments ${ }^{8}$. Elle rapporte que les chiliennes et chiliens s'émerveillent devant sa petite dernière et reproduit phonétiquement leur exclamation : «a bonitte Alemansitte, hi muyie cordo!» (esp. La bonita alemancita, y muy gorda! - La bonne

\footnotetext{
${ }^{1}$ J. Unold, Op. Cit., p. 58: „Das Deutschtum zeit sich hier so sest und überlegen, dass - ein seltener Fall deutscher Kolonisationsgeschichte - die Einheimischen mehr das Deutsche zu lernen genötigt find als umgekehrt. In Valdivia, Osorno und Puerto Montt gibt es Familien, wo namentlich die Frauen trotz zwanzigoder dreissigjährigen Aufenthaltes kaum einige Worte der Landesprache verstehen.“

${ }^{2}$ Entrée du 8.09.1840 dans I. Schwarzenberg (éd.), « Aus Granny’s Nachlass », Op. Cit., p. 8.

${ }^{3}$ Lettre du 10.11.1854 dans I. Schwarzenberg (éd.), Dokumente, Op. Cit., VI, p. 13 : „Mit der Sprache geht es mir schon ganz leidlich, da hilft mir [...] mein bishen Französisch recht viel, meine Einkaüfe an Munition wie Milch, Eier, Gemüse, was alles in's Hause gebracht wird kann ich mir selbst abmachen“.

${ }^{4}$ A. Lübke, Op. Cit., p. 158.

${ }^{5}$ Lettre du 25.12.1852 dans G. Schwarzenberg (éd.), Geschichtliche Monatsblätter, Op. Cit., XII, p. 6 et lettre du 2.09.1889 dans K.Konrad, Op, Cit., p. 43.

${ }^{6}$ Lettre du 23.02.1853 dans G. Schwarzenberg (éd.), Geschichtliche Monatsblätter, Op. Cit., XII,, p. 46 et lettre du 21.02.1852 dans G. Böhm (éd.), Dokumente, Op. Cit., V, p. 42.

${ }^{7}$ Lettre du 28.02.1855 dans M. B. Aichele, Op. Cit., p. 3. Le nom correct de la ville est Puerto Montt, du nom du président, mais elle pense qu'il vient de sa forme en demi-lune, Mond signifiant lune.

8 Lettres du 27.12.1854, 25.03.1855, 2.06.1855, 28.09.1855, 16.10.1855, 20.02.1856, 11.09.1856, 14.03.1857, 24.04.1857, 1.09.1857, 10.11.1857, 16.04.1858, 7.10.1859 dans I. Schwarzenberg (éd.), Dokumente, Op. Cit., VI, pp. 17, 19, 25, 34, 42, 45, 48, 57, 65, 73, 76, 85, 88 et 98.
} 
petite allemande, et qu'elle est grassouillette !) ${ }^{1}$. Dans une autre lettre, elle utilise le «mui Malo » (esp. muy malo - très mal ou mauvais) et un « so este boene mein Mutterchen » (esp. esta bien, Mein Mutterchen - c'est bien, ma petite mère $)^{2}$. L'orthographe souvent erronée des termes démontre que Sophie maîtrise un espagnol uniquement oral et qu'elle est en contact avec des autochtones. Ce vocabulaire fonctionne comme autant de termes de références qui lui permettent de se repérer dans une conversation.

En réalité, ces femmes n'ont peut être pas urgence à maîtriser l'espagnol, outre un vocabulaire de base pour pouvoir vendre les produits et gérer leur maison. Pendant la première génération surtout, elles vivent dans un milieu presque exclusivement germanophone et les premières années sont si difficiles que la préoccupation première n'est pas l'intégration ${ }^{3}$. Peter Waldmann rappelle le contexte des premières années :

« Il convient en outre d'avoir présent à l'esprit que les colons allemands se virent jetés dans ce que l'on peut qualifier de «vide culturel». La région était non seulement économiquement inexplorée mais aussi à peine peuplée, et en outre loin de la région centrale du Chili qui dominait politiquement, économiquement et socialement. Par conséquent il manquait totalement la moindre pression d'acculturation $»^{4}$.

D'ailleurs, il serait temps de remarquer que les hommes de la première génération ne parlaient pas non plus beaucoup espagnol. Cinq ans après l'arrivée au Chili, Gustav von Bischhoffshausen n'est pas plus avancé que son épouse Sophie, qui révèle en effet que leur fils aîné Carl est indispensable à son époux parce qu'il parle parfaitement espagnol, fonctionnant comme un intermédiaire avec la population locale. Gustav connait bien quelques mots, mais est incapable de tenir une conversation et donc de gérer seul ses affaires ${ }^{5}$. La grande majorité des textes montrent ainsi que les enfants fonctionnent comme des intermédiaires dans l'apprentissage de la langue. Pauline Metzdorf constate : «Nos enfants apprendront la langue plus vite que moi. La fille du ministre aime s'entretenir avec notre Martha; celle-ci ne peut pas encore parler, mais elle comprend déjà un peu ${ }^{6}$. Au contact des employés et des autres enfants, ils apprennent plus facilement et rapidement l'espagnol, parfois de manière divertissante. Sophie von Bischhoffshausen raconte par exemple que son fils Georg, âgé de 9 ans, se plaît à donner des cours d'espagnol aux oies. Tous ses enfants parlent parfaitement espagnol, même entre eux. Ainsi, la mère immigrée s'intègre aussi à travers

\footnotetext{
${ }^{1}$ Lettre du 16.10.1855 dans I. Schwarzenberg (éd.), Dokumente, Op. Cit., VI,. p. 46.

${ }^{2}$ Lettre du 6.02.1856 dans Ibid., p. 22.

${ }^{3}$ K. Schobert, Op. Cit., p. 304 et P. Waldmann, Op. Cit., p. 445.

${ }^{4}$ Ibid., p. 441 : "Conviene además tener presente que los colonizadores alemanes se vieron arrojados a lo que podemos calificar de vacio cultural. La región se encontraba no solo económicamente inexplorada, sino también escasamente habitada, y además lejos de la región central de Chile que dominaba política, económica y socialmente. Por consiguiente faltaba en absoluto las mas mínima presión de aculturación”.

${ }^{5}$ Lettre du 7.10.1859 dans I. Schwarzenberg (éd.), Dokumente, Op. Cit., VI, pp. 101-102.

${ }^{6}$ Lettre du 10.05. 1851 dans G. Böhm (éd.), Dokumente, Op. Cit., V, p. 26 : „Unsere Kinder werden die Sprache eher erlenen als ich. Die Tochter des Ministers unterhält sich gern mit unserer Martha; sprechen kann diese nocht nicht, aber schon Einiges verstehen“. Il s'agit de la fille de l'intendant Pérez Rosales.
} 
les relations sociales de l'enfant, notamment avec les parents de ses camarades, ce que note également Paula Zaldivar dans le cas des Italiennes du Chili ${ }^{1}$.

Ainsi, en dépit des obstacles linguistiques, les Allemandes ont développé leurs propres formes d'intégration. Leur «confinement» domestique ne les empêche pas de s'intégrer à la société locale, justement parce qu'elles partagent avec d'autres femmes cette inclination. Des extraits attestent de contacts avec les femmes chiliennes, par exemple en ce qui concerne la lessive et le tissage. Plusieurs témoignages mentionnent que les femmes allemandes ont appris des femmes chilotes, qui migrent sur le continent pour travailler, à laver, filer et tisser la laine pour l'usage familial ou la vente ${ }^{2}$. Ces femmes adoptent aussi des manières de vivre locales. Elles apprennent à monter à cheval, font dormir les enfants dans les caisses de mules et les nourrissons dans des fourrures de mouton, «à la chilienne » comme dit Sophie ${ }^{3}$. Il faut en déduire que se réalisent des visites de voisinage, et d'ailleurs, Sophie choisit comme marraine de sa petite Elisabeth sa voisine chilienne, l'épouse du juge local, avec laquelle elle dit avoir une bonne relation, « jusqu'où le lui permet [sa] méconnaissance de l'espagnol ${ }^{4}$. Il existe par conséquent, chez les femmes, un langage des gestes, de l'oralité, des expériences et activités communes qui leur permettent d'entrer en relation, en communication avec leur environnement local, dont elles ne sont absolument pas isolées, pour satisfaire ainsi aux besoins de leur famille. A ce sujet, les historiennes françaises, auteures de l'article : «Culture et pouvoir des femmes », ont développé le concept de «culture féminine », une culture qui s'exprime en grande partie de manière non officielle, notamment pas le biais de la culture orale 5 . Ce concept permet de mettre en évidence des sphères de pouvoirs féminins, dans le domaine du social, du culturel, invitant à composer «une histoire interne du pouvoir familial, social et politique ». Concrètement, Louise Tilly et Joan Scott rappellent ainsi que si «les hommes avaient le pouvoir physique et légal, [...] dans les familles pauvres, les ressources financière étaient aux mains de la femme, ainsi dans les maisonnées des classes populaires, il semble qu'il n'y ait pas une seule source de pouvoir mais plusieurs » ${ }^{6}$. De la même manière, dans sa réflexion sur «le pouvoir et l'impuissance des femmes », Jean Elsthain remet en cause la définition positiviste et unidimensionnelle du pouvoir - comme pression qu'exerce une personne contre une autre dans le but d'imposer sa propre volonté - pour élaborer une dimension multiple et davantage relationnelle, mettant ainsi en évidence des lieux de pouvoir informels :

\footnotetext{
${ }^{1}$ P. Zaldivar, Op. Cit., p. 113.

2 «Der deutsche Siedlerfrau » dans 75 Jahre, Op. Cit., p. 137 et J.-P. Blancpain, Les Allemands au Chili, Op. Cit., p. 353.

${ }^{3}$ Lettres du 12.07.1855, 23.09.1855 et 16.10.1855 dans I. Schwarzenberg (éd.), Dokumente, Op. Cit., VI, pp. 36,43 et $48:$ :,nach chilener Art“.

${ }^{4}$ Lettres du 20.08.1855 dans Ibid, p. 38 : "so weit das bei der grossen Unkenntnis der Sprache geht"

${ }^{5}$ C. Dauphin, A. Farge, G. Fraisse (et al.), «Culture et pouvoir des femmes : essai d'historiographie », Annales ESC, 2/mars-avril 1986, pp. 271-293.

${ }^{6}$ L. A. Tilly, J. W. Scott, Op. Cit., p. 104.
} 
«Aux frontières relationnelles, contextuelles et mouvantes du pouvoir, [...] les femmes peuvent être vues comme ayant l'aptitude d'agir sur une personne ou une chose, en particulier sur les enfants, et par conséquent, de manière puissante ${ }^{1}$.

Le pouvoir féminin se situe clairement, selon Elsthain, dans le domestique : «Dans la société, passée comme présente, où le «foyer » est le nid de la vie humaine [...] les femmes sont souvent les dépositaires de divers sens de pouvoir en lien avec cette sphère $»^{2}$. Michelle Perrot évoque même un «contre-pouvoir efficace » au sein de la famille rurale particulièrement ${ }^{3}$. Le rôle d'éducatrice des femmes allemandes émigrées au Chili est de ce point de vue fondamental.

\subsection{Le rôle maternel en contexte migratoire}

Dans les correspondances des immigrées, les enfants apparaissent au centre des préoccupations. «Au XIX ${ }^{\mathrm{e}}$ siècle, l'enfant est, plus que jamais, au centre de la famille. Il est l'objet d'un investissement de tous ordres : affectif, certes, mais aussi économique, éducatif, existentiel », résume Michelle Perrot qui dégage le modèle de la «famille triomphante ${ }^{4}$.

\subsubsection{Des taux de fécondité et de mortalité infantile importants}

Yvonne Knibiehler remarque qu'au XIX ${ }^{\mathrm{e}}$ siècle, le taux de fécondité des immigrées est en général plus élevé que celui des autres femmes ${ }^{5}$. La dimension économique apparaît nettement dans la mesure où les enfants constituent un apport de main d'œuvre non négligeable, ce qui explique en partie le fort taux de fécondité des ménages germano-chiliens. Jean Pierre Blancpain a démontré l'extraordinaire taux d'accroissement de ces «belles familles», qu'il explique comme un «impératif familial $»^{6}$ :

«Il faut défricher la «chacra », la mettre en valeur au plus vite, pour obtenir, avec un titre de propriété, le droit de pouvoir l'agrandir. On a enfin l'assurance que les enfants, sitôt mariés, s'en verront attribuer une autre. La croissance démographique a conditionné et accompagné le développement économique de la colonie » conclut t-il ${ }^{7}$.

L'accroissement naturel de la colonie allemande chilienne est important, avec une moyenne de 6 à 10 enfants par famille, encore à la seconde, voire à la troisième génération. Un exemple : la famille

\footnotetext{
${ }^{1}$ J. B. Elshtain, «The Power and Powerlessness of Women » dans G. Bock y S. James, Op. Cit., p. 114 : "Within the relational, contextual and shifting boundaries of power [...] women can be seen as having the ability to act upon a person or thing, particularly children, hence as powerful"

${ }^{2}$ Ibid., p. 116 : "In society, past and present, in which the "home" is the hub of human life, [...] women are often the repositories of several understandings of power with that sphere"

${ }^{3}$ M. Perrot, « Figures et rôles », Op. Cit., p. 128.

${ }^{4}$ Ibid., p. 134.

${ }^{5}$ Y. Knibiehler, « Corps et cœurs » dans G. Duby, M. Perrot, (dir.), Op. Cit., p. 412.

6 J.-P. Blancpain, Les Allemands au Chili, Op. Cit., pp. 304-315. Jean Roche a démontré un même dynamisme démographique dans les colonies brésiliennes, avec, chez les familles catholiques émigrées en 1826-1828, une moyenne était de 8,5 enfants à la première génération, de 10,4 à la seconde. Cela se maintient sur tout le XIXe, puisque la moyenne d'enfant dans une famille catholique en 1933 est de 10,8. Cf. Jean Roche, Op. Cit., p. 128.

${ }^{7}$ J.-P. Blancpain, Les Allemands au Chili, Op. Cit., p. 305
} 
Schmidt. Le 14 février 1855, Anna Bittner épouse Franz Schmidt à Puerto Montt ${ }^{1}$. De leur mariage naissent sept enfants. Leurs enfants ont eux-mêmes entre dix et treize enfants chacun. A la cinquième génération, les Schmidt ont 312 descendants $^{2}$. De même Sophie et Gustav von Bischhoffshausen ont eu 8 enfants, dont les deux aînés, Karl et Julius, ont à eux seuls 19 enfants entre 1874 et 1895 . Louise Tilly et Joan Scott ont calculé qu'à l'époque préindustrielle, « le taux élevé de mortalité infantile, et la forte fécondité qui s'ensuivait, faisait qu'au moins deux tiers des années de mariage d'une femme étaient consacrés à l'activité reproductrice $»^{3}$.

Le fort taux de fécondité est en effet l'indice d'un régime démographique encore ancien, prétransitoire, marqué par des taux de mortalité infantile élevés. Toute les familles sont affectées par la perte d'au moins un enfant. La mort d'Elisabeth, née au Chili quelques mois après l'installation des von Bischhoffshausen sur le domaine du Roble, est douloureusement vécue par Sophie. Le 20 janvier 1856, elle la décrit comme un nourrisson «bien dodu», qui «mange et boit bien, fait ses nuits, rit beaucoup et gazouille toute la journée ${ }^{4}$. Le 20 février, elle n'attend plus que la délivrance de l'enfant, malade depuis trois semaines : «Ah mon Dieu, je n'ai plus d'espoir ! Cela me déchire le cœur de voir l'enfant gésir ainsi et je prie souvent Dieu d'y mettre bientôt un terme et de rappeler l'enfant auprès de lui, plutôt que de la laisser souffrir encore longtemps ${ }^{5}$. Le 24 mars, elle annonce : «Ma petite Elisabeth est morte ! », avant de raconter les derniers jours d'agonie du «petit ange », l'enterrement au cimetière allemand d'Osorno, la douleur aussi de ses frères et sœurs, qui pleurent et «cherchent encore souvent, le soir, parmi les étoiles, celle où le bon Dieu aurait placé la petite Elisabeth $»^{6}$. «Ma douleur, je la tairai, conclue Sophie. Vous savez malheureusement bien comme on souffre de la mort d'un enfant » confie-t-elle à ses parents ${ }^{7}$. Elle passe ensuite à la ligne, pour reprendre dans le paragraphe suivant le cours normal de la lettre, décrire les activités quotidiennes, raconter le déroulement de la récolte et donner des nouvelles de toute la maisonnée. Quelques jours plus tard, elle reçoit des lettres de sa famille, et à les lire, il semblerait qu'elle n'a même pas encore appris la naissance de l'enfant qui vient de mourir ${ }^{8}$. Dans de telles situations, le décalage temporaire induit par les communications postales de l'époque

\footnotetext{
${ }^{1}$ Il s'agit du premier mariage célébré dans la communauté. Cf. Matrimonios Puerto Montt, Op. Cit.

2 Arbre généalogique des Schmidt, manuscrit, AGS, Op. Cit.

${ }^{3}$ L. A. Tilly, J. W. Scott, Op. Cit., p. 108.

${ }^{4}$ Lettre du 20.01.1856 dans I. Schwarzenberg (éd.), Dokumente, Op. Cit., VI, p. 53 : « Das ist eine liebes Ding ; dick und gross, isst, trinkt und schläft vorzüglich und lacht springt und kräht den ganzen Tag“.

${ }^{5}$ Lettre du 20.02.1856 dans Ibid., p. 55 : „Ach Gott ich habe keine Hoffnung ! es zerreisst mir das Herz das Kind so da liegen zu sehen, und ich muss oft den lieben Gott bitten, bald ein Ende zu machen, und das Kind zu sich zu nehmen, als es noch länger so leiden zu lassen“.

${ }^{6}$ Lettre du 24.03.1856 dans Ibid., pp. 56-57: „,mein Elschen ist tot!“, „,suchen noch jetzt ofts abends den Stern am Himmel auf der den liebe Gott Elschen gebracht hätte“.

${ }^{7}$ Ibid. : „Von meinem Schmerz schweige ich. Ihr weisst ja leider auch wie wehe der Tot eines Kindes thut“.

${ }^{8}$ Lettre du 27.03.1856 dans Ibid., p. 58. Sophie date sa lettre du 27 février mais elle est en réalité postérieure à la précédente. La confusion temporelle en dit beaucoup sur son état émotionnel.
} 
semble cruel ${ }^{1}$. L'impossibilité de partager la douleur ne fait que retarder le deuil. Bientôt, elle apprend aussi la mort de son «bon père tant aimé », formulant péniblement une réponse où les mots illisibles et l'écriture relâchée trahissent sa douleur ${ }^{2}$. Fin juin, elle revient encore sur la mort d'Elisabeth, à la fin d'une lettre jusque là ordinaire :

«Ah! Petite mère chérie, comme ma petite Elisabeth me manque! Le 28 de ce mois elle aurait eu un an, elle aurait pu déjà marcher, et parler [...] Ah! Au lieu de cela, mon petit amour gît sous la terre humide et froide. Ah petite mère ! Comme $j$ 'ai pu pleurer ces deux pertes douloureuses survenues en si peu de temps, mais à quoi bon se lamenter! Je ne voulais pas parler de cela, mais je veux t'envoyer une mèche de cheveux de l'enfant, que je lui avais coupé pour toi lorsqu'elle vivait encore. Elle avait de si jolis cheveux, comme aucun autre enfant. $»^{3}$

Après trois mois de silence, Sophie reprend la plume, en septembre, pour raconter qu'elle a gardé le lit pendant six semaines. Elle ne veut pas s'attarder sur la maladie, mais elle ne sait pas bien ce qui lui est arrivé : elle n'avait plus d'appétit, rendait tout ce qu'elle s'efforçait d'ingérer et avait de fortes migraines. Et un jour, elle a repris des forces. Sophie a fait son deuil et de nouveau, elle raconte le quotidien ${ }^{4}$.

La mortalité infantile est importante dans les campagnes du Sud du Chili. Sophie relate l'expérience de la marraine d'Elisabeth, qui, alors qu'elle met au monde son dixième enfant a perdu tous les précédents. Elle-même subit, à peine six mois après la mort d'Elisabeth, celle de son petit Heinrich, âgé de 9 ans, malheur qui affecte profondément le couple, et en particulier son époux : «la douleur de Gustav fut épouvantable. Heino était de loin son préféré » ${ }^{5}$. La vie de ces femmes est ainsi jalonnée de pertes douloureuses. Par conséquent, « les enfants sont omniprésents dans les lettres. On parle de leur santé, de leurs loisirs, de leurs vêtements, de leurs études », note Caroline Chotard-Lioret ${ }^{6}$. Sophie donne régulièrement la taille de ses enfants, parce qu'à une époque où la pédiatrie est peu développée, un enfant qui grandit bien est un enfant en bonne santé. C'est bien là une caractéristique des correspondances féminines. Les pères de famille, «étant de

\footnotetext{
${ }^{1}$ La relève postale passe toutes les huit semaines. Ainsi, quand Sophie reçoit une réponse, elle en donne une également. L'échange est donc systématiquement décalé, puisqu'elle ne peut répondre à la lettre reçu que deux mois après. $C f$. Lettre du 10.11.1857 dans I. Schwarzenberg (éd.), Dokumente, Op. Cit., vI, p. 88.

${ }^{2}$ Lettre du 27.03.1856 dans Ibid., p. 58 : “ des geliebten guten Vaters”.

${ }^{3}$ Lettre du 19.06.1856 dans Ibid., p. 61 : ,Ach geliebtes Mutterchen, wie vermisse ich mein Elschen! Den 28 d.M. wär es ein Jahr al, es könnte wohl schon laufen und sprechen [...] Ach und mein Liebling liegt in der nassen, kalten Erde, ach Mutterchen! Was habe ich doch in so kurzer Zeit für zwei harte Verluste zu beweinen, doch wozu das Klagen! Ich wollte gar nicht's davon schreiben, aber ein Löckschen von dem Kinde will ich dir schicken, was ich ihm noch bei Lebzeiten für dich abgeschnitten hatte, es hatte ja so schöne lange Hährchen wie kein's von den anderen Kindern“.

${ }^{4}$ Lettre du 11.09.1856 dans Ibid., p. 63.

${ }^{5}$ Lettre du 11.01.1857dans Ibid., p. 69 : „Gustavs Schmerz war schrecklich, Heino war ja von eher sein Liebling".

${ }^{6}$ C. Chotard-Lioret, «Correspondre en 1900, le plus public des actes privés ou la manière de gérer un réseau de parenté », Ethnologie française, 15-1/1985, p. 66-67.
} 
très 'rares' éducateurs, sont souvent de bien piètres informateurs », explique à ce sujet Bernard Lahire ${ }^{1}$.

\subsubsection{L'accouchement}

En réalité, la vie de l'enfant est menacée dès son origine. L'accouchement se réalise à domicile, dans un acte rigoureusement privé et féminin, dans son déroulement comme dans son récit. Ainsi, « la naissance de l'enfant se faisait au sein d'une “complicité de femme", grâce à l'expérience des membres féminins de la famille ou du voisinage ${ }^{2}$. Pour la mère et l'enfant, la naissance reste une épreuve périlleuse et dramatique. Les textes relatent souvent le cas d'enfants mort-nés ou de femmes mortes en couche, comme Magdalena Barbara Aichele, en 1857, et ce jusqu'à la fín du $\mathrm{XIX}^{\mathrm{e}}$ siècle ${ }^{3}$. L'accouchement est par conséquent redouté et, pour ne pas inquiéter la famille, on tait la grossesse. La naissance d'un enfant est toujours décrite comme une surprise : «Pensiez-vous, ici aussi il y a des cigognes ! Le 28 du mois dernier, à dix heures du matin, l'une est entrée tout d'un coup par la fenêtre et m'a apporté dans mon lit une toute petite fille bien portante et potelée », écrit Sophie ${ }^{4}$. Lorsque naît, après la mort d'Elisabeth et d'Heinrich, une autre petite fille, Elsa, 22 juin 1857, elle décrit un miracle : «Le bon Dieu nous a renvoyé une autre petite $\mathrm{El} \gg .^{5}$ Les deux filles, Elisabeth et Elsa, ont en effet le même surnom, «petite El », Elschen en allemand. On donnait souvent le même nom à plusieurs enfants successifs, anticipant le fait qu'un seul survivrait ${ }^{6}$. Le silence qui entoure la grossesse révèle, au-delà de la crainte d'un dénouement funeste, que la maternité, comme expérience féminine, est véritablement «non représentée » dans la culture écrite. De sexualité, il n'en est jamais question dans les lettres, symptôme de cette « désarticulation » entre les fonctions sexuelle et maternelle de la femme que met en évidence Silvia Vegetti Finzi ${ }^{7}$. En revanche, l'accouchement est un «thème inlassable des conversations entre femmes », remarque Michelle Perrot ${ }^{8}$, de «chatter», dit Vegetti ${ }^{9}$. L'expérience maternelle se transmet essentiellement par communication orale, créant ainsi un espace de culture féminine propre, indépendant de celui des hommes, et de ce point de vue, analogue aux lieux de pouvoir féminin «dissimulés» qu'identifie Elsthain.

\footnotetext{
${ }^{1}$ B. Lahire, «Masculin-féminin. L'écriture domestique » dans D. Fabre, Par écrit. Ethnologie des écritures quotidiennes, Paris, Maison des Sciences de l'Homme, 1997, p. 148.

${ }^{2}$ O. Hufton cité dans L. A. Tilly, J. W. Scott, Op. Cit., p. 108.

${ }^{3}$ Lettre du 17.08.1890 dans R. Held, Op. Cit., p. 127 qui rapporte la mort en couche de Thérèse Kolcker.

${ }^{4}$ Lettre du 12.07.1855 dans I. Schwarzenberg (éd.), Dokumente, Op. Cit., VI, p. 35 : „Denkt nur es gibt hier auch Störche ! am 28. vorigen Monats morgens früh $10 \mathrm{H}$ kommt auf einmal ein solcher zum Fenster herein und bringt mit eines kleines dickes fettes Mädelchen in's Bett".

${ }^{5}$ Lettre du 8.07.1857 dans Ibid., p. 79 : "Der liebe Gott hat uns eine Elschen wieder geschenkt!"

${ }^{6}$ L. A. Tilly, J. W. Scott, Op. Cit., p. 111.

${ }^{7}$ Silvia Vegetti Finzi, "Female Identity between Sexuality and Maternity" dans G. Bock, S. James, Op. Cit., pp. 126-145.

${ }^{8}$ M. Perrot, «Figures et rôles », Op. Cit., p. 138.

${ }^{9}$ S. Vegetti, "Female Identity", Op. Cit., p. 137.
} 
Quelques lignes après l'annonce fabuleuse de la naissance, les peurs et douleurs du moment s'incarnent pourtant. Sophie raconte qu'elle a bien cru ne pas survivre dans de telles conditions. Elle a accouché seule, avec l'aide de ses bonnes, sans sage-femme et le seul médecin disponible, à quatre heures de cheval, était immobilisé par la dysenterie. De manière spontanée, se mettent cependant en place des réseaux féminins d'assistance spécifique aux femmes en couche, pour combler, comme dans de nombreux autres domaines, les défaillances de l'Etat chilien ${ }^{1}$. En 1856, un rapport de l'Intendant de la Province de Llanquihue mentionne le cas de Frederica Juana Mödinger, sage-femme qui pratique sous la tutelle du docteur Fonck, l'époux de Fanny, médecin officiel de la colonie ${ }^{2}$. Ce dernier sollicite pour elle, auprès de l'Intendant Mancilla, une compensation financière pour services rendus auprès de deux femmes, Mme Lafrentz en avril 1856 et Mme Emhart le mois suivant. La sollicitation est portée à connaissance du ministre de l'intérieur, Antonio Varas, par l'Intendant, qui précise que Llanquihue ne dispose pas d'une «matrone subventionnée », tel que cela se fait dans les autres provinces chiliennes, et que les appels à celle de Puerto Montt restent infructueux, vue la distance qui la sépare des colonies ${ }^{3}$. Dans une lettre de juin 1856, Varas confirme la rétribution demandée, précisant en effet que le lac de Llanquihue ne dispose pas de «sage-femme chargée de l'assistance aux femmes des colons », et précise que Llanquihue est en dehors du territoire d'exercice de la matrone de Puerto-Montt ${ }^{4}$. Ainsi, à défaut d'avoir une sage-femme subventionnée, la colonie se dote, avec l'assentiment de son médecin, d'une sage-femme, de manière non officielle au début, avec rétribution ponctuelle par le gouvernement, puis, dans un cadre officiel. Le 16 juin 1857, en effet, le gouvernement nomme deux femmes matrones subventionnées pour la colonie : Friedrike Mödinger et Cristine Pawlitza, toutes deux femmes de colons de Llanquihue ${ }^{5}$.

\subsubsection{L'éducation des enfants}

Une fois la survie de l'enfant assurée, venait le temps de son éducation. Le rôle de la mère dans l'éducation des enfants a toujours été reconnu comme fondamental. C'est elle qui assure premièrement l'apprentissage de la langue, qu'on dit toujours «maternelle ». D'ailleurs, en 1907, préoccupé par le recul de la langue allemande au sein de la communauté germano-chilienne, le Valdivia's Deutsche Zeitung émet un rappel à l'ordre aux femmes allemandes :

«Il est plus correct qu'une mère allemande s'occupe de ses enfants en bas-âge, plutôt que de les confier au personnel hispanophone et entretenir la maison et la cuisine, au lieu du contraire. La langue se fixe chez l'enfant uniquement au cours des six premières années de sa vie, au contact de la mère qui la garde toujours en elle ; en général, le père n'est à la maison que quelques heures par jour et ne se réunit avec les enfants que pour le repas ou le

\footnotetext{
${ }^{1}$ J. Ojeda-Ebert, Op. Cit., p. 98.

${ }^{2}$ Lettres de Franz Fonck des 20.04 et 20.05.1856 dans AHN, MINT, vol. 308, Op. cit. s. p.

${ }^{3}$ Lettre de Manuel Mancilla, trois fois intendant de 1856 à 1882, du 1.05.1856 dans Ibid, s. p.

${ }^{4}$ Lettre d'Antonio Varas du 19.06.1856 dans Ibid., s. p.

${ }^{5}$ E. Held Winkler, "Servicio de enseñanza y Médico en la Colonia del Lago" dans P. Legarraga, Op. Cit., p. 85.
} 
soir pour quelques courtes heures. Le maintien de la langue allemande incombe donc à la mère [...]. Ici, à Valdivia et dans tout le Sud du Chili nous sommes plutôt bons de ce point de vue et nous espérons que la femme allemande maintiendra toujours la langue allemande ${ }^{1}$.

De ce point de vue, le rôle des femmes allemandes du Sud dans le maintien de l'identité de la communauté est fondamental. Nombreux sont les voyageurs surpris, encore au $\mathrm{XX}^{\mathrm{e}}$ siècle, par la pureté et la vitalité de la langue, au sein de la quatrième ou cinquième génération ${ }^{2}$. Il est à remarquer que les femmes allemandes de Valparaíso n'ont pas ce même rôle, évoluant dans un milieu plus cosmopolite, s'exprimant aussi bien en anglais et français qu'en allemand ${ }^{3}$. Dans l'apprentissage de la langue allemande, les contes, les chants et les jeux jouent un rôle fondamental. Les livres sont emportés lors du voyage, importés, envoyés depuis la patrie par la famille et circulent de familles en familles ${ }^{4}$. Sophie von Bischhoffshausen raconte ainsi que pendant que ses bonnes Hannchen et Gretchen se chargent de la maison selon ses ordres, elle «éduque les petits ». Elle leur lit des contes, notamment, Hansel et Gretel, qu'elle se remémore et doit même inventer, parce qu'elle n'a plus de livre neuf, ses réserves se sont épuisées ${ }^{5}$.

Le système scolaire apparaît comme un élément clé du processus d'assimilation des populations immigrées $^{6}$. Or, à l'arrivée des colons, l'instruction des enfants pose problème dans un pays où l'enseignement primaire chilien est extrêmement faible ${ }^{7}$. Pour des émigrés entièrement alphabétisés et disposant tous d'une formation élémentaire, l'instruction des générations, même dans les conditions de vie les plus difficiles, est une priorité. Pendant les premières années, les enfants sont donc instruits à la maison, par un professeur particulier dans les familles les plus aisées ou par la mère. Sophie montre un souci constant dans les progrès scolaires de ses enfants. Tandis qu'elle assure l'instruction élémentaire des plus petits, les trois aînés, filles comme garçons, suivent les cours de leur professeur particulier, Mr Röhner. Elle critique cependant ses cours, estimant que sa

\footnotetext{
${ }^{1}$ Valdivia's Deutsche Zeitung, 11.04.1907, p. 1 : „Es ist viel richtiger, wenn eine deutsche Mutter sich lieber mit ihren kleinen Kindern beschäftigt, statt sie spanisch sprechenden Dienstboten zu überlassen und selbst Küche und Haus zu bedienen, statt umgekehrt. Die Sprache der Kinder beruht aber lediglich auf den ersten sechs Lebensjahren um Umgang mit der Mutter, die sie immer im sich hat; der Vater ist im allgemeinen nur wenige Stunden des Tages im Hause und kommt auch dann wohl nur zur Essenszeit oder Abends auf kurze Studen mit den Kindern zusammen. Auf der deutsche Mutter ruht also das Bestehen auch der deutschen Sprache [...] Hier in Valdivia und im ganzen Süden Chiles sind wir ja in dieser Beziehung gut daran und hoffen wir, dass die deutsche Frau immer die deutsche Sprache erhalten wird. »

${ }^{2}$ Parmi ces voyageurs, Gerstaecker, Koebel, Zöller, Plüschow. Cf. J.-P. Blancpain, Les Allemands au Chili, Op. Cit., pp. 565-566.

${ }^{3}$ Ainsi, dans la famille Claude, les deux derniers enfants, Willy et Charles, qui sont nés et ont vécu leurs premières années en Angleterre, sont anglophones, tandis que les deux premiers, Adolph et Jeannette, sont germanophones. Minna doit ainsi parler allemand aux plus grands, anglais aux petits, et même espagnol au dernier, Richard, né au Chili. Entrées du 31.10.1840, 2.11.1840, 5.06.1842 et 24.07.1842 dans I. Schwarzenberg (éd.), « Aus Granny's Nachlass », Op, Cit., pp. 13, 15, 61, 63.

${ }_{5}^{4} \mathrm{La}$ Bibliothèque Emilio Held Winkler en possède quelques exemplaires, dont certains figurent en annexe.

${ }^{5}$ Lettre du 20.08.1857 dans I. Schwarzenberg (éd.), Dokumente, Op. Cit., VI, p. 37.

${ }^{6}$ K. Schobert, Op. Cit., pp. 282-283.

${ }^{7}$ En 1853, sur 1,5 millions d'habitants, le Chili compte 23130 élèves inscrits dans 571 écoles publiques ou privées. A la fin du XIXe, la scolarisation n'est encore que de 30\%. Cf. J.-P. Blancpain, Les Allemands au Chili, Op. Cit., p. 648-649.
} 
fille Théo présente de graves lacunes en histoire, en particulier sur les années les plus récentes, ce qui témoigne de sa préoccupation pour l'histoire contemporaine, et en particulier les événements révolutionnaires du milieu du siècle, et que Röhner évite trop facilement les sujets qui touchent au religieux, ce qui empêcherait selon Sophie de comprendre certains faits historiques ${ }^{1}$.

Dans les régions isolées, la consolidation institutionnelle de l'école est difficile, et encore au début $\mathrm{du} \mathrm{XX}^{\mathrm{e}}$ siècle, beaucoup d'Allemandes éduquent leurs enfants à la maison, au moins pendant les premières années scolaires ${ }^{2}$. De 1854 à 1867, se met en place l'école itinérante allemande, la Deutsche Wanderlehre, pour s'adapter à l'habitat dispersé $\mathrm{du} \mathrm{lac}^{3}$. Les ruraux qui en ont les moyens envoient ensuite leurs enfants dans les collèges des villes, où se met en place un système de pension chez les autres émigrés, qui aident aussi aux devoirs. Sophie pense ainsi à plusieurs reprises à mettre sa fille Théodora en pension chez Mme Windemuth à Valdivia ${ }^{4}$. Son école, créée en 1854, propose un programme complet de lecture, écriture, grammaire espagnole, histoire, géographie, arithmétique, français, anglais et allemand et couture ${ }^{5}$. Les écoles allemandes sont rapidement créées dans les villes : à Osorno en 1854, à Valdivia en 1858, à La Unión en 1860, à Puerto Montt en $1869^{6}$. Tous les Allemands, mêmes ceux qui n'ont pas d'enfants scolarisés, se sentent concernés par la vie de l'école, considérée comme l'institution principale du Deutschtum et dont le principal relais, à Valdivia, est l'organe de presse de la communauté, le Valdivia's Deutsche Zeitung $^{7}$. Les fêtes de fin d'année et les grands anniversaires donnent lieu à des célébrations où participe l'ensemble de la communauté. Les statuts et histoires des écoles montrent que l'administration du collège était assurée par des hommes ${ }^{8}$, mais les textes attestent que les femmes étaient activement présentes dans les réunions parentales, la préparation des événements, notamment les fêtes de fin d'année. Les professeures venaient quant à elle directement d'Allemagne?.

\footnotetext{
${ }^{1}$ Lettre de 7.10.1859 dans I. Schwarzenberg (éd.), Dokumente, Op. Cit., VI, p. 99.

${ }^{2}$ K. Schobert, Op. Cit., p. 231.

${ }^{3}$ J.-P. Blancpain, « La tradition paysanne allemande », Op. Cit, p. 38.

${ }^{4}$ Lettre du 8.07.1857 et 26.08.1858 dans I. Schwarzenberg, Dokumente (éd.), Op. Cit., VI, p. 79 et 96.

${ }^{5}$ G. Guarda, Nueva Historia de Valdivia, Op. Cit., p. 608.

${ }^{6}$ Sur les écoles allemandes au Sud du Chili voir J. Frey, «Die deutschen Schulen in Chile » dans Die Deutsche Arbeit in Chile, Op. Cit., 1, pp. 341-349 ; K. Bauer, Op. Cit. ; 75 Jahre Deutsche Schule Valdivia, Op. Cit. ; F. Zajadacz, 100 Jahre Deutsche Schule zu Osorno :1854-1954, Valparaíso, Impr. Victoria, 1954, 156 p., Deutsche Schule Puerto Montt, Op. Cit. .

${ }^{7}$ On veille ainsi à ce qu'aucun enfant allemand ne soit écarté du système éducatif allemand, et les familles à revenus modestes bénéficient ainsi d'un système de solidarité avec bourses. $C f$ C. Gleisner, La conservación de la germanidad, Op. Cit., p. 84. La publication des nouveaux statuts est vécue comme un véritable événement par le Valdivia's Deutsche Zeitung, le 2.11.1901. Cf. C. Gleisner, La conservación de la germanidad, Op. Cit., p. 84.

${ }^{8} 75$ Jahre Deutsche Schule Valdivia, Op. Cit.; F. Zajadacz, Op. Cit. ; Deutsche Schule Puerto Montt, Op. Cit.

${ }^{9}$ C'est le cas de la mère de Gertrud Muñoz, qui raconte notamment comment les femmes participent aux fêtes de l'école allemande de Valdivia par la préparation des gâteaux, la confection des costumes de théâtre et l'organisation des jeux. $C f$. G. Muñoz, Op. Cit., pp. 14-31.
} 


\subsection{Religion, genre et migration}

Outre l'instruction des enfants, la femme tient un rôle important dans leur éducation morale et dans le maintien des traditions religieuses. Les immigrants des régions du Sud sont en majorité protestants, et même si la religion catholique est la seule officielle au Chili, la tolérance est de fait. «Concernant la religion, chacun a le loisir de croire ce qu'il veut. Les natifs sont certes tous catholiques, mais on peut louer et servir Dieu chacun à sa manière ", explique à ses parents Magdalena Barbara Aichele ${ }^{1}$. Dès 1844, les mariages entre non-catholiques sont validés, consignés dans les registres paroissiaux catholiques. En 1855, un cimetière protestant est crée à Santiago et en 1865 est autorisée la pratique privée des cultes dissidents. Surtout, dans les années 1880, après un débat de trente ans, est édicté un ensemble de lois laïques : la loi des cimetières laïcs (1883) autorise l'enterrement de dissidents dans les cimetières publics, la loi de mariage civil (1884) ôte à l'Eglise la compétence d'enregistrer légalement l'institution du mariage et la loi du registre civil (1884) institue un registre civil, indépendant des registres paroissiaux, des naissances, mariages et décès $^{2}$. Cette législation profite directement aux colons protestants, qui n'ont plus désormais à passer par l'Eglise catholique pour valider leur état civil. Rosine Held révèle ainsi que sa fille Anna, récemment mariée par le pasteur Beckmann, a effectué les démarches du mariage civil, « introduit ici il y a cinq ans », dit-elle bien informée ${ }^{3}$.

Pour délivrer les sacrements, on manque de pasteurs. Il n'existe pas de synode protestant au Chili avant 1906 et il faut donc les faire venir d'Allemagne. Emigrés en 1852, Hermann Friedrich Geisse et Manns sont les deux seuls qui baptisent, marient, catéchisent, parallèlement à leur travail de colons ${ }^{4}$. Le premier pasteur allemand, le Dr. Tyszka, arrive à Puerto Montt en 1865, desservant tour à tour pour huit mois Puerto Montt puis Osorno et s'arrêtant lors du voyage sur les rives du Llanquihue, afin de dispenser quelques sacrements aux ruraux ${ }^{5}$. En 1868, le pasteur Franz Renz le remplace et lors de son deuxième séjour à Osorno, il confirme Pauline Hube qu'il épouse en $1875^{6}$. Dans ce contexte, l'impression d'abandon des colons protestants est réelle, au point que certains se rapprochent des Catholiques. La question du baptême se pose pour les familles du lac. «Mon enfant n'est pas encore baptisé. Nous n'avons pas de pasteur et je crois que nous le ferons baptiser

\footnotetext{
${ }^{1}$ Lettre du 28.02.1855 dans M. B. Aichele, Op. Cit., p. 3. Poeppig confirme la tolérance religieuse qui règne au Chili, Cf. E. Poeppig, Op. Cit., p. 75 : „Die Reliogiosität eines Volkes und selbst der Einzelnen wird grossentheils von der Höhe der allgemeinen sittlichen Cultur bedingt, die sie ihr eigen nennen dürfen. Glücklicherweise herrscht unter den Chilenen weder Unglaube noch Bigoterie. Überhaupt ist das Vorurteil sehr ungegründet, welches bei Nennung südamerikanicher Religionsverhältnisse an spanische Inquisition, Scheiterhaufen, und mindestens an Gehässigkeit und Intoleranz denken macht. Der Chileno hängt seinem Glauben an, ohne deshalb Andersdenkende zu verachten oder gar zu verfolgen, und auf jeden Fall besitzt er mehr Toleranz als viele protestantische Secten der vereinigten Staaten [...]. Man lebt als Europäer eines andern Glaubens sehr ungestört und ohne je eine Zeichen von Abneigung [...] zu bermerken“.

${ }^{2}$ N. Cruz, P. Whipple, Op. Cit., p. 330.

${ }^{3}$ Lettre du 17.08.1890 dans R. Held, Op. Cit., p. 129.

${ }^{4}$ J.-P. Blancpain, Les Allemands au Chili, Op. Cit., p. 605.

${ }^{5}$ P. Renz, Op. Cit., p. 3.

${ }^{6}$ Ibid., p. 6.
} 
à la chilienne » se résout Sophie von Bischhoffshausen ${ }^{1}$. Son second enfant, elle espère le faire baptiser par le pasteur Mann, installé à Valdivia, mais se résout finalement à l'amener à un prêtre italien de la mission jésuite de Trumao ! ${ }^{2}$ De même, pour les mariages, il n’y a pas plus de cérémonies religieuses que pour les baptêmes. Alors on met en scène une cérémonie d'engagement en présence des proches ${ }^{3}$.

Chez ces protestantes, la piété est par conséquent individuelle, sentimentale, toute intérieure.

«Quand viennent des jours sombres, je vais prier le Seigneur, confie Marie Konrad, Oh! Jamais encore, Il ne m'a rien refusé. Partout dans le jardin, je peux élever mes prières et supplications au Sauveur. Comme il est bon de prier sous un ciel libre. Au dessus sont assis les oiseaux, et ils chantent à Dieu leur reconnaissance. Alors je m'agenouille en dessous et prie Dieu qu'il me donne la force du corps et de l'âme. Oh, je le porte en moi partout dès le matin au lever, et je vais au jardin et je lui rends grâce. » ${ }^{4}$

La communion avec la nature est souvent perçue par les femmes comme l'instant privilégié de la communication avec le Seigneur. Sophie ironise à ce sujet :

En Allemagne, la première sortie de l'enfant se fait à l'Eglise, ici, on les promène encore non baptisés pour voir le bétail. [...] Dans la magnifique forêt, entourés du chant des oiseaux, nous sentons la présence de Dieu, bien plus forte souvent que lors d'un mauvais sermon à l'Eglise $»^{5}$.

La religion protestante est un puissant facteur d'équilibre des sexes, parce qu'elle valorise la femme dans son rôle d'épouse et de mère, et non de vierge ou de religieuse, comme dans l'idéal catholique $^{6}$. Elle lui accorde par conséquent une responsabilité partagée avec l'époux dans la réussite affective et l'ascension culturelle et sociale de la famille. L'accès à la lecture des femmes est généralisé et son rôle dans la transmission de la foi est fondamental. Le manque d'encadrement sacerdotal renforce encore ce rôle au sein des colonies allemandes. Les femmes lisent et commentent ainsi les Ecritures. Sophie von Bischhoffshausen fait elle-même la lecture de sermons le dimanche :

«Les Chiliens vont à l'Eglise tous les jours, mais nous, les Allemands, n'avons ni église ni salle de prière, alors les gens deviennent paresseux et négligents envers leur Dieu. Je lis maintenant chaque dimanche au personnel et aux enfants un passage des livres de sermons et de prières, ce que j'ai fait souvent aussi sur le bateau dans l'entrepont, et c'est ainsi qu'ensemble, nous louons le Seigneur, nous prions pour vous et pour notre bien-être.

\footnotetext{
${ }^{1}$ Lettre du 20.08.1855 dans I. Schwarzenberg (éd.), Dokumente, Op. Cit., VI, p. 38.

${ }^{2}$ Lettres du 8.07.1857 et 16.04.1858 dans Ibid., p. 80 et 92.

${ }^{3}$ Lettre du 24.03.1856 dans Ibid., p. 57.

${ }^{4}$ Citée dans E. Held, H. Schuenemann, C. von Plate, Op. Cit., p. 138. Lettre de 1889 : «Kommen trübe Tage, geh ich im Gebet zum Herrn. Oh, Er hat mir noch keine Bitte abgeschlagen... Ich habe überall meine Plätzchen im Garten, wo ich meine Bitten und Flehn zu meinem Heiland bringe, ach wie betet sich's so schön unter freiem Himmel; oben sitzen die Vögel und singen den lieben Gott ihre Danklieder und unten knie ich und bitte den lieben Gott um Gesundheit und Kräfte und Stärke an Leib und Seele ... Oh, ich nehme ihn mir immer mit in aller Frühe, wenn ich aufstehe, da geh ich in den Garten und dann sag ich : Gob Gott zuerst die Ehre."

${ }^{5}$ Lettre du 28.09.1855 dans I. Schwarzenberg (éd.), Dokumente, Op. Cit., VI, p. 43 : „,...] In Deutschland macht man den ersten Ausgang mit dem Kinde womöglich in die Kirche, hier bringt man's noch ungetauft zwischen das Rindweh [...] dort in dem wunderschönene Wald beim Gesang der vielen Vögel fühlten wir uns Gott näher als oftmals bei einer schlechten Predigt in der Kirche“.

${ }^{6}$ J. Baubérot, « La femme protestante » dans G. Duby, M. Perrot (dir.), Op. Cit., pp. 241-259.
} 
Même sous d'autres cieux et sous d'autres étoiles, c'est toujours notre bon vieux Seigneur qui est avec nous » ${ }^{1}$.

Les Catholiques sont tout aussi mal desservis en écoles et églises. Jusqu'en 1860, on trouve un curé à Osorno, un autre à Cabulco. Quand les premiers immigrants catholiques débarquent, Silésiens en majorité, il n’y a pas de prêtre à Puerto Montt. Les colons catholiques de Playa Maitén restent aussi sept années sans l'assistance d'un prêtre. Aussi, faute d'encadrement, la foi est entretenue à la maison, et, comme les protestantes, les mères catholiques lisent les Evangiles à leurs enfants ${ }^{2}$.

Par conséquent, chez les protestants comme les catholiques, le manque d'encadrement sacerdotal a renforcé le rôle de la mère dans la transmission de la foi. Les figures de ces femmes immigrées se place bien dans la lignée féminine constituée par Anne et Marie, érigées, selon Estrella RuizCalvez, en modèles d'éducatrices ${ }^{3}$. Surgissent puissamment de cette expérience migratoire les caractéristiques propres de la religiosité féminine, qui privilégie le contact direct avec le divin et est prompte à se dispenser de tout intermédiaire ${ }^{4}$. Là encore, les conditions d'isolement de la colonie mises en avant par J.-P. Blancpain contribuent bel et bien à réaménager les rôles masculins et féminins, à l'intérieur de la communauté, de la famille, comme du couple.

\subsection{Les formes de sociabilité des immigrées}

On connait bien les sociétés masculines allemandes, les Deutsche Vereine, mais rien n'a été écrit sur les associations de femmes ${ }^{5}$. Nous n'avons pu identifier de formes de sociabilité féminine aussi organisée que la sociabilité masculine allemande pour la première génération. Le sujet mérite sans doute une étude et une recherche plus approfondie. La sociabilité féminine semble se développer plus nettement au cours de la deuxième, voire de la troisième génération, mais là encore, nous n'avons trouvé que peu de sources.

Paula Zaldivar note que les Italiennes émigrées au XXe siècle, «assurent un rôle important au sein de la société des immigrants dans la mesure où elles contribuent de manière déterminante précisément à cause de leur marginalisation de l'environnement étranger - à la création et la

\footnotetext{
${ }^{1}$ Lettre du 6.02.1855 dans I.Schwarzenberg (éd.), Dokumente, Op. Cit., VI, p. 32 : „So gehen die Chilenen jeden Tag in die Kirche aber für die Deutschen giebt es weder Kirche noch Betssaal, so flau und nachlässig werden die Menschen hier sogar gegen ihren Gott! Ich lese nun jeden Sonntag den Leuten und Kindern etwas aus den Predigt un Gebet Büchern vor, was ich auch schon auf dem Schiffe öffentlich im Mitteldeck gethan habe, und so loben wir unsern Gott, und bitten für Euer wie unser Wohl wenn auch ein andrer Himmel mit ganzen fremden Sternen über uns ist er dich unser alter Gott geblieben“.

${ }_{2}^{2}$ J.-P. Blancpain, Les Allemands au Chili, Op.Cit., pp. 608-609.

${ }^{3}$ E. Ruiz-Calvez, «Religion de la Mère, religion des mères » dans J. Delumeau (dir.), La religion de ma mère, le rôle des femmes dans la transmission de la foi, Paris, Les Éditions du Cerf, 1992, 87 p.

${ }^{4}$ C. Leduc, A. Fine, «Femmes et religion» [En ligne], dans Clio, 1/1995, Femmes et religion, s.p. mis en ligne le 24 mars 2003. Accessible à l' URL : http://clio.revues.org/document485.html [Consulté le 30 avril 2008]

${ }_{5}^{5}$ Sur les associations allemandes, voir P. Fürstenberg, «Deutschen Vereine in Chile » dans Die deutsche Arbeit in Chile, Op. Cit., vol. 2, pp. 149-174.
} 
consolidation de la "communauté italienne" ». Dans les réunions de femmes, elle note l'émergence d'une représentation et d'un souvenir commun de l'expérience de la migration. Les femmes en parlent entre elles et c'est donc aussi à travers cette expérience commune que se reconstitue la communauté. La célébration des coutumes est un véritable moment de sociabilité et la maison est comme un sanctuaire où la communauté se retrouve, remarque-t- elle ${ }^{2}$. Chez les Allemandes, il en est sans doute de même. Les premières formes de sociabilité féminine allemande qui naissent au Chili semblent émaner de pratiques spontanées et centrées sur la vie domestique et le domicile, c'est-à-dire relevant de cette «culture féminine» identifiée par les historiennes françaises ${ }^{3}$. Ainsi, les réunions autour d'un thé sont fréquentes, dans le cadre du Kaffeeklatsch du dimanche. L'analyse des écrits d'immigrées a montré que les réseaux de solidarité sont efficaces au moment de l'accouchement par exemple, et en ce qui concerne les enfants en général, notamment au moment des événements scolaires, mais aussi au moment des tâches ménagères les plus prenantes, comme la préparation des repas en temps de récolte ou la grande lessive à la sortie de l'hiver'.

A la seconde et troisième génération, c'est-à-dire au tournant du siècle, se mettent en place des formes d'association plus organisées. Leurs actions sont souvent une prolongation directe du rôle domestique de la femme, à savoir le soin aux autres, la charité, dans un mouvement marianiste général au Chili ${ }^{5}$. Philippe Rygiel et Natacha Lylio de remarquer que « les formes de l'engagement et la participation active dans la société civile des migrants aussi se déclinent selon le genre ${ }^{6}$. En 1870 est attestée dans l'Eco del Sur, quotidien publié à partir de 1869, l'activité de femmes germano-chiliennes qui organisent des campagnes de charité à Valdivia, notamment au profit de l'hôpital ${ }^{7}$. Ce sont là des prémices aux diverses associations de charité qui sont créées à la fin du $\mathrm{XIX}^{\mathrm{e}}$ siècle et au début du XX $\mathrm{XX}^{\mathrm{e}}$. Ainsi, à Osorno, Berta Klix, épouse de Schwarzenberg (18291926) fonde le 30 janvier 1894 la Sociedad de Socorros de Señoras, dont elle est la première présidente $^{8}$. Comme ses statuts l'attestent, approuvés par décret le 6 novembre de cette même année, l'association a pour objectif d' "assister à domicile les patients qui, en des circonstances spéciales, ne peuvent pas se rendre à l'hôpital; et fournir les moyens nécessaires aux familles

\footnotetext{
${ }^{1}$ P. Zaldviar, Op. Cit, p. 164 : "Ellas asumen un rol importante en el seno de la sociedad de los inmigrantes, en cuanto contribuyen de manera determinante - precisamente en causa de su marginación respecto al ambiente extranjero - en la creación y consolidación de la "comunidad italiana"”.

${ }^{2}$ Ibid., p. 170.

${ }^{3}$ C. Dauphin, A. Farge, G. Fraisse (et al.), Op. Cit.

${ }^{4}$ L'aide régulière que reçoit ainsi Sophie von Bischhoffshausen de son ancienne bonne, Riekchen, en temps difficiles, fait ainsi partie de cette «solidarité féminine ». Lettres du 30.03.1855, 20.02.1856, 11.9.1856 et 10.11.1857 dans I.Schwarzenberg (éd.), Dokumente, Op. Cit., VI, pp. 26, 56, 63 et 90.

${ }^{5}$ S. Serrano, Virgenes viajeras, Op. Cit., p. 15. Sur le mouvement du marianismo au Chili, voir G. Salazar et J. Pinto, Historia contemporánea de Chile. IV, Hombría y Feminidad, Santiago, LOM, 2002, pp. 121-164

${ }^{6}$ N. Lillo, P. Rygiel, « Avant propos », Op. Cit., p. 13.

${ }^{7} \mathrm{Je}$ remercie Andrea Larrouceau pour cette précieuse information.

${ }^{8}$ Les archives de la Sociedad De Socorro De Señoras d'Osorno sont en partie conservées aux Archives Emilio Held, mais les documents concernent surtout la seconde moitié du $\mathrm{XX}^{\mathrm{e}}$ siècle.
} 
indigentes qui ont perdu temporairement ou définitivement leurs soutiens ${ }^{1}$. Sa direction se compose d'autant de dames «germano-chiliennes » (Berta Klix de Schwarzenberg, Eduvigis R. v. de Siegle, Cristiana L. de Kraushaar entre autres) qu'«ibéro-chiliennes ». (Trinidad M. v. de Ramos, Vicenta B. de Burgos, Carmen C. de Cavada entres autres), ce qui prouve une intégration croissante des immigrées à l'environnement local. A Valdivia, l'association des femmes, le Frauenvereine, est créée le 13 décembre 1901 sous l'égide de l'Eglise luthérienne, par Matilde Pensell et compte 180 associées. Ses réunions sont faites de «culture, art, anecdotes et souvenirs $»^{2}$. Elle comporte une section d'éducation et d'aide aux personnes en difficulté ${ }^{3}$. L'association est venue en aide, en particulier pendant la Seconde Guerre Mondiale, à des familles allemandes. Elle ouvre au cours du $\mathrm{XX}^{\mathrm{e}}$ siècle orphelinats et maisons de retraite. Son plus beau résultat est le Hogar Luterano à destination des personnes âgées. A Valdivia également, en 1907, Guillerma Frick Asenjo de Harnecker fonde, avec l'aide de Carmela Mackenna Subercaseaux, la maison des Orphelins dont elle est la première présidente, située rue Picarte, proche de l'école allemande ${ }^{4}$. En 1917, une autre association, la Gota de Leche, qui œuvre à la vulgarisation de la puériculture, compte parmi son premier directoire Luise Rudloff, Angelina Asenjo de Urrutia, Elena Anwandter, Luise Deppe de Hoffmann, Elena Haverbeck de Skalweit, Klara de la Guarda de Lorca ou encore Maria Stegmaier, autant de noms qui indiquent la présence de femmes germanochiliennes. Significativement, ces diverses associations de charité ont des appellations castillanes, et non allemandes, ce qui témoigne d'une relative assimilation de ces groupes de femmes descendants d'immigrées, qui conduisent leurs actions conjointement à des femmes chiliennes. Les formes de sociabilité féminine permettent ainsi de poser les jalons d'un processus d'intégration au fil des générations.

L'étude du quotidien immigré démontre que c'est la femme qui assure le maintien des traditions allemandes dans la famille. Concrètement, c'est elle qui se préoccupe d'enseigner la langue aux enfants, de décorer le foyer à l'allemande et de cuisiner des plats typiques de la patrie. Le devenir des mariages mixtes éclaire significativement ce fait. Johannes Unold note à ce sujet :

\footnotetext{
${ }^{1}$ Cité dans V. Sánchez Olivera, Historia de Osorno [en ligne], Biblioteca Virtual Miguel Cervantès, 2002 : "Atender en su propio domicilio a aquellos enfermos que por circunstancias especiales no pueden pasar al Hospital; y proporcionar los recursos necesarios para su mantención a las familias indigentes que temporalmente o para siempre hayan perdido sus sostenedores". Accessible à l'URL : http://www.cervantesvirtual.com/servlet/SirveObras/12478309722361506098435/p0000004.htm\#I_131 [consulté le 8 août 2008]

${ }^{2}$ Cité dans G. Guarda, Nueva Historia de Valdivia, Op. Cit., p. 648.

${ }^{3}$ Ibid., p. 654.

${ }^{4}$ Ibid.
} 
«Les femmes et mères sont ici, comme partout, les gardiennes victorieuses de la langue allemande et de la nature allemande ([note de bas de page 1] : 1'homme n'y parviendra jamais dans un mariage mixte dans un pays étranger) [...] Les mariages entre Allemands et Chiliennes débouchent souvent sur le malheur de l'homme, où le manque de vie domestique et du repas régulier pousse l'homme à la taverne » ${ }^{1}$.

De fait, les enfants de père allemand et de mère chilienne parlent espagnol et, sont baptisés catholiques. En revanche, lorsque dans un couple mixte, la mère est allemande, le mode de vie reste allemand. Gertrud Muñoz, de mère autrichienne et père chilien, explique qu'elle et son frère ont été éduqués dans le bilinguisme, mais avec prédominance de l'allemand comme langue maternelle. En effet, leur père, avec lequel elle parle espagnol, est moins présent, sauf le soir à table et le dimanche $^{2}$. Elle est en outre éduquée dans la religion protestante ${ }^{3}$. L'homme, seul, sans femme, semble donc incapable de maintenir l'identité d'origine et de l'imposer dans son foyer. S'il ne trouve pas de femme au Chili, il n'hésitera pas à rentrer en Allemagne pour s'y marier ${ }^{4}$. Par conséquent, c'est bien la femme qui assure la préservation du «capital symbolique » de la famille, selon le mot de Bourdieu, et du lien à la patrie ${ }^{5}$. Curieusement, ce rôle de maintien de la tradition est souvent perçu négativement dans les recherches sur les migrations. Nancy L. Green constate à ce sujet :

«Elle a beau suivre ou émigrer de son propre gré, la femme, même migrante, qui garde le foyer traditionnel, représente la figure emblématique d'une triple opposition: homme/femme, travail/foyer, modernité/tradition. L'immigrée est donc d'abord perçue comme un vecteur privilégié, voire obtus, de tradition en mal d'adaptation $»^{6}$.

Jean-Pierre Blancpain voit ainsi le rôle maternel comme la preuve d' « un conservatisme constructif fondé sur le travail, la famille, la propriété et la conformité la plus stricte aux expériences des pionniers $»^{7}$. Maintenir les traditions allemandes n'empêche pourtant pas de s'adapter dans la société locale, par le travail, l'échange, la vente, et bien sûr, au sein de la communauté allemande, sous diverses formes de sociabilité. Tradition et intégration ne sont donc pas incompatibles. Nancy Green propose ainsi de revaloriser la notion de tradition elle-même et de la redéfinir dans son opposition à la modernité.

\footnotetext{
1 J. Unold, Op. Cit., p. 58-59: «Die Frauen und Mütter sind hier wie überall die erflogreichsten Bewahrerinnen [1. Der Mann wird es in gemischter Ehe in fremden Landen nie fertig bringen, dass Frau und Kinder seine Sprache annehmen »] deutscher Sprache und deutschen Wesens. [...] Darum schlagen die Ehen zwischen Deutschen und Kreolinnen so häufig zum Unglück des Mannes aus, indem der Mangel an Häusligkeit, an dem gewohnten Essen den Mann in Wirtshaus treibt. »

${ }^{2}$ G. Muñoz, Op. Cit., p. 14.

${ }^{3}$ Ibid., p. 26.

${ }^{4}$ J.-P. Blancpain, Les Allemands au Chili, Op. Cit., p. 574.

${ }^{5}$ P. Zaldivar, Op. Cit., p. 163.

${ }^{6}$ N. L. Green, Repenser les migrations, Op. Cit., p. 117.

${ }^{7}$ J.-P. Blancpain, Les Allemands au Chili, Op. Cit., p. 361.
} 


\section{GENRE ET NATION DANS LE CONTEXTE DE MIGRATION}

Selon Pierre Bourdieu, la femme, bien d'échange au sein du marché matrimonial, assume la fonction de «gardienne principale du capital symbolique » de la famille. Ainsi, « une part très importante du travail domestique qui incombe aux femmes a [...] pour fin de maintenir la solidarité et l'intégration de la famille en entretenant les relations de parenté et tout le capital social, [...] d'où les échanges de cadeaux, de visites, de lettres ou de cartes postales [...] » ${ }^{1}$ explique t'il. Dans l'expérience migratoire, c'est à travers la lettre que les femmes assurent le maintien de ce lien. Ainsi, la correspondance occupe une partie importante de leur emploi du temps et correspond à une pratique régulière, rythmée par les arrivées et départs des bateaux. Sorte de pont entre le lieu d'émigration et d'immigration, la lettre est un vecteur entre la mère patrie et le pays d'accueil. A travers elle se dessinent les éléments d'une identité construite dans l'expérience de la migration, à la fois collective et individuelle. Roger Chartier en résume les enjeux :

«Les usages de l'écrit, dans leurs variations, sont décisifs pour comprendre comment les communautés ou les individus construisent des représentations du monde qui est le leur et investissent de significations plurielles, contrastées, leurs perceptions et leurs expériences. Dans une histoire culturelle, redéfinie comme le lieu où s'articulent pratiques et représentations, le geste épistolaire est un geste privilégié. Libre et codifiée, intime et publique, tendue entre secret et sociabilité, la lettre, mieux qu'aucune autre expression, associe le lien social et la subjectivité. Chaque groupe vit et formule à sa manière ce problématique équilibre entre le moi intime et les autres. Reconnaître ces diverses façons de manier l'aptitude à correspondre est sans doute mieux comprendre ce qui fait qu'une communauté existe, cimentée par le partage des mêmes usages, des mêmes normes, des mêmes rêves $»^{2}$.

Chez les immigrées allemandes au Chili, la lettre rend visible les modes de construction, les points de référence et les discours qui sous-tendent l'élaboration d'une identité culturelle et nationale, toujours genrée ${ }^{3}$.

\subsection{La lettre comme recomposition du tissu communautaire}

L'échange épistolaire en lui-même nourrit régulièrement le sentiment d'appartenance commune. «Une lettre est une conversation entre absents.[...] Pour y réussir, figurez-vous donc que vous êtes en présence de celui qui vous lira, qu'il entend le son de votre voix et a les yeux fixés sur les vôtres » conseille la Grande Encyclopédie au XIX ${ }^{\mathrm{e}}$ siècle $^{4}$. L'utilisation de l'oralité est fortement présente dans les lettres d'émigrées et elle apparait comme l'un des moyens de reconstituer la communauté originelle brisée par l'expérience migratoire.

\footnotetext{
${ }^{1}$ P. Bourdieu, Op. Cit., p. 104-105.

${ }^{2}$ Roger Chartier, « Avant-propos » dans R. Chatier (dir.), La correspondance, Op. Cit., pp. 8-9.

${ }^{3}$ Mireille Bossis, Op. Cit., p. 86

4 Cité dans C. Dauphin, «Les manuel épistolaires au XIXe siècle» dans R. Chartier (dir.), La correspondance, Op. Cit., p. 229.
} 


\subsubsection{L'illusion du dialogue épistolaire}

L'oralité permet à la rédactrice d'interpeller les membres de la famille, et de recréer l'illusion d'un dialogue. La simulation du dialogue est nettement associée à l'écriture chez Pauline Metzdorf et Sophie von Bischhoffhausen: «Mes parents très aimés et mes chers frères et sœurs! A mon tour de prendre la plume pour m'entretenir un peu avec vous, mes chers. J'aimerais tant vous raconter tout cela de vive voix en une petite minute », écrit la première ${ }^{1}$. "J'écrirai aussi souvent que possible, c'est mon activité préférée, m'entretenir avec vous» écrit la seconde ${ }^{2}$. Antonie Exss s'adresse également de manière directe aux destinataires: «Ah, si seulement $\mathrm{j}$ 'avais en ce moment des nouvelles de vous aussi, mes chers, qu'est ce que je ne donnerai pas pour cela, mais j'ai espoir $»^{3}$. Dans les lignes suivantes, se trame un long dialogue, marqué par l'interpellation directe des proches :

«Mon cher Hermann, merci à toi d'abord pour ce joli poêle, pour toutes les autres choses aussi, et toi, ma chère Friederike, mille mercis, ah merci pour toutes ces choses [...] C'est un vraie fête pour nous de savoir comment vous allez. Et maintenant, mon cher Bernhard, que fais-tu ? Que fait notre chère Aurora... et Trudchen et comment va la petite? ${ }^{4}$.

Ainsi, le dialogue épistolaire vise à combler les brèches que le moment de l'émigration a ouvertes dans la cohérence spatiale et affective de la communauté. L'oralité est alors la manière la plus directe de retisser cette toile communautaire. Or, selon les tenants des cultural studies, la culture occidentale associerait traditionnellement l'homme à l'écrit et la femme à l'oral. Cette dichotomie s'insère dans toute une série d'oppositions prêtées à la différence sexuelle, selon laquelle le féminin aurait à voir avec le naturel, la spontanéité, l'émotion, et le masculin à la culture, l'ordre, la raison. Sherry Ortner souligne que, de manière générale, dans la majorité des cultures, les différences sexuelles fonctionnent sur une opposition entre nature et culture ${ }^{5}$. Carole Pateman prolonge cette opposition à celle du public et privé. Elle explique :

«La culture finit par s'assimiler à la création et au monde des hommes parce que la biologie et le corps des femmes les situent plus proches de la nature que les hommes, et parce que leurs tâches de maternage et d'intérieur, qui ont à voir avec des nourrissons non socialisés et des matières premières, les amènent à une relation plus proche de la nature ${ }^{6}$.

\footnotetext{
${ }^{1}$ Lettre du 10.05.1851 dans G. Böhm (éd.), Dokumente, Op. Cit., V, p. 43 : „Innigst geliebte Eltern und theure Geschwister! Auch ich ergreife die Feder um mich mit Euch, Ihr Lieben, ein wenig zu unterhalten. Auch was gebe ich darum, könnte ich es auch nur eine Minute mündlich“.

${ }^{2}$ Lettre du 30.03.1855 dans I. Schwarzenberg (éd.), Dokumente, Op. Cit., VI, p. 27 : „Ich werde schreiben so oft ich kann, es ist ja so meine liebste Beschäftigung mich mit Euch zu unterhalten“.

${ }^{3}$ Lettre du 25.12.1852 dans G. Schwarzenberg (éd.), Geschichtliche Monatsblätter, Op. Cit., XII, p. 4 : „Ach wüsste ich es doch in diesem Augenblick auch von Euch allen, meine Lieben, was würde ich darum geben, doch ich hoffe es“.

${ }^{4}$ Ibid., p. 5: „Mein lieber Hermann, dir zuerst unsern Dank für deinen schönen Ofen, für alles andere und Dir, meine liebe Friederike, Tausend Dank, ach Dank für alle die vielen Sachen [...] Es ist ein grosses Fest für uns zu hören, wie es Euch geht. Nur, mein lieber Bernhard, was machst du? Was mach unsere liebe Aurora und Trudchen und das kleine Mädchen?"“

${ }^{5}$ S. B. Ortner, H. Whitehead, "Indagaciones acerca de los significados sexuales" dans M. Lamas (dir.), El género, la construcción cultural de la diferencia sexual, México, 1996, pp. 127-177.

${ }^{6}$ C. Pateman, Op. Cit., p. 125 : "Culture becomes identified as the creation and the world of men because women's biology and bodies place them closer to nature than men, and because their child-rearing and
} 
De cette «nature féminine » surgirait la capacité émotive... et la propension des femmes à écrire des lettres. La lettre surgit en effet chez les immigrées allemandes comme un moyen d'expression sentimentale, au moment d'une douleur, d'un manque, d'un souvenir nostalgique. Dans ce contexte, elle apparaît comme un «geste d'improvisation», selon le terme de Bernard Beugnot ${ }^{1}$. Les larmes sont souvent évoquées : «L'adieu a été aussi dur qu'avec vous, mes chers. Le cœur saigne de nouveau mais que voulez-vous, c'est ainsi ; espérons nous revoir un jour. Dieu l'a voulu ainsi, restons donc le cœur confiant $»^{2}$ confie Antonie Exss. De même, formules de remerciement et témoignages d'affection inondent la lettre d'Anna Exss à ses frères et sœurs :

«Il reste encore une petite place dans la lettre de maman et je veux l'utiliser pour vous remercier également pour toutes les belles et nombreuses choses que vous nous avez envoyé. Recevez mes plus sincères et profonds remerciements, mes chers frères et sœurs, nous avons pleinement ressenti votre amour et c'est par des larmes de profonde émotion que nous vous en avons remercié $»^{3}$.

Adelheid Kindermann exprime également le chagrin qui ne passe pas : «Je pensais que le temps soulagerait les larmes que je verse pour vous, mais il n'y a rien à faire ; il en coule toujours plus $»^{4}$.

A l'oralité de la lettre et l'illusion du dialogue s'ajoutent les retrouvailles imaginées. Ainsi, dans une lettre à ses frères et sœurs, Adelheid Kindermann explique : «Lorsque je [vous] lis, je suis déjà avec vous, même si vous ne me voyez pas $»^{5}$. Par le biais de la lettre, les absents se font présents. $\mathrm{Au}$ moment où Sophie von Bischhoffshausen prend la plume pour raconter son quotidien à ses parents, elle donne l'impression d'entrer dans un songe : " A ce moment-là, dans mon esprit, je suis chez vous, dans le salon, et j'oublie complètement la distance infinie qui nous sépare ${ }^{6}$. Le moment de l'écriture semble ainsi abolir le temps et la distance. Sophie raconte ainsi que «[Ses] pensées traversent plus rapidement que [ses] lettres le temps et l'espace $»^{7}$. Elle s'imagine, à la

domestic tasks, dealing with unsocialized infants and with raw materials, bring them into closer contact with nature".

${ }^{1}$ B. Beugnot, «De la manière épistolaire : à la manière de soi » dans M. Bossis, C. Porter (dir.), Op. Cit., p. 28.

${ }^{2}$ Lettre du 25.12.1852 dans G. Schwarzenberg (éd.), Geschichtliche Monatsblätter, Op. Cit., XII, p. 7 : „Der Abschied ist schwer gewesen wie von Euch, meine Lieben ; das Herz blutete wieder von neuem, aber ach es soll einmal so sein und einstens sehen wir uns ja wieder. Gott will es so, also still Herz".

${ }^{3}$ Lettre du 25.12.1852 dans Ibid, p. 9: „Es ist noch ein leeres Plätzchen in Mutters Brief; das will ich benutzen, um Euch auch meinen Dank zu sagen für alle die schönen und vielen Sachen, die ihr uns gesendet. Nehmet denn meinen herzlichsten, innigsten Dank hin, meine theruern Geschiwister, wir haben tief Eure Liebe empfunden und Euch mit Thränen der innigsten Rührung beim Empfangen derselben gedankt“. Anna écrit à la suit de sa mère mais c'est bien une lettre à part entière, avec titre et formule de salutation finale.

${ }^{4}$ Lettre du 18.02.1853 dans Ibid., p. 43 : „Ich glaubte, die Zeit würde die Trennung von Euch mildern, die vermag es aber doch nicht; immer fliessen neue Thränen“.

${ }^{5}$ Lettre du 23.02.1853 dans Ibid., p. 44 : „Wenn ich dann das lese, bin ich ja bei Euch, wenn Ihr mich aucht nicht seht".

${ }^{6}$ Lettre du 27.12.1854 dans I. Schwarzenberg (éd.), Dokumente, Op. Cit., VI, p. 20 : „Dann bin ich im Geiste bei Euch in der Wohnstube, und vergesse ganz das so eine so unendlich weite Strecke zwischen uns liegt".

${ }^{7}$ Lettre du 30.03.1855 dans I. Schwarzenberg (éd.), Dokumente, Op. Cit., VI, p. 28 : „Meine Gedanken überspringen viel leichter den Raum als meine Briefe". 
lecture de la lettre : «Je suis alors avec vous, et vous me racontez tout ce que je lis ici $»^{1}$. MarieClaire Grassi analyse en ces termes les fondements de la « fiction épistolaire » :

«La lettre se place dans le temps du présent fragile marqué par le sceau de l'attente. Elle se situe entre le passé révolu et le futur attendu, entre la nostalgie de la présence abolie et l'anticipation anxieuse d'un retour. Mais le présent se veut négation de l'absence, abolition des distances géographiques et temporelles, et instaure donc un mode de discours fictionnel $»^{2}$.

L'illusion du dialogue épistolaire est maintenue par l'échange, lui-même ponctué par l'attente de la réponse. «Toute lettre mérite réponse » rappellent les auteurs unanimes des manuels qu'étudie Cécile Dauphin ${ }^{3}$. Répondre relève du code de la politesse mais traduit aussi un rapport au temps spécifique à la correspondance. Contrairement à la communication orale, l'échange peut être à tout moment interrompu, pours des raisons diverses, qui peuvent inquiéter les épistolières. Il est en tout cas toujours différé, selon le temps qu'il faut pour acheminer la lettre et sa réponse. Ainsi, «la lettre bavarde sur la lettre », résume ainsi Danièle Poublan : de celle qui s'écrit, que l'on a reçu ou que l'on attend ${ }^{4}$. Ainsi, Les émigrées évoquent souvent ce temps de l'attente, ce temps suspendu, telle Sophie von Bischhoffshausen, qui écrit :

« Depuis votre chère lettre du 15 octobre de l'année dernière, je n'ai pas encore reçu de nouvelles de vous. A présent, le bateau est au port de Corral depuis le 15 de ce mois avec une caisse pleine de nouveautés, mais je ne peux rien recevoir, parce qu'elle se trouve dans une malle destinée à Geisse, qui a eu la grande obligeance... de la laisser à Valdivia, par conséquent avec la mienne. Qui sait combien de temps encore devrais-je attendre, c'est à devenir folle. $»^{5}$

Lorsque les réponses ne parviennent pas, la rédactrice entre dans un état d'angoisse intense qui génère de longs monologues, en forme de phrases interminables et sans ponctuation. Sophie semble désespérée lorsqu'elle écrit :

«Mes chers parents!

Voilà cinq mois que nous sommes ici et ne pas entendre un mot de vous pendant tout ce temps est terrible pour moi. Deux bateaux de Hambourg, chargés de nouveaux immigrants sont déjà arrivés, et j'espérais que les deux m'amèneraient des nouvelles de vous mes chers, en particulier le dernier, où se trouvaient tant de gens de Cassel. Tous ont reçu des lettres et des nouvelles des leurs de la patrie, et moi ! Non! Pas un seul mot ! [...] Je ne peux dire le chagrin infini et douloureux que me provoque votre silence, jamais vous ne m'avez laissé tant de temps sans nouvelles. L'idée que peut être m'avez-vous oublié ne me vient pas à l'esprit, mais le motif, si ! Votre silence me fait terriblement souffrir ! ${ }^{6}$

\footnotetext{
${ }^{1}$ Lettre du 16.10.1855 dans Ibid., p. 45 : „Als stände ich bei Euch und Ihr erzähltet mir alle, was ich da lese“.

${ }^{2}$ Marie-Claire Grassi, Lire l'épistolaire, Paris, Armand Colin, 2005, p. 6.

${ }^{3}$ C. Dauphin, «Les manuel épistolaires au XIXe siècle », Op. Cit., p. 235.

${ }^{4}$ D. Poublan, «Écriture et rôle social. La place des femmes dans une correspondance familiale au XIX ${ }^{\mathrm{e}}$ siècle » dans Christine Planté (éd.), L'épistolaire, un genre féminin?, Honoré Champion, Paris, 1998, p. 210.

${ }^{5}$ Lettre du 6.02.1855 dans I. Schwarzenberg, Dokumente, Op. Cit., VI, p. 23 : „Seid Eurem lieben Brief vom $15 \mathrm{t}$ October v. J. habe ich ja nichts von Euch gehört, und nun ist das Schiff mit einer Kiste voll Neuigkeiten schon seit den $15 \mathrm{t}$ d. M. in Coral und ich kann nichts erhalten, da es in einer Kiste an Geise ist und der die grosse Gefälligkeit hat ruhig in Valdivia... zu lassen und meine also mit, wer weiss wie lange ich da noch warten muss, es ist zum toll werden."

${ }^{6}$ Lettre du 25.03.1855 dans Ibid., p. 25 : „Mein innig geliebte Eltern ! Fünf Monate sind es nun schon seid wir hier sind, und in der ganzen langen Zeit nicht eine Silbe von Euch zu hören ist ganz schreklich für mich! Zwei Hamburger Schiffe mit Einwanderer sind nun schon eingelaufen, beide begrüsste ich mit der frohen
} 
Abondent ensuite les détails sur son quotidien, ses tâches, la récolte, le soin des maladies et des blessures, et sur toutes les personnes qui constituent le foyer, comme pour combler l'absence et le silence des autres. Les longs passages sur les activités familiales, les événements quotidiens dans la maison et au travail, la description des membres de la famille, du personnel, des voisins, des autres émigrés allemands, des objets, de la décoration de la maison, visent à rendre présente la vie familiale, malgré la distance. Dans cette « description exacte et fidèle de nos activités », selon le mot d'Adelheid Kindermann ${ }^{1}$, c'est aussi la famille qui se reconstitue, dans un sens large. En effet, dans l'économie rurale, la famille est constituée de tous "ceux qui vivaient et travaillaient ensemble [...] qu'ils aient été ou non apparentés par le sang », rappellent Louise Tilly et Joan Scott $^{2}$. Se répète ainsi, dans les lettres, un rituel consistant à donner des nouvelles de chacun de ses membres, en particulier des enfants ${ }^{3}$. En échange, on demande des nouvelles de tous ceux qui sont restés en Allemagne, nommant chaque personne, une par une. Sophie von Bischhoffshausen demande ainsi à sa mère : «S'il te plaît petite mère, réponds-moi très vite et raconte moi tout sur vous et tous les proches et amis, c'est ma seule distraction dans ce séjour si solitaire et monotone, si loin de vous tous, mes chers $»^{4}$. Les salutations finales constituent souvent une longue énumération de noms. «Comme si elles ne se résolvaient pas à la séparation, elles font durer le moment des adieux, multipliant les formules finales » constate ainsi Danièle Poublan au sujet des épistolières ${ }^{5}$. De cette juxtaposition, par dénomination, des êtres absents et présents, renaît la communauté.

\subsubsection{Ces objets de la patrie}

La lettre reçue est aussi perçue par les immigrées comme un «signe de vie », selon le mot de Sophie von Bischhoffshausen ${ }^{6}$. Tous les émigrés et émigrées qui partent à l'âge adulte craignent d'apprendre un jour ou l'autre la mort des parents. Leur lettre se transforme alors en un objet d'amour et un vecteur de souvenir. Antonie Exss confesse qu'elle a relu plusieurs fois la lettre récemment reçue, qu'elle l'embrasse et la caresse ${ }^{7}$. En 1868, elle raconte l'arrivée d'une lettre, après dix ans de silence. Elle est déjà vieille d'un an et est arrivée avec des biens que la famille

Hoffnung dass sie mir irgend eine Kunde von Euch Lieben brächte, besonders das Letzte, auf dem so viele Casselener kamen, und alle Bekannte hatten Briefe und Nachricht von der Ihrigen aus der Heimat nur ich keine Silbe! - sogar Hubenthal den ich aufsuchte versicherte mir kein Wort von Euch gehört zu haben, obgleich er mehrere mal in Wolfsanger gewesen habe er doch Niemand von Euch gesehen; welche unendlich schmerzliche Thränen mich dies Euer Schweigen kostet kann ich nicht sagen, so lange bin ich noch nie ohne Nachricht von Eurem Ergehen gewesen, der Gedanke ih könntet mich vergessen haben, der kommt mir nicht in den Sinn, aber das Warum? Ihr schweigt quält mich so entzetzlich“.

${ }^{1}$ Lettre du 23.02.1853 dans G. Schwarzenberg, Geschichtliche Monatsblätter, Op. Cit., XII, p. 44.

${ }^{2}$ L. A. Tilly, J. W. Scott, Op. Cit., p. 38.

3 Lettres du 10.11.1854, 25.02.1855, 4.09.1855, 16.10.1855, 12.12 .1856 et 11.09 .1857 dans I. Schwarzenberg, Dokumente, Op. Cit., VI, p. 13, 25, 41, 46, 66 et 86.

${ }^{4}$ Lettre du 1.09.1857 dans Ibid., p. 87 : „Bitte liebes Mutterchen schreibe mich recht bald mal wieder und recht viel von Euch und allen Verwandten und Freunden, es ist ja die einzige frohe Abwechslung in meinen so einförmigen einsamen Aufenthalt"“

${ }_{6}^{5}$ D. Poublan, «Écriture et rôle social », Op. cit., p. 210.

${ }^{6}$ Lettre du 16.10.1855 dans I. Schwarzenberg (éd.), Dokumente, Op. Cit., VI, p. 45 : „Lebenzeichen“.

${ }^{7}$ Lettre du 25.12.1852 dans G. Schwarzenberg (éd.), Geschichtliche Monatsblätter, Op. Cit., XII, p. 5. 
Anwandter a fait venir d'Europe ${ }^{1}$. La réception de cette lettre depuis la patrie enclenche une recomposition spontanée de la communauté familiale émigrée. C'est Hugo, un des fils du couple Exss, qui l'a reçue et l'a tout de suite renvoyée à sa mère. Il est prévu qu'il passe le soir même à vingt heures pour la lire. La fille Elizabeth essaie alors de lire la lettre mais l'émotion l'en empêche. «C'est donc Hantelmann qui nous a lu la lettre, mais je n'ai pas tout entendu. Mes oreilles bourdonnaient, et vos portraits, ah, mes chers tendres, je ne faisais que les regarder et pensais, ah si seulement tu pouvais les étreindre une fois tous, mes chers tous $»^{2}$. Antonie a les sens si troublés qu'elle a besoin de sortir prendre l'air, raconte-elle. Elle envisage d'aller chez Adelheid Kindermann le soir même, avec qui elle est parente, pour lui lire la lettre.

Les lettres circulent ainsi de mains en mains, dessinant un espace communautaire relativement large. La rédactrice demande souvent d'envoyer ses lettres aux autres membres de la famille, et confirme qu'elle-même fait passer les lettres de la patrie à d'autres membres de la communauté, telle Sophie von Bischhoffshausen, Adelheid Kindermann ou Antonie Exss ${ }^{3}$. Il faut rappeler ici que l'émigration allemande au Chili s'est faite par «contact», selon la typologie de Georges Dupeux ${ }^{4}$. Il s'agit d'une émigration de village, par aire de solidarité familiale et vicinale. A titre d'exemple, la ville de Cassel, dans la Hesse, est particulièrement touchée par l'émigration au Chili. Dans ce type d'émigration, le rôle des lettres d'émigrants et émigrantes est fondamental, parce que ces dernières peuvent entraîner le recrutement de nouveaux colons ${ }^{5}$. Nombreuses sont celles qui mentionnent ou espèrent l'émigration future des membres de la famille, comme chez Magdalena Barbara Aichele ou Klara Anwandter ${ }^{6}$. D'ailleurs, les lettres de Pauline Metzdorf ont fait l'objet d'un usage public. Écrites en 1851et 1852, elles furent publiées dès 1853 par un journal spécialisé

\footnotetext{
${ }^{1}$ Lettre du 30.10 .1868 dans Ibid., p. 21.

${ }^{2}$ Ibid. : ,So hat uns denn Hantelmann die Briefe vorgelesen, aber ich habe nicht alles gehört ; mir brauste es vor den Ohren, Eure liebn Bilder, ach, wie alle von Euch so theuer, besah ich nur und dachte, könntest du sie nur einmal selbst umarmen, die Lieben alle“.

${ }^{3}$ Lettres de du 9.11.1854 et 28.10.1855 dans I. Schwarzenberg (éd.), Dokumente, Op. Cit., VI, p. 11 et 49, lettre du 18.02.1853 dans G. Schwarzenberg (éd.), Geschichtliche Monatsblätter, Op. Cit., XII, p. 51 et lettre du 25.12.1852 dans Ibid., p. 3. Il serait intéressant de ce point de vue de reconstituer l'itinéraire d'une lettre envoyée depuis le Chili en Allemagne pour rendre compte du réseau social qu'elle couvre.

${ }^{4}$ Georges Dupeux, Op. Cit., p. 4.

${ }^{5}$ Pour preuve, la supercherie qu'aurait mise en place l'intendant Vicente Pérez Rosales: "Para que la recién iniciada labor de colonización no fracasase por las noticias desfavorables que los alemanes desengañados podrían enviar a su patria, Vicente Pérez Rosales hizo una diablura, si de tal puede ser calificada una astucia, emanada de su seguridad de triunfar al fin, contra tanto obstáculo y de sus ferviente entusiasmo por la colonización alemana en bien de Chile. Anuncio una combinación postal para Europa; Como en natural, llovieron grandes cantidades de cartas dirigidas a Alemania y conteniendo frases de desaliento; pero esas cartas no fueron al correo, sino a un arca del señor Pérez Rosales, y como poco después recibiera la noticia del descubrimiento del fácil paso al lago Llanquihue y pudiera notificar a los inmigrantes el pronto viaje al Sur, la irritación y desaliento de estos, como ocurre siempre en el corazón humano, trocase inmediatamente en franca alegría y satisfacción, expresadas en otras nuevas cartas que esta vez fueron al correo y salieron para Alemania" dans Diego Aranda, José María Llarena, Rafael Tejano, La colonia alemana en Chile, Santiago de Chile, Imprenta Claret, 1920, p. 53.

${ }^{6}$ Lettre du 25.02.1855 dans M. B. Aichele, Op. Cit. pp. 1-2 et lettre du 25.06.1850 dans I. Schwarzenberg (éd.), Dokumente, Op. Cit., III, p. 7.
} 
dans l'émigration, l'Allgemeinen Auswanderungs Zeitung ${ }^{1}$. Le journal, édité à Rudolstadt par Günther Fröbel, entre 1846 et 1871, paraissait en période de forte demande trois fois par semaine et dispensait conseils aux candidats à l'émigration et récits d'expériences d'émigrés.

Les émigrés allemands, une fois au Chili, s'orientent vers une même zone de colonisation. Les rives du lac Llanquihue sont ainsi occupées selon la provenance régionale, et des réseaux de solidarité qui fonctionnaient déjà en Allemagne sont ainsi reconstitués. La colonisation de Punta Larga se fait en 1855 par les familles bohémiennes Kuschel, Neumann et Niklitschek. En 1856 arrivent des familles de Saxe, de Silésie et de Hesse et en 1857 de Prusse. Elles entament la colonisation de la rive Est du lac, jusque Quillanto, ainsi que du Nord Est où s'installent les familles Püschel, Konrad, Gerlach, Mandorf, Appel, Willer, Trautmann, Raddatz y Prüschle. A Frutillar, les familles silésiennes Richter, Winkler, Nannig, Kloss, Galle et Witwert, à Los Bajos, les familles Hechenleitner, Dausel, Brugger y Niepel, à la Fabrica, les familles Junkel, Minte etc. ${ }^{2}$. Dans l'émigration de l'Allemagne au Chili, ce sont donc des réseaux communautaires qui interviennent et agissent, et dans une lettre, se transmettent des nouvelles de toute la communauté émigrée au Chili en direction de la communauté restée en Allemagne. Danièle Poublan résume en ces termes cette réalité :

«Au nom unique de l'adresse s'opposent les multiples prénoms appelés par le texte. Très souvent, la formule finale distribue compliments et amitié à toute la maisonnée. Dans le corps même de la lettre, on s'adresse aux uns et aux autres. Le destinataire est chargé des messages oraux. [...].

Les lettres, en général adressées à une seule personne, sont en fait lues, partiellement ou totalement, par plusieurs. Le cercle des lecteurs dépasse la maisonnée, il s'élargit aux membres plus lointains du réseau familial ou amical. Nous seulement les nouvelles sont transmises, mais les lettres elles-mêmes $»^{3}$.

La lettre se convertit ainsi en objet et non plus seulement en texte : objet témoin de vie, objet d'amour mais aussi objet venue de la patrie que l'on caresse et embrasse. La lettre est aussi un morceau de terre natale. A travers elle se transfère alors le lieu physique de la patrie. Cette donnée invite à repenser et redéfinir la territorialité de la Nation. Tous les objets qui viennent d'Allemagne sont autant de lieux du souvenir et du Heimat, la maison/patrie, ce qui explique leur profusion dans les foyers germano-chiliens. Parmi ces objets, les représentations des parents absents, sous formes de portraits, dessins ou photographies, jouent un rôle vectoriel important ${ }^{4}$. Il en est souvent question dans les correspondances. Les émigrés emmènent avec eux des photographies des

1 Allgemeinen Auswanderungs Zeitung, $\mathrm{n}^{\circ} 14,1$. Februar 1853 [en ligne]. Accessible à l'URL : http://zs.thulb.uni-

jena.de/servlets/MCRFileNodeServlet/jportal_derivate_00035503/AWZ_07_1853_Nr014.pdf_[consulté le 24 juin 2008]. La digitalisation avec accès gratuit en ligne du Allgemeinen Auswanderungs Zeitung et de son supplémente Der Pilot est une réalisation des Bibliothéques régionale et universitaire de Thuringe (Thüringer Universitäts- und Landesbibliothek) et des Archives de Turinge (Thüringischen Staatsarchiv) de Rudolstadt. $C f$. annexes.

${ }^{2}$ D. Arranda, J.-M. Llarena, R. Tejano, Op. Cit., pp. 56-57.

${ }^{3}$ D. Poublan, « «Affaires et passions. Des lettres parisiennes au milieu du XIXe siècle » en R. Chartier (dir.), La correspondance, Op. Cit., p. 391.

${ }^{4}$ Cf. M. Perrot, « Pratiques de la mémoire féminine » dans M. Perrot, Les femmes, Op. Cit., pp. 15-16. 
membres de leur famille, et une fois au Chili, en demandent davantage. Sophie von Bischhoffshausen réclame à plusieurs reprises un portrait de sa mère et de son oncle, les seuls manquant à sa collection ${ }^{1}$. Pauline Metzdorf décrit quant à elle la nostalgie qui l'envahit à la réception de photographies familiales : «Merci beaucoup, cher frère Adolph et chère sœur Albertine, pour vos lettres et vos portraits ! Quelle joie ce fut pour moi, combien de souvenirs ont refait surface en regardant l'image $»^{2}$. Les émigrés favorisent aussi la diffusion du daguerréotype puis de la photographie au Chili, très demandeurs en portraits de famille qu'ils composent pour leurs parents d'Allemagne'.

Les photographies sont clairement un moyen de rendre présent les absents et de perpétuer la communauté. Elles fonctionnent aussi comme des objets auxquels la rédactrice peut s'adresser pendant qu'elle écrit : «Sous le miroir, se trouve ta photo, mon Bernhard, avec celle de Trüdchen en dessous» décrit Antonie Exss ${ }^{4}$. Les portraits constituent des repères de l'identité comme lieux du Heimat. Antonie a ainsi aménagé dans sa chambre une sorte de sanctuaire familial de photographies et portraits. Ils sont disposés en forme d'arbre généalogique, autour d'un miroir où chacun peut se regarder, comme pour se positionner dans la communauté familiale ${ }^{5}$. Chez Sophie, ce «sanctuaire » photographique est fantasmé : «Comme je souhaiterais avoir une image de chacun d'entre vous [...] je les disposerai toutes dans ma nouvelle chambre et là dans cette atmosphère chaleureuse, je rêverais que je suis parmi vous » écrit-elle ${ }^{6}$. Sophie rapporte qu'elle utilise souvent les portraits comme vecteur mémoriel. Lorsqu'elle parle de son père à ses enfants, c'est en s'appuyant sur une photographie du grand-père. Or, selon Michelle Perrot, les grandsparents constituent bien, pour chaque génération, «la limite en amont de la mémoire familiale ${ }^{7}$. Le procédé de Sophie semble fonctionner puisque les enfants inventent eux-mêmes, dans leurs jeux, des situations où ils voyagent en Allemagne pour rendre visite aux grands parents ${ }^{8}$. Elle relate également que la petite dernière, Elsa, née au Chili, embrasse les portraits de ses grands-parents et tantes ${ }^{9}$. Ainsi, malgré l'émigration, le lien familial reste vivant sur les trois générations. « Tableaux

\footnotetext{
${ }^{1}$ Lettres du 4.09.1855, 24.04.1857 et 10.11.1857 dans I. Schwarzenberg (éd.), Dokumente, Op. Cit., VI, pp. 41,78 et 89 .

${ }^{2}$ Lettre du 21.02.1852 dans G. Böhm (éd.), Dokumente, Op. Cit., V, p. 43 : „Herzlichen Dank, lieber Bruder Adolph und liebe Schwester Albertine, für Eure Briefe und für Euer Bildniss! Welche Freude war für mich, welche Erinnerungen tauchten in mir auf bei Anschauung des Bildes!“

${ }^{3}$ Sur l'usage de la photographie et du daguerréotype, $c f$. Alain Corbin, «Le secret de l'individu » dans P. Ariès, G. Duby (dir.), Op. Cit., pp. 392-395. Les archives photographiques Emilio Held Winkler recèlent une importante collection de ces «scènes de famille », comme par exemple celles de la famille du Docteur Martin, à Puerto Montt ( $c f$. annexes).

${ }^{4}$ Lettre du 25.12.1852 dans G. Schwarzenberg (éd.), Geschichtliche Monatsblätter, Op. Cit., XII, p. 8 : „Unter dem Spiegel Dein bild, mein Bernhard, mit Trudchens Härchen“

${ }^{3}$ Ibid.

${ }^{6}$ Lettre du 24.04.1857 dans I. Schwarzenberg (éd.), Dokumente, Op. Cit., VI, p. 78 : «Wie sehr wünsche ich mir von jedem von Euch Lieben ein Bild [...], ich würde alle in meine neue Stube hängen und dann in der lieben Umgebung träumen ich wäre zwischen Euch“".

${ }^{7}$ M. Perrot, «La vie de famille » dans P. Ariès, G. Duby (dir.), Op. Cit., p. 156.

${ }^{8}$ Lettre sans date (sans doute juin 1856) dans I. Schwarzenberg (éd.), Dokumente, Op. Cit., VI, p. 60.

${ }^{9}$ Lettre du 26.07.1858 dans Ibid., p. 97.
} 
ou photos : ces galeries d'ancêtres sont un moyen de visualiser le lignage. Représentations, ils sont aussi les moyens d'une mémoire dont le souci s'intensifie au cours d'un siècle évolutionniste qui inscrit sa durée dans l'enchaînement des générations »explique Michelle Perrot ${ }^{1}$. Ainsi, les photographies permettent de reconstituer, ordonner et hiérarchiser la communauté familiale. Les immigrées allemandes au Chili ont le souci constant de rendre vivant, notamment chez les enfants, le souvenir de la communauté familiale et de manière générale, de la patrie.

\subsubsection{Le genre de la nation}

A ce point précis de l'analyse du discours migratoire émerge l'efficacité de la combinaison des concepts de nation, d'émigration et de genre. La famille et la génétique constituent un objet fondamental du discours national - «c'est par la petite patrie qu'on s'attache à la grande » écrivait Rousseau. Autrement dit, c'est à travers l'unité génétique de la famille que se dessine celle de la nation. Or, la conception de la nation est profondément genrée. Léora Auslander et Michelle Zancarini-Fournel soulignent que, traditionnellement, l'État est plutôt du genre masculin tandis que la nation prend une connotation féminine, notamment dans sa symbolique ${ }^{2}$. En Allemagne, Germania représente, à l'image de la Marianne française, une nation dont elle n'est pourtant pas citoyenne. Dans la pratique en effet, la femme ne peut acquérir la nationalité qu'à travers l'homme, en tant qu'épouse ou fille. En allemand, la patrie c'est le Vaterland, le «pays du père ». La famille est donc, à l'image de la structure étatique, centralisée autour de son chef. Par conséquent, remarque Alexandra Lübke, « la biologisation de la famille comme 'unité génétique' la transforme en une structure fondamentale (nationale) soi-disant naturelle de l'unité génétique du Peuple $»^{3}$.

Or, paradoxalement, les théories patriarcales comme libérales accordent à la femme un rôle majeur dans la transmission et l'entretien du sentiment national ${ }^{4}$. Force est de constater que les femmes immigrées sont très attachées à cette mission. Il n'est pas anodin de remarquer que la généalogie germano-chilienne est souvent une affaire de femmes, au premier chef d'entre elles, Ingeborg Schwarzenberg. A l'échelle familiale, ce sont les femmes aussi, souvent, qui retracent l'histoire des ancêtres, des siens comme ceux de son époux, et reconstituent l'arbre généalogique, à l'image de Hélène Biel Linke, épouse Scheel ${ }^{5}$.

L'analyse comparée de la position des immigrés et des immigrées face à la question du changement de nationalité illustre les divergences de rapport de genre à la nation. Patricio Bernedo analyse un

\footnotetext{
${ }^{1}$ M. Perrot, «La vie de famille » dans P. Ariès, G. Duby, (dir.), Op. Cit., p. 169.

${ }^{2}$ L. Auslander et M. Zancarini-Fournel, «Le genre de la nation et le genre de l'État », Clio, 12/2000, Le genre de la nation. Accessible en ligne à l'URL : http://clio.revues.org/document161.html [consulté le 30 avril 2008], s.p.

${ }^{3}$ A. Lübke, Op. Cit. p. 170, voir aussi pp. 67-74: „Die Biologisierung der Familie als 'genetische Einheit' macht sie zur so genannten natürlichen (nationalen) Grundstruktur der ,genetichen Einheit Volks “"

${ }^{4}$ C. Pateman, Op. Cit., p. 43.

${ }^{5} \mathrm{H}$. Scheel, Op. Cit., L'exemplaire transmis par sa petite fille, Gisela Scheel, comporte en première page une généalogie de la famille.
} 
questionnaire du 17 novembre 1850 produit par les quatre-vingt cinq émigrés du «Hermann», arrivés quatre jours plus tôt, en majorité des exilés politiques fuyant l'échec de la révolution de $1848^{1}$. Parmi eux se trouvent soixante-dix hommes dont Karl Anwandter, le porte-parole du groupe, qui remet à l'intendant Pérez Rosales un questionnaire de dix-huit interrogations résumant les préoccupations des émigrés. Les trois premières d'entre elles portent sur les droits politiques, les cinq suivantes sur l'exercice de la religion et de la liberté de penser et les dernières sur l'acquisition de terres. Ces hommes démontrent clairement le souci de s'intégrer comme citoyens dans le nouveau pays et les archives de l'intendance de Valdivia reflètent la constance des demandes de naturalisation, toutes menées par des hommes au nom de leur famille ${ }^{2}$. De manière significative, la disposition des émigrées allemandes à changer de nationalité est pratiquement nulle, comparée à celles des hommes. C'est bien là une formalité administrative dont se chargent les hommes, qui, au-delà de la nationalité, sont surtout intéressés par la citoyenneté et la possibilité de participer à la vie politique locale ${ }^{3}$. Les femmes y trouvent par conséquent moins d'intérêt, exclues qu'elles sont de cette citoyenneté.

\subsection{L'émigration ou la définition du national}

De manière générale, l'émigration entre dans un ensemble d' «expériences de la distance », selon le mot de Carlos Sanhueza, qui favorisent le recul, la réflexion et par conséquent l'élaboration d'une identité nationale et culturelle, collective et individuelle.

\subsubsection{Une communauté nationale imaginée dans la migration}

Analysant les récits de voyageurs allemands au Chili et de voyageurs chiliens en Allemagne au $\mathrm{XIX}^{\mathrm{e}}$ siècle, Sanhueza définit l'identité nationale non dans un sens étatique et essentialiste, mais comme une identité à multiples facettes, résultat d'autoreprésentations changeantes, mobiles et même contradictoires et virtuelles. «Dans ce sens la Nation, plus que de la concevoir comme une réalité objective et objectivable, un ensemble, un catalogue ou une conscience précoce, se recherche en tant que forme de positionnement culturel et historique », explique l’historien chilien ${ }^{4}$.

\footnotetext{
${ }^{1}$ P. Bernedo, Bürgertum und Moderniesierungansätze, Op. Cit., pp. 128-131.

${ }^{2}$ Voir par exemple : Lettre de Karl Anwandter du 10.2.1854 dans AHN, MINT, vol. 328, Op. Cit. et lettre de Manns, Haverbeck, Bischoff, Rudloff, Wenzenl du 5.10.1883dans AHN, MINT, vol. 753, Intendencia de Valdivia. On relèvera la formule devenue fameuse d'Anwandter : «Seremos chilenos honrados y laboriosos como el que mas lo fuere. Unidos a la fila de nuestros compatriotas, defenderemos nuestro país adoptivo contra toda agresión extranjera con la decisión y firmeza del hombre que defiende a su patria, a su familia y a sus intereses ».

${ }^{3}$ J.-P. Blancpain a démontré que les émigrés allemands sont davantage intéressés par la vie politique locale que nationale. Ce sont eux qui fournissent les premiers maires et conseillers au Sud. J.-P. Blancpain, Les Allemands au Chili, Op. Cit., pp. 613-628.

${ }^{4}$ C. Sanhueza, Chilenos en Alemania y alemanes en Chile: viajes y nación en el siglo XIX, Santiago de Chile, Dirección de Bibliotecas, Archivos y Museos, Centro de Investigaciones Diego Barros Arana, LOM Ediciones, 2006p. 21 : "La nación, en este sentido, más que concebirse como una realidad objetiva y
} 
Cette définition se rapproche du concept de «communauté imaginée » de Benedict Anderson, qui démontre que la nation est née avant tout de représentations individuelles et collectives. Elle est une construction sociale et même imaginée puisque l'identification nationale suppose la référence à un groupe abstrait :

«Dans un esprit anthropologique, explique Anderson, je proposerai donc de la nation la définition suivante: une communauté politique imaginaire, et imaginée comme intrinsèquement limitée et souveraine. Elle est imaginaire parce que même les membres de la plus petite des nations ne connaitront jamais la plupart de leur concitoyens : jamais ils ne les croiseront ni n'entendront parler d'eux, bien que dans l'esprit de chacun vive l'image de leur communion ${ }^{1}$.

Ainsi, chez les migrants et migrantes, au moment du départ et de l'éloignement, la patrie peut être repensée, redéfinie, géographiquement, culturellement et symboliquement, comme une «communauté imaginée ». La nation se forge donc aussi dans le discours d'émigration. «L'ingrédient perturbateur et transformateur qu'est le voyage parvient à rendre visibles des aspects qui normalement passent inaperçus dans l'habitat original» constate Carlos Sanhueza ${ }^{2}$. Cela ne veut pas dire que les déplacements antérieurs n'auraient pas généré d'autodéfinition similaire au contact de populations lointaines. Mais au XIX ${ }^{\mathrm{e}}$ siècle, note l'historien chilien, le contexte dans lequel s'inscrivent les voyageurs s'est modifié, puisque la préoccupation principale est devenue la définition de la nation ${ }^{3}$.

L'évolution du discours allemand sur l'émigration au $\mathrm{XIX}^{\mathrm{e}}$ siècle éclaire ce point. Alexandra Lübke note que l'émigration est perçue dans un premier temps comme une trahison de la patrie. C'est pourquoi, dans divers États allemands, sont promulguées des lois visant à la « réguler», comme en Prusse à travers la loi de citoyenneté de 1842 et la loi d'émigration de 1853. Ensuite, l'émigration est considérée comme un «problème national » évoqué notamment à l'assemblée nationale de Francfort en 1848 om elle est déclarée «droit civique » ${ }^{4}$. L'émigration passe ensuite pour un mal nécessaire au rééquilibrage social et économique d'une Nation surpeuplée. Les candidats idéaux sont alors les miséreux, les criminels et les gens de mauvaises mœurs et dans ce cadre, l'émigration est assimilée à un processus de "purification» nationale. Bientôt, la perspective s'inverse et elle devient un élément fondamental de l'élaboration nationale. Elle devient colonisation, assimilée à un projet d'expansion « de l'élément allemand à tous les pays de la terre ». Ainsi, conclut Lübke,

«Emigration et Nation se constituent mutuellement. Parce que c'est à travers l'émigration que l'identité nationale se (re)définit territorialement et culturellement. L'abandon de la

objetivable, un conjunto, un catálogo o conciencia temprana, se indaga en tanto formas de situarse cultural e históricamente".

${ }^{1} \mathrm{~B}$. Anderson, L'imaginaire national. Réflexions sur l'origine et l'essor du nationalisme, Paris, La Découverte, 1996, pp. 18-19.

${ }^{2}$ C. Sanhueza, Chilenos en Alemania, Op. Cit., p. 22 : “el ingrediente perturbador y transformador del viaje logra hacer visibles aspectos que normalmente pasan desapercibidos en el hábitat original".

3 Ibid., p. 23.

${ }^{4}$ A. Lübke, Op. Cit., p. 38. 
Nation permet en même temps de concevoir les frontières spatiales et culturelles d'une nation et la définit dans ses contours $»^{1}$.

Lübke souligne la première le rôle fondamental que jouent les Allemandes émigrées au Chili dans la définition de l'identité nationale et culturelle du groupe. Certes, on ne trouvera pas, dans leur discours, des doctrines ou une idéologie toute faite de la nation, des impositions «par le haut », au sens d'Agulhon, mais il s'agit d'observer les frontières culturelles et symboliques de différenciation qu'elles dessinent au contact avec le lointain et l'étrange(r).

Dans un sens andersonien, Helmut Berding rappelle qu'en Allemagne, à la moitié du XIXe siècle, les différents territoires impériaux, dans leur majorité de taille réduite, sont souvent désignés comme la «patrie » (Vaterland ou Heimat) et génèrent un sentiment d'appartenance collective. La représentation individuelle et identitaire se fonde ainsi sur un espace d'origine et de vie défini ${ }^{2}$. Pourtant, les Allemandes émigrées au Chili mentionnent toutes également, dans leur correspondance, l' «Allemagne » (Deutschland) comme leur «patrie », avant même la réalisation de l'unité par la Prusse de Bismarck. Certaines, telle Adelheid Kindermann, évoquent également l'Europe comme leur terre natale ${ }^{3}$. Ainsi, la rupture avec la patrie démontre aussi la fragilité de la nationalité et de l'identité nationale. Sous le prisme de l'émigration, les contours de la nation, de la terre natale, deviennent flous et on note, à mesure que passe le temps, un élargissement de son territoire « imaginaire », de la région d'origine, par exemple la Hesse, le Brandebourg ou la Silésie, à l'Allemagne voire même à l'Europe. De même, dans les correspondances les plus longues de la première génération, mais surtout dans celles de la deuxième, s'inversent progressivement l'opposition entre un « ici » qui désigne la patrie et un «là-bas » qui désigne l'étranger, le pays d'émigration, comme chez Pauline Metzdorf :

«Comme on aimerait pouvoir être encore une fois là-bas, où l'on a laissé tant d'amis! Tu crois, ma chère sœur, que je vais retourner un jour en Allemagne, mais je ne pense pas, parce que nous sommes vraiment bien ici et pourquoi devrait-on en partir, alors que s'offre à nous et nos enfants un bel avenir ? [...] Ce n'est pas pire qu'en Allemagne, et on peut même penser que c'est beaucoup mieux " ${ }^{4}$.

C'est que le sentiment d'appartenance commune, qui sous-tend le sentiment national, ne se construit par seulement sur un passé partagé, mais aussi sur la sensation d'un avenir commun. Cette double temporalité collective se projette par conséquent spatialement du pays d'émigration vers

\footnotetext{
${ }^{1}$ A. Lübke, Op. Cit., p. 43 : „Auswanderung und Nation konstituieren sich wechselseitig. Denn durch die Auswanderung wird nationale Identität territorial und kulturell (neu) bestimmt. Das Verlassen der Nation lässt gleichzeitig räumliche und kulturelle Grenzen einer Nation denkbar werden und umreisst diese darin gleichzeitig“.

${ }^{2}$ H. Berding, «Staatliche Identität, nationale Integration und politischer Regionalismus », Blätter für deutsche Landesgeschichte, 121, 1985, pp. 371-393.

${ }^{3}$ Lettre du 23.02.1853 dans G. Schwarzenberg (éd.), Geschichtliche Monatsblätter, Op. Cit., XII, p. 48.

${ }^{4}$ Lettre du 21.02.1852 dans G. Bôhm (éd.), Dokumente, Op. Cit., V, p. 43 : "Wie sehr sehnt man sich, noch einmal dort zu sein, wo man so viele Freunde zurückgelassen hat! Du, liebe Schwester, glaubst, dass ich noch einmal wieder nach Deutschland zurückkehren werde, ich glaube dies aber nicht, denn es geht uns hier recht gut, und warum sollten wir wieder fort von hier, wo sich uns und unsern Kindern eine recht gute Zukunft darbietet! [...] Schlechter, wie es in Deutschland ist, ist es hier nicht, und man darf glauben, dass es noch viel besser wird“".
} 
celui d'immigration ${ }^{1}$. «De mon côté, je voulais rentrer en Europe encore l'année dernière, et ne plus revenir pendant deux ans, mais depuis l'année dernière, ca me plait et je suis heureuse ici », confie Antonie Exss' ${ }^{2}$. L'adoption du Chili comme seconde patrie est nettement visible dans les correspondances de la deuxième génération, où l'on parle de la situation politique au Chili de manière très informée, contrairement à la première où les faits sont à peine mentionnés, sauf lorsqu'ils touchent directement la vie des colonies. Dans ses lettres à son amie Marie Rummler, Rosine Held, l'épouse de Julius, décrit les conséquences pour les protestants de l'adoption des lois laïques au Chili, les élections présidentielles de 1891 et ses agitations antérieures ${ }^{3}$. Conjuguée à la perte progressive des parents et proches destinataires, cette adaptation au pays d'accueil explique peut-être la diminution au cours de la deuxième génération de correspondances à destination de l'Allemagne au profit de souvenirs et de lettres internes au Chili, échangées entre les différentes branches d'une même famille émigrée, comme chez les Konrad ou les Holzapfel ${ }^{4}$. Ainsi, les lettres de Marie Püschel, épouse Konrad, à ses enfants, dans les années 1890, évoquent tour à tour les événements chiliens et allemands, témoignant d'une identité qui se construit dans l'entre-deux ${ }^{5}$.

\subsubsection{Le positionnement culturel entre nouveau et ancien Heimat}

De manière générale, à travers l'expérience de la migration, la dichotomie entre ancien et nouveau Heimat devient constitutive du discours et de la construction identitaire. Au Chili, la communauté allemande émigrée constitue un repère fondamental, comme le souligne Sophie von Bischhoffhausen lorsqu'elle évoque les nombreuses visites qui se réalisent à l'arrivée ${ }^{6}$. Au sein de cette communauté, la langue remplit une fonction centrale d'identification. Jean-Pierre Blancpain a noté que, s'ils arrivent avec leur parler local, les Allemands et Allemandes émigrés au Chili recherchent vite l'unification autour du Hochdeutsch, le «haut allemand », bien avant même son adoption comme langue nationale suite à l'unification ${ }^{7}$. L'allemand est consubstantiel à la construction de la nation allemande, en même temps qu'il se fixe avec elle. C'est en Hochdeutsche que s'exprime le prussien Johann Fichte dans ses Discours à la Nation allemande au moment de l'occupation française en $1807-1808^{8}$. Ainsi, la langue allemande fonctionne comme un repère d'identification pour les épistolières des lettres, qui écrivent toutes en cette langue. De fait, le contraste entre langue maternelle et langue étrangère devient un support de construction de l'unité ethnique et de l'identité culturelle du groupe. «Les gens sont très bons et aimables, dommage que je ne puisse encore pas parler avec eux, j'ai vraiment du mal à apprendre la langue, je parle très

\footnotetext{
${ }^{1}$ A. Lübke, Op. Cit., p. 64.

${ }^{2}$ Lettre du 23.02.1853 dans G. Schwarzenberg (éd.), Geschichtliche Monatsblätter, Op. Cit., XII, p. 49.

${ }^{3}$ Lettres du 17.08.1890, 14.11.1890 et 04.1891 dans R. Held, Op. Cit., pp. 129, 132 et 142

${ }^{4}$ C'est le cas dans la famille Konrad, $c f$. K. Konrad, Op. Cit. ou encoré dans la famille Holzapfel, $c f$. Epistolario Holzapfel, Archivo del museo histórico e antropológico Maurice van de Maele, Valdivia, Chili.

5 Ibid., p. 37.

${ }^{6}$ Lettre du 9.11.1854 dans I. Schwarzenberg (éd.), Dokumente, Op. Cit., VI, p. 10.

${ }^{7}$ J.-P. Blancpain, Les Allemands au Chili, Op. Cit., pp. 564-565.

${ }^{8}$ J. G. Fichte, Reden an die deutsche Nation, Berlin, Realshulbuchhandlung, 1808 (première édition).
} 
peu » confie Pauline Metzdorf ${ }^{1}$. Le fait de comprendre, ou plutôt de ne pas comprendre la langue, est un point de référence central dans le positionnement culturel de celle qui écrit. Il permet de tracer la frontière des communautés. Sophie von Bischhoffshausen évoque le fait que ses quelques connaissances de la langue française l'aident à faire ses courses ${ }^{2}$. Ainsi, la référence à ce qui est «familier», ou «connu» amène à la (re)constitution d'une opposition entre l'Europe et le Nouveau Monde. L'expérience migratoire intercontinentale permet ainsi la constitution de lieu de référence tel que l'Europe, point déjà constaté.

La communauté allemande du Chili, qui s'amplifie au rythme des arrivées, constitue un réservoir de références identitaires permanent. Elle permet la construction efficace d'une différenciation puissante entre «nous» et les «autres». Ces différences émergent chez Sophie von Bischhoffshausen, particulièrement au moment des fêtes de fin d'année :

«Ce n'est, mes chers parents, que le premier Noël dans le pays étranger, si loin, si loin de vous mes chers, ah! Et quelle différence entre autrefois et maintenant ! [...], ah, tout, tout est si différent de chez vous, et c'est très difficile de s'y habituer, je n'aurais presque pas pu m'imaginer que je pourrais installer un arbre de Noël, mais Monsieur Röhner avait repéré un très joli myrte en fleurs et moi j'avais cuisiné les sucreries traditionnelles, les noix dorées qui manquaient ont été remplacées par des fleurs des plus belles couleurs, si bien que notre arbre arborait les plus belles couleurs, il ne manquait que les bougies alors nous en avons en forme d'étoile autour et à l'intérieur de l'arbre, il était tellement beau, comme jamais un arbre de Noël ne le fut en Allemagne. [...] Ah, mais ce n'était pourtant pas un sapin de Noël comme chez nous, le jour suivant déjà, sa splendeur était fanée, mais quelle différence entre l'Europe et ici! Chez vous ce sont les jours les plus courts et les plus froids, au contraire, ici on dirait constamment que c'est la Pentecôte $»^{3}$.

Les fêtes de fin d'année sont des moments privilégiés où s'exprime la nostalgie provoquée par l'expatriation. Le sapin de Noël, introduit en Allemagne depuis la Suède lors de la Guerre de Trente Ans, s'y est popularisé au début du XIX ${ }^{\mathrm{e}}$ siècle. Autour de lui s'organise une fête familiale et privée, empreinte de traditions bien réglées qui font de l'Allemagne un modèle du Noël en famille ${ }^{4}$. Noël, et en particulier son sapin, constitue ainsi un point de discours récurent, à partir duquel s'élabore un modèle de différenciation général. On ne sait pas bien en effet quel est ce

\footnotetext{
${ }^{1}$ Lettre du 10.05.1851 dans G. Böhm (éd.), Dokumente, Op. Cit., V, p. 26 : „Die Leute sind sehr gut und freundlich, schade nur, dass ich nich nicht mit ihnen sprechen kann. Die Sprache wird mir schwer zu erlernen, ich hann erst sehr wenig“.

${ }^{2}$ Lettre du 10.11.1854 dans I. Schwarzenberg (éd.), Dokumente, Op. Cit., VI, p. 13.

${ }^{3}$ Lettre du 27.12.1854 dans Ibid., p. 15 : „Dies meine geliebten Eltern sind nun die ersten Weihnachten in dem fremden Lande so weit so weit von Euch Geliebten, ach und welcher Unterschied zwischen sonst und jetzt! [...] Ach, es ist ja hier alles alles anders als bei Euch, und es köstet Mühe sich daran zu gewöhnen, so hätte ich es mir kaum möglich gedacht hier einen Christbaum anstecken zu können, Herr Röhner aber hatte einen so schönen blühenden Mirtenbaum ausgemacht, ich das gewöhnlich Zuckerwerk gebacken, die fehlenden Goldnüsse wurden von Blumen der schönsten Farben ersetzt, sodass unser Baum un den schönsten Farben brangte aber nun fehlten die Lichterchen so wir denn Stäerinlichter in und um den Baum banden so sah er denn so schön wie möglich aus, wie nie in Deutschland ein Christbaum gewesen ist [...] ach es war aber doch kein heimatlicher Tannenbaum, schon der anderen Tag verwelkte seine herrlichkeit, welch einen Unterschied aber auch zwischen Europa und hier! Bei Euch die kürzesten Tage, und hier umgekehrt, stets denkt man es müsste Pfingsten sein“.

${ }^{4}$ A. Martin-Fuguier, «Les rites de la vie privée bourgeoise » dans P. Ariès, G. Duby, (dir.), Op. Cit., p. 196. Au Chili au contraire, comme le notent les voyageurs allemands, parmi eux Treutler, il s'agit d'une fête plus collective et célébrée à l'extérieur, notamment sur la place de l'église. Cf. : Paul Treutler, Op. Cit., p. 500.
} 
«tout, tout », qui est si différent : l'absence de la tradition du sapin de Noël au Chili, l'éphémère du myrte décoré ... ou les traditions du pays d'immigration en général ?

Pour faire face à ces différences, les émigrées tentent de reconstituer le plus fidèlement possible un environnement similaire à celui du Heimat. Les descriptions du logis et de son quotidien abondent :

«Ma maisonnée est bien réglée, comme on l'a en Allemagne, annonce fièrement Adelheid : tous les jours, on sert des légumes et de la viande frais, le dimanche, la viande de bœuf enroulée de lard, dorée dans la graisse plutôt que dans le beurre et ensuite cuite à la vapeur dans une casserole bien scellée, c'est un beau morceau de viande, semblable à la viande de cerf. Ensuite on sert aussi du bouillon [...] Pour cuire au four, il y a des pommes de terre, ou du choux ou encore des pommes qui sont très goûteuses ici cuisinées comme cela ${ }^{1}$,

De nombreuses évocations de l'Allemagne ont trait en tout cas à la nourriture, d'où l'importance des traditions culinaires dans les foyers germano-chiliens. La maison fonctionne de manière générale comme un référent identitaire fort sur laquelle on projette sa propre réussite dans le pays d'immigration. Une maison à l' «allemande » est le signe de plusieurs années de difficultés surmontées, mais elle est aussi le témoin d'une fidélité à sa culture et à soi-même. C'est ainsi que Jean-Pierre Blancpain éclaire les enjeux du maintien des traditions : «Il ne s'agit pas de rester fidèle à une Allemagne qui change, écrit-il, mais de perpétuer une tradition pour rester fidèle à soi même $»^{2}$.

L'acquisition d'une «maison à soi » revêt une grande importance pour ces femmes, ainsi que le soin qu'elles y apportent pour l'aménager «à l'allemande». De cette manière, dans l'imaginaire des émigrées allemandes, se forme un archétype de LA maison allemande, sans que l'on sache réellement quelles en sont les caractéristiques ... sans que l'on puisse non plus en trouver un équivalent en Allemagne, où chaque région à son propre type de construction, comme elle a sa propre langue. La description précise de cette «maison allemande » est un passage important dans l'écriture épistolaire. Elle arrive à un moment où la rédactrice estime que sa maison est digne d'être présentée. Sophie von Bischhoffshausen écrit ainsi :

«Maintenant je veux encore écrire quelque chose pendant que tout le monde est au lit. Et d'abord comment nous vivons et sommes installés! Je ne sais pas si je vous ai déjà décrit la maison, mais je le fais encore une fois ! Et dès que je pourrai je vous en enverrai un dessin $»^{3}$.

\footnotetext{
${ }^{1}$ Lettre du 23.03.1853 dans G. Schwarzenberg (éd.), Geschichtliche Monatsblätter, Op. Cit., XII, p. 46: «Meine Haushaltung ist ganz so einrichtet, wie man sie in Deutschland hat; alle Tage frisches Fleisch und Gemüse aller Art, des Sonntags wird das Rindfleisch gespickt mit Speck u. In Rinderfett statt der Butter braun gebraten und dann in einsem feste verschlossenen Topf gedämpft [...] Dann gibt er noch Suppe von Brühe [...] Zum braten gibt es Kartoffel, oder Krautsallat oder Backobst von Aepfeln, die hier als solche sehr schmackhaft sind“".

${ }_{2}^{2}$ J.-P. Blancpain, «La tradition paysanne allemande au Chili », Op. Cit., p. 3.

${ }^{3}$ Lettre du 2.06.1855 dans I. Schwarzenberg (éd.), Dokumente, Op. Cit., VI, pp. 33-34 : „Nun will ich versuchen wenn alle zu Bette sind noch etwas zu schreiben. Vorerst mal wie wir nun leben und eingerichtet sind! Ich weiss nicht habe ich Euch schon das Haus beschrieben oder nicht, so thue es nun noch einmal! Und so blad ich kann schicke ich Euch eine Zeichnung davon“. $C f$. Les plans de maisons en annexe.
} 
En réalité, Sophie avait déjà évoqué la maison, mais jamais avec de tels détails comme ici, où elle poursuit avec la description de la distribution précise des pièces, de leur usage, de leur mobilier et de leur décoration. Les descriptions antérieures étaient plus évasives, se rapportant surtout aux travaux d'agrandissement et de réparation réalisés sur le corps de maison original. Adelheid Kindermann décrit également l'intérieur de son «logement amélioré » avec un «grand miroir» dans le salon, une «horloge au dessus du canapé » et des « rideaux blancs aux fenêtres » ${ }^{1}$. Le poêle qui trône dans tous les salons représente un élément de décoration et de confort essentiel à la demeure allemande, mais aussi un élément de différenciation puissant, puisque absent des maisonnettes chiliennes. Dans la description, les objets et meubles emmenés par les émigrés, déjà connus de leur famille, sont autant de points de repères que l'on restitue dans le nouvel Heimat, de même que les cadeaux envoyés par la famille, au premier chef le poêle. Leur emplacement exact est toujours précisé par rapport aux autres objets, conformant ainsi un univers familial unique et intime qui reconstitue encore une fois la communauté brisée par la migration ${ }^{2}$. Les listes de commandes et de souhaits indiquent également comment se reconstitue le foyer à la manière allemande et permettent de maintenir le lien à la patrie. «Les échanges épistolaires, tissés entre les membres d'une même parentèle, sont un moyen privilégié pour sauvegarder un lien que l'éloignement met en péril. La lettre, régulière, obligée, manifeste à chacun l'existence de ce «front familial » à l'intérieur duquel circulent renseignements, marchandises et services » rappelle à ce sujet Roger Chartier ${ }^{3}$.

Il n'y a pas que la maison qui se transforme en lieu de délimitation et d'identification culturelle. Le jardin aussi est un puissant espace intermédiaire entre l'intérieur et l'extérieur, auquel il signifie toute la vitalité de la culture allemande. La description du jardin est toute aussi nécessaire que celle de la maison: «Dans le petit jardin, que je veux aménager plus tard avec des fleurs comme celui de Neuenrode, fleurissent déjà aussi de très jolies fleurs » raconte Sophie von Bischhoffshausen ${ }^{4}$. Le lieu d'origine de la rédactrice, Neuenrode, le domaine hessois des barons, constitue un modèle pour ce que doit devenir le jardin du nouvel Heimat. L'arrangement du jardin et du potager est l'objet d'échanges permanents entre la rédactrice et sa famille :

«J'aimerais bien avoir aussi des semences de fleurs, en particulier des primevères et des mauves. Ne pourrait-on pas également semer des groseilliers à maquereau et rouge ? [...] Est-ce que mon vieil arbre vit encore ? Comme je le rappelle avec nostalgie et mélancolie, et aussi notre petite cabane $»$ confie-t-elle .

\footnotetext{
${ }^{1}$ Lettre du 23.02.1853 dans G. Schwarzenberg (éd.), Geschichtliche Monatsblätter, Op. Cit., XII, p. 47 : „verbesserte Wohnung“, ,grossen Spiegel“, „Stutzuhr über Sopha“, „,weissen Gardinen an den Fenstern“.

${ }^{2}$ A. Lübke, Op. Cit., p. 217.

${ }^{3}$ R. Chartier, «Entre public et privé : la correspondance, une écriture ordinaire » dans R. Chartier (dir.), La correspondance, Op. Cit., p. 451.

${ }^{4}$ Lettre du 28.09.1855 dans I. Schwarzenberg (éd.), Dokumente, Op. Cit., VI, p. 44 : „In dem kleinen Gärtchen welches ich mur später ganz wie das Neuenröder zu Blumen einrichten will, blühen jetzt auch schöne Blumen“".

${ }^{5}$ Lettre du 28.09.1855 dans I. Schwarzenberg (éd.), Dokumente, Op. Cit., VI, p. 44 : „Auch hätte ich gern etwas Blumen saamen, besonders Auriekel und Malva. Sollte man nicht auch so Stachel- und
} 
Au vu du zèle et du temps qu'elle consacre à son jardin, Sophie a sans doute en réalité surpassé son référent, Neuenrode. Son jardin devient bientôt une réserve miniature de tous les types de fleurs, de légumes et d'arbres fruitiers qu'elle fait importer d'Allemagne. La symbolique de la terre est ici évidente. D'une part ce jardin bien réglé et dressé «à l'allemande » contraste avec le désordre et la sauvagerie de la nature environnante, mais il est aussi un «bout» de terre, un sanctuaire de la nature allemande, ce qui amène de nouveau à repenser la territorialité de la Nation. Grâce à ces jardins, les émigrés avaient l'impression d'être en Allemagne. C'est aussi l'impression des visiteurs, tels que Paul Teutler, qui associe directement l'entretien d'un jardin et la bonne apparence de la maison à une maîtresse de maison allemande ${ }^{1}$.

La description du quotidien correspond, quant à elle, à un autre moment important de «positionnement culturel» dans le nouveau pays. La lettre est comme « un dire féminin du quotidien » selon le mot de Françoise Simonet-Tenant, mais également du domestique ${ }^{2}$. Sophie von Bischhoffshausen évoque d'ailleurs la tache de beurre que vient de réaliser son enfant sur la lettre, ce qui suggère les différents lieux de l'écriture, des pièces intimes et féminines comme la cuisine ou la chambre ${ }^{3}$. Sophie raconte également comment l'ordre de la maisonnée nouvellement installée respecte scrupuleusement une organisation réputée allemande, avec les valeurs qui lui sont attachées :

«C'est vraiment une grande joie de mettre tout à sa place et de s'installer comme si l'on était à la maison, en fait, nous y sommes maintenant, avec quel plaisir je ressens cela chaque jour: depuis un an, nous avons du nous en passer et je sens vraiment que lorsque tout sera dans l'ordre et le calme, je vais me sentir vraiment bien, et que seule votre proximité, mes très chers, me fera défaut $»^{4}$.

La marche qui s'impose dans la maison est réglementée : lever matinal, emploi du temps précis, distribution raisonnable des fonctions au personnel, hygiène quotidienne. La famille fonctionne ainsi comme une communauté autonome et régulée, « un réseau d'accumulation, de savoir-faire et de solidarité », selon le mot de Michelle Perrot, qui par son travail quotidien assure la bonne marche des affaires ${ }^{5}$.

\footnotetext{
Johannisbeeren sähen können? [...] Lebt denn mein alter Baum noch? Wie oft gedenke ich seiner mit Sehsucht und Wehmut, auch unser Hüttchen dabei“".

${ }^{1}$ Paul Treutler, Op. Cit., p. 431.

${ }^{2}$ F. Simonet-Tenant, Op. Cit., p. 241.

${ }^{3}$ Lettre du 2.06.1855 dans I. Schwarzenberg (éd.), Dokumente, Op. Cit., VI, p. 33.

${ }^{4}$ Lettre du 28.05.1855 dans Ibid., p. 32 : „Und es ist eine rechte Freude das so alles an Platz zu bringen und sich's einzurichten als wäre man zu Hause, das sind wir ja nun auch, mit welchem Vergnügen empfinde ich das jeden Tag; seit einem Jahr hat man entberen müssen, und ich fühle recht dass wenn erst alles in Ordnung und Ruhe ist, ich mich recht wöhnlich fühlen werden, wo mir denn nur noch Eure nähe Ihr geliebten Meinigen recht fehlen wird“".

${ }^{5}$ M. Perrot, «Fonctions de la famille » dans P. Ariès, G. Duby (dir.), Op. Cit., p. 96.
} 


\subsubsection{Travail féminin/travail masculin : le positionnement de genre}

Dans le discours des émigrées, le travail apparait comme une valeur fondamentale d'identification. Les mots de Magdalena Barbara Aichele montrent qu'il est constitutif du quotidien et de la représentation que s'en font les émigrés :

« Ici on ne voit rien d'autre pendant les deux premières années que du travail comme vous pouvez l'imaginer, mais ensuite, les choses s'arrangent. [...] Les colons sont bien, bien sûr il y a encore des différences, celui qui ne veut pas travailler doit rester dehors, ils n'arrivent à rien, ici comme en Allemagne ${ }^{1}$.

La rédactrice se positionne ici comme pionnière travailleuse. Le récit des travaux quotidiens et des peines associées est un élément central de la narration des émigrées. Toutes leurs correspondances racontent en détail leurs tâches quotidiennes, dans la maison comme à l'extérieur, décrivent la répartition des travaux entre les différents membres de la famille et les employés, et se focalisent particulièrement sur des activités centrales comme la récolte ou la cuisine, faisant de la maison un réel «système de reproduction $»^{2}$. Le discours sur le travail que tiennent les émigrées est fortement inspiré de la conception bourgeoise occidentale, et en particulier protestante ${ }^{3}$. Traditionnellement, il y a association entre la culture, la civilisation, la masculinité et le travail, et elle est évidente dans le champ discursif de l'émigration. La mise en culture de la région du Sud, «naturelle », « vierge », et donc féminisée, se fait par le civilisateur allemand, mâle. Toutes les correspondances content finalement ce progrès régulier. Le protagoniste de la croissance et du développement est toujours l'homme travailleur. Dans les lettres des émigrées, il est souvent question du travail de l'époux. Adelheid écrit ainsi :

«Kindermann démontre dans tous ses travaux une énorme volonté de fer et de cette manière il vient à bout avec son zèle infatigable des travaux les plus pénibles, et avec la meilleure volonté [...] Malgré la dureté du travail, il se sent très heureux ici. Il travaille sans arrêt toute la semaine, le dimanche il s'accorde du repos. Moi je m'agite du matin au soir pour me faire la plus utile possible et organise tout cela de la manière la plus économique qui soit pour gérer au mieux $»^{4}$.

Tout émigré Allemand est décrit comme travailleur. Magdalena Barbara Aichele, arrivée célibataire au Chili, mentionne brièvement dans une lettre à ses parents son emploi au service de l'Agent d'immigration Pérez Rosales. Elle évoque plus longuement les projets pour la terre qu'elle recevra bientôt du gouvernement. En effet, au milieu de la description de la vie en pays d'immigration surgit la phrase : «Je me suis mariée avec David Roeth de Ruith, le 16 sept. 1854. Mais je suis restée en service ». Elle poursuit par une indication sur ses revenus et son travail, avant

\footnotetext{
${ }^{1}$ Lettre du 28.02.1855 dans M. B. Aichele, Op. Cit., pp. 1-2 : „Hier sieht man in den ersten zwei Jahren nichts anderes vor sich, als viele Arbeit wie Euch denken könnt, aber bekommt man es bessser [...]

${ }^{2}$ A. Lübke, Op. Cit., p. 237.

${ }^{3}$ Ibid., pp. 239-250.

${ }^{4}$ Lettre du 18.02.1853 dans G. Schwarzenberg (éd.), Geschichtliche Monatsblätter, Op. Cit., XII, p. 40 : „Kindermann zeigt bei allen seinen Arbeiten einen ungeheuren festen Willen und auf diese Weise setzt er mit seinem unermüdlichen Fleisse die beschwerlichsten Abeiten dur und hat dabei die beste Laune [...] Es fühlt sich trotz der harten Aribeiten hier sehr glücklich. Die ganze Woche arbeitet er ununterbrochen, des Sonntags gönnt er nur seinem Körper Ruhe. Ich tummle mich von früh bis spät, um aus dem geringsten Nutzen zu ziehen, und richte alles so sparsam wie möglich ein, um so gut wie möglich zu wirtschaften“".
} 
de revenir sur la nouvelle : « N'ayez pas de crainte au sujet de mon mariage. Il a un bon revenu, un thaler par jour et aucun frais. Un charpentier a en fait le meilleur métier ici » ${ }^{1}$. L'artisanat est bien le symbole matériel de la construction, de l'activité et du labeur.

Dans les mots de Magdalena Barbara comme d'Adelheid surgit l'image de l'émigré producteur, zélé et droit, mais aussi de la femme qui lui correspond. En effet, si la colonisation de la région vierge se fait par des hommes vigoureux, ces derniers doivent être accompagnés d'une femme « qui s'agite du matin au soir », pour répondre à la moindre des nécessités familiales. Les manuels de savoir-vivre répètent bien que « la maîtresse de maison est en principe la première levée et la dernière couchée $»^{2}$, et dans le discours des émigrées sur le travail ressortent clairement les conceptions bourgeoises occidentales, qui, en particulier depuis le $\mathrm{XVIII}^{\mathrm{e}}$ siècle, instituent un partage sexuel des tâches : le domaine productif et public pour l'homme, le domaine reproductif et privé pour la femme.

«Les concepts soi-disant naturels de masculinité et féminité sont ainsi le produit d'une évolution historique dans laquelle le travail revêt une fonction centrale, et c'est pourquoi le travail doit aussi être conçu comme une catégorie genrée » explique Alexandra Lübke³.

Au sein de la famille, hommes et femmes ont des tâches spécifiques, dans une répartition conforme à la conception que l'on se fait des corps : l'homme dehors, la femme à l'intérieur, comme «ange gardien du foyer ». Mais c'est bien sur le couple homme travailleur/femme besogneuse que se fonde le projet d'immigration chilien. "Avec l'émigration ou plutôt l'immigration dans le nouvel Heimat et ce qu'implique de coloniser, civiliser et cultiver, les femmes ne sont pas un complément passif, mais bien actif » remarque Lübke ${ }^{4}$. Les émigrées se positionnent ainsi comme des femmes qui travaillent et qui participent activement, on l'a vu, à l'économie familiale. Certes, ces activités restent dans le domaine du domestique, mais celui-ci se projette aussi dans la sphère publique ${ }^{5}$. L' «ange de la famille » du discours bourgeois prend donc ainsi dans le pays d'immigration une autre forme. Antonie Exss raconte l'application qu'elle met, avec toute la famille, à l'administration de la terre, du bétail, des produits de la terre, tandis que certaines tâches lui sont bien spécifiques comme le beurre ou le pain ${ }^{6}$. En effet, dans la description minutieuse de la vie quotidienne domestique, parmi les portraits de la famille, des amis et des connaissances, la rédactrice indique également quelle est sa place : le travail domestique et jardinier, le soin des

\footnotetext{
${ }^{1}$ Lettre du 28.02.18855 dans M.B. Aichele, Op. Cit., p. 2 : „Ich habe mich verheiratet mit David Hoerz von Ruith, den 16. sept. 1854. Ich bin aber in meinen Dienst geblieben, bei Kassier, wo in namen Peres hier war unb bin schon 11 Monat bei ihm. Er war ledig und habe 6 Th per Monat. [...] Ihr dürft nicht erschrecken dass ich geheiratet habe. Er hat einen guten Verdienst, per Tag eine Th. aber kein Kost. Ein Zimmermann hat überhaupt das beste Handwerk hier [...] er wird auch euch an die Hand gehen, wenn ihr seine Eltern wäret“"

${ }^{2}$ A. Martin-Fuguier, Op. Cit., p. 183.

${ }^{3}$ A. Lübke, Op. Cit., p. 227.

4 Ibid., p. 270 : „Mit der Auswanderung beziehungsweise Einwanderung in die neue Heimat und den Implikationen des Kolonisierens, Zivilisierens, Kultivierens werden die Frauen aber nicht zu einem passiven Komplement sonder zu einem tätigen“.

${ }^{5}$ M. Morokvasic, Op. Cit., p. 888.

${ }^{6}$ Lettre du 25.12.1852 dans G. Schwarzenberg (éd.), Geschichtliche Monatsblätter, Op. Cit., XII, pp. 5-9.
} 
enfants, la préoccupation constante pour eux et le mari, l'administration du budget, le soin des maladies etc. Le récit de la vente des produits, de la gestion financière, de la mise en culture et de la tenue du jardin correspond bien à un moment d'identification de la femme émigrée à un travail qu'elle effectue. Adelheid explique :

«J'ai organisé mes travaux ainsi : au lever du soleil je me lève, vers 4 h30 les jours longs, $6 \mathrm{~h}$ les jours courts. Alors je traie ma vache, la bonne a fait du feu et mis à chauffer l'eau du café ; après le café, je donne à manger aux poules et aux cochons, ensuite je me coiffe, je fais mon lit et celui de mon mari ; ensuite je sors la viande et je vais chercher les légumes au jardin en été $»^{1}$.

Les comptes-rendus de travaux de Sophie von Bischhoffshausen sont similaires. Elle se décrit comme une épouse émigrée, zélée et active. Le fait qu'après son mariage Magdalena Barbara continue à travailler démontre, une fois encore, que dans un contexte d'émigration où la situation du marché du travail diffère de celle du pays d'émigration, les femmes trouvent dans le travail une forme d'émancipation, mais aussi qu'elles s'identifient à ce modèle de femmes qui travaille et nourrit sa famille, générant des revenus dans une proportion égale à celle du mari. Ainsi, « le desserrement de l'espace et de ses contraintes introduit un jeu propice à l'affirmation de soi », écrit Michelle Perrot ${ }^{2}$. Or, dans le cas des femmes allemandes, cette affirmation se fait dans le sens d'un renforcement des rôles sexués et selon des modèles traditionnels de vertus féminines que les femmes sont les premières à partager et diffuser, notamment auprès de leur propre fille. Sophie a ainsi à cœur d'associer sa fille Théo aux taches spécifiquement féminines qu'elle réalise ${ }^{3}$. La généalogie féminine est ainsi perpétuée au-delà de la migration. La comparaison avec la mère est fondamentale pour l'épistolière : «Je reste tranquillement avec mes enfants, joue avec eux et leur raconte des histoires, comme ma petite mère le faisait aussi autrefois » écrit Sophie ${ }^{4}$. Bernard Lahire explique, au sujet des femmes, qu' «elles trouvent dans la figure de leur mère - qui généralement écrit elle-même toutes les lettres familiales et amicales et conserve plus volontiers le courrier que son conjoint - une référence immédiate pour construire leur identité, indissociablement sexuelle et scripturaire $»^{5}$.

Les femmes allemandes émigrées au Chili se décrivent finalement comme des archétypes de ce que doit être la femme selon les manuels de conduite. Le Valdivia's Deutsche Zeitung, organe de

\footnotetext{
${ }^{1}$ Lettre du 18.02.1853 dans Ibid., p. 48 : „Meine Arbeiten habe ich so eingeteilt: Mit Sonne-Aufgang wird aufgestanden, in den langen Tagen $41 \frac{1}{2} \mathrm{Uhr}$, in den kurzen gegen 6 Uhr. Dann milche ich meine Kuh, u. das Mädchen hat Feuer angemacht u. Kaffeewasser aufgesetzt, dann werden die Hühner gefüttert u. Schweine, nach diesem Kaffee getrunken, denn die (Haare) gemacht u. Mein u. Meines Mannes Bette; dann gebe ich das Fleisch heraus u. hole, wenn es Sommer ist, das Gemüse aus dem Garten“.

${ }^{2}$ M. Perrot, « Sortir » dans G. Duby, M. Perrot (dir.), Op. Cit., p. 557.

${ }^{3}$ Lettre du 1.10.1859 dans I. Schwarzenberg, Dokumente, Op. Cit., VI, p. 100.

${ }^{4}$ Lettre du 20.08 .1855 dans Ibid., p. 37 : "So bleibe ich ganz ruhig bei meinen Kindern, spiel emit ihnen und erzähle Geschichten wie's einst mein Mutterchen auch gethan“.

${ }^{5}$ B. Lahire, $O p$. Cit., p. 149. En outre, les mots de Sophie révèlent aussi que la patrie abandonnée s'associe à un certain temps de la vie. Se forme en effet une image complètement idéalisée du pays, surtout chez celles qui n'y sont jamais retournées. Elles oublient les moments difficiles pour associer spontanément la patrie au monde de l'enfance et de l'adolescence, lui-même idéalisé.
} 
presse de la communauté germano-chilienne du Sud, est en ce sens le premier à construire et rappeler ce modèle de «la femme allemande » ${ }^{1}$. Dans un article de 1904 sont édictés les «dix commandements de la femme allemande », lui expliquant surtout comment plaire à son époux :

«A l'intention de nos femmes, nous proposons dix commandements dont le suivi permettra d'éviter des désagréments et de favoriser un bien-être confortable dans la maisonnée. 1. Garde-toi bien de la première dispute. 2. N'oublie pas, que tu es mariée à ton époux, que ton époux est un être humain, et que l'être humain a aussi des faiblesses humaines. 3. Ne le tourmente pas continuellement à propos d'argent, mais contente toi de la somme fixée mensuellement. 4. Si ton mari n'a pas de cœur, il a sans doute un estomac. Tu feras bien de t'attirer sa faveur grâce à un plat bien préparé. 5. De temps en temps, pas trop souvent, laisse-lui le dernier mot ; cela le réjouira et ne te causera pas de grande perte. 6. Lis, outre les romans, annonces de naissance, fiançailles et décès, les autres contenus des journaux, instruis-toi des choses qui se passent à l'étranger. Il s'émerveillera de pouvoir parler de politique et d'actualités à la maison, sans avoir à se rendre à la taverne. 7. Sois toujours polie avec lui, souviens toi que tu l'admirais lorsqu'il était ton fiancé - ne le méprise jamais à présent. 8. Dans les moments appropriés, laisse lui savoir plus que toi, cela entretiendra son amour propre et te donne l'avantage, si une fois tu admets ton erreur, de ne pas être tout à fait parfaite. 9. Sois une amie pour ton époux s'il est un homme intelligent ; s'il ne l'est pas, cherche à le gagner comme ami. Supporte-le mais ne le rabaisse pas. 10 . Respecte les parents de ton mari, en particulier sa mère, elle l'a aimé bien avant toi. »

Si le journal estime nécessaire de rappeler à l'ordre les dames germano-chiliennes, c'est sans doute parce qu'à l'époque, celle de la deuxième voire troisième génération, le modèle de « la femme allemande » se perd aussi. Pour la première génération, il y a cependant convergence, selon les termes d'Ana Maria Stuven, entre « voix » et « représentations » de la femme ${ }^{3}$. C'est bien dans le champ domestique que ces femmes trouvent leur honneur, leur indépendance et leur identité culturelle et sexuelle mais également dans leur rôle d'épistolière du quotidien ${ }^{4}$.

A travers les écrits des émigrées émergent donc la construction d'une identité collective mais aussi personnelle. De ce point de vue, la lettre émerge bien «à la croisée de l'individuel et du social »,

\footnotetext{
${ }^{1}$ Nous renvoyons à l'article sur la langue allemande, Valdivia's Deutsche Zeitung, 11.04.1907, p. 1.

${ }^{2}$ Valdivia's Deutsche Zeitung, 07.07.1904, p. 2 :,Zehn Gebete für die Frauen. Für unsere Frauen stellen wie hier zehn Gebete auf, durch deren Befolgung manche Unannehmlichkeit verhütet und das behagliche Wohlbefinden in der Häuslichkeit gefördet werden dürfte. 1. Hüte dich vor dem ersten Streit. 2. Vergiss nicht, dass du an einen Mann verheiratet bist, dass ein Mann ein Mensch ist und dass ein Mensch auch menschliche Schwäche hat. 3. Quäle ihn nicht fortwährend um Geld, sondern siche mit der festgesetzeten Monatsumme auszukommen. 4. Wenn dein Gatte kein Herz haben sollte, so hat er unzweifelhaft einen Magen. Du wirst gut tun, dir durch gut zubereitete Speisen seine Gunst zu erwerben. 5. Dann und wann, nicht zu oft, lasse ihm das letzte Wort; es erfreut ihn und bringt dir keinen Verlust. 6. Lies ausser den Romanen, Geburts, Verlobungs, Todesanzeigen auch den sonstigen Inhalt der Zeitungen und sei über Dinge unterrichtet, die im Auslande passieren. Er wird sich bei Gelegenheit wundern, im Hause über Politik und Tagesereignisse sprechen zu können ohne ins Wirtshaus gehen zu müssen. 7. Seit stets höflich gegen ihn, errinere dich, dass du zu ihm aufsahest, als er dein Bräutigam war - sieh' jetzt nicht auf ihn nieder. 8. In Zwischenpausen lasse ihn auch einmal mehr wissen als du; es wird sein Selbstgefühl erhalten und dir bringt es Vorteil, wenn du einmal zugibst, nicht ganz unfehlbar zu sein. 9. Sei deinem Gaten eine Freundin wenn er ein kluger Mann ist; ist er es nicht, so suche ihn zu deinem Freund zu erheben. Erlebe ihn, aber steige nicht zu ihm nieder. 10. Achte die Verwandten deines Mannes, besonders seine Mutter, sie liebte ihn weit früher als du.,,

${ }^{3}$ Ana Maria Stuven, "Voces y Representaciones Femeninas: Modernidad y Secularización en Chile durante el siglo XIX" dans Centro de Estudios del Desarrollo, Patriotas y Ciudadanos, Santiago: 2003, pp. 65-94.

${ }^{4}$ D. Poublan, «Écriture et rôle social », Op. Cit., p. 215.
} 
selon le mot de Mireille Bossis ${ }^{1}$. La création d'un «soi-même» et d'un «nous » nécessite cependant une contrepartie, qui renforcerait sa propre image.

\subsection{Pays d'immigration/pays d'émigration : limites et frontières de l'identité nationale.}

La migration et le contact avec l'étranger favorisent l'ouverture d'un espace où l'altérité intervient dans la définition de soi-même, tandis que l' "autre » est toujours redéfini dans ses attributions et significations. Ainsi, de la confrontation entre le «propre » et l' «étranger», surgissent des éléments fondamentaux de différenciation dans la constitution de l'identité culturelle $^{2}$. De nombreux préjugés sur l'étranger sont si récurrents qu'ils apparaissent comme des abstractions théoriques ${ }^{3}$. Il existe cependant de grandes divergences, chez une même rédactrice mais également entre elles, entre des descriptions détaillées prétendant à l'objectivité ou au contraire des clichés rapides et faciles à mobiliser. «Fiction romanesque et/ou témoignage véridique: c'est entre ces deux pôles d'attraction que se situe, tant bien que mal, la correspondance » rappelle Mireille Bossis ${ }^{4}$.

\subsubsection{La lettre et ses lecteurs}

Souvent, la description du nouveau se fait par comparaison à ce qui est connu de la rédactrice et de ses destinataires. Il y a recherche permanente des similitudes, sans qu'il n'y ait pas moins étonnement et surprise lorsque quelque chose est « exactement comme à la maison ». Entre ici la notion de 1'«horizon d'attente» (Erwartungshorizont), développée Hans Robert Jauss, dans son esthétique de la réception, qui démontre qu'un texte écrit s'articule avec la société consommatrice et son public lecteur. Jauss explique :

Le texte nouveau évoque pour le lecteur [...] tout un ensemble d'attentes et de règles du jeu avec lesquelles les textes antérieurs l'ont familiarisé et qui, au fil de la lecture, peuvent être modulées, corrigées, modifiées ou simplement reproduites [...] Lorsqu'elle atteint le niveau de l'interprétation, la réception d'un texte présuppose toujours le contexte d'expérience antérieure dans lequel s'inscrit la perception esthétique: le problème de la subjectivité de l'interprétation et du goût chez le lecteur isolé ou dans les différentes catégories de lecteurs ne peut être posé de façon pertinente que si l'on a d'abord reconstitué cet horizon d'une expérience esthétique intersubjective préalable qui fonde toute compréhension individuelle d'un texte et l'effet qu'il produit.» ${ }^{6}$

\footnotetext{
${ }^{1}$ M. Bossis, La lettre à la croisée de l'individuel et du social, Paris, Ed. Kimé, 1992, 254 p.

${ }^{2}$ A. Lübke, Op. Cit., p. 143.

3 C. Gödde, Percepción del "otro" en cartas de inmigrantes alemanes alrededor de 1850, travail de recherche, Pontificia Universidad Católica de Chile, 2000, p. 11.

${ }^{4}$ M. Bossis, «Préface » dans M. Bossis, C ; Porter (dir.), Op. Cit., p. 9.

${ }^{5}$ Lettre du 27.12.1854 dans I. Schwarzenberg (éd.), Dokumente, Op. Cit., VI, p. 18.

${ }^{6}$ H. R. Jauss, Pour une esthétique de la réception, Paris, Gallimard, 1978, p. 51.
} 
Carlos Sanhueza démontre ainsi clairement que les récits de voyage qu'il analyse prétendent répondre à «certaines requêtes sociales et intellectuelles spécifiques : satisfaction de la curiosité quant aux peuples étrangers, connaissance de nouvelles espèces, évaluation de certaines possibilités d'immigration ou d'exploitation des ressources naturelles, la comparaison des systèmes sociaux et politiques $»^{1}$. En bref, à la soif d'exotisme.

Dans les écrits des émigrées interviennent ainsi les représentations mentales déjà en place avant l'arrivée au Chili. Dans leur imaginaire, les textes produits sur le Nouveau Monde depuis sa «découverte» fonctionnent comme autant de référents. Les lettres des émigrées sont une infirmation ou confirmation constante de ces représentations, qui ne sont que des «fables » ou non, selon le mot de Sophie ${ }^{2}$. Cette constatation amène alors à prendre en compte une deuxième notion littéraire, celle de l'intertextualité. «C'est que les marges d'un livre ne sont jamais nettes ni rigoureusement tranchées : par delà le titre, les premières lignes et le point final, par delà sa configuration interne et la forme qui l'autonomise, il est pris dans un système de renvois à d'autres livres, d'autres textes, d'autres phrases : nœud dans un réseau » explique Michel Foucault ${ }^{3}$. Les récits des émigrées fonctionnent en ce sens comme des «nœuds dans un réseau », formant, avec d'autres textes, un tissu discursif à propos du «Nouveau Monde», du «sauvage » et de la « colonisation » du XIX ${ }^{\mathrm{e}}$ siècle.

\subsubsection{Un paradis sur terre}

L'intertextualité est particulièrement prégnante dans les descriptions de la nature. L'Amérique du Sud fascine particulièrement les Allemands, qui, à la suite de Humboldt, y multiplient les voyages d'expédition. Elle devient au XIX ${ }^{\mathrm{e}}$ siècle «l'objet colonial préféré des Allemands », selon le mot d'Alexandra Lübke, exerçant son influence dans les arts comme le théâtre, le ballet, le roman et dans les récits de voyages ${ }^{4}$. Le sous-continent devient, dans sa réinvention, un lieu de projection et d'imagination coloniale, dans un phénomène d' " occidentalisme », équivalent cardinal de l'orientalisme qu'étudie le britannique Edward Saïd ${ }^{5}$. La « redécouverte » scientifique du continent, notamment en géologie, botanique et zoologie, au début du XIX ${ }^{\mathrm{e}}$ siècle, conditionne dans une large mesure le récit de l'émigration européenne. Les textes d'Alexander von Humboldt constituent une référence pour les émigrés, même si Humboldt n'est jamais descendu dans son périple jusqu'au Chili. Selon Mary Pratt, «Humboldt a réinventé l'Amérique du Sud d'abord et surtout comme

\footnotetext{
${ }^{1}$ C. Sanhueza, Chilenos en Alemania, Op. Cit., p. 38 : "Este llena ciertos requerimientos sociales e intelectuales específicos: satisfacción de la curiosidad respecto de pueblos extraños, conocimiento de nuevas especies, evaluación de ciertas posibilidades de inmigración o de explotación de recursos naturales, comparación de sistemas sociales y políticos".

${ }^{2}$ Lettre du 9.11.1854 dans I . Schwarzenberg (éd.), Dokumente, Op. Cit., VI, p. 12.

${ }^{3}$ M. Foucault, Op. Cit., p. 34.

${ }^{4}$ A. Lübke, Op. Cit., p. 113 : „kolonial Lieblingsobjekt der Deutschen“.

${ }^{5}$ E. W. Saïd, Culture et impérialisme, Paris, Fayard, 2000.
} 
nature $»^{1}$. Elle met en évidence trois formes de représentations centrales du sous-continent américain :

«Trois images en particulier, toutes canonisées par les Tableaux de Humboldt, ont contribué à formé la représentation métonymique courante du «nouveau continent » : des forêts tropicales abondantes (l'Amazonie et l'Orénoque), des montagnes enneigées (la Cordillère des Andes et les volcans du Mexique) et les vastes plaines intérieures (les llanos vénézuéliens et la pampa argentine) $»^{2}$.

Le continent apparait dans les Tableaux de la Nature comme une nature vierge, généreuse et abondante, pratiquement déshumanisée. L'insistance de Humboldt sur l'harmonie et les forces cachées relève nettement de l'influence de l'esthétique spiritualiste du Romantisme ${ }^{3}$.

Influencé par Humboldt, Eduard Poeppig est celui qui a redécouvert le Chili. Son récit est publié en 1835 et est connu des émigrés ${ }^{4}$. Ses textes participent à la mise en place à propos de la région australe du mythe d'une nature sauvage, d'une terra virginea destinée à être conquise et fertilisée par l'homme ${ }^{5}$. A travers ces textes, le Chili se fait ainsi connaître de l'Allemagne, et devient un passage obligé du «voyage de formation » (Bildungsreise) autour du monde, que rêve de réaliser tout jeune bourgeois de l'époque Biedermayer ${ }^{6}$. Dans l'ombre de Humboldt et Poeppig, il accueille des Meyen, Tschudi, Wied, Martius, Burmeister, Philippi, Stübel, Reisse, Rugendas, Bellerman, Hildebrandt, Grashof, Gerstäcker ou encore Treutler, autant de scientifiques, voyageurs, artistes ou simples aventuriers qui ont laissé leur description des territoires chiliens, à des degrés divers de fantaisie ${ }^{7}$. A l'imitation de ces récits, les textes des émigrées sont abondants en description du climat et du paysage. Sophie parle souvent des fleurs et dresse régulièrement un bilan pluviométrique. La flore et la faune sont objets de comparaison constante avec ce qui est connu d'Allemagne. Les légumes, par exemple, y sont décrits comme plus gros, mais pas forcément meilleurs ${ }^{8}$. «On a dit aussi qu'il n'y avait pas d'oiseaux chanteurs et que les chiens n'aboyaient plus ici ? Ce ne sont que des fables. C'est juste qu'il n'y pas de rossignol » ajoute Sophie'.

\footnotetext{
${ }^{1}$ M. L. Pratt, Imperial Eyes. Travel writing and Transculturation, London, New York, Routledge, 1992, p. 120 : "Humboldt reinvented South America first and foremost as nature"

${ }^{2}$ Ibid. p. 125 : "Three images in particular, all canonized by Humboldt's Views, combines to form the standard metonymic representation of the 'new continent' : superabundant tropical forests (the Amazon and the Orinoco), snow-capped mountains (the Andean Cordillera and the volcanos of Mexico), and vast interior plains (the venezuelan llanos and the Argentine pampas)"

${ }^{3}$ M. L. Pratt, Op. Cit., p. 124.

${ }^{4}$ Il est évoqué par exemple par Anwandter, qui a lu tous les ouvrages de sciences naturelles, les récits historiques et les carnets de voyage sur le Chili. Des lectures collectives avaient aussi lieu sur le bateau. Cf. J.-P. Blancpain, Les Allemands au Chili, Op. Cit., p. 139 et 232.

${ }^{5}$ On peut observer qu'au Chili se construit une image genrée des marges du pays. Manuel Vicuña, analysant les images du désert d'Atacama, démontre que ce dernier acquière, comme région stérile et dépeuplée, des attributs biologiques relevant de la masculinité, tandis que le Sud, plus précisément la région des lacs et des rivières, est traditionnellement assimilé à la femme. $C f$. M. Vicuña Urrutia, La imagen del desierto de Atacama (XVI-XIX): del espacio de la disuasión al territorio de los desafíos, Santiago, 1995.

${ }^{6}$ C. Sanhueza, Op. Cit., p. $42-59$.

${ }^{7}$ G. Young, The Germans in Chile, Op. Cit., p. 24.

${ }^{8}$ Lettre du 25.03.1855 dans I. Schwarzenberg (éd.), Dokumente, Op. Cit., VI, p. 26.

${ }^{9}$ Lettre du 9.11.1854 dans Ibid., p. 12 : „Es wurde doch noch gesagt, es gäbe keine Singvögel und die Hunde bellten hier nicht mehr? Das sind aber nur Fabeln, freilich haben wir keine Nachtingal“"
} 
Dans les récits d'émigrées, à l'image des récits de Humboldt, Poeppig ou encore Philippi, le nouveau pays est fréquemment associé à un paradis que l'on redécouvre. Sophie von Bischhoffshausen décrit en ces termes son arrivée au Chili et le défilé naturel qui accompagne son arrivée à Coral, l'annexe portuaire de Valdivia :

«Pour l'amour de Dieu, nous y sommes !!! [...] que de fleurs ici ! Toutes les montagnes qui se jettent dans la mer sont couvertes de fleurs des plus belles couleurs! Comme j'aimerais que tu vois cela, c'est indescriptible, lorsque l'on lit un livre, on pense que c'est une fable, mais vous pouvez me croire vraiment, il n'y a rien de plus beau ! Dès le matin nous aperçûmes les montagnes au loin, et nous nous approchions à grande vitesse à la faveur du vent, et bientôt avec joie nous les vîmes couvertes d'arbres si beaux, si remarquables et couverts des plus belles nuances de vert [...] Par un temps printanier des plus beaux nous entrâmes dans le port, cerclé de hautes montagnes comme dans un bassin merveilleux, entouré de jolies petites maisons et habité par d'innombrables oiseaux colorés. Juste devant nous se trouve Coral [...] avec au milieu entre-temps des pommiers, des myrtes et d'autres arbres en fleurs dont l'un de fleurs pourpres, comme des pervenches et l'un même avec des fleurs scintillantes ${ }^{1}$.

Chez Pauline Metzdorf, la description de l'arrivée est similaire :

« Mais si l'on pénètre plus loin dans la forêt vierge, non, mes chers parents, vous ne pouvez pas vous imaginer. Des arbres qui s'élèvent jusqu'aux nuages, sur lesquels s'enroulent des plantes grimpantes avec au bout de précieuses fleurs rouges. Certains endroits sont si recouverts qu'on ne peut y pénétrer. Plus loin dans l'intérieur, le pays doit être encore plus beau et l'on doit moins peiner pour l'éclaircir $»^{2}$.

Ces descriptions laissent ressurgir l'influence des discours sur l'Amérique des temps modernes, et particulièrement de sa découverte, des discours mêlant les références médiévales, antiques et bibliques, en particulier le topos du Locus divinae amoenitatis, du paradis terrestre et de l'âge d'or'. Tout porte à croire que les immigrés seront heureux sur ces terres divines. Sophie décrit son voyage au domaine du Roble comme un voyage vers la «terre promise »:

«Demain, si Dieu le veut bien et si le temps le permet, nous entreprendrons le voyage avec tous les enfants, les chiens, les volailles et le bétail. Ce sera un convoi, comme lorsque les juifs se rendirent sur la terre promise, sauf que, eux, ils ont du traverser le désert, et nous, les montagnes. Je ne sais pas quel est le pire des deux $»^{4}$.

\footnotetext{
${ }^{1}$ Lettre du 27.10.1854 dans Ibid.: „Gott lob sind wir da !!! [...] Was gibt es hier für Blumen! Alle Berge die sich steils ins Meer senken sind mit Blühten von den schönsten Farben bebeckt! Wie wünsche ich Dir den Anblick, es ist nicht zu beschreiben, liest man es im Buche man hält es für eine Fabel, mir könnt ihr fest glauben; es giebt nichts Schöneres! - Schon des Morgens sahen wir die fernen Berge denen wir bei gutem Wind mit rasender Schnelligkeit näherkamen und wir sahen nun mit Freude die so schönen grossartigen mit dem schönsten Grün übersäten Bäume bedeckt [...]. Bei schönsten Frühlingswetter fuhren wir die Hafen, der von hohen Bergen eingeschlossen wie ein wunderschönenes Bassin dalieft, das von kleinen niedrigen Häusern umgeben und von zahllosen bunten Vögeln belebt ist gerad vor uns liegt Coral [...] Mitten zwischen Apfelbäumen, Myrten und anderen blühenden Bäumen wovon einer mit purpur Blüthen, wie das Immergrün, und einer mit eben solchen die leuchtensen sind“".

${ }^{2}$ Lettre du 10.05.1851 dans G. Böhm (éd.), Dokumente, Op. Cit., V, p. 27 : „Kommt man aber hinten in den Urwald, nein liebe Eltern, davon haben Sie keinen Begriff; Bäumen ragen bis in die Wolken, an ihnen wicklen sich Schlingspflanzen mit köstlichen rothen Blumen in die Höhe, auf manchen Stellen ist aber auch so verwachsen, dass man gar nicht eindringen kann. Weiter im Innern soll das Land nicht viel schïner sein und weniger Mühe brauchen zum Reinmachen“.

${ }^{3}$ A. Lübke, Op. Cit., p. 134.

${ }^{4}$ Lettre du 30.03.1855 dans I . Schwarzenberg (éd.), Dokumente, Op. Cit., VI, p. 27 : "Morgen wird es nun wenn es der liebe Gott will und gutes Wetter schikt auf die Reise gehen mit allen Kindern, Hunden, Feder
} 
L'allusion biblique qui se dégage de cet extrait révèle que les Juifs, qui dans d'autres textes et contextes représentent un référent négatif, deviennent ici soudainement une figure d'identification positive ${ }^{1}$. Comme acteurs d'une histoire familière, ils deviennent un point de repère dans le voyage vers l'inconnu. En effet, le pays de colonisation, «éden sud-américain », est décrit comme un lieu imaginaire, inconnu, finalement, comme un non-lieu, une utopie, un «nulle-part » sans retour ${ }^{2}$.

\subsubsection{Les bons sauvages}

Au sein de cette nature abondante, généreuse et vierge, émerge aussi la figure de celui qui l'habite. Un procédé narratif récurrent consiste à souligner le contraste entre la nature et ses habitants. Un extrait de la première lettre de Sophie von Bischhoffshausen, après son arrivée, à sa famille en Hesse, rend compte de manière explicite du lien qui est fait entre la nature et les hommes :

«Autant la nature, elle, est d'une beauté indescriptible et provoque une impression exaltante et agréable, autant les Chiliens indigènes ont l'air repoussants et ridicules. Ils sont sur leur trente-et-un mais ne connaissent pas les souliers, ou les portent en mauvais état. Ainsi, le responsable des douanes ne portait aux pieds que des pantoufles déchirées et son secrétaire allait pieds-nus $»^{3}$.

Sophie décrit cela lorsque le bateau, arrivé à Corral, poursuit son chemin jusqu'à Valdivia. Elle n'a pas encore mis un pied sur terre, et décrit la nature et ses habitants de loin - à plusieurs sens - à destination d'un lecteur déjà connu, en l'occurrence sa famille restée en Europe, elle-même empreinte des représentations traditionnelles du «Nouveau Monde». Sophie répond donc aussi aux attentes du lecteur, à cet «horizon d'attente », et cette rencontre rappelle dans sa description de la nature subjuguante et de l'autochtone une mise en scène déjà connue : celle de l'arrivée des Européens en Amérique, gravée maintes fois par les chroniqueurs. Là encore, comme dans la description paradisiaque des paysages, l'intertextualité surgit. Les émigrées utilisent diverses appellations pour qualifier les résidents du pays : les Ibéro-chiliens ou Chiliens, aussi désignés comme Espagnols, et les indigènes, indiens ou Araucans, ce dernier terme étant beaucoup plus rare $^{4}$. A l'arrivée, cette différenciation est pratiquement absente, et les descriptions se font dans une

und sonstigen Vieh, das wird ein Zug, ähnlich als wie die Juden in's gelobte Lans zogen, nur dass die durch die Wüste und wir über die Berge wandern müssen, noch weiss ich nicht wer's schlimmer hat".

${ }^{1}$ A. Lübke, Op. Cit., p. 173. Sur l'antisémitisme en Allemagne voir H. Berding, Histoire de l'antisémitisme en Allemagne, Editions de la Maison des sciences de l'homme, Paris, 1991, en particulier pp. 63-69 («Les formes de l'antisémitisme rural en Allemagne »). Phénomène ancien, fondé sur une opposition religieuse au sujet de la mort du Christ, l'antisémitisme tend à devenir de plus en plus social au fil des siècles, mais également économique au $\mathrm{XIX}^{\mathrm{e}}$ siècle. Les révoltes rurales de 1819,1830 et 1848 s'expriment systématiquement contre les propriétés juives, au point que Berding considère les actes antijuifs un révélateur des crises économiques.

2 Ibid., p. $123-124$ et 173.

${ }^{3}$ Lettre du 27.10.1854 dans I. Schwarzenberg (éd.), Dokumente, Op. Cit., VI, p. 10 : „So unbeschreiblich schön die Natur ist und so einen erhebenden und freundlichen Eindruck sir macht, so wiederlich und lächerlich sehen die eingeborenen Chilenen aus, Putz ist ihnen alles, aber eine Fussbekleidung kennen sie nicht, oder ist sie schlecht, so hatte der ober steuerbeamte nichts an den Füssen al zerrissenen Pantoffel und sein secretär ging barfuss“.

${ }^{4}$ Sur ce point précis, la transcription et la traduction pose un double problème. Les émigrées utilisent beaucoup le terme «Eingeboren », soit littéralement, le natif, l'autochtone. Dans les traductions à 
perspective générale et homogénéisée. L'extrait de la lettre de Sophie est révélateur des premières impressions à l'arrivée au Chili. Elles s'arrêtent souvent sur les vêtements. Deux thèmes récurrents, l'absence de chaussures et l'attrait des Chiliens pour les vêtements de soie, apparaissent comme une contradiction aux yeux des Allemands, la soie étant synonyme de luxe, tandis que les chaussures font partie de l'équipement de base, remarque Sophie ${ }^{1}$. Le poncho, qui prend toutes les orthographes possibles, représente, dès l'arrivée, un élément de différenciation fondamental. Il incarne l'autre, l'étranger par excellence, même si toutes finissent par reconnaître son utilité contre le climat pluvieux de la région.

La dichotomie entre Vieux Monde civilisé et Nouveau Monde sauvage constitue un élément essentiel dans le processus de différenciation. L'étranger, en contrepoint duquel l'on se définit, n'apparaît pas individualisé mais bien dans un processus de généralisation. «Malgré leur subtilité et leur structure réticulée, les formes culturelles intégrantes qui traitent de contextes périphériques non européens sont donc, quant aux «indigènes », très nettement idéologiques et sélectives »² commente à ce sujet Edward Saïd. Un mois après son arrivée au Chili, Sophie commence à différencier les Chiliens des indiens, les Huilliches, tribu de Mapuches, dressant une description contrastée :

« Nous visitons le pays et les gens. Le premier est merveilleux mais les seconds beaucoup moins. Les Chiliens ressemblent à des juifs, parmi lesquels se trouvent quelques vraies beautés remarquables, en revanche les indiens sont aussi hideux que la nuit, ils ont des corps petits et trapus, avec des têtes grandes et grosses, autour de laquelle pend une longue et épaisse chevelure noire comme le charbon, attachée par un bandeau sur le front. Les hommes lient souvent un foulard sur leur front et laissent pendre la queue dans la nuque. Les femmes portent un bandeau brodé de perles, dont les bouts sont ornés de multiples pendentifs, comme par exemple des sortes de dés à coudre, qui pendent derrière les oreilles. Cela ressemble à une peau de pis de vache qui est placée sur la tête comme un bonnet, dont les quatre tiges restent en l'air comme des cornes, c'est leur plus grande tenue. Chaque femme porte un foulard, non pas comme chez nous en triangle, mais entièrement déplié et épinglé avec une aiguille d'une longueur d'une demi aune avec un bouton aussi gros qu'une belle pomme. Enfin pour le bas elles ne portent qu'un bout de tissu qu'elles lient bien à plat sur les hanches avec un bandeau, c'est le seul vêtement, en fait, le haut du corps n'est pas couvert ${ }^{3}$.

l'espagnol, le terme a été souvent traduit par « indigenas », soit l'indigène, en l'occurrence ici les mapuches, quand peut-être il évoque tout simplement les Chiliens en général.

${ }^{1}$ Lettre du 27.10.1854 dans I . Schwarzenberg (éd.), Dokumente, Op. Cit., VI, p. 10.

${ }^{2}$ E. Saïd, Op. Cit., p. 244.

${ }^{3}$ Lettre du 27.12.1854 dans I. Schwarzenberg (éd.), Dokumente, Op. Cit., VI, p. 17 : "Wir besuchen Land und Leute. Ersteres ist wunderschön Letzteres aber weit minder. Die Chilenen sehen aus wie Juden, unter denen es einige rechte picante Schönheiten giebt aber die Indier sind so hässlich wie die Nacht, kurze gedrungenen Gestalten mit breiten dicken Köpfen um die die langen dicken kohlschwarzen Haare ganz schlicht herum hängen mit eine Banden über die Stirn zusammen gebunden oder die Männer meist ein Tuch über die Stirn gebunden und die Zipfel im Nachen hängen, die Frauen haben das Band mit Perlen gestickt und die Enden mit allerlei Zierath behängt wie z. B. ein Portion Fingerhüte wo hinter jedem Ohr ein Ende hängt, wie eine Haut von Kuheuter was dann wie eine Kappe auf den Kopf gesetzt wird und die vier Striche stehen wie Hörner in die Höhe das ist der grösste Stat, und das Tuch was eine jede Frau, nicht wie wir dreieck, sondern den langen Weg um hat, wird einer Nadel eine hable Elle lang mit einem Kopf so dick wie ein guter Apfel zugesteckt, drunter raus guckt dann nur ein Stück Zeug was sie ganz glatt mit einem Bande um die Hüften brinden, das ist ihre ganz Bekleidung, der Oberkörper hat weiter nichts an“". 
Visiblement, dans cet extrait, Sophie tente d'établir une observation ethnographique « objective » et s'efforce de faire preuve d'authenticité. On remarquera qu'elle distingue nettement les «Chiliens » des « indiens », et l'ordre du récit est éloquent. Elle respecte parfaitement l'ordre des différents groupes sociaux et ethniques issus de l'histoire coloniale du pays. Elle introduit avec les Chiliens un rapport triangulaire dans lequel l'autre est décrit selon un parallèle avec des étrangers que la rédactrice connaît déjà, à savoir les Juifs. Ici encore, les Juifs reçoivent une connotation positive, et permettent d'inscrire les Chiliens dans un ensemble de références européen, les rapprochant par conséquent indirectement de ce que connaissent la rédactrice et ses destinataires. Dans un second temps sont décrits les indiens. Comme dans de nombreuses autres lettres, ils ne sont pas appelés «Indianer» mais «Indier », ce qui traduit l'influence des discours sur la découverte du Nouveau Monde. A la suite en effet de l'arrivée des Européens en Amérique, les habitants du continent furent dénommés, en allemand, les «Indern». «Indier» est une déformation de ce terme originel qui se retrouve dans des textes plus ou moins scientifiques du $\mathrm{XIX}^{\mathrm{e}}$ siècle, et en particulier dans le récit de voyage d'Eduard Poeppig ${ }^{1}$. Alexandra Lübke remarque que, dans ce tissu discursif que forme l'intertextualité, la reproduction des signifiants n'est jamais identique et fidèle ${ }^{2}$. A travers l'attribut bestial du «pis de vache» et des «cornes», l'indien est représenté comme un sauvage et un barbare. Il apparait dans tous les textes comme orné de parures et de bijoux, mais à moitié nu. La référence constante aux pieds nus, déjà mentionnée, et au déguisement renvoie clairement à l'image de la sauvagerie et de la nudité des peuples primitifs. Ainsi infantilisés, ils correspondent finalement plutôt bien à cette nature vierge, non développée et encore au commencement de la civilisation que décrit la rédactrice ${ }^{3}$. Chez Sophie, la hiérarchisation ethnique propre au Chili est donc rapidement intériorisée. L'autre est donc double et dans une comparaison directe entre les «Indiens » et les «Chiliens », c'est une hiérarchisation entre le moins et le plus civilisé qui se dessine et où l'observatrice se place naturellement au sommet. Plus loin dans la même lettre, les Chiliens sont décrits plus précisément. Sophie introduit même des nuances à l'intérieur même du groupe des «Chiliens » :

«Seuls les Chiliens les plus aisés ont des bas et des chaussures, mais presque tous ont des vêtements de soie, ce que l'on voit dès le petit matin lorsqu'ils vont à la messe, parce qu'ils vont à l'église dans leurs plus beaux habits, un tapis enroulé sur le bras (celui qui en a le fait porter par un enfant), personne ne doit porter de chapeau, qui par ailleurs sont très rares ici, mais tous ont de grands châles de laine sur la tête, noirs, et qui pendent tout simplement jusqu'au sol, et ils sont enroulés sur la tête si bien que l'on voit à peine le visage et qu'il tombe sur toute la silhouette, c'est très joli $»^{4}$.

\footnotetext{
${ }^{1}$ E. Poeppig, Op. Cit., tome 1, chapitres IV et V, en particulier la description des Pehuenche près d'Antuco, pp. 381-405.

A. Lübke, Op. Cit., p. 197.

${ }^{3}$ A. Lübke, Op. Cit, p. 199-200.

${ }^{4}$ Lettre du 27.12.1854 dans I . Schwarzenberg (éd.), Dokumente, Op. Cit., VI, p. 18 : “trümpfe und Schuhe haben nur die allervornehmsten Chilenen, aber seiden Kleider fast alle was man recht des morgens früh wenn sie zu Messe gehen sieht, dann gehen in die schönsten Kleidern einen gewirkten Teppich über den Arm (wer's hat lässt ihn von einem Kinde tragen) in die Kirche, einen Hut die hier überhaupt sehr selten sind, darf
} 
Le contraste entre les indigènes nus et les Chiliens habillés n'échappe pas à Sophie.

Cependant, jamais la dichotomie entre nature merveilleuse et hommes repoussants et hideux ne disparaît. Les hommes lui apparaissent toujours comme des étrangers, à double sens : par rapport à elle, mais aussi par rapport à cette nature, qu'ils ne mériteraient pas.

«On ne peut pas s'imaginer comme c'est ici, parce que, si la nature ne laisse rien à désirer et que l'on se sent vraiment bien dehors à l'air libre, les hommes sont tellement étranges et sinistres que l'on ne se sent pas attiré par eux, imaginez-vous une sorte de visage d'orgueil et d'amour propre comme aucun Allemand ne le porte $\gg$.

Le Chilien est donc orgueilleux, mais aussi lâche, paresseux, fainéant, voleur, criminel, en référence aux actes commis contre les premiers colons. Il est superstitieux aussi. La description du magique ne fait pas défaut. Ana Schmidt fait référence à un sort « araucan » qu'aurait pratiqué une Chilienne sur sa mère atteinte du typhus : « un poulet noir entier fut découpé vivant au milieu de la pièce, et les deux moitiés furent placées et bandées encore bien chaudes sur le buste de la malade $»^{2}$. Au quotidien, les clichés abondent. Les Chiliens vont tous les jours à la messe, ils se lèvent tard, ce qui ne serait pas permis dans la maison de Sophie ${ }^{3}$, ils ne comprennent pas que la richesse vient de l'agriculture et du labeur, et non de l'oisiveté, le personnel mange à la table des maîtres et se sert du café à volonté ${ }^{4}$. Enfin, les Chiliens ne savent pas lire et par conséquent il y a très peu de livres pour s'instruire et se divertir ${ }^{5}$. La description des maisons chiliennes s'établit en opposition nette avec celle de la maison «allemande». Sophie von Bischhoffshausen décrit des cabanes en bois, avec peu de fenêtres, par conséquent peu ventilées, sans poêle, mais avec un feu de charbon au milieu de la pièce, et un trou dans le toit pour laisser échapper la fumée. Elles sont en outre dotées de peu de meubles ${ }^{6}$. Les Chiliens seraient trop paresseux pour se rendre la vie plus confortable, conclut Sophie. Au contraire, les Allemands se donnent les moyens d'embellir et de consolider leur demeure, favorisant le développement d'un marché de l'artisanat inexistant à leur arrivée. Charpentiers, menuisiers et ébénistes allemands sont les auteurs des réalisations architecturales les plus remarquables de la région et sont décrits comme les «porteurs de civilisation» par excellence ${ }^{7}$. A son arrivée, Pauline Metzdorf décrit Valdivia comme une ville « sans commodité », plantée dans un environnement sauvage et inhabité, sans chemin dur, si bien que tout devient boue par temps de pluie. Sophie évoque régulièrement quant à elle l'isolement et

da keine aufsetzen, sondern alle haben grosse wollne Tücher über den Kopf hängen, schwarz und ganz einfach hängen bis auf die Erde, und sind um den Kopf gezogen dass kaum das Gesicht heraus sieht und so um die ganze Figur fällt, was sehr gut aussieht".

${ }^{1}$ Lettre du 10.12.1854 dans Ibid., p. 13 : Dort kann man sich doch gar keinen Begriff machen wie es hier ist den wenn auch die Natur nichts zu wünschen übrig lässt und man sich draussen im freien recht wohl fühlt, so sind doch die Menschen so ganz fremd und unheimlich dass man sich von ihnen nicht angezogen fühlt, denkt Euch eine Art Gesichter von Stolz und Selbstgefühl wie kein Deutscher je hat".

${ }^{2}$ A. Schmidt, Op. Cit., p. 251 : „« ein ganz schwarzes Huhn wurde lebendig in der Mitte zerteilt und die beiden Hälften noch ganz warm der Kranken auf die Brust gebunden“.

${ }^{3}$ Lettre du 6.02.1855 et du 28.05.1855 dans I. Schwarzenberg, Dokumente, Op. Cit., VI, pp. 21 et 34.

${ }^{4}$ Lettre du 28.05.1855 et du 12.12.1856 dans I . Schwarzenberg, Dokumente, Op. Cit., VI, pp. 32 et 67

${ }^{5}$ Lettre du 1.09.1856 dans Ibid., p. 65.

${ }^{6}$ Lettre du 12.07.1855 dans Ibid , p. 36.

${ }^{7}$ A. Lübke, Op. Cit., p. 215. 
les mauvaises communications postales ${ }^{1}$. Une plainte récurrente porte généralement sur l'absence de « culture $»$ et de « civilisation » dans la région, le manque « d'humanité », dit Sophie 2 .

\subsubsection{Une opposition de « races».}

A travers la description dichotomique entre Monde Ancien civilisé, développé, travailleur et propre et Monde Nouveau barbare, paresseux et sale, à travers la confrontation entre un sujet observateur issu du premier et un objet observé relevant du second, c'est bien le concept de «races » qui émerge du discours de l'émigration. De manière générale, le discours que tiennent les Allemands sur les Chiliens est similaire à celui que tiennent ces mêmes Chiliens sur leurs propres autochtones. Le discours chilien des races produit clairement une dépréciation culturelle et biologique des natifs et métis, ce qui se traduit dans la différence d'accès à la citoyenneté. Au niveau politique circule un discours à l'objectif clair et généralisé d' « européanisation de la société chilienne » ${ }^{3}$. Poeppig note, au début des années 1830, cette réalité au sein des couches sociales aisées chiliennes :

«La forte influence que la civilisation européenne exerce sur les hautes classes sociales du Chili est très visible à notre époque, notamment quant aux relations sociales. [...] Seul le Chileno des couches inférieures reste fidèle à ses coutumes nationales », note t-il ${ }^{4}$.

C. Ruiz montre ainsi qu'une idée commune considère ainsi le Chili comme l'un des pays d'Amérique latine les plus «blanchis », biologiquement et culturellement ${ }^{5}$. Ainsi, pour la classe politique de l'époque, le projet d'immigration européenne répond à des préoccupations d'ordre économique mais contient également une dimension ethnique et raciale. Dans les discours de l'époque comme dans l'historiographie moderne chilienne, l'immigration est sans cesse valorisée comme un processus-clé de la seconde moitié du XIX ${ }^{\mathrm{e}}$ siècle, alors qu'elle n'en est pas une caractéristique exclusive. En outre, par immigration s'entend un certain type d'immigration, à savoir européenne. En Amérique latine en général, les indigènes, les noirs et les immigrés asiatiques sont classés dans les «races inférieures » tandis que l'européen jouit d'un statut « supérieur », ce qu'illustre l'idéologie brésilienne du «blanchiment» d'une population marquée par le passé esclavagiste. En conséquence, se formule automatiquement l'exclusion des immigrants de tous les autres continents. Dès les années 1840, les immigrés chinois, qui se trouvaient déjà au Nord du Pérou et envisageaient de s'installer au Chili, sont rejetés. Parallèlement, de ce projet est également exclu l'indien, considéré comme barbare et donc incapable de mettre en valeur ces territoires. Après la conquête de la Frontera, de 1860 à 1884, les indiens sont presque anéantis et les

\footnotetext{
${ }^{1}$ Lettres du 2.06.1855, 24.03.1856, 24.04.1857 et 16.04.1858 dans I . Schwarzenberg (éd.), Dokumente, Op. Cit., VI, p. 34, 58, 77, 95.

${ }^{2}$ Lettre du 10.11.1857 dans Ibid., p. 88.

${ }^{3}$ J. Ojeda-Ebert, Op. Cit., pp. 4 et 31.

${ }^{4}$ E. Poeppig, Op. Cit., tome 1, p. 75 : «Sehr sichtbar ist in unsern Zeiten der grosse Einfluss, welchen die europäische Civilisation auf den geselligen Umgang unter den höhern Classen Chiles hat. [...] Nur der Chileno des geringeren Standes ist seinen Nationalsitten treu geblieben »

${ }^{5}$ C. Ruiz Rodriguez, "El mestizaje en Chile. Aspectos ideologicos" dans M. Vovelle (et al.), Historia de las mentalidades. Homenaje a Georges Duby, Santiago, Universidad de Chile, 2000, p. 254.
} 
survivants relégués dans des réserves. Patricio Bernedo conclut que le projet d'immigration chilien fut donc marqué par une double discrimination: contre les non-Européens, et contre les Mapuches ${ }^{1}$.

Le processus d'immigration est donc bien un processus de sélection fondé sur des critères et préjugés raciaux qui définissent l'Européen et en particulier l'Allemand, comme «travailleur », «honnête », «économe ». Ignacio Domeyko, partisan de l'immigration au Chili, affirme en 1850 que :

«L'objectif principal de la colonisation au Chili à travers l'immigration étrangère, ne peut pas être l'augmentation de la population, mais l'éducation pratique, la moralisation du peuple, l'introduction chez les travailleurs de l'ordre domestique, de l'esprit d'épargne, de l'amour du travail, des méthodes pratiques en agriculture, adéquates au tempérament et au sol des provinces du Sud. Enfin, l'inoculation de l'activité propre aux peuples septentrionaux de l'Europe, avec la certitude des avantages qui résultent du croisement des races $»^{2}$.

Le «croisement des races » est abondamment invoqué dans la légitimation de l'immigration

allemande, comme l'expriment ces lignes d'un ouvrage écrit en 1920 et dédié «aux chiliens descendants d'Allemands [...] comme témoignage pratique de consolation en ces temps de peine et d'affliction pour eux $»^{3}$ :

«Le sang hispano-chilien qui coule dans leur veine et leur donne une capacité de compréhension rapide, de vivacité, se trouve amélioré par le sang allemand de leurs ancêtres qui a modéré cette vivacité, l'a disciplinée, qui à la vive intelligence a ajouté le méthodisme sévère et la volonté énergique avec laquelle l'allemand surpasse et parfois avantage la conception rapide de la race hispano-américaine. C'est là la raison de leurs succès, en sciences comme en art, en agriculture comme en commerce, en industrie comme en université. [...] Jusqu'à la race aborigène, criminellement négligée et abrutie par l'élément national, les pauvres Araucans qui vivaient avilis par l'alcool [...] ont été évangélisés par des missionnaires allemands qui se sont imposés le pénible devoir de vivre avec eux, étudier leur langue et conquérir leurs âmes pour Dieu et leur intelligence pour la civilisation et la culture $»^{4}$.

\footnotetext{
${ }^{1}$ P. Bernedo, Bürgertum und Moderniesierungansätze, Op. Cit., p. 67.

2 Domeyko est surtout connu comme le géologue d'origine polonaise qui contribua au développement de l'exploitation minière au Chili. Cf. Ignacio Domeyko, Memoria sobre la colonizacion de Chile, Santiago, Impr. Julio Belén y Ca., 1850, p. 5: "el objeto, pues, principal de la colonización en Chile, mediante la inmigración extranjera, no puede ser el aumento numérico de la población, sino la educación práctica, la moralización del pueblo, la introducción entre la gente trabajadora del orden domestico, del espíritu de economía, del amor al trabajo, de los métodos prácticos en la agricultura, adecuados al temperamento y el suelo de las provincias del sur: en fin, la inoculación de aquella actividad propia de los pueblos septentrionales de Europa y el asegurar las ventajas que resultan del cruzamiento de las razas".

${ }^{3}$ Les auteurs se réfèrent à la perte de la première guerre mondiale et aux difficultés économiques que connait alors l'Allemagne. $C f$. Diego Arranda (et al.) Op. Cit., p. VIII : "A los chilenos descendientes de alemanas, ofrendamos esta obra, como práctico testimonio de consuelo en estos tiempos para ellos de pena y aflicción".

${ }^{4}$ Ibid., p. 3-5 : "La sangre hispano-chilena que llevan en sus venas y que los hace de comprensión rápida, de su vivacidad, hallase mejorada por la sangre alemana de sus progenitores que ha templado esa vivacidad, que le ha disciplinado, que a la despierta inteligencia ha añadido el severo metodismo y la enérgica voluntad con que el alemán supera, y a veces aventaja, a la rápida concepción de la raza hispano-americana. He ahí la razón de sus triunfos, así en la ciencia como en el arte, en la agricultura como en el comercio, en la industria como en la cátedra $[\ldots]$ Hasta la raza aborigen, criminalmente desatendida y embrutecida por el elemento nacional, los pobres araucanos que vivían envilecidos por el alcohol [...] han sido evangélicamente atendidos
} 
Edward Saïd repère, au sujet du discours orientaliste, un «éternel retour de certaines figures rhétoriques », de clichés sur les «mentalités », de «l'idée de la 'civilisation' qu'on apporte à des peuples primitifs ou barbares» qui se vérifie dans la représentation des Chiliens ${ }^{1}$. Au Chili s'élabore aussi le mythe du colon allemand «civilisateur », «instructeur », «éducateur » de l' «élément national », qui apparaît de la pire espèce et doit être « vacciné » de ses vices à travers l'acculturation. L'Allemand est un «manuel vivant de labeur, d'esprit domestique et d'hygiène pratique » selon Benjamin Vicuña ${ }^{2}$. La même idée surgit chez Marcial Gonzalez :

«Comment augmenter la population masculine, intelligente, sobre, éduquée, travailleuse et morale dont nous avons tant besoin ? Par un seul moyen uniquement : en la faisant venir de l'extérieur, avec son industrie et civilisation, avec ses habitudes de moralité et d'ordre, avec ses fabriques, ses machines, ses capitaux et surtout, avec son esprit de labeur, qui aura plus d'influence sur l'amélioration de nos peuples que les conseils de tous les libres et les leçons de milliers de maitres. Une bonne émigration, une colonie de gens travailleurs et habiles, serait l'exemple le plus éloquent, le modèle le plus parfait que l'on pourrait proposer comme imitation à nos rotos gauches et paresseux $»^{3}$.

Ainsi, la politique d'immigration chilienne avait nettement pour objectif l'amélioration culturelle, morale et raciale de la Nation ${ }^{4}$. En ce sens, le discours sur l'émigration du lieu d'émigration et le discours sur l'immigration du lieu d'immigration concordent donc parfaitement. Ces voix qui proviennent des deux côtés de l'océan produisent une généalogie de l' "élément allemand »au Chili, qui trouve sa représentation dans la littérature spécialisée dans l'idée d'un Deutschtum chilien. L'émigration allemande au Chili devient ainsi le résultat d'un processus naturellement déterminé et historiquement inévitable, dans une histoire linéaire, orientée vers le développement et le progrès. D'anciennes publications comme Helden der Arbeit de Kurt Bauer ou l'ouvrage commémoratif de la Société scientifique allemande de Santiago, Die deutsche Arbeit in Chile témoignent d'une constante narrative fondamentale: colonisation, civilisation, travail. L'arrivée des Allemands au Chili est toujours associée à l'idée de progrès, que ce soit à Valdivia,

por misioneros alemanes que se impusieron el penoso deber de convivir con ellos, estudiar su lengua y conquistar sus almas para Dios y su inteligencia para la civilización y cultura".

${ }^{1}$ E.Saïd, Op. Cit, p. 11.

${ }^{2}$ B. Vicuña Mackenna, Op. Cit., p. 13 : “cartilla viva de laboriosidad, de espíritu domestico, de higiene practica".

M. Gonzalez, La Europa i la América, o, La emigración europea, en sus relaciones con el engrandecimiento de las repúblicas americanas, Santiago de Chile, Imp. del Progreso, 1848, p. 41 : « ¿Como aumentar la población viril, intelijente, sóbria, educada, laboriosa y moral de que tanto necesitamos? Por une medio solamente - haciéndola venir de fuera, con su industria y civilización, con sus hábitos de moralidad y de orden, con sus fabricas, sus artefactos, sus capitales, y sobretodo, con su espíritu de laboriosidad, que tendrá mas influjo en la mejora de nuestros pueblos que los consejos de todos los libros y las lecciones de millares de maestros; una buena emigración, una colonia de gentes laboriosas y hábiles, seria el ejemplo mas elocuente, el modelo mas perfecto que pudiéramos presentar a la imitación de nuestros inhábiles y perezoso rotos".

${ }^{4}$ Le nationalisme chilien émerge au début du XXe siècle, entraînant un changement d'image du colon étranger, ce qu'illustrent les publications de Tancredo Pinochet Le Brun, La conquista de Chile en el siglo $X X$, Santiago de Chile, Imprenta, Litografía y Encuadernación "La Ilustración”, 1909 ou de Nicolás Palacios, Raza chilena; libro escrito por une chileno y para los chilenos, Imprenta y Litografía alemana de Augusto Schäfer, 1904. Le soutien officiel à l'immigration finit par se suspendre, parallèlement à des mesures législatives qui promeuvent le nationalisme économique. Cf.: R. Coyoumdjian, A. Rebolledo, Op. Cit., p. 122. 
dans la région des lacs, à Valparaiso, à Santiago ou dans le grand Nord minier, non seulement dans les ouvrages germano-chiliens mais également chiliens, anciens comme actuels. A Valdivia, la colonisation allemande est associée au renouveau et à l'âge d'or d'une ville alors en crise dans la première moitié du XIX ${ }^{\mathrm{e} 1}$. Le voyageur José Alonso décrit en 1900 un processus de modernisation capitaliste mené dans toute la région australe et à Valdivia par l'Etat et l'élite germano-chilienne :

«Partout dans la ville se constate ce bien-être, cette aisance propre aux peuples dont les entreprises prospèrent grâce au travail quotidien, patient et à la vertu des anciens ; Travail, épargne, foi, c'est là le secret de la prospérité de Valdivia, c'est là le secret de la force d'expansion de la civilisation allemande $»^{2}$.

Ces quelques lignes résument la teneur du discours colonialiste et en particulier du discours sur l'immigration allemande, où sont mis en avant les «caractéristiques nationales de l'émigré allemand » : l'épargne, le zèle, l'honnêteté. Adelheid Kindermann raconte les changements induits par l'arrivée des Allemands, tant dans l'architecture que dans la mode des Chiliens eux-mêmes ${ }^{3}$ :

«Ce que les Allemands ont apporté comme changement à Valdivia, depuis que nous sommes arrivés, et maintenant, est indescriptible. En un an se sont érigées trois maisons de deux étages, sans compter celles d'un étage, qui sont déjà habitées par des Allemands. Il y a trois ans, les dames chiliennes sont allées au bal sans bas et seulement en botte; maintenant elles portent tous des chapeaux à la mode $»^{4}$.

En même temps, les caractéristiques qui sont prêtées aux Allemands les empêchent de s'intégrer, de se «chiléniser », puisque c'est justement pour ces caractéristiques différentes que le gouvernement chilien a favorisé leur immigration. Les contacts immédiats avec les Chiliens sont faits de méfiance instinctive, d'hostilité, et les préjugés règnent. Au lac Llanquihue, la distance culturelle et sociale et importante. Il n'y a qu'à Valdivia où s'opère un brassage entre les couches les plus aisées des deux groupes ethniques ${ }^{5}$. Dès, 1858, les intendants de Puerto Montt s'inquiètent de la «séparation des races » autour du lac, tout en soulignant la réussite de la colonisation. En 1881, au cours de débats à la chambre des députés précédant la création de l'Agence pour la colonisation en Europe, les doutes surgissent quant à la capacité d'intégration des Allemands. Les Espagnols, et en particulier les Basques, apparaissent comme une bonne alternative, pouvant s'assimiler plus facilement, tandis que les Allemands «forment une espèce de peuple à part ». La même année, un mémoire du ministère des Affaires étrangères révèle que « voilà 25 ou 30 ans que

\footnotetext{
${ }^{1}$ Sur Valdivia, voir P. Bernedo, Bürgertum und Moderniesierungansätz, Op. Cit.; R. Araya, Op. Cit. ; J.-P. Blancpain, Les Allemands au Chili, Op. Cit., pp. 44-69 et 366-448.

${ }^{2}$ J. Alfonso, Un viaje a Valdivia, Op. Cit., p. 17 : "Por todas partes en la ciudad se nota ese bienestar, esa holgura propia de los pueblos en que las industrias florecen al amparo de la diaria, paciente labor y de la honradez de procederes. Trabajo, economía, buena fe, he ahí el secreto de la prosperidad de Valdivia, he ahí el secreto de la fuerza expansiva de la civilización alemana"

${ }^{3}$ Lettre du 18.02.1853 dans G. Schwarzenberg (éd.), Geschichtliche Monatsblätter, Op. Cit., XII, p. 40.

${ }^{4}$ Lettre du 23.02.1853 dans Ibid., p. 50 : "Was die Deutschen für eine Umwandlung hier in Valdivia hervorgebracht haben, seitdem wir angekommen sind, und jetzt, ist nicht zu beschreiben. In einem Jahr sind drei 2stöckige Häuser in Bau begriffen ohne die Einstöckigen, die jetzt schon von Deutschen bewohnt werden. Vor drei Jahren sind die Chilenischen Damen noch ohne Strüpfe blos in Schnürstiefel zum Ball gegangen; jetzt tragen sie schon alle Hüthe nach der Mode aufgeputzt".

${ }^{5}$ J.-P. Blancpain, « La tradition paysanne », Op. Cit., p. 9.
} 
[l'Allemand] s'est établit au sud, et jamais il n'est parvenu à s'assimiler à la race naturelle de notre pays $»^{1}$.

L'opposition de « races » qui se dessine dans les textes des immigrées fonctionne particulièrement bien autour du thème du travail. Le rapport au travail leur permet de tracer la limite des deux «communautés imaginées ». Sophie von Bischhoffshausen écrit ainsi:

«Tout le monde va sans soulier, et sans occupation, l'homme ne travaille que quand il n'a plus de centapo dans la poche, mais la femme ne travaille jamais, on la voit plantée là ou assise devant la porte de sa maison, et on laisse les petits sous la surveillance des grands $»^{2}$.

Sophie est ici empreinte d'un discours occidental sur le travail et dans cette construction identitaire, l'opposition zélé/fainéant est fondamentale. «Les gens ici sont très fainéants. On travaille peu la terre, alors il y a peu de fruits et légumes; nous n'avons pas encore mangé de haricots, de concombre, de salade ou d'autres légumes » constate également Pauline Metzdorf ${ }^{3}$. «Si seulement nous avions quelques pauvres gens d'Allemagne ici qui pourraient nous servir, les Chiliens sont bien trop fainéants!» s'exclame encore Sophie. ${ }^{4}$ Le moment des récoltes est un repère fondamental dans cette comparaison constante, parce que c'est là qu'apparaissent les fruits du travail :

«Cette année nos cultures sont redevenues si bonnes que, à moins qu'un malheur particulier ne vienne, nous ferons une merveilleuse récolte, tandis que les Chiliens ne récolteront que peu encore, voire rien, et ainsi les produits se maintiendront à un bon prix, ce qui est très bon pour nous, ainsi nous reviendrons plus vite $»^{5}$.

L'opposition entre l'Allemand émigré travailleur et l'autochtone chilien paresseux devient si courante qu'elle se transforme en un stéréotype, en «stratégie discursive » fondamentale dans le positionnement des épistolières ${ }^{6}$.

Surtout, la comparaison avec les Chiliennes est fondamentale dans la définition de l'identité culturelle et sexuelle des émigrées. Au moment où elle met au monde sa fille, Sophie von Bischhoffshausen raconte sa détresse : «il n'y a pas de sage-femme ici, à part des Chiliennes dont

\footnotetext{
${ }^{1}$ Cités dans P. S. Martínez, « La inmigración en Chile: el caso de los colonos vascos (1882-1883)» dans Historia 22/1987, Santiago, Pontificia Universidad Católica de Chile, pp. 287-311 : "Forman una especie de pueblo aparte", "Despuès de 25 o 30 años que se halla establecida en el sur, jamás ha llegado a asimilarse a la raza natural de nuestro país".

${ }^{2}$ Lettre du 27.10.1854 dans I . Schwarzenberg (éd.), Dokumente, Op. Cit., VI, p. 10 : „Ohne Schuh geht alles, und ohne Beschäftigung, der Mann arbeitet nur wenn er keine Centapo (eine kleine Münze) in der Tasche hat, die Frau aber niemals, die wir da sahen lagen oder sassen vor ihrer Hausth£ur, und liessen die kleinen Kinder von den grossen warten“. [centavo en réalité]

${ }^{3}$ Lettre du 10.05.1851 dans G. Böhm (éd.), Dokumente, Op. Cit., V, p. 27 :

${ }^{4}$ Lettre (sans date) de 1856 dans I . Schwarzenberg (éd.), Dokumente, Op. Cit., VI, p. 60 :

${ }^{5}$ Lettre du 10.11.1857 dans Ibid., p. 88 : „Dieses Jahr steht unsere Frucht wieder so brillant, dass wenn nicht ein besonderer Unglücksfall kommt, wir eine herrliche Ernte thun, wärhend wieder die Chilenen wenig und ach gar nicht's ernten, so wird denn die Frucht einen guten Preis behalten was wieder sehr gut für uns ist, dann kommen wir noch früher zurück“. L'allusion au retour en Allemagne, comme visite temporaire, est fréquente chez Sophie comme chez les autres émigrées. Dans la majorité des cas, il ne se réalise jamais.

${ }^{6}$ A. Lübke, Op. Cit., p. 231.
} 
l'art me provoque un tel dégoût que je préférerais mourir plutôt que de me livrer à elles $»^{1}$. Concernant les travaux ménagers, notamment la lessive pour laquelle il vaut mieux ne «pas avoir besoin des Chiliennes », elles sont tout aussi incapables ${ }^{2}$. La différenciation au sujet du travail est de ce point de vue intéressante, et en particulier pour ce qui se rapporte aux activités féminines. Les Chiliennes ne correspondent pas du tout au modèle de la femme au foyer efficace et indépendante auquel s'identifient les Allemandes et la comparaison implicite leur sert aussi à se mettre en valeur. Les Chiliennes sont décrites comme inactives, dépendantes et fonctionnent finalement comme un contre-modèle sur lequel se construit l'identité des femmes Allemandes. «Les Chiliennes sont encore plus fainéantes que les hommes et considèrent que c'est une insulte de servir, c'est donc difficile de trouver une bonne, autrement je m'en serai trouvée déjà une $»^{3}$. La contradiction est exemplaire dans ce passage : cette «fainéantise » générale trouve déjà sa place dans le récit avant même qu'une servante chilienne ne soit réellement arrivée, mais déjà sa qualité de «fainéante » la définit. Or, Sophie révèle justement que les Chiliennes refusent de servir... comment pourrait-elle donc juger leur travail si elle n'a jamais pu engager une Chilienne ? Cette présence/absence du fainéant agit finalement presque comme un garde-fou, un rappel constant de leur devoir.

Cependant, à mesure que la rédactrice vit dans le pays, le discours se transforme, et les observations sur le travail s'appliquent également au groupe des Allemandes immigrées. Le discours de Sophie von Bischhoffshausen change de ton lorsqu'elle écrit :

«Les Chiliennes sont horriblement paresseuses, et les Allemandes, lorsqu'elles arrivent ici, croient que les poulets rôtis leur tombent directement du ciel dans la bouche et qu'il n'y a pas besoin de se donner la peine de les plumer, presque la majorité des jeunes gens mène une vie sans effort. Lorsque la nécessité les y pousse alors ils travaillent chez un artisan jusqu'à rassembler assez d'argent pour pouvoir en vivre un temps ${ }^{4}$.

Il s'agit ici d'un discours typique d'une génération sur celle qui la suit, forcément toujours plus fainéante, mais également d'une critique des autres femmes de la communauté germano-chilienne. Dans une autre lettre, Sophie explique encore qu'elle ne voudrait «plus de bonne allemande » parce qu'elles sont «toutes trop fainéantes et insupportables » ${ }^{5}$. Elle commente plus tard à ses destinataires que «les gens ne sont pas plus des anges chez vous», sans doute en référence à des

\footnotetext{
${ }^{1}$ Lettre du 12.07.1855 dans I . Schwarzenberg (éd.), Dokumente, Op. Cit., VI, p. 35 : Eine Hebamme giebt es hier nicht ausser Chileninen vor deren Kunst ich aber einen solchen Abscheu habe dass ich eher sterben mögte als mich denen anvertrauen“.

${ }^{2}$ Lettre du 12.07.1855 dans Ibid., p. 36.

${ }^{3}$ Lettre du 20 janvier 1856 dans Ibid., p. 52: "die Chilenischeninenen sind nocht fauler als die Männer und halten es füt einen schimpf zu dienen, da hält es schwer ein Mädchen zu bekommen, ich würde sonst schon längst mich um eine bemüht haben“".

${ }^{4}$ Lettre du 16.10.1855 dans I . Schwarzenberg (éd.), Dokumente, Op. Cit., VI, p. 49 : „Die Chileninen sind erschreklich faul, und die Deutschen wenn sie her kommen, meinen auch die gebratenen Tauben flögen einem so in den Mund, da mag sich keiner die Mühe geben, sie zu rupfen, fast die Meisten jungen Leute führen ein rechtes schlaraffen Leben, und wenn dann die Noth sie treibt so arbeiten sie bei einem Handwerker so lange bis sie Geld genug haben um wieder eine Zeit lang davon leben zu können, wenige machen's besser".

${ }^{5}$ Lettre du 16.04.1858 dans Ibid., p. 92 : „Nun muss ich mich auch wieder nach einem anderen Mädchen umsehen, was jetzt schon nicht mehr schwer wird zu bekommen, aber von Deutschland verschreibe ich mir nie wieder eines, die Leute sind kaum zu etragen“.
} 
problèmes dont lui a fait part sa mère ${ }^{1}$. La critique envers les hommes allemands n'est pas moins voilée. Elle mentionne le cas d'un vol commis dans les environs par un Allemand. Si les Chiliens sont fainéants, ils sont au moins «faciles à contrôler » et ne volent finalement que «par faim et soif », tandis que viennent de plus en plus d'Allemands, des « canailles », qui commettent «par ici des horreurs » comme « vol et meurtre $»^{2}$. Le positionnement de l'épistolière ne se fait donc non plus seulement par rapport aux Chiliens fainéants mais également par rapport aux autres Allemands. Elle reconstitue finalement un groupe homogénéisé d'autres femmes «paresseuses » qui fonctionne comme un point de répulsion dans son positionnement à la fois culturel et sexuel.

En outre, bien que les modèles de description sur les Chiliens restent actifs, ils ne sont pas exclusivement représentés de manière négative. Dans diverses lettres, ils apparaissent comme «bons », « gentils », « beaux », « aimables », comme chez Pauline Metzdorf ${ }^{3}$. Cependant, toutes ces représentations surgissent dans la description de personnes plutôt aisées. Les «bons autres Chiliens » sont des personnes de rang social intermédiaire voir élevé avec lesquelles la rédactrice entre personnellement en relation, comme par exemple «la très adorable et magnifique » épouse chilienne d'un voisin ${ }^{4}$ ou la «très bonne et gentille» épouse du juge local, que Sophie a choisit comme marraine d'Elisabeth, ce qui suppose des relations d'amitié et de confiance entre les deux couples $^{5}$. La naissance de cet enfant dans le Nouveau Monde est signe d'une union entre les mondes, ce que symbolise le prénom qui lui est donné : «Elisabeth Rosawitta Esmeralda », le premier étant ce lui de la mère de Sophie, les deux autres, de la marraine de l'enfant. En dépit des caractéristiques négatives qui sont prêtées aux Chiliens, les émigrées doivent bien entretenir des relations, au quotidien, pour les affaires. La description n'est donc pas homogène et au milieu du discours stéréotypé sur l'habitant du Nouveau Monde surgissent des brèches ponctuelles. Le positionnement de la rédactrice se réalise donc entre les «indiens », les «mauvais » et le «bons » Chiliens et Chiliennes, les «mauvais » et les «bons » Allemands et Allemandes, permettant ainsi une définition culturelle de la rédactrice elle-même et de son groupe.

\footnotetext{
${ }^{1}$ Lettre du 26.07.1858 dans Ibid., p. 96 : „Allenfals die Leute, doch die sind bei Euch auch keine Engel [...]“.

${ }^{2}$ Lettre du 1.09.1857 dans Ibid., p. 85 : ,Es ist alles fruchtbar teuer und Frucht gar nicht zu haben, was für uns in einer Hinsicht recht schlimm ist, denn wenn die armen Leute nichts zu essen haben so stehlen sie die Vieh, was sie dann schlachten [...] Die Chilenenn sind ein falues und feiges Volk die leicht mit Ordnung zu halten sind, sie stehlen nur aus Hunger oder Durst, dem Drunk sind sie leidenschaftlich ergeben; aber von Raub un Mord hört man hier nie etwas ; leider aber mit der zunehmenden Bevölkerung aus Deutschland kommen auch solche Gräuel hier her, hört man von einem Einbruch, so war ein Deutsch dabei, und vor ein paar Wochen hat sogar ein Deutscher ein geborener Sachse, eine ganze Familie, Mann, Frau, und drei Kinder um 100rt willen ermordet; man schämt sich ordentlich Deutscher zu sein, wie viel Geld verschwendet jährlich die Regierung an die Einwanderer und welche Voerrechte geniessen sie und nun diese Schande, wäre die Provinz nicht so entsetzlich menschenarm, un ein so ergiebiger Strich Landes, sie Wûrden besser thun die Fremden alle wieder fort zu jagen".

${ }^{3}$ Lettre du 10.05.1851 dans G. Böhm (éd.), Dokumente, Op. Cit., tome V, p. 26.

${ }_{5}^{4}$ Lettre du 27.12.1854 dans I . Schwarzenberg (éd.), Dokumente, Op. Cit., tome VI, p. 18.

${ }^{5}$ Lettre du 20.08.1855 dans Ibid., p. 38.
} 
L'étude des lettres des émigrées allemandes au Chili démontre que, outre les discours élitistes, politiques et les «artifices culturels», les éléments non rationnels, affectifs, voire sentimentaux jouent également un rôle dans la construction et la représentation de l'identité nationale. Il existe bien une construction «sensible» de la nation. Cette dernière n'est pas seulement «rationnelle, masculine et élitiste», selon le mot de Carlos Sanhueza ${ }^{1}$. Ainsi, «la construction et l'entretien de l'Etat et du sentiment national sont «genrés », c'est-à-dire qu'il est attribué aux hommes et aux femmes des rôles, des fonctions et des pouvoirs spécifiques. [...] Les hommes sont censés servir l'État dans les domaines politique, militaire et économique : c'est le territoire du rationnel. Les femmes, en revanche, sont censées créer la nation dans les domaines de l'éducation, du domestique et du culturel et c'est l'espace de l'affectif » notent Léora Auslander et Michelle Zancarini-Fournel ${ }^{2}$. Ainsi, les émigrés allemands servent l'idée nationale par leur travail de colon, dans tous les sens du terme, tandis que leurs épouses contribuent à la transmettre et à l'entretenir dans la sphère domestique et ses prolongations dans l'espace public. Par ailleurs, D'autre des éléments souvent négligés pour leur connotation négative comme les préjugés, les peurs et les stéréotypes, sont également des facteurs de création d'identité communautaire, au même titre que les éléments classifiés comme «positifs ». L'étude des lettres des Allemandes au Chili démontre que les préjugés raciaux et les ségrégations jouent aussi leur rôle dans la définition $\mathrm{du}$ «nous ». Ainsi, la dimension constructive de la nation ne doit pas négliger la dimension dialogique et interculturelle que toute conformation nationale suppose.

\footnotetext{
${ }^{1}$ C. Sanhueza, Chilenos en Alemania, Op. Cit., p. 34 : « ¿Es que acaso la nación es sólo racional, masculina e elitaria?».

${ }^{2}$ L. Auslander et M. Zancarini-Fournel, Op. Cit., s.p.
} 


\section{CONCLUSION}

L'objectif premier de cette recherche était de combler un manque historiographique évident. Il était nécessaire d'écrire sur les Allemandes du Chili, parce qu'en «oubliant» l'expérience féminine, l'historiographie se privait d'éléments fondamentaux dans la compréhension du processus d'immigration. Les femmes ont eu une présence active, tant dans la mobilité, l'intégration, la sociabilité que dans le positionnement culturel et identitaire de la communauté germano-chilienne.

Les Allemandes émigrées au Chili dans la seconde moitié du $\mathrm{XIX}^{\mathrm{e}}$ siècle furent peu nombreuses, tout au plus quelques quatre milliers. Alors, leur faible quantité numérique contraste avec la vigueur de leur influence dans ce pays, et en particulier au Sud. Le souci de la conservation des traditions n'est pas unique aux Germano-chiliennes. Le pays a connu d'autres vagues d'immigration, originaires d'Angleterre, de France, d'Italie mais aussi des pays slaves, arabes, de la Chine et du Japon. Ainsi, la colonie française au Chili présente des caractéristiques semblables en termes de constitution d'associations, de presse francophone et d'écoles, notamment avec la fondation de l'Alliance Française de Traiguen, en $1883^{1}$. Mais au Chili, conclue le sociologue Kurt Schobert, aucun groupe ethnique ne s'est mieux maintenu que les émigrés allemands et leurs descendants ${ }^{2}$.

Le maintien des traditions allemandes au Sud du Chili est tellement réussi que, pour tout voyageur allemand, la description des colonies germano-chiliennes devient un passage obligé, attendu par les lecteurs potentiels. «Croquer la vie des Allemands au Chili est devenu tout un procédé qui permettait de souligner des aspects propres - le côte familial, le foyer - qui, souvent, prennent une valeur positive », explique Carlos Sanhueza ${ }^{3}$. A l'image des récits de voyage, sont mis en évidence dans les lettres des immigrées les « qualités » de l'Allemand, telles que le goût du travail, de la vie familiale et intime, mais aussi les apports des immigrés en terme de progrès, dans les domaines de l'architecture, de l'urbanisme, des techniques agricoles, etc. en bref, de civilisation.

Michelle Guillon remarque que «les événements migratoires [...] participent à la construction de l'ethnicité à la fois à l'intérieur et à l'extérieur des groupes ${ }^{4}$. L'ensemble des observations et des commentaires surgis de l'expérience migratoire contribuent en effet à la construction de la «germanité »(Deutschtum). La langue, la maison, l'homme, la femme, le travail

\footnotetext{
${ }^{1}$ J.-P. Blancpain, Francia y los franceses en Chile, Op. Cit., p. 197.

${ }^{2}$ K. Schobert, Op. Cit. pp. 180-181.

${ }^{3}$ C. Sanhueza, Op. Cit., p. 207 : «Caracterizar la vida de los alemanes en Chile llegó a ser todo un recurso que permitía destacar aspectos propios - lo familiar, el hogar-, que, la mayor parte de las veces, eran valorados positivamente».

${ }^{4}$ Michelle Guillon, « Editorial » [en ligne], Revue Européenne des Migrations Internationales, 15-2/1999, Emploi, genre et migration, p. 7-8. Accessible à l'URL : http://remi.revues.org/document2260.html [consulté le 23 mars 2008].
} 
etc. ont toute une manière «allemande » de se concevoir, en référence à une «Allemagne », qui n'est pas encore unifiée ou qui l'est depuis peu et à une «patrie » à laquelle s'identifient des colons qui n'ont pourtant pas la même origine régionale ${ }^{1}$. Les composantes de la nation, qui furent élaborées par les théoriciens du nationalisme allemand au moment de l'inexistence de l'État-nation allemand, s'affirment ainsi pleinement dans les lettres des immigrées ${ }^{2}$. La langue, la culture, la généalogie sont des critères fondamentaux de l'identité des Germano-chiliens, encore aujourd'hui. Ainsi, la «germanité » comme identité nationale et culturelle, se construit aussi dans les colonies allemandes de l'étranger, au Chili, mais aussi au Brésil et ailleurs ${ }^{3}$. Les colons des fronts pionniers américains, en particulier, apparaissent bien comme des «fers de lance » du Deutschtum.

Le géographe Hervé Théry, analysant, à la suite de Pierre Monbeig, les dynamiques d'occupation de l'espace amazonien, remarquait que les fronts pionniers sont des sortes de «palimpsestes » des logiques socio-économiques de «l'avant» (l'espace d'origine), reproduites de manière caricaturale, notamment dans leurs inégalités ${ }^{4}$. De la même manière, on pourrait dire de la communauté germano-chilienne qu'elle est aussi une «caricature» de son «avant», à savoir l'Allemagne, reproduisant à l'extrême et sur la longue durée ce qui lui semble incarner les « caractères » de l'Allemand.

Avec le temps cependant, le discours issu de l'émigration tend aussi à figer la nation dans une image qui ne correspond plus à la réalité du moment. Peter Waldmann résume en ces termes le contraste entre les colonies allemandes et la patrie.

«Adaptation sans assimilation, c'est ainsi que nous pourrions résumer le résultat de notre enquête sur le comportement des immigrants originaires d'Allemagne et de leurs descendants au Chili. Cette formule, cependant, ne définit pas l'idée de la culture allemande à laquelle les immigrants allemands restaient fidèles, ni la manière dont évolua leur relation à l'Allemagne, à sa politique, sa culture et sa société, au fil du temps. Peu ont pu se payer le luxe de retourner en Europe de temps en temps pour se tenir au courant des changements intervenus. Les Germano-chiliens conservaient dans leur majorité une image de leur ancienne patrie qui correspondait à la situation que connaissait l'Allemagne au moment où leurs ancêtres la quittèrent. Se référant pendant plusieurs générations avec une ténacité remarquable à certains usages, normes de conduite et formes sociales, ils ont maintenu un ordre social attesté pour la seconde moitié du XIXe siècle $»^{5}$.

${ }^{1}$ C. Sanhueza, Op. Cit., p. 213.

${ }^{2}$ Cf. W. Ruf, « La conception de la Nation en France et en Allemagne », Hommes \& Migrations, 1223/ janvier-février 2000, Regards croisés France-Allemagne, pp. 12-19.

${ }^{3}$ Nous renvoyons aux études de K. Ilg, Pionniere, Op. Cit., J. Roche, Op. Cit et H. Fröschle, Op. Cit.

${ }^{4} \mathrm{H}$. Théry, Rondônia : mutations d'un territoire fédéral en Amazonie brésilienne, thèse de doctorat sous la direction de Michel Rochefort, Université Paris I Panthéon-Sorbonne, 1976.

${ }^{5}$ P. Waldmann, Op. Cit., p. 445 : “Adaptación sin asimilación, así podríamos resumir el resultado de nuestras observaciones sobre el comportamiento de los inmigrantes provenientes de Alemania y sus descendentes en Chile. Esta formula, sin embargo, no defina cual era la idea de cultura alemana a la que los inmigrantes alemanes guardaban fidelidad, y tampoco en que forma se desarrollo su relación con Alemania, con su política, su cultura y su sociedad en el transcurso del tiempo. Fueron pocos los que podrían permitirse el lujo de regresar a Europa ocasionalmente para así estar al corriente de los cambios acontecidos. La gran parte de los ciudadanos chileno-alemanes conservaba una imagen de su antigua patria que correspondía casi exactamente a las condiciones que prevalecían en Alemania en el momento en que sus antepasados la abandonaron. Aferrándose durante varias generaciones con notable tenacidad a ciertos usos, normas de 
Ce décalage temporel n'échappait pas non plus aux observateurs contemporains. Le voyageur Hugo Kunz de remarquer en 1891 que les us et coutumes des Valdiviens correspondaient à des usages démodés en Allemagne depuis une quarantaine d'années ${ }^{1}$.

L'affirmation d'une identité nationale individuelle et collective ne manifeste pas une réticence à l'intégration, mais simplement un désir de fidélité à soi-même. Paula Zaldivar écrit que «partir, c'est aussi faire mourir les autres, au moins symboliquement, et en même temps, s'exposer au risque de se perdre soi-même $»^{2}$. Toutes les émigrées italiennes qu'elle écoute lui confient que, «à la maison, ils sont tous morts ». Alors, elles ont peur, elles aussi, de «mourir » ${ }^{3}$. Ces figures de «l'entre-deux » que sont les migrants et migrantes s'appuient donc sur la réaffirmation constante de l'identité d'origine pour se retrouver elles-mêmes et en tant que groupe. Marie-Antoinette Hily et Deidre Menteil rappellent ainsi que « les identités culturelles ou ethniques ne témoignent pas d'un repli sur soi, ni d'une simple fidélité aux origines que les membres du groupe se devraient de garder, mais aussi et surtout de la nature des ressources symboliques qui sont mobilisées pour signifier l'existence de ce groupe et de sa culture et pour rallier les générations plus jeunes ${ }^{4}$.

Pierre Bourdieu soulignait le rôle de la femme dans le maintien « du capital symbolique » du groupe familial, et dans le contexte migratoire, la correspondance en est l'un des moyens privilégiés. Bernard Lahire démontre ainsi que «la culture épistolaire familiale est essentiellement une affaire de femmes » et Danièle Poublan confirme cette observation :

«Donner sans cesse des nouvelles est nécessaire pour gérer les affects et les intérêts du groupe familial. Cette tâche indispensable, répétitive, jamais terminée, est souvent l'affaire des femmes. Écrire au quotidien relève, en priorité, de leurs compétences. L'épouse, la sœur, la fille aînée, racontent la vie de la maisonnée, se faisant les porte-parole de leurs proches [...] Elles soulignent leur rôle d'intermédiaires, leur place 'd'entre-deux' dans la communication $»^{5}$.

La correspondance n'est pas qu'une affaire de femmes. Les hommes écrivent aussi, mais ils n'écrivent pas les mêmes choses, et sans doute poussés par des intentions différentes. La description du quotidien familial reste bien l'apanage des correspondances féminines. Ces «petites choses de la vie » couchées sur papier permettent concrètement de maintenir le lien affectif à la famille, à la patrie. Elles donnent également des indications sur le positionnement culturel de ces femmes en contexte de migration. L'étude de l'expérience des Allemandes du Chili montre que, à travers l'expérience de la migration, les relations de genre se redéfinissent dans le quotidien. En

conducta y formas sociales, mantuvieron un orden social que se había valido en la segundo mita del siglo diecinueve".

${ }^{1}$ H. Kunz, Op. Cit., p. 586.

${ }^{2}$ P. Zaldivar, Op. Cit., p. 80 : «Partir es también hacer morir a los otros, por lo menos simbólicamente, y al mismo tiempo exponerse al peligro de la pérdida de sí mismo".

3 Ibid., p. 80 : "En casa están todos muertos"

${ }^{4}$ M.-A. Hily, D. Meintel, «Célébrer la communauté », Revue Européenne des Migrations Internationales, 16-2/2000, Fêtes et rituels dans la migration, pp. 7-8. Accessible en ligne à l'URL : http://www.persee.fr/showPage.do?urn=remi_0765-0752_2000_num_16_2_1724 [consulté le 23 mars 2008].

${ }^{5}$ D. Poublan, «Écriture et rôle social », Op. Cit., p. 203. 
effet, si elles persistent, elles prennent des contenus différents, parce que les conditions de leur élaboration s'alternent aussi.

Ainsi, l'étude croisée de vie de migrantes, célibataires comme mariées, a permis de conclure à des cas d'émancipation. Il faut cependant prendre en compte ici la polysémie du terme «émancipation», pour entendre comment elle agit sur ces femmes. Philippe Rygiel rappelle en effet :

«L'émancipation est parfois jaugée à l'aune d'un modèle petit-bourgeois de respectabilité et tout rapprochement formel entre pratiques des populations migrantes et pratiques des classes moyennes occidentales est interprété comme l'indice d'une libération. La force de ce schéma ne vient cependant pas seulement de la contamination de la production scientifique par l'air du temps, mais aussi de la difficulté de proposer un macro-récit alternatif. Nous savons, en effet, que la migration transforme l'environnement matériel des rapports de genre, à la fois parce que les migrants sont confrontés à une nouvelle organisation des espaces sexués et parce que les conditions concrètes d'accomplissement des tâches féminines diffèrent généralement entre société de départ et société d'accueil » ${ }^{1}$.

Pour entendre la manière dont l'expérience migratoire agit sur les dynamiques et l'identité d'un groupe, il apparaît nécessaire de prendre en considération le milieu d'origine tout comme le milieu d'arrivée dans lequel se réalise la migration. Nancy Green souligne que, dans l'étude de l'intégration des sociétés immigrées, se confrontent deux théories, qu'elle qualifie de «culturaliste » versus « structuraliste ». Elle explique :

«Les premiers soulignent l'importance des valeurs, coutumes ou qualifications importées par les immigrés pour rendre compte de leurs parcours dans la société d'adoption. La continuité prime sur la rupture. Les seconds mettent en avant les structures des pays d'accueil pour expliquer les contraintes nécessaires à l'adaptation. L'expérience de rupture est ici l'aspect le plus pertinent pour comprendre l'expérience migratoire $»^{2}$.

La migration est une expérience qui gagne à être analysée à la lumière de la catégorie du genre parce que, comme rupture, elle met clairement en évidence le fonctionnement des relations de genre en même temps qu'elle contribue à leur réaménagement. L'étude du marché du travail sud-chilien a par exemple mis en évidence des possibilités professionnelles élargies pour les femmes et l'image de la femme comme « ange domestique » prend alors des contenus différents. L'image masculine est quant à elle également redéfinie dans le sens d'une revalorisation de la virilité. Le colon se définit essentiellement à travers le travail de mise en culture d'une terre vierge et sauvage. Sur ce point, une analyse plus poussée des écrits d'hommes, dans une lecture nouvelle croisant les perspectives de genre et de migration, permettrait de dire si ce qui est observé dans les écrits de femmes s'y confirme. Les lettres des femmes migrantes sont donc de précieux documents historiques qui renseignent sur la construction des identités culturelles à la lumière des concepts de genre et de nation.

\footnotetext{
${ }^{1}$ P. Rygiel, «Le genre de l'émigrant(e) et ses transformations », Op. Cit., p. 22.

${ }^{2}$ N. Green, «L'histoire comparative », Op. Cit., p. 1340.
} 
Les prolongements qui pourraient émerger de ce premier travail sont multiples. L'une de ses limites est l'espace réduit accordé à l'analyse des écrits d'hommes. Les allusions comparatives épisodiques ne prétendent pas y remédier. La correspondance féminine était en réalité suffisamment riche pour décider d'y consacrer pleinement cette recherche annuelle. Il reste donc à analyser la correspondance des migrants à la lumière de la catégorie d'analyse du genre, afin de reconstituer une histoire plus complète et complexe des relations de genre en migration, dans le cas de la colonisation allemande au Chili.

La dimension comparative dans son ensemble n'a pu être menée avec exhaustivité. La comparaison avec d'autres communautés d'immigrées au Chili est limitée, d'une part parce que la bibliographie les concernant est quasi inexistante, hormis les Italiennes, objets de l'étude de Paula Zaldivar, et d'autre part parce que le temps imparti pour cette recherche ne permettait pas de dépouiller d'autres fonds. Il faut en outre préciser que seule la communauté germano-chilienne possède un centre d'archives aussi bien organisé et accessible que le centre Emilio Held Winkler, preuve sans doute de son dynamisme et souci de mémoire. Il reste donc à retracer l'expérience migratoire d'autres groupes de femmes, comme les Françaises, les Basques ou les Espagnoles du Chili, si toutefois les archives le permettent.

La dimension comparative à l'échelle latino-américaine pourrait être également plus poussée. L'Argentine, le Brésil ou le Pérou offrent aussi des cas de migrations allemandes, et européennes en général, peu étudiées sous l'angle du genre. L'approche «structuraliste », qui prend en compte les milieux d'arrivée des migrants dans les processus d'intégration, permettrait de dégager plus nettement les spécificités de la communauté allemande au Chili ou au contraire des similitudes avec ses autres versions latino-américaines. Ainsi, la comparaison sur le modèle « divergent » que propose Nancy Green n'a pu être abordée, par manque de temps et de matériel. Elle pourrait être réalisée précisément par une comparaison des variantes chiliennes, brésiliennes, argentines et péruviennes du courant migratoire allemand, à l'échelle du groupe ou d'une de ses familles. Par exemple, la famille von Bischhoffhausen mériterait à elle seule une monographie. Depuis, le XVIII ${ }^{\mathrm{e}}$ siècle, elle a essaimé dans divers pays européens et américains. On trouve ainsi des von Bischhoffshausen en Allemagne, en Autriche, en Pologne, en Hongrie, en Bohême, au Royaume-Uni, aux Etats-Unis, en Australie, en Argentine, au Chili et au Pérou ${ }^{1}$. Ses branches latino-américaines pourraient ainsi faire l'objet d'une étude croisée.

Ce travail de recherche constituerait la première étape d'un élargissement possible vers une étude comparée du genre en migration. Pourraient être traitées les migrations intercontinentales, mais aussi les migrations au sein de l'Amérique latine, peu abordées jusqu'à présent en termes de genre.

\footnotetext{
${ }^{1} C f$. La généalogie complète, établie par Werner von Bischhoffshausen, de 1300 à 1900, accessible en ligne à l'URL : $\quad$ http://familytreemaker.genealogy.com/users/v/o/n/Werner-Vonbischhoffshausen/TREE/0001 tree.html [consulté le 5 juillet 2008].
} 


\section{ANNEXES}

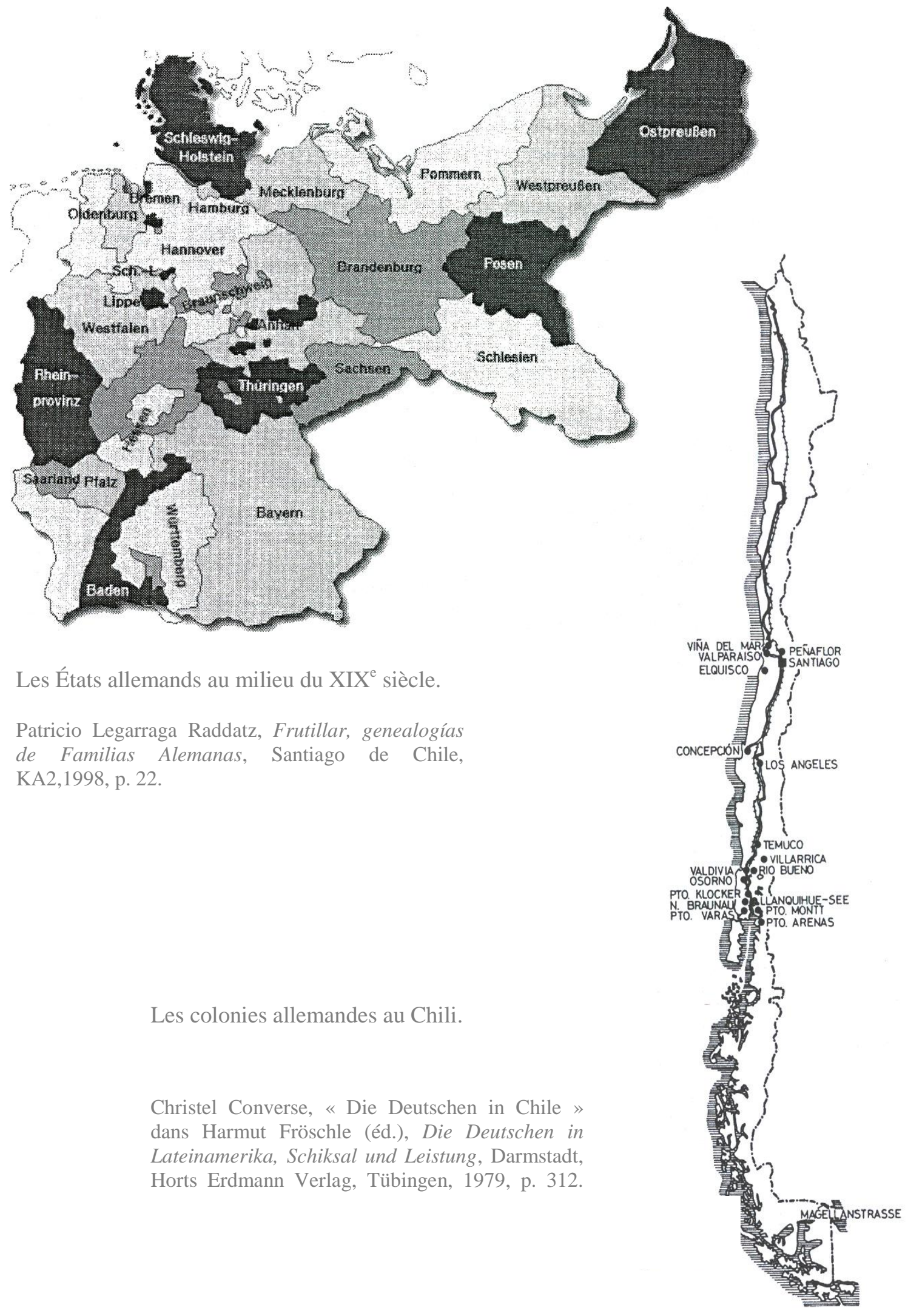




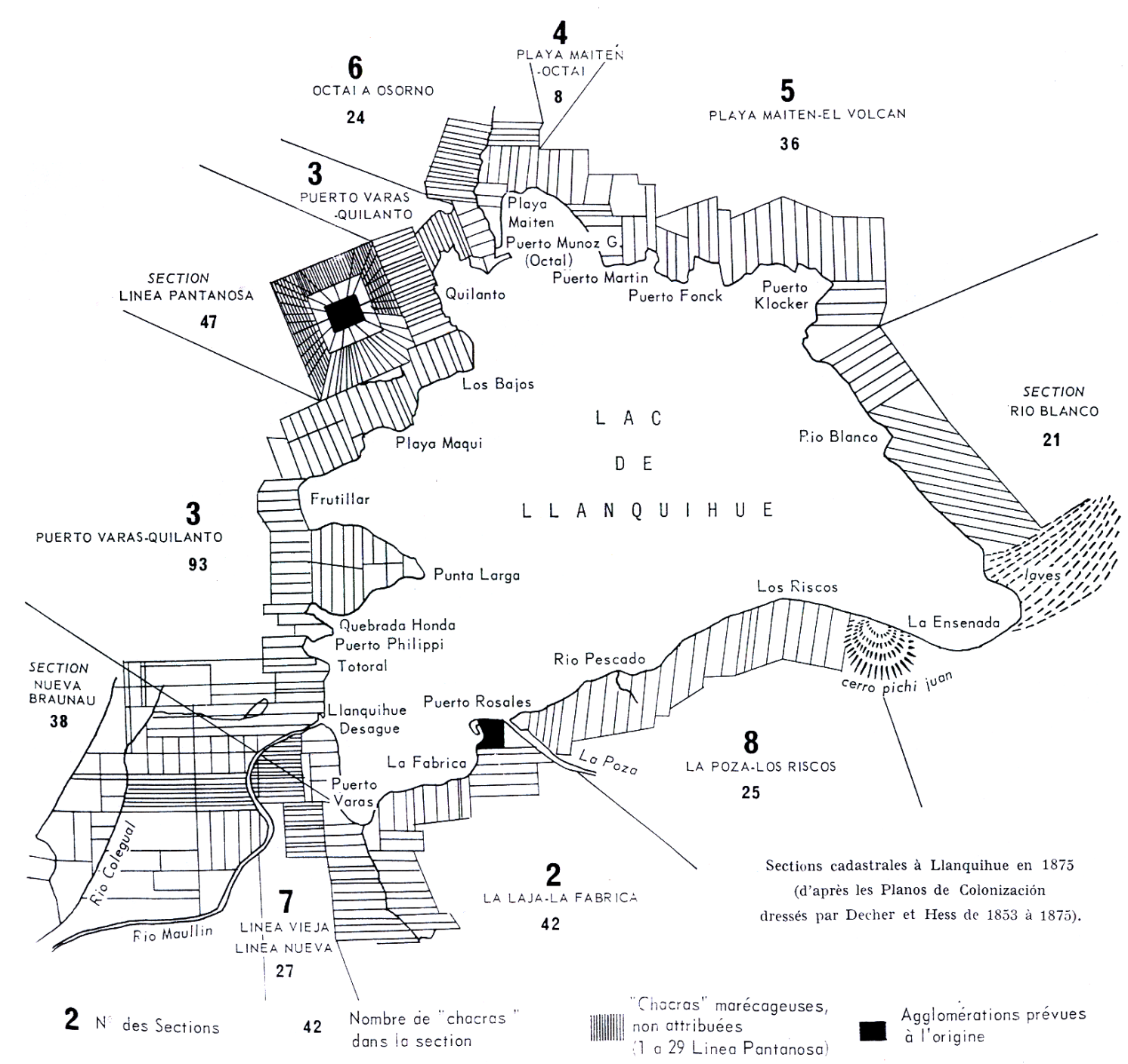

Jean-Pierre Blancpain, « La tradition paysanne allemande au Chili. La colonie de Llanquihue (1850-1920) », Cahiers des Amériques latines 4/1969. 


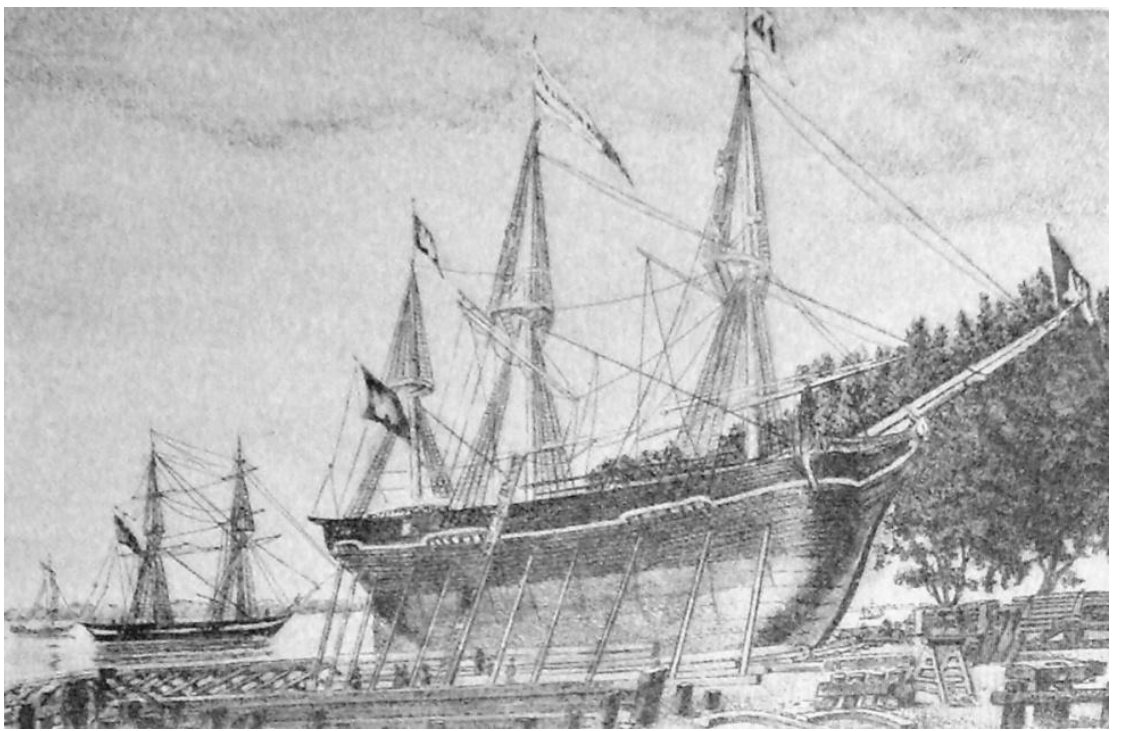

Construction du

«Gasbrook» sur le chantier des Somm vers 1850 .

Armin Clasen «Die Schiffe der Chile-Auswanderung über Hamburg 1850-1875 und die Schiffbauerfamilie von Somm », Zeitschrift für Niedersächsiche Familienkunde, 38. Jahrgang, 1/1963, planche.

Tasse de matelot de 1' «Iserbrook» construit en 1853 par les chantiers Somm pour la compagnie Godeffroy

Armin Clasen «Die Schiffe der ChileAuswanderung über Hamburg 1850-1875 und die Schiffbauerfamilie von Somm », Zeitschrift für Niedersächsiche Familienkunde, 38. Jahrgang, 1/1963, planche s. p.
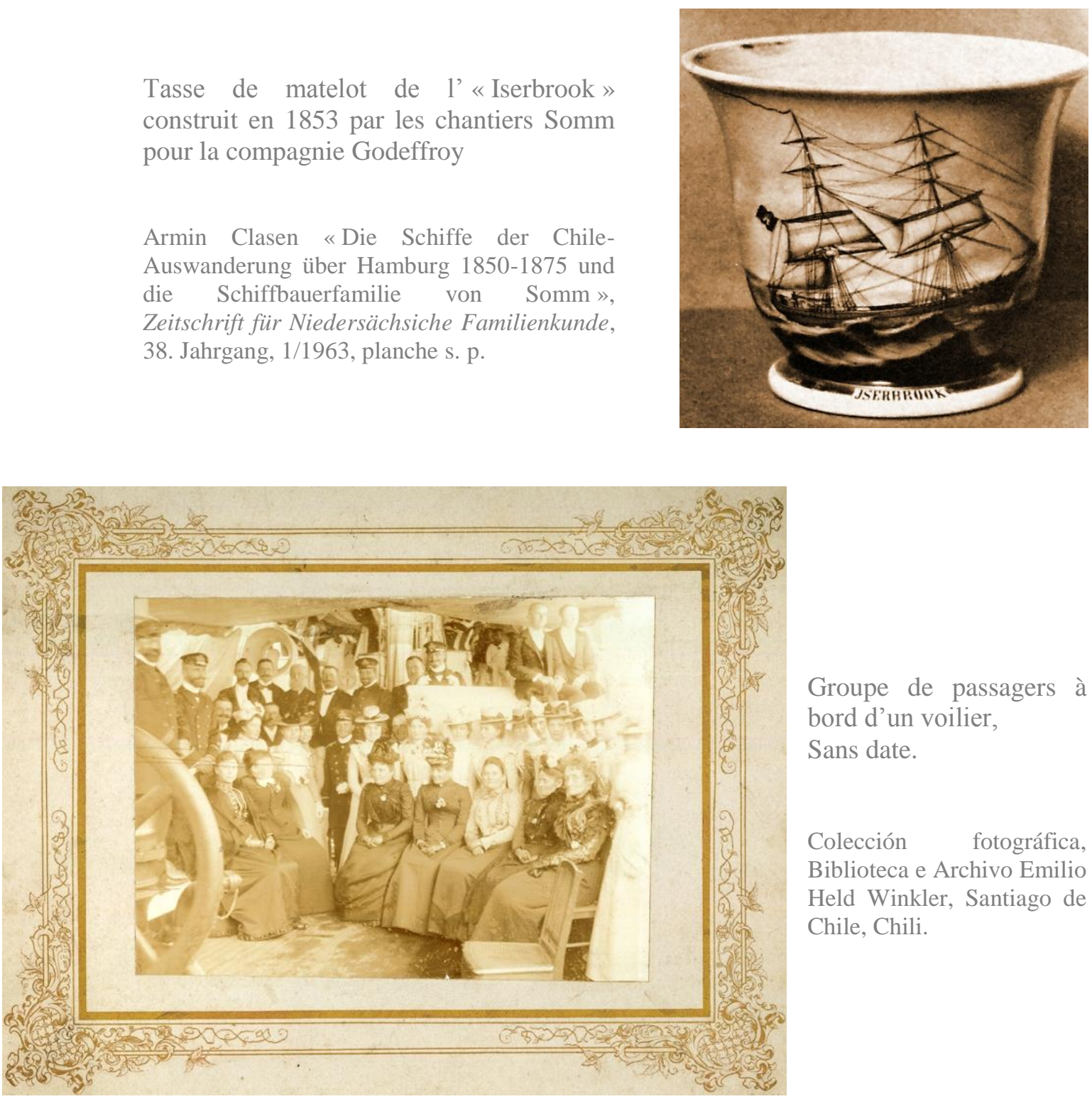

Groupe de passagers à bord d'un voilier, Sans date.

Colección fotográfica, Biblioteca e Archivo Emilio Held Winkler, Santiago de Chile, Chili. 


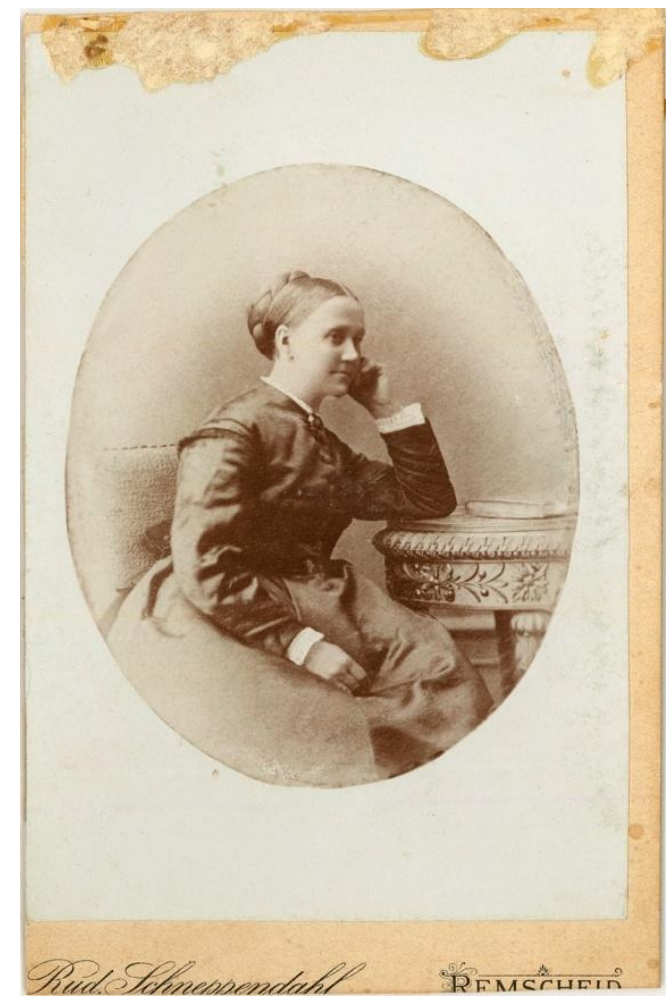

Portrait de Fanny Fonck, née Zöhrer par Rud, Schneppendahl, Remscheid, Allemagne, don de Alfredo Fonck Bade.

Colección fotográfica, Biblioteca e Archivo Emilio Held Winkler, Santiago de Chile, Chili.

Portrait de Sophie von Bischoffshausen, née von Eschwege, jeune.

Collection particulière de Werner von Bischhoffshausen, Santiago de Chile, Chili.
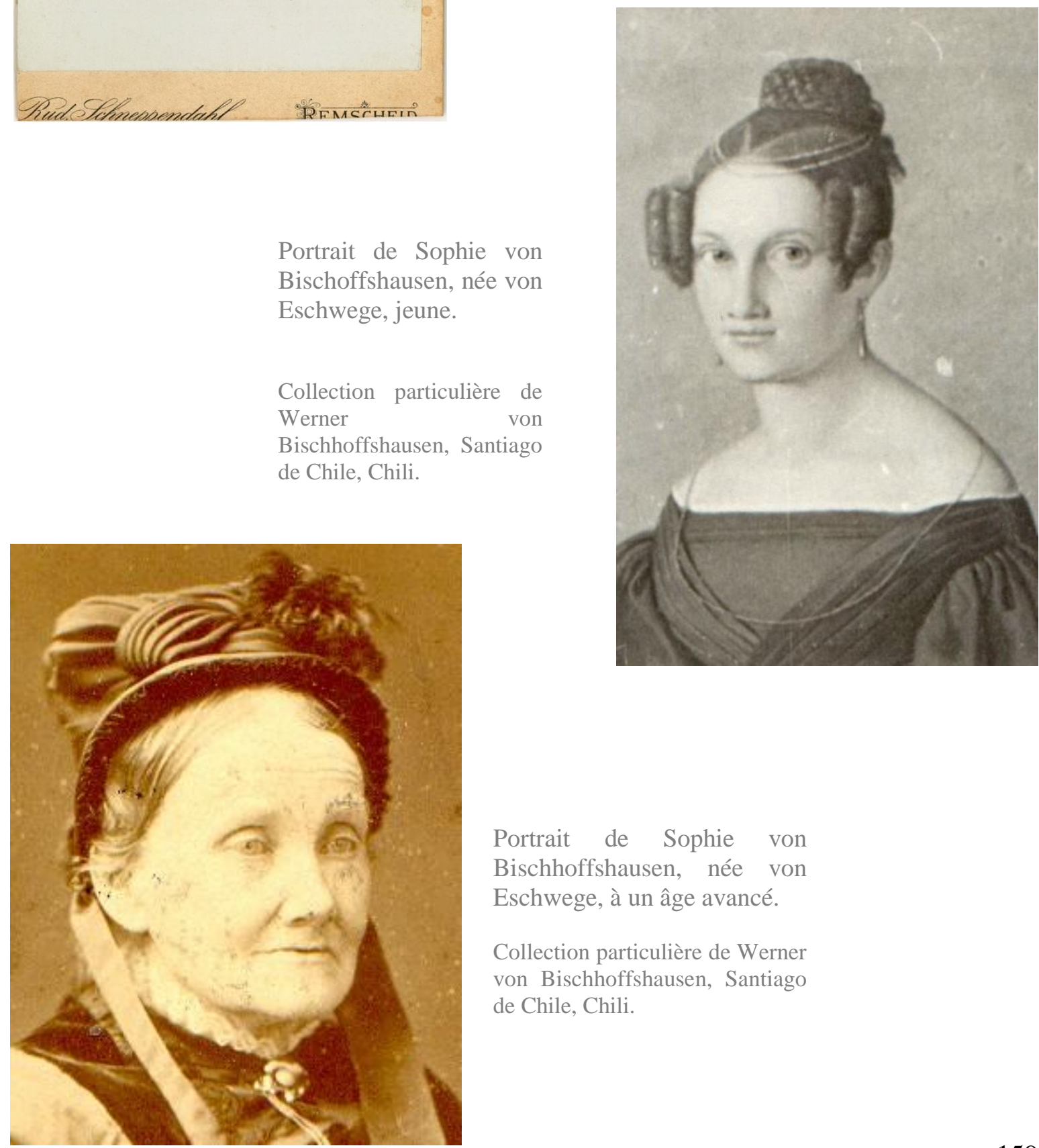

Portrait de Sophie von Bischhoffshausen, née von Eschwege, à un âge avancé.

Collection particulière de Werner von Bischhoffshausen, Santiago de Chile, Chili. 


\section{FIfgemeine 2 Iแ⿴囗十)}

\author{
Eir Sote \\ ywifgen ber atten unb neuen Welt. \\ Eirbenten Jabrganget 1. Eemerper.

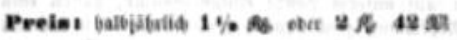

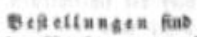 \\ ntat betili gerleger unuittelbar, \\ inater:

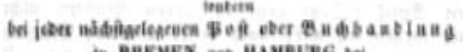

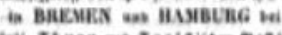

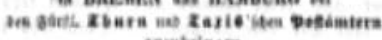 \\ anjultinge.
}

Pubolftabt, ten 1. Zebruar

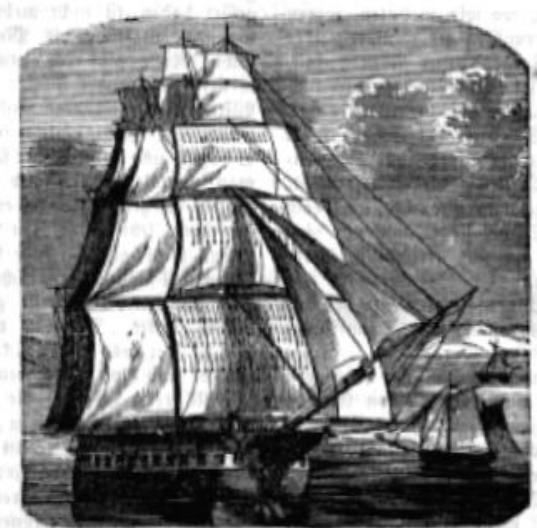

Unter Berantwortlidfeit bed 3 erfegero

robigiti oen

(5. \$2. v. Mtoes

ant merb. Mnerifa.

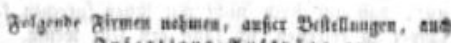

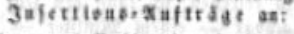

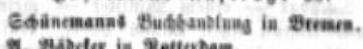

ต. Pubcter in Mettembaie.

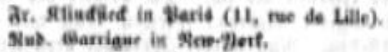

3. E. Eseffelberit in Et. Youis.

1853.

N2 14.

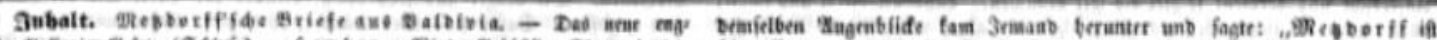

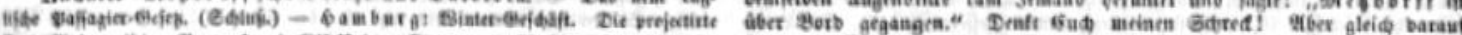
Dumptisit jwif

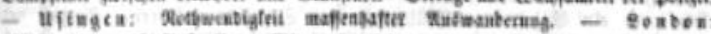

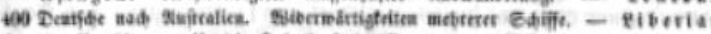

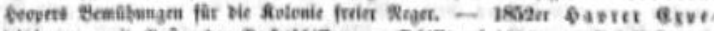

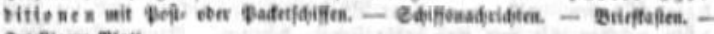
3atriligangetiatt.

S bes. Dollar, Et. beb. $8 \mathrm{ent}, 100 \mathrm{Gt}$. (8 witt ob. Bbilingt) $=1 \mathrm{~s}$.

Driefe aus DalDivia ${ }^{*}$ in Süd-gamerika

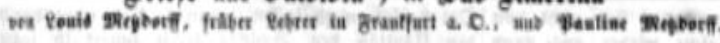

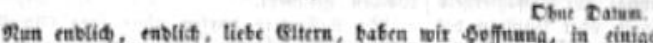

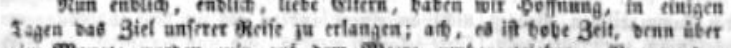

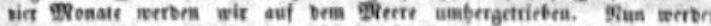

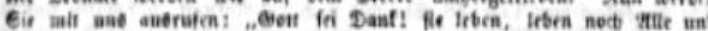

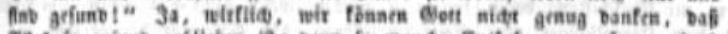

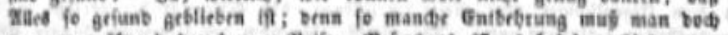

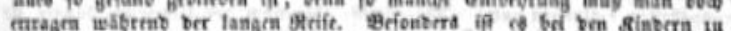

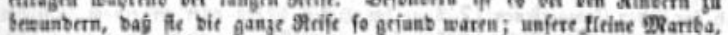

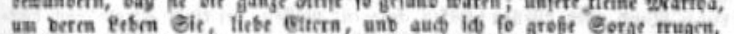

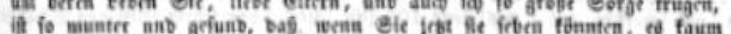

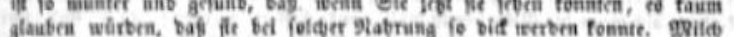

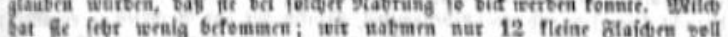

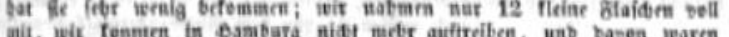

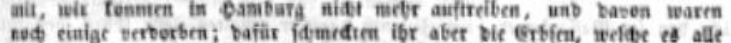

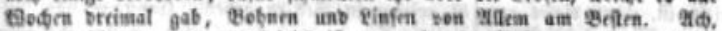

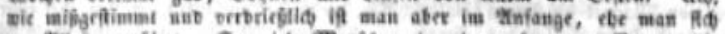

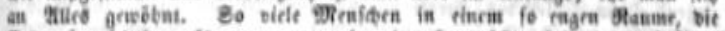

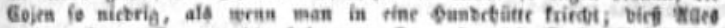
nellte mir jurrt gat nidet brbagen. Dam fam bie Grofranfbrit baja;

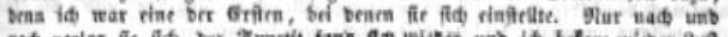

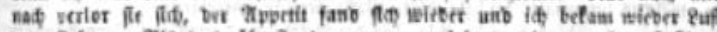

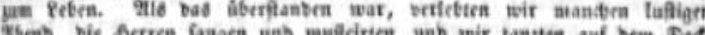

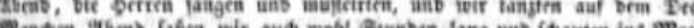

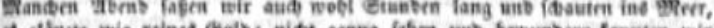

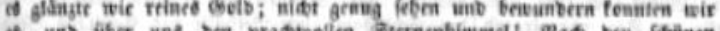

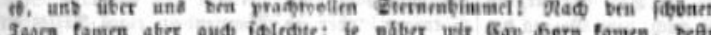
Tagra faisen aber aud folcdete; ie natber wit Gay born famen, befo

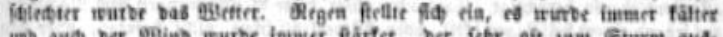

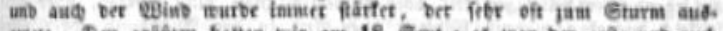

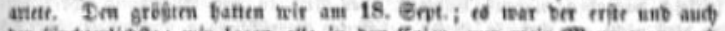

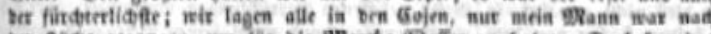

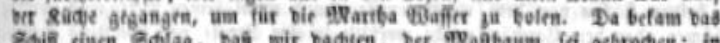

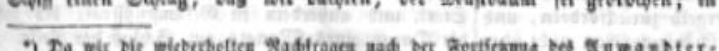

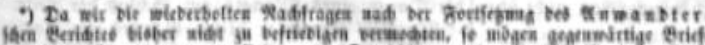

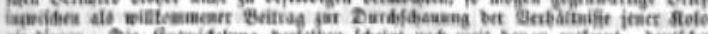

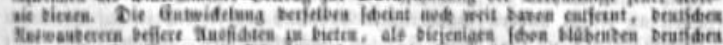

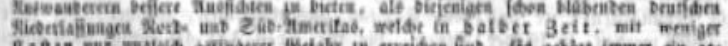

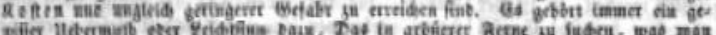

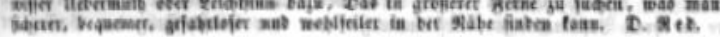

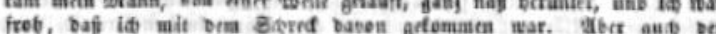

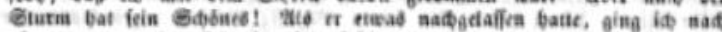

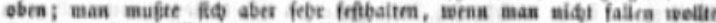

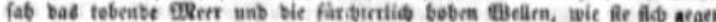

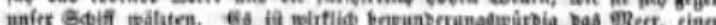

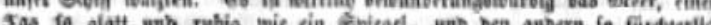
Tag to glatt unb rabig wie sin evirget, unb ben anbern fo furdtetilid

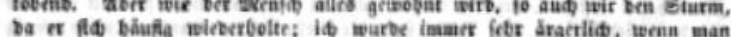

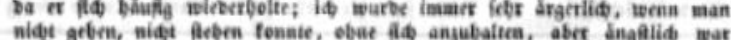

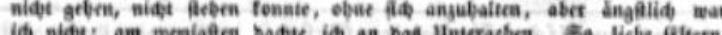

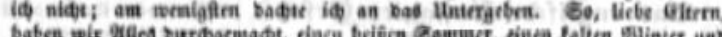

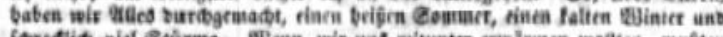

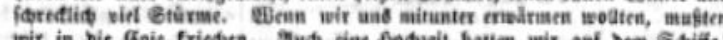
wir in bie Goje friedern. And rine Godjeit batten wit anf bea Estiffe!

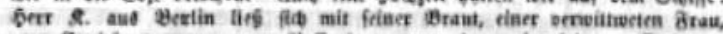

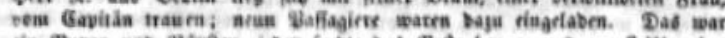

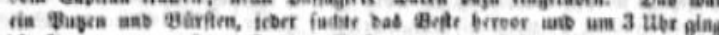

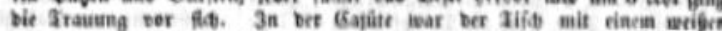

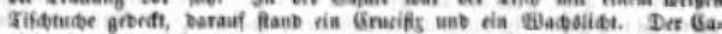

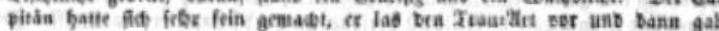

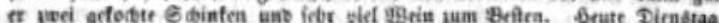

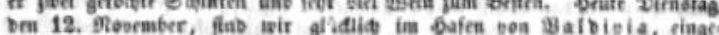

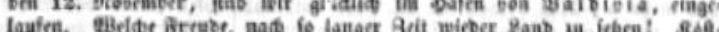
lis

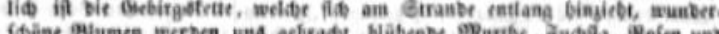

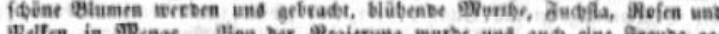

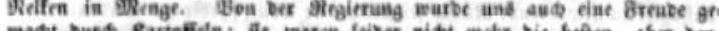
mackt butd sarteficln; fit waten leiber nidst mrter bie befen, aber ben.

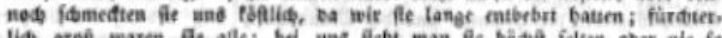

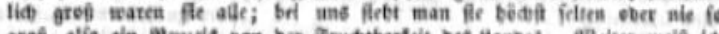

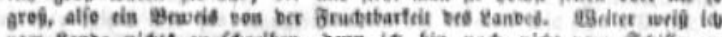

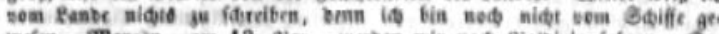

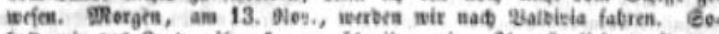

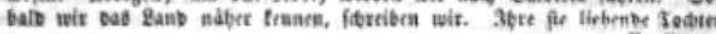

$$
\text { u. }
$$
Ventiane.

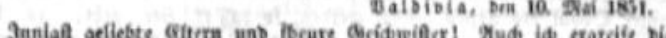

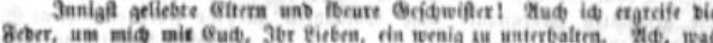

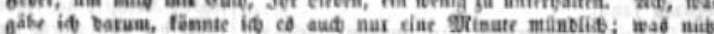

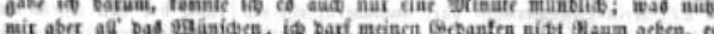
fane is nidt feis.

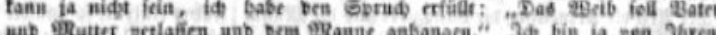

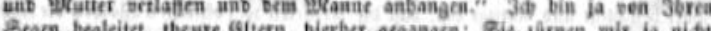

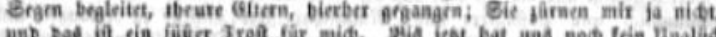

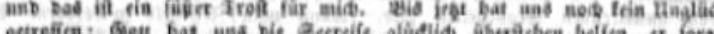

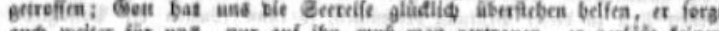

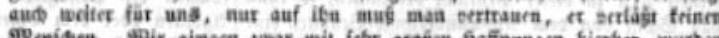

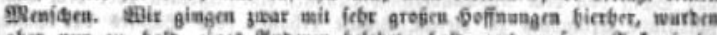

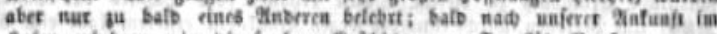

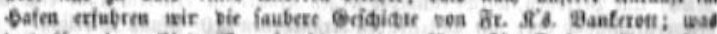

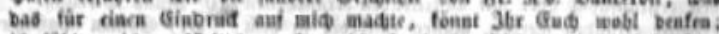

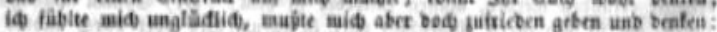

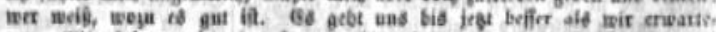

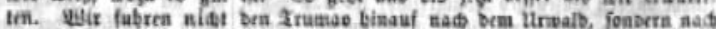

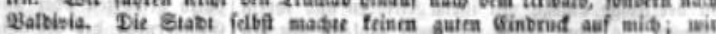

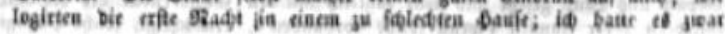



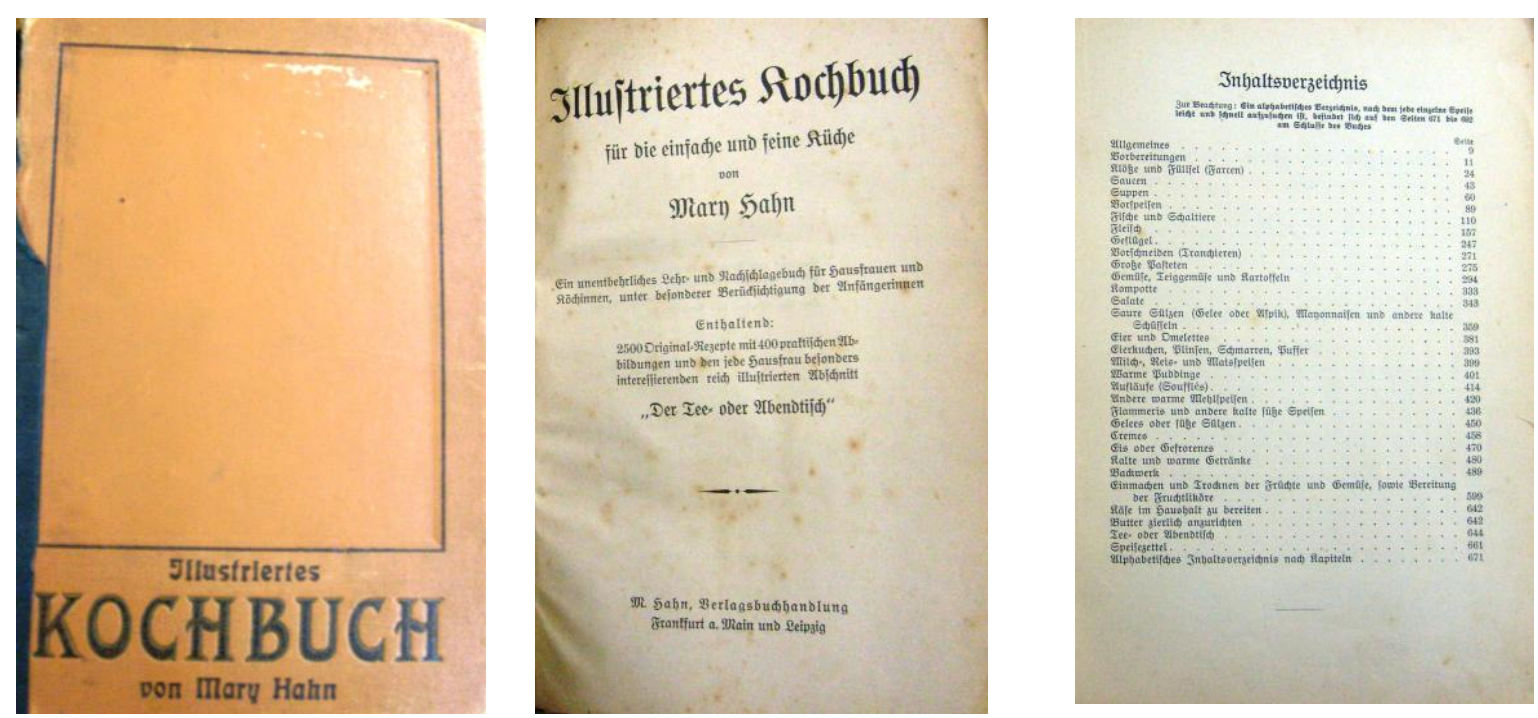

HAHN Mary, Illustriertes Kochbuch für die einfache und feine Küche, 33e et 34e édition, Berlin, Mary Hahn's Kochbuch-Verlag, 1928.
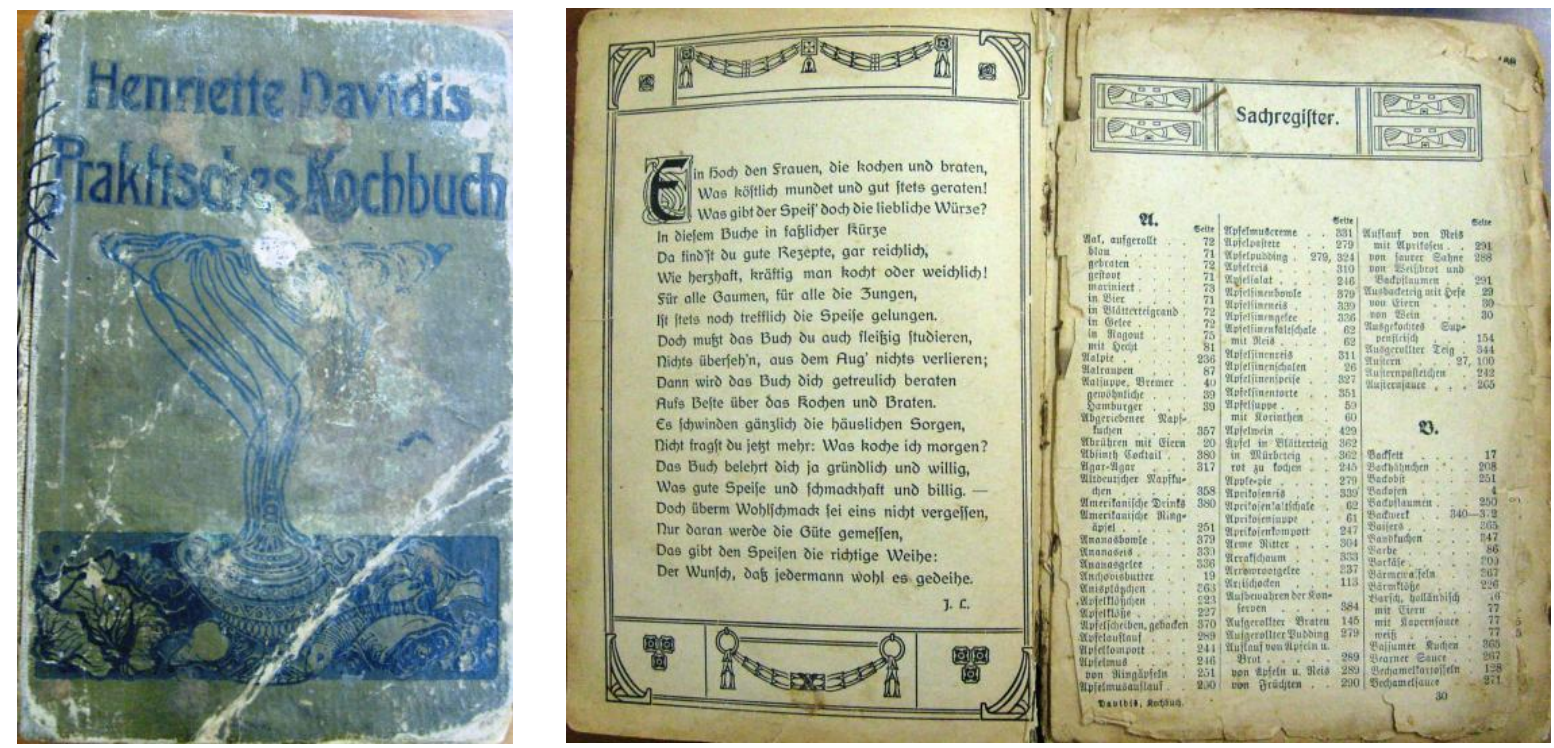

DAVIDIS Henriette, Praktisches Kochbuch für die gewöhnliche und feinere Küche, 38e édition révisée et augmentée par Luise Holle, Bielefeld, Verlag von Velhagen\&Klasing, 1900.
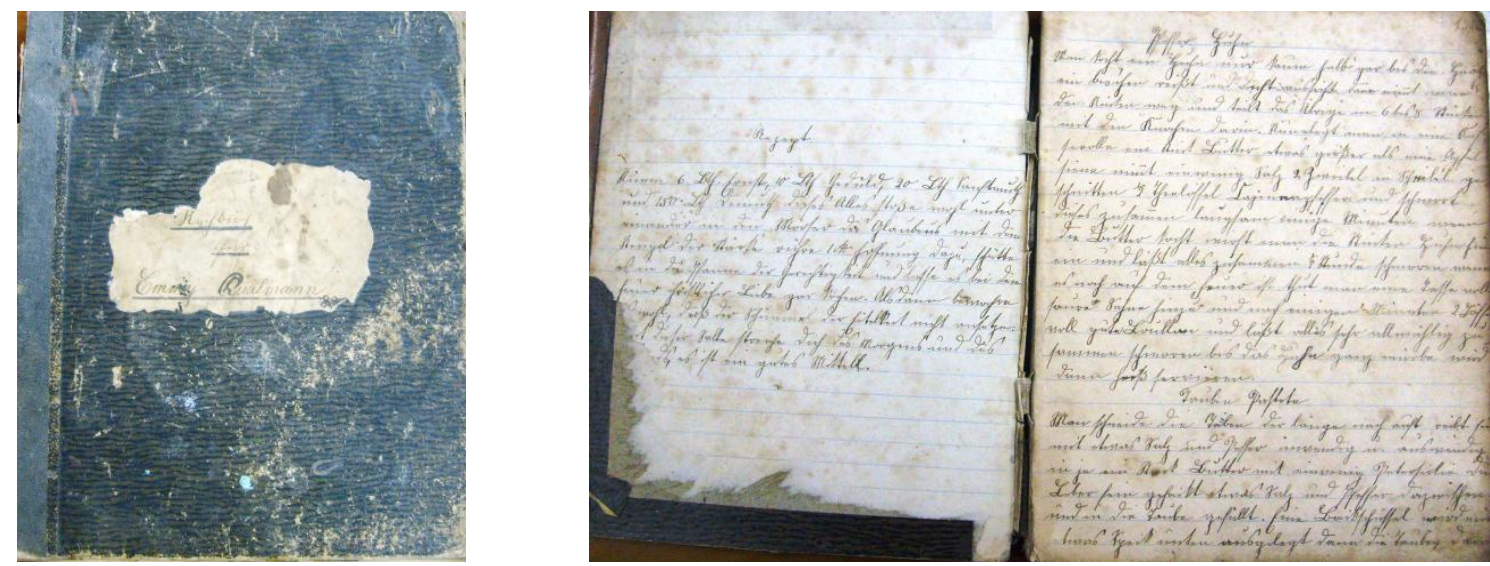

Livre de recette familial

Collection d'ouvrages anciens, Biblioteca e Archivo Emilio Held Winkler,, Santiago de Chile, Chili. 


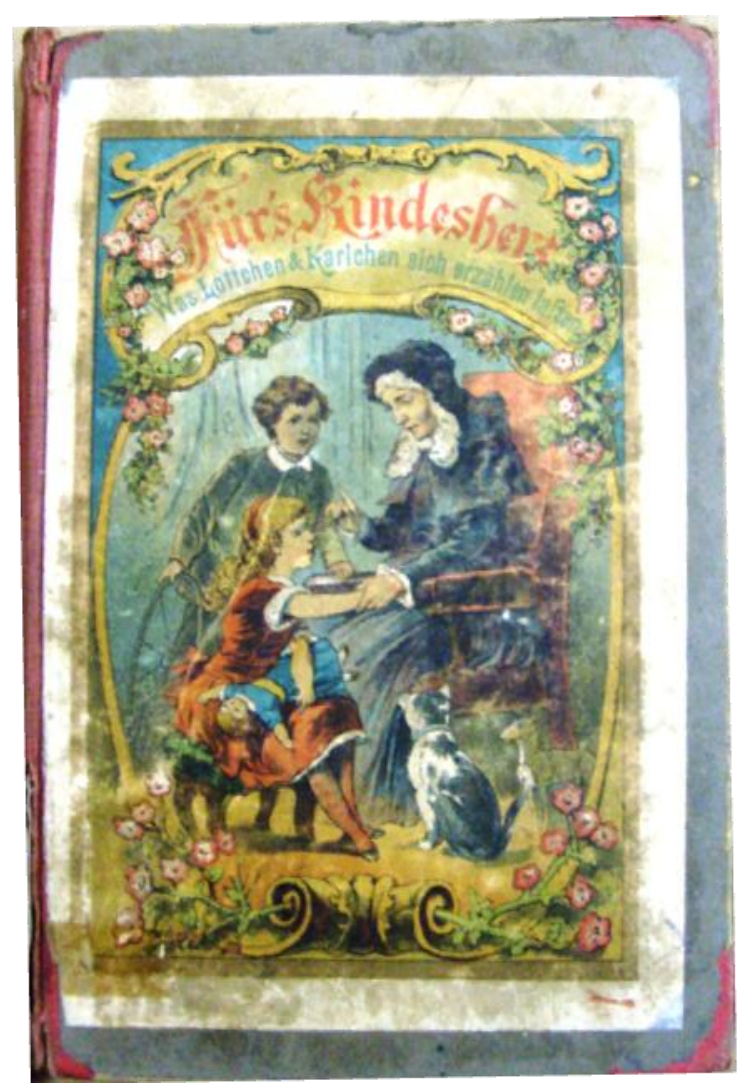

Neue deutsche Märchen, Märchen für Knaben und Märchen.

Livre appartenant à Carlos Finsterbusch (Altenburg, Gutenberg-Str 2r)

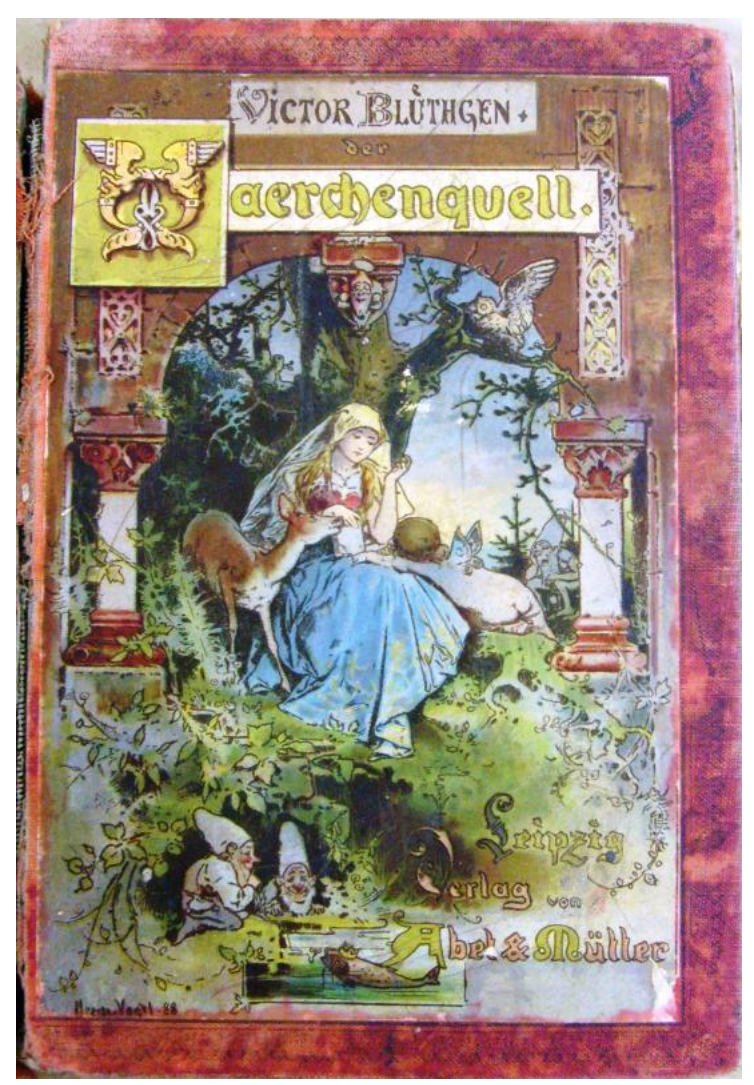

Für's Kindersherz, Was Lottchen und Karlchen sich erzählen lassen, Livre appartenant à la famille Meyerholz.

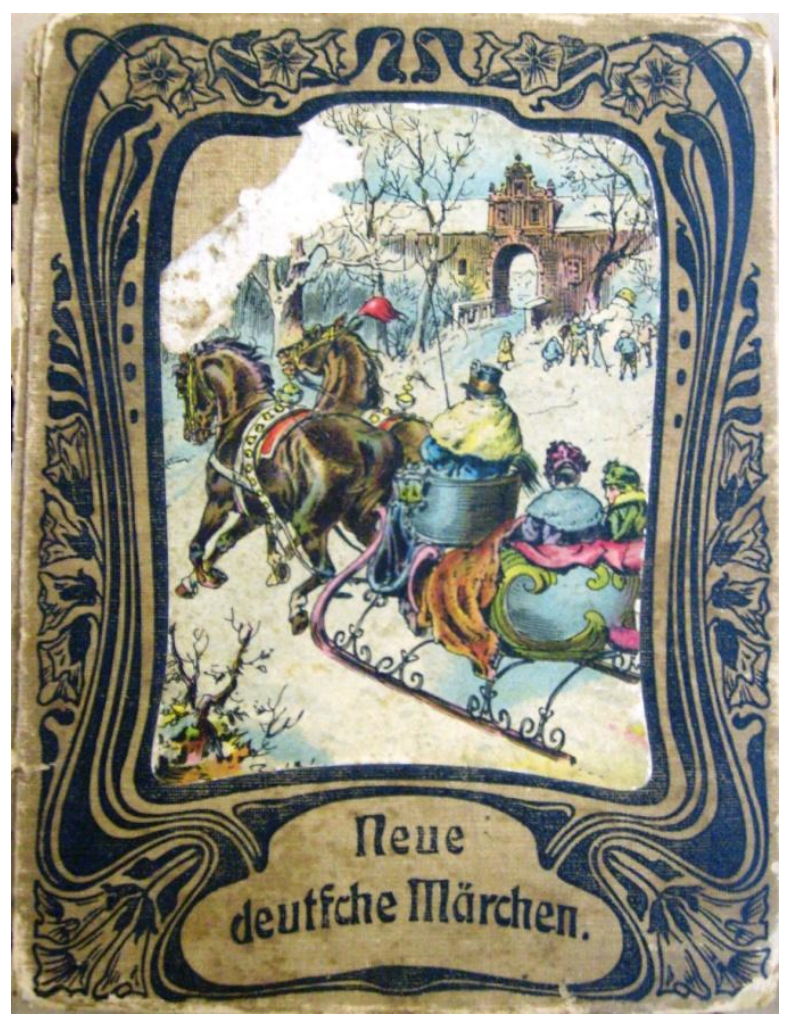

Victor Blüthgen, Märchenquell, Leipzig, Verlag von Albert \&Müller, 1900

Collection d'ouvrages anciens,

Biblioteca e Archivo Emilio Held Winkler, Santiago de Chile, Chili. 


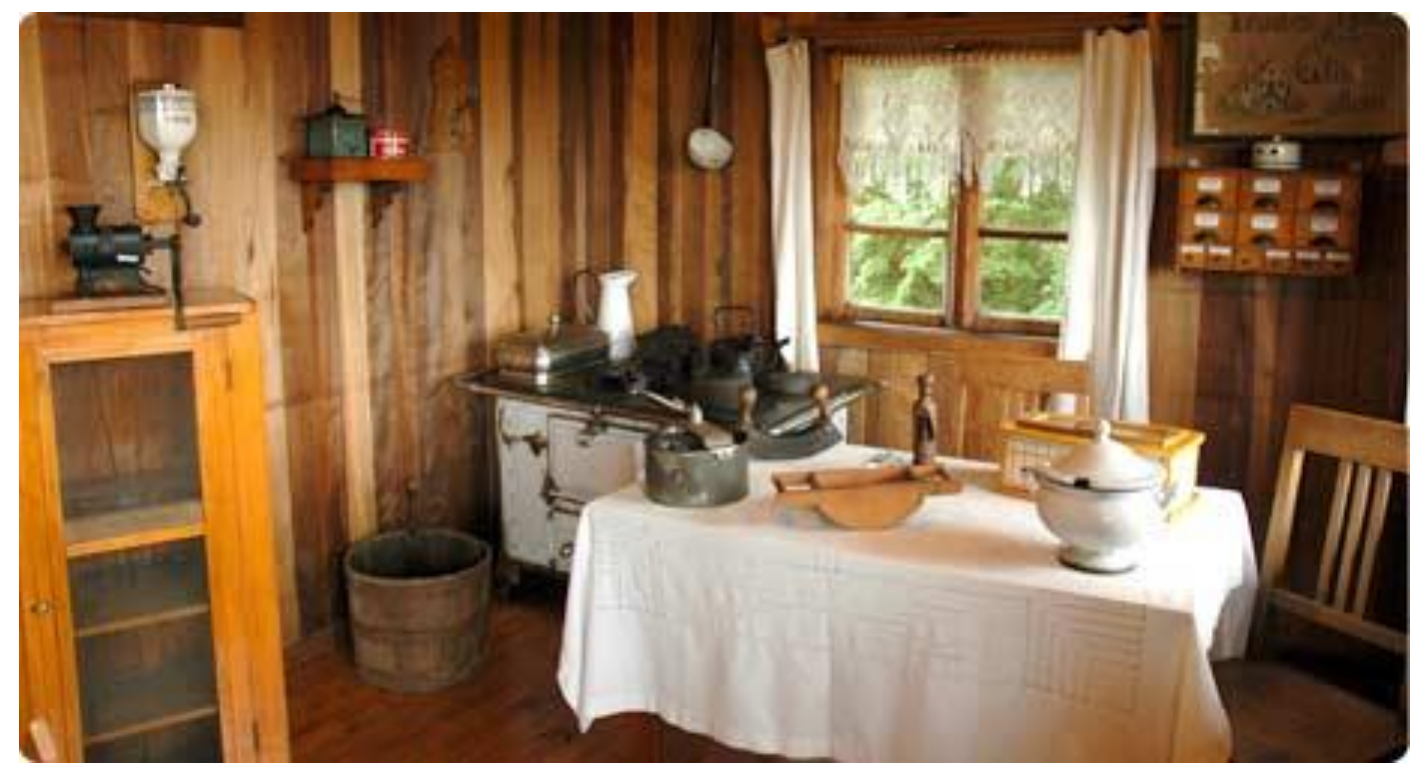

Cuisine de la maison du forgeron, Museo Colonial Alemán de Frutillar, Chili

Photographie : Pauline Bilot.
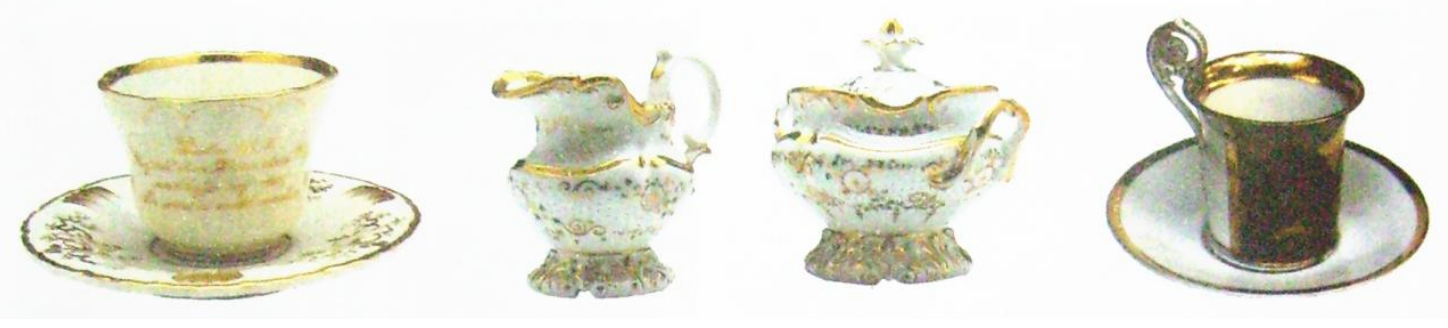

Tasses de porcelaine, importée d'Allemagne lors du voyage à Valdivia vers 1840, Museo Maurice van de Maele, Valdivia, Chili.

Gabriel Guarda, Nueva Historia de Valdivia, Santiago de Chile, Ed. Universidad Católica de Chile, 2001, p. 524. 

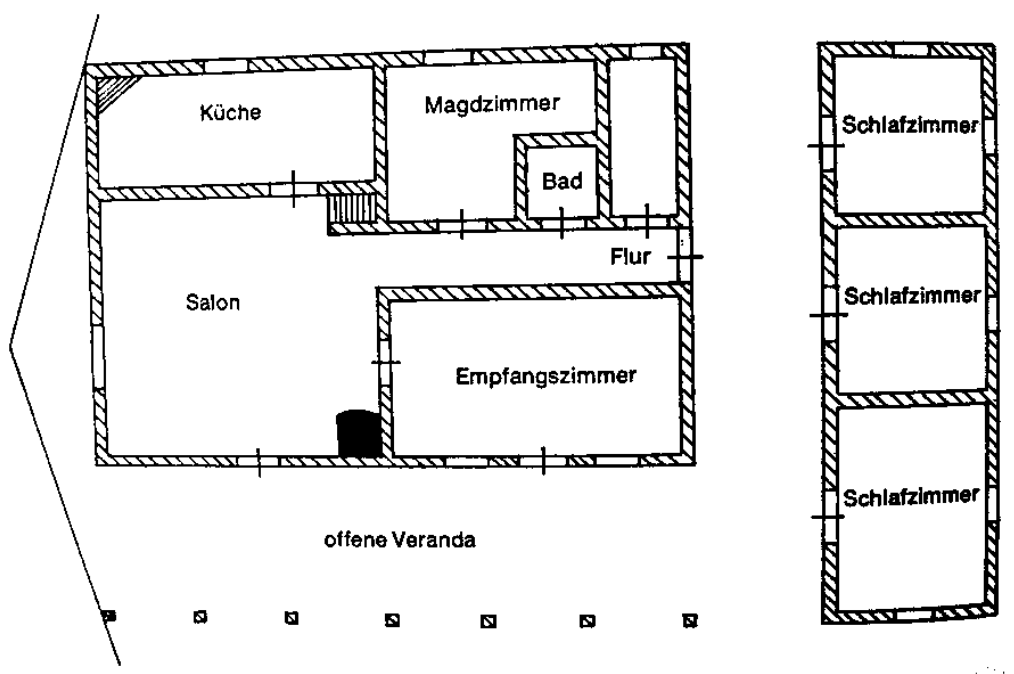

Maison de paysans à Frutillar au début de la colonisation ${ }^{1}$.

Kar Ilgl, Pioniere in Argentinien, Chile, Paraguay und Venezuela. Durch Bergwelt, Urwald und Steppe erwanderte Volkskunde der deutschsprachigen Siedler, Tyrolia-Verlag, Innsbruck, Wien, München, 1976, p. 252

Maison d'une famille allemande de Valdivia au début de la colonisation.

Kar Ilgl, Op. Cit, p. 256

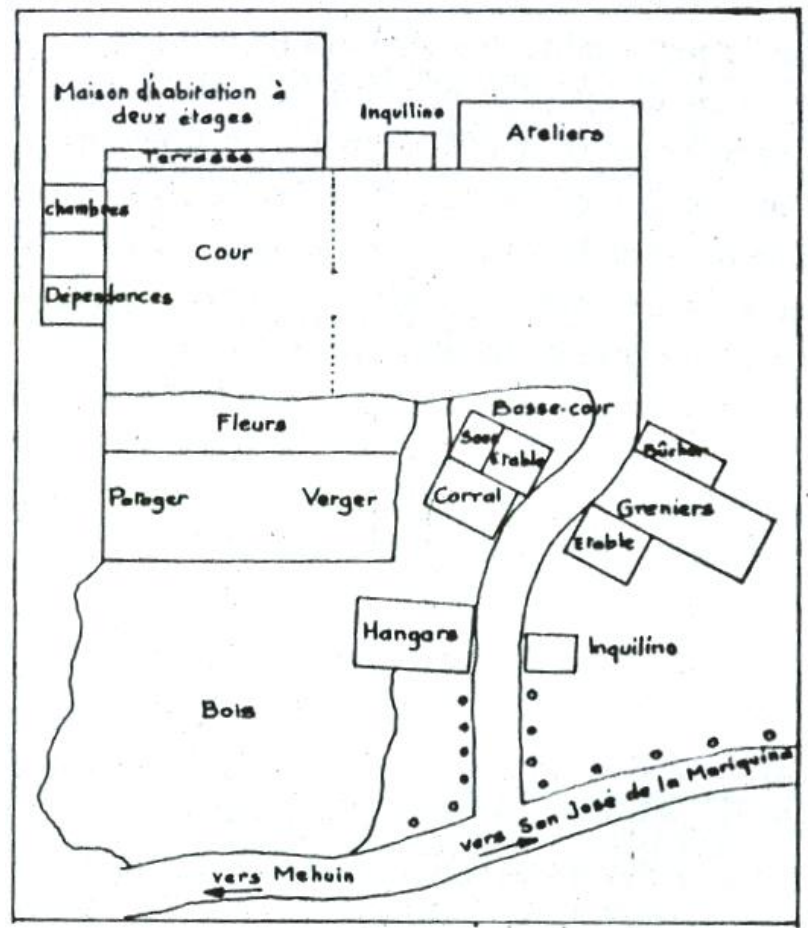

Ferme de colon allemand.

Province de Valdivia, région côtière, exploitation de 1300ha.

Jean-Pierre Blancpain, Les Allemands au Chili, Köln, Bölhau Verlag, 1974, p. 356.

\footnotetext{
${ }^{1}$ Küche : cuisine, Zimmer ou Kammer : chambre, Flur : couloir, Empfangszimmer ou Wohnzimmer Stube : salon, pièce de réception, $B a d$ : salle de bain, Magdzimmer : chambre de bonne
} 


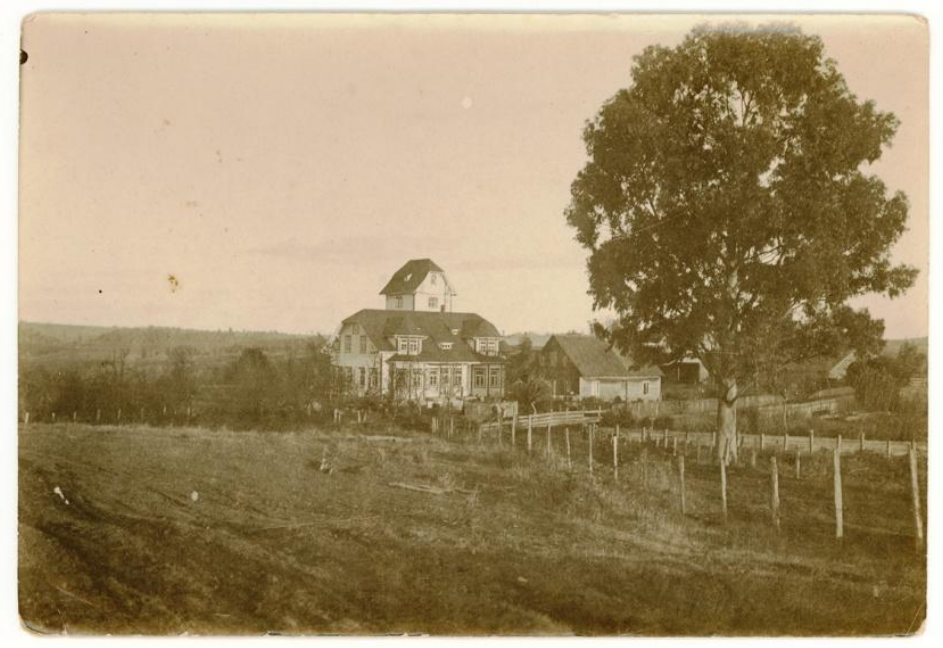

Maison de campagne à Llanquihue (Evaldo Gebauer), 1890, don d'Emilio Held Winkler

Famille de colon devant sa maison, Llanquihue, sans date.
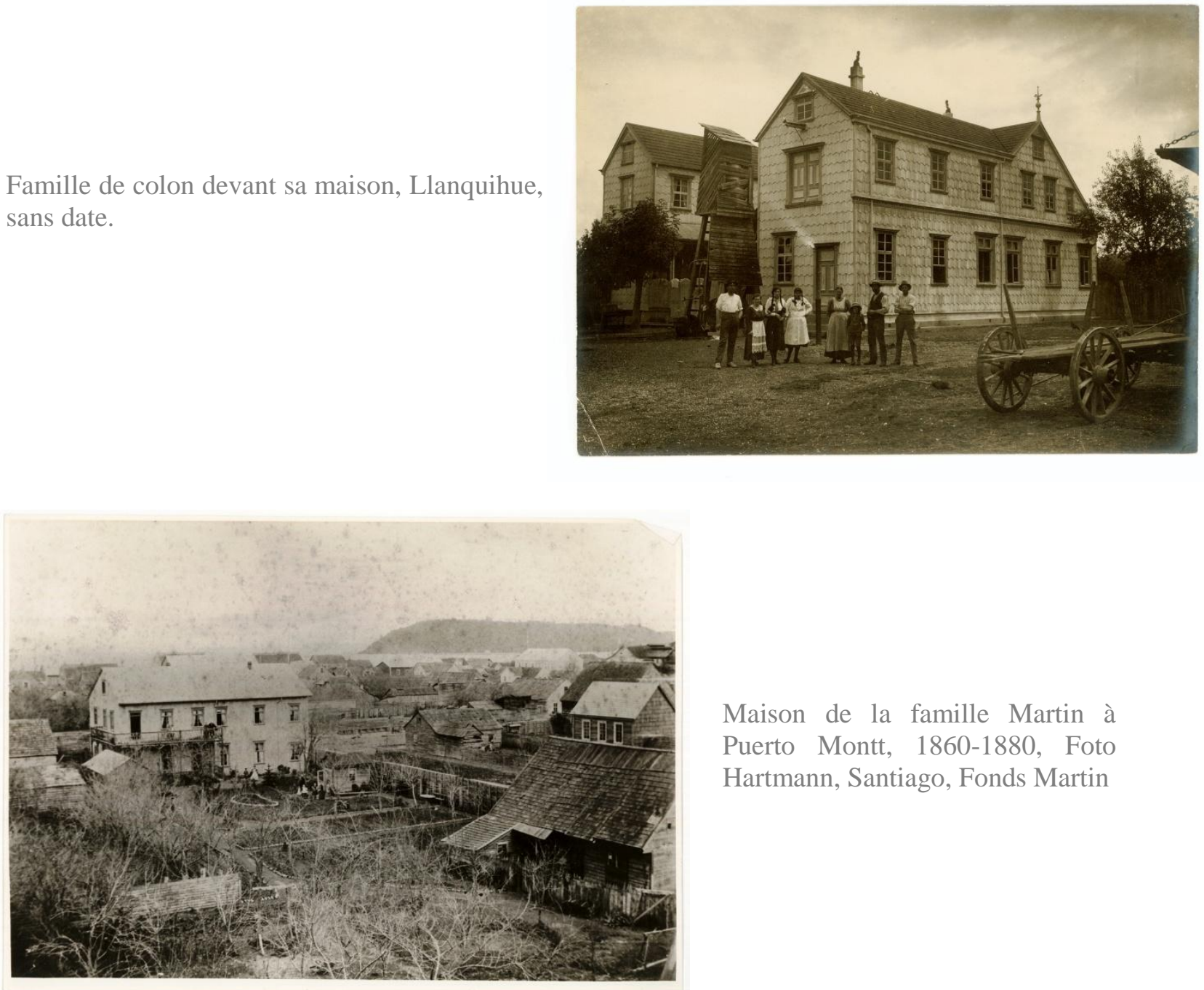

Maison de la famille Martin à Puerto Montt, 1860-1880, Foto Hartmann, Santiago, Fonds Martin

Colección fotográfica, Biblioteca e Archivo Emilio Held Winkler, Santiago de Chile, Chili. 
Scène de femmes bordant, Valdivia, entre 1860 et 1900.

Par R. Gunckel R., fonds Carl Martin

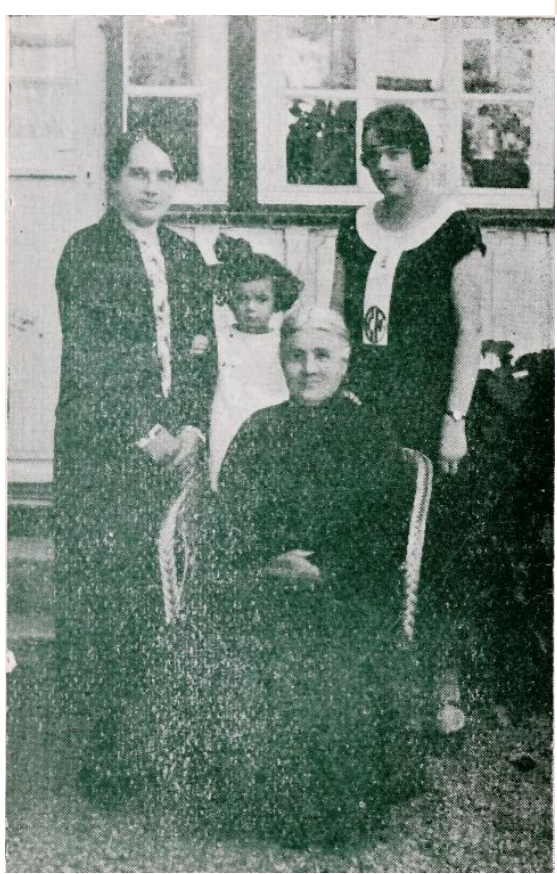

Mathilde von Bischhoffshausen à Puerto Varas avec sa fille, sa petite-fille et son arrière petite-fille.

Scène de famille: les Martin dans le jardin de leur maison, 1890. Fonds Carl Martin.

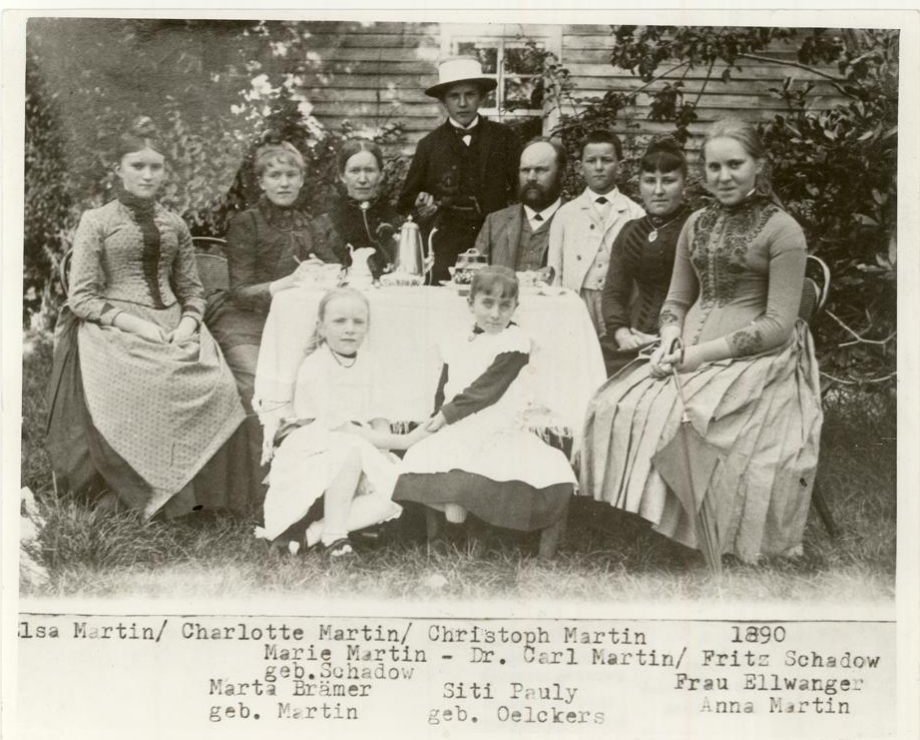

Colección fotográfica, Biblioteca e Archivo Emilio Held Winkler, Santiago de Chile, Chili. 


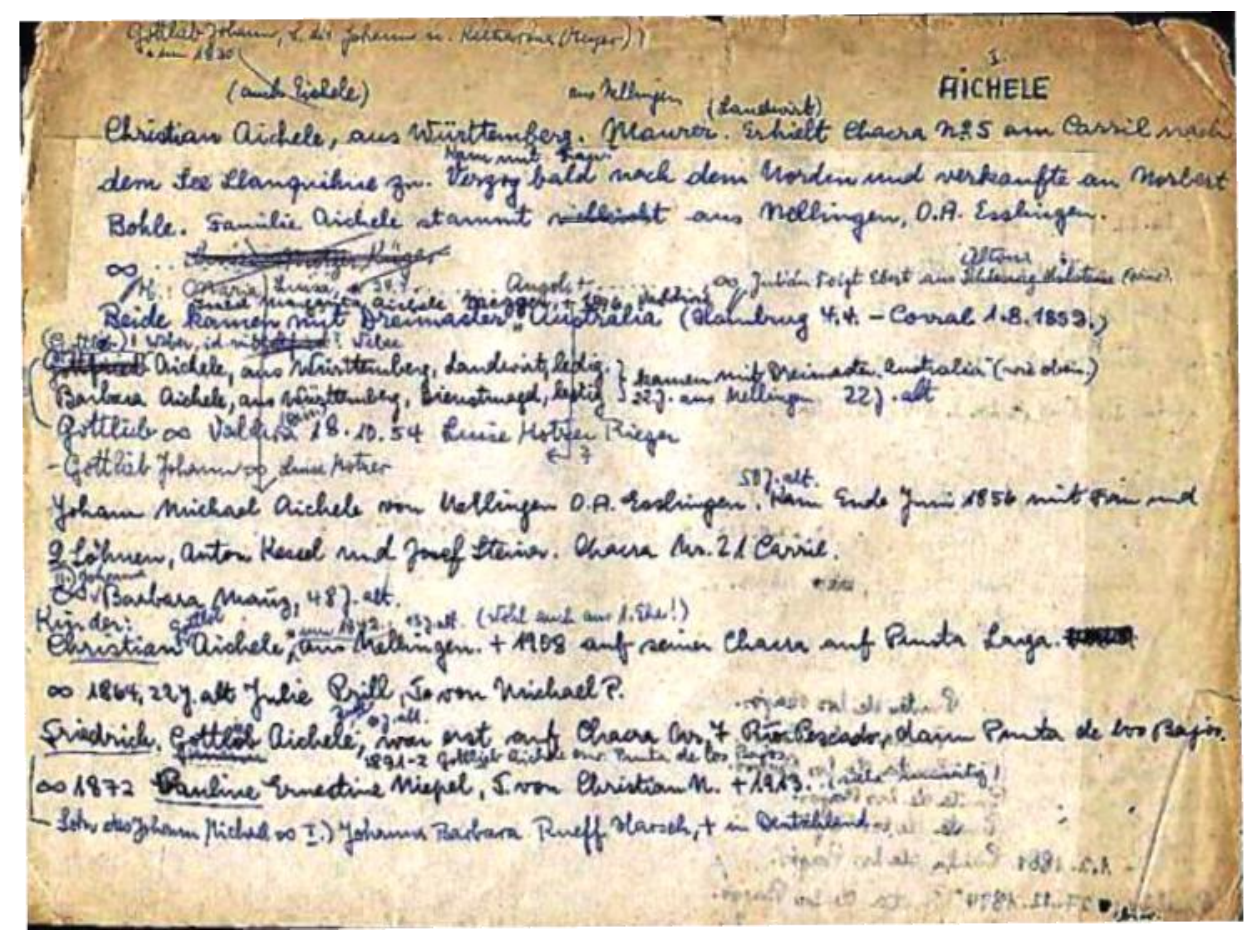

Un document de travail: les notices généalogiques d'Ingeborg Schwarzenberg, épouse Schmalz. Ici, la notice «Liga01796 Aichele».

Archivo Genealógico Ingeborg Schwarzenberg de Schmalz, Archivo Emilio Held Winkler, Santiago de Chile, Chili.

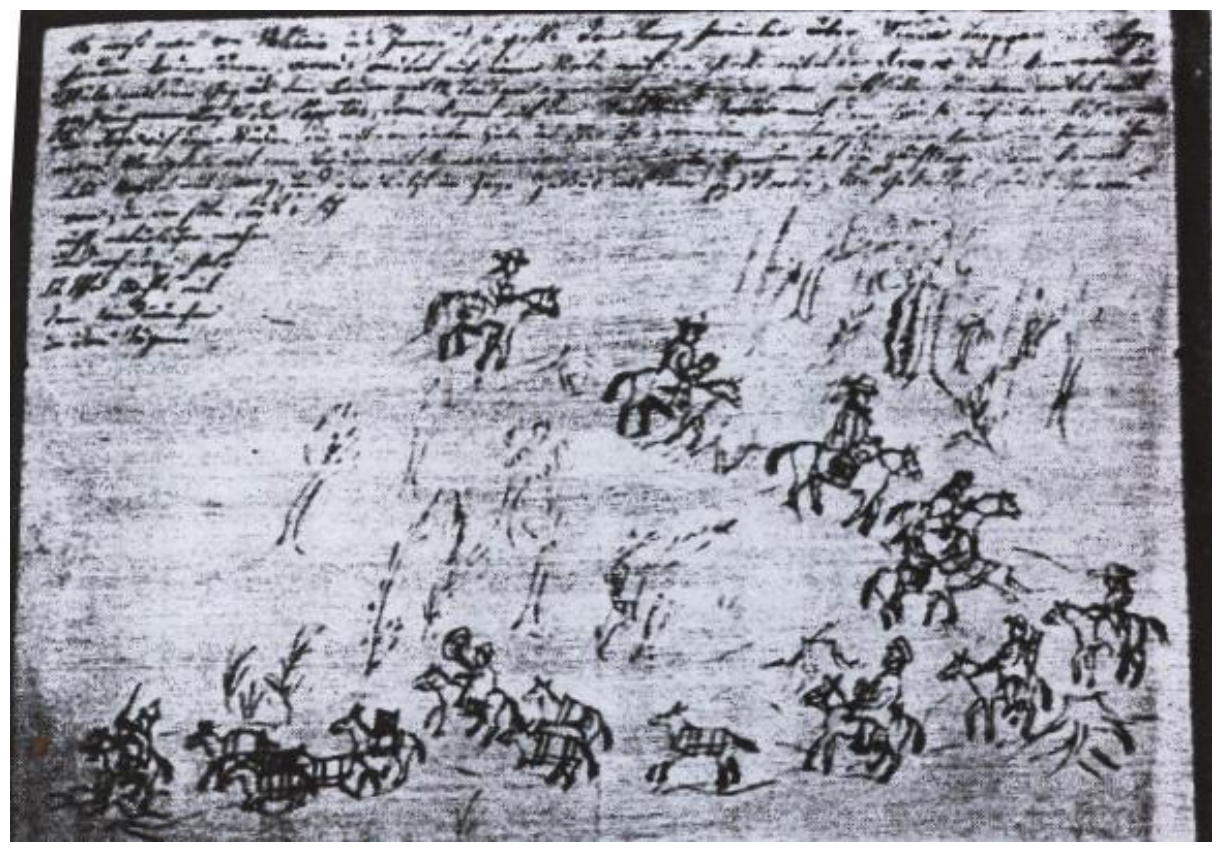

Lettre de Sophie von Bischhoffhausen, née von Eschwege. Les dessins accompagnent la description de la chevauchée réalisée à travers monts et forêts vers le domaine de Roble.

Collection privée de Werner von Bischhoffshausen, Santiago de Chile, Chili. 


\section{SOURCES ET BIBLIOGRAPHIE}

\section{1. $\quad$ Sources}

\subsubsection{Sources non publiées}

\section{- Archivo Nacional, Santiago de Chile, Chile}

Les Archives nationales du Chili offre un corpus d'archives sur l'émigration allemande incontournable mais déjà minutieusement analysé et présenté par J.P. Blancpain ${ }^{1}$. De nombreux volumes des fonds ministériels ${ }^{2}$ et notariaux sont consacrés à la colonisation et permettent de retracer les difficultés de l'installation et des premiers temps de défrichement, le lent établissement d'infrastructures de communication, les rapports avec la société chilienne et les notables, les conflits de propriété etc., ce qui présentait finalement peu d'intérêt dans la mesure où l'on ne proposait pas de réécrire l'histoire des Allemands au Chili. En conséquence, peu d'information donc sur la question des femmes ou de la famille outre les volumes suivants :

- Ministerio del Interior (MINT):

Vol. 273: Colonización Alemana (1849 - 1852)

Vol. 308: Colonización de Llanquihue (1852 - 1854)

Vol. 328: Oficios recibidos de la Intendencia de Valdivia (1854 - 1855)

Vol. 389: Colonización de Llanquihue (1857 - 1859)

Vol. 403: Oficios recibidos de la Intendencia de Llanquihue (1859-1863)

Vol. 419: Oficios recibidos de la Intendencia de Llanquihue (1860 - 1882)

Vol. 463: Oficios recibidos de la Intendencia de Llanquihue (1864 - 1868)

Ministerio de Relaciones Exteriores (MREL):

Vol. 280: Oficios recibidos de la Intendencia de Llanquihue (1883 - 1884)

- Biblioteca e Archivo Emilio Held Winkler, Liga Chileno-Alemana, Santiago de Chile, Chile

La bibliothèque et les archives du Deutsch-Chilenischer Bund (DCB)/Liga Chileno-alemana, soit l'association chileno-allemande, porte le nom de leur principal donateur, mais il existe d'autres fonds tout aussi capitaux, notamment celui d'Ingeborg de Schwarzenberg. La fréquentation du site s'est avérée indispensable pour compléter la bibliographie germanophone qu'on ne trouve pas à la Biblioteca Nacional ou dans les bibliothèques universitaires chiliennes, mais aussi pour constituer le corpus de sources primaires qui servent de fondement à la présente étude ${ }^{3}$.

\section{FONDO SCHWARZENBERG}

ARCHIVO GENEALOGICO Ingeborg Schwarzenberg de Schmalz (AGS):

- Catalogue électronique de notices généalogiques numérisées (de Liga01454 à Liga 27964)

- Arbres généalogiques des familles Schmidt, Hausdorf, Wulf, Hitschfeld, Werner, Matzner, Teuber et Appel, manuscrits.

\footnotetext{
${ }^{1}$ Blancpain J.P., Les Allemands au Chili, Op. Cit., p. 900-913.

2 La colonisation a successivement relevé des ministères de l'Intérieur des Affaires étrangères, de l'Instruction publique et des Cultes, puis, au début du XXe, des Terres et de la Colonisation. Cf. Ibid. p. 275.

${ }^{3}$ Pour une présentation de la Biblioteca e Archivo Emilio Held Winkler, voir «Historia y documentos sobre la colonización alemana en Chile »[en ligne], entretien de Lisette Winkler avec Christine Gleisner et Eduardo Carrasco $(1: 17: 57)$, réalisé le 20 décembre 2007 à Santiago du Chili, Accessible à l'URL : http://www.archivesaudiovisuelles.fr/1516/introduction.asp?id=1516 [consulté le 14 août 2008]. Christine et Eduardo, historiens de la Pontifica Universidad Católica de Chile, ont travaillé ensemble trois années aux archives, jusqu'en mars 2008.
} 


\section{FONDO FONCK}

Boîte (caja) 12 - Fanny Zöhrer ép. Fonck

Dossier (carpeta) 4 : Documents décès Fanny Zöhrer

4. a. Certificat de décès de Fanny Zöhrer à Liegau, le 15 mai 1873, Consulat du Chili à Dresde, 18 janvier 1875

4. c. Traduction manuscrite en espagnol par Francisco Fonck du certificat de décès et de sépulture de Francisca Zöhrer, datée du 12 avril 1875.

Dossier 6 : Manuscrit du journal de bord de Fanny Zöhrer, 1854.

6. a. Journal de bord de Fanny Zöhrer de Hambourg à Valparaiso à bord du voilier le «Fortunata », du 2 mai au 16 août 1854.

Dossier 10 : Copies manuscrites et transcriptions Fanny Zöhrer

10. a. Journal de Fanny Zöhrer, copie manuscrite sur papier de soie jaune par Emilie, le 14 janvier 1911, 24 pages.

10. c. Transcription dactylographiée du certificat de décès de Fanny Zöhrer à Liegau, le 15 mai 1873.

Dossier 11 : Presse Fanny Zöhrer

11. a. «In 120 Tagen von Hambourg über Karp Hoorn nach Valparaiso. Aus dem Reisetagebuch der Fanny Fonck von 1853» dans Condor, Santiago, 24 avril 1993, p. 10-11.

\section{- FONDO HELD}

Schiffslisten, 1850-1854, (PER 907 EH) [Copies des listes originales des passagers des Archives d'État de Hambourg].

Berichte, Erinnerungen und Briefe der Anfangszeit der Kolonisation im Süden Chiles Tome V (PER $953 \mathrm{EH}$ ), documents originaux et transcriptions dactylographiées [souvenirs de Anna SCHMIDT, pp. 247-251, de Berta ROBERT née Schoebitz, pp. 85-89 et de Berta SCHWARZENBERG née Klix, pp. 79-84]

Briefwechsel Schubert-Held-Aurich und andere (PER 906 EH), documents originaux et transcriptions dactylographiées [Lettres de Rosine HELD née Schönherr, pp. 127-144].

Errinerungen von Pauline RENZ, geb. Hube (PER 966 EH), document original et transcription dactylographiée, $17 \mathrm{p}$.

Matrimonios Puerto Montt (1855-1884) (EH 5000 PM)

Nacimientos Puerto Montt (1856-1885) (EH 5001 PM)

Documentos parroquiales y otros de Osorno (EH 5000 OS)

Matrimonios Osorno (EH 5001 OS)

Nacimientos Osorno (EH 5002 OS)

Documentos Escuelas Colonia Llanquihue, 9.2.1857-23.4.1888 (EH 5106 LL)

Livre de visite de la bibliothèque privée d'Emilio Held [Tenu de 1962 à 1993, on y découvre toutes les personnes qui ont visité, par intérêt personnel ou à finalité de recherche, la collection privée que Held a rassemblé sur les Allemands au Sud du Chili. On y rencontre ainsi Blancpain et Schobert. On notera l'absence de Young]

FONDO GENERAL :

AICHELE Magdalena Barbara, lettre, transcription dactylographiée, s. d, 3 p.

Censo de familias alemanas y familias chilenas de origen alemán, 1916/1917, Liga chilenoalemana, 2 vol.

GLEISNER Clémentine Friederike, Tagebuch, transcription dactylographiée, s. d, s.p. (PER 100 GLE)

MUÑOZ Gertrud, Kindheitserinnerungen aus Valdivia, transcription dactylographiée (de 1984), 36 p. 


\section{- Archivo del museo histórico e antropológico Maurice van de Maele, Valdivia, Chili}

Les archives documentaires du Musée historique et anthropologique Maurice van de Maele de Valdivia (ancienne maison Anwandter) conservent principalement l'épistolaire de la famille Holzapfel ${ }^{1}$.

En particulier :

Lettre à Margarethe Hantelmann de Holzapfel de l'une de ses filles (1886), document original, 8 p. Lettres d'Ana Holzapfel à sa sœur Luise Holzapfel de Exss (1896 - 1897), quatre lettres, documents originaux, $18 \mathrm{p}$.

Lettre d'Else Gundul à Luise Holzaphel de Exss (1896 - 1897), quatre lettres, documents originaux, $22 \mathrm{p}$.

Lettres de Margarethe Holzapfel de Gundul à sa sœur Luise (1896 - 1897), trois lettres, documents originaux, $6 \mathrm{p}$.

Fragment du journal de voyage de Luise Holzapfel au Sud du Chili, sans date, document original, $41 \mathrm{p}$.

Lettres de Margarethe Hantelmann de Holzaphel à sa fille Luise (1896 - 1897), dix-huit lettres, documents originaux, $60 \mathrm{p}$.

Lettre de Luise Holzapfel Exss à sa sœur Ines Holzapfel de Bohnet (1903), document original, 8 p.

Lettres de Luise Holzapfel Exss à sa sœur Margarethe Holzapfel de Gundel (1897 - 1914), six lettres, documents originaux, $49 \mathrm{p}$.

Lettres de Luise Holzapfel, ép. Exss, à ses parents Margarethe et Alejandro Holzapfel (1895 1914), documents originaux, $122 \mathrm{p}$.

\section{- Archives privées}

Histoire familiale et mémoires écrites par Hélène Scheel, née Biel Linke, document original et dactylographié conservé par la famille Scheel.

\subsubsection{Sources publiées}

- Recensements de population :

Censo general de la República de Chile: levantado en abril de 1854, por la Oficina de Estadística, Santiago de Chile, Imp. Del Ferrocarril, 1858, 2-1 p. (43 tableaux sans pagination).

Censo general de la República de Chile levantado el 19 de abril de 1865, Santiago de Chile, Impr. Nacional, 1866, 4-XXVII-3-392 p.

Quinto Censo general de la Población de Chile: levantado el 19 de abril de 1875, compilado por la Oficina Central de Estadística en Santiago, Valparaíso, Impr. del Mercurio, 1876. LVIII, 6-LVIII-674 p.

Sesto Censo general de la Población de Chile: levantado el 26 de noviembre de 1885, compilado por la Oficina Central de Estadística en Santiago, Valparaíso, La Patria, volumen 1, 1889, volumen 2, 1890, 2-XVI-499-5 p.

Sétimo Censo general de la Población de Chile: levantado el 28 de noviembre de 1895, compilado por la Oficina Central de Estadística, Santiago de Chile, La Oficina, 1900-1904, s.p.

- Lettres, journaux de vie, récits de voyages et publications diverses :

ALFONSO DEL BARRIO José Antonio, Un viaje a Valdivia. La civilización alemana en Chile, Santiago de Chile, Imprenta Moderna, 1900, 47 p.

\footnotetext{
${ }^{1}$ Ce corpus n'a pas pu être pleinement exploité dans le présent travail, faute de temps, mais pourrait faire l'objet d'une recherche ultérieure.
} 
ANWANDTER Carl, Desde Hamburgo a Corral: diario de viaje de Carl Anwandter a bordo del velero Hermann, Valdivia, Universidad Austral de Chile, Santiago de Chile, Pehuén, 2001, $198 \mathrm{p}$.

ARANDA Diego, LLARENA José María, TEJANO Rafael, La colonia alemana en Chile, Santiago de Chile, Imprenta Claret, 1920, X, 835 p.

BAUER Kurt, Das Gewissen der Stadt. Geschichte der deutschen Schule zu Valdivia in Chile. Concepción, Verlag des Wissenschaftlichen Archiv von Chile (Abteilung des Deutschchilenischen Bund), 1925, 221 p.

, Helden der Arbeit, Ein Buch vom deutschen Seebauer Chiles, Stuttgart, Ausland und Heimat Verlags, Reihe A, Band 23, 1929, 168 p.

, Um Heimat undVolk, Valparaiso, 1934.

BÖHM Günther (éd.), « Briefe und Berichte von Karl von Numers, Karl Anwandter, Louis und Pauline Metzdorff, Auguste Schulz, John Fehland »dans Dokumente sur Geschichte der deutschen Einwanderung, Heft V, Santiago de Chile, Talls. Gráfs. Claus von Plate, 1974, 64 p. [Lettres de Pauline Metzdorff, pp. 23-43].

BÜRGER Otto, Acht Lehr- und Wanderjahre in Chile, Leipzig, Dietrich's Verlagsbuchhandlung, 1909 (2nde édition 1923), XII-410 p.

DAVIDIS Henriette, Praktisches Kochbuch für die gewöhnliche und feinere Küche, 38e édition révisée et augmentée par Luise Holle, Bielefeld, Verlag von Velhagen\&Klasing, 1900.

Deutsche Schule Puerto Montt, 1869-1939: 70 Jahr-Teier, Santiago, Impr. Cervantes, 1939, 69 p.

75 Jahre Deutsche Schule Valdivia, 1858-1933, Valdivia, Imprenta Borneck, 1934, 144 p.

75 Jahre Deutschtum in Llanquihue, Deutsch-chilenisches Bund, Santiago de Chile, 1927. Sonderherft Nr. 3, Deutsche Monatshefte für Chile, Jahrg. 7, Heft 9/10.

Die deutsche Arbeit in Chile, Festschrift des Deutschen Wissenschaftlichen Vereins zu Santiago zur Centenarfeier der Republik Chile, Santiago de Chile, 2 vol. : vol. 1,1910, 325 p. ; vol. 2, 1913, 202 p. [le premier volume a été traduit en castillan sous le titre Los Alemanes en Chile cité ci-dessous].

DOMEYKO Ignacio, Memoria sobre la colonización de Chile, Santiago de Chile, Impr. Julio Belen y Ca., 1850, $14 \mathrm{p}$.

ESCOBAR V. Aníbal, Francia: la Colonia Francesa en Chile, Santiago de Chile, 1920, 472 p.

GAEDICKE Fritz, Die deutsche Kolonie am See Llanquihue (Chile), Valparaiso, Imprenta Germania, 1910, $54 \mathrm{p}$.

GERSTAECKER Friedrich, Achtzehn Monate in Süd-Amerika und dessen deutschen Kolonien, Leipzig, 1864, 2 Bde, I, 544 p., II, 516 p.

GONZÁLEZ D. Marcial, La Europa i la América, o, La emigración europea, en sus relaciones con el engrandecimiento de las repúblicas americanas, Santiago de Chile, Imp. del Progreso, 1848, $51 \mathrm{p}$.

GRAHAM María, Diario de una residencia en Chile, reedité par Neville Blanc Renard, Santiago de Chile, Andros, 2007 (1824), 514 p.

HAHN Mary, Illustriertes Kochbuch für die einfache und feine Küche, 33e et 34e édition, Berlin, Mary Hahn's Kochbuch-Verlag, 1928.

HELD WINKLER Emilio, Documentos sobre la colonización del Sur de Chile, Santiago de Chile, Talleres Grafico Claus Von Plate, 1970, 214 p.

Colonización alemana del Sur de Chile, Documentación de su origen, Santiago de Chile, Iges, 1996, $372 \mathrm{p}$.

HELD WINKLER Emilio, SCHUENEMANN Helmut, VON PLATE Claus, 100 Jahre deutsche Siedlung in der Provinz Llanquihue, Santiago de Chile, Verlag Condor, 1952, 202 p.

HOESTEREY Laura, ép. GRISAR, Tagebuch und Briefe von Laura Hoesterey 1854-1855, Édition privée, Imprenta Victoria-Valparaíso 1938, 154 p.

KUNZ Hugo, Chile und die deutschen Kolonien, Leipzig, Comissions-Verlag, Julius Klinkhardt, 1891, IX, 633, $134 \mathrm{p}$.,

Von LOE Elisabeth (ed.), Marie Bülling: Una institutriz Alemana en Valparaíso. Diario de vida, 1850-1861, Trad. del alemán: Rosemarie Kempf Titze. Valparaíso, Universidad de Playa Ancha, 2004, 324 p. [Journal intime de Marie Bülling, traduit et commenté]. 
Los Alemanes en Chile: Homenaje de la Sociedad Científica Alemana de Santiago a la Nación chilena en el centenario de su independencia, Santiago de Chile, Imprenta Universitaria, 1910 [traduction du premier volume de Die Deutsche Arbeit in Chile cité ci-dessus].

PALACIOS Nicolás, Raza chilena; libro escrito por une chileno y para los chilenos, Imprenta y Litografía alemana de Augusto Schäfer, 1904.

PÉREZ ROSALES Vicente, Recuerdos del pasado (1814-1860), Santiago de Chile, Zig-Zag, 1943, $500 \mathrm{p}$.

, Essai sur le Chili, Hambourg, F.H. Nestler \& Melle, 1857, XXI-445 p.

PINOCHET LE BRUN Tancredo, La conquista de Chile en el siglo XX, Santiago de Chile, Imprenta, Litografía y Encuadernación "La Ilustración", 1909

POEPPIG Eduard, Reise in Chile, Peru und auf dem Amazonenstrome während der Jahre 18271832, Stuttgart, F.A. Brockhaus, 1960 (Leipzig, Friedrich Fleischer, 1835-1836), 2 tomes en 1 volume

SAUSER Eckart, Die Zillertaler Inklinanten und ihre Ausweisung im Jahre 1837, Innsbruck, Üniversitätsverlag Wagner, 1959, 105 p.

SCHWARZENBERG Georg (éd.), Geschichtliche Monatsblätter. Quellensammlung und Beiträge zur Geschichte der Deutschen Einwanderung, Heft XII, Valdivia, 1918 [Lettres de Anna et Antonie EXSS, pp. 3-22 et de Adelheid KINDERMANN pp. 39-51].

, «Tagebuch der Frau Fanny Fonck, geb. Zöhrer, Ehefrau des Kolonie-Arztes Dr. Franck Fonck, ihrer Reise auf dem Schiffe „Fortunata“ nach Chile», Geschichtliche Monatsblätter. Quellensammlung und Beiträge zur Geschichte der Deutschen Einwanderung, Heft IX, Valdivia, 1917, pp. 156-170 [Journal de Fanny Fonck née Zöhrer. Version originale aux Archives Emil Held Winkler, Santiago].

SCHWARZENBERG de SCHMALZ Ingeborg (éd.), " Theodor Körner (Die Besiedlung von Arique) », Dokumente zur Geschichte der deutschen Einwanderung/Documentos para la historia de la inmigración Alemana, Heft III, Santiago de Chile, Talls. Gráfs. Claus von Plate, 1973, [Lettres de Klara Anwandter, p. 7-8].

, «Los Geisse en Chile », Dokumente zur Geschichte der deutschen Einwanderung/ Documentos para la historia de la inmigración Alemana, Heft IV, Santiago, Talls. Gráfs. Claus von Plate, 1973, $106 \mathrm{p}$.

, «Sophie von Bischhoffshausen geb. von Eschwege (Aus dem Nachlass von Frau Elenita Richter geb. von Bischhoffshausen) ", Dokumente zur Geschichte der deutschen Einwanderung/ Documentos para la historia de la inmigración Alemana, Heft VI, Santiago de Chile, Talls. Gráfs. Claus von Plate, 1973, 119 p.

, «Aus Granny's Nachlass, Briefe und Tagebuch aus den Jahren 1840-1849 », Sonderabdruck der Geschichtlichen Monatshefte des Deutsch-chilenischen Bundes, Santiago de Chile, DCB, 1933, 113 p. [Compilation des publications du journal et des lettres de Minna Claude dans le Geschichtlichen Monatshefte des Deutsch-chilenischen Bundes, Heft 8/1932 (p. 235-251), 9/1932 (269-284), 10/1932 (313-322), 11/1932 (354359), 12/1932 (391-396), Heft 1/1933 (p. 20-45), 2/1933 (64-86), 3/1933 (104-110)]

TREUTLER Paul, Andanzas de un alemán en Chile (1851-1863), Santiago de Chile, Editorial del Pacifico S.A., Traducción de Carlos Keller, 570 p.

UNOLD Johannes, Das Deutschtum in Chile : Ein Zeugnis erfolgreicher deutschen Kulturarbeit, München, J.F. Lehmann, 1900, 68 p.

VEGA Nicolás, La inmigración europea en Chile, 1882 a 1895, Paris, Agencia General de Colonización del Gobierno de Chile, 1896, 194 p.

VON PLATE Claus (éd.), Puro Chile, Ein Heimatbuch, Santiago de Chile, Verlag des „Condor“, $1967,252 \mathrm{p}$.

VICUÑA MACKENNA Benjamín, Bases del informe presentado al supremo gobierno sobre la inmigración extranjera, Santiago de Chile, Imprenta Nacional, 1865, 230 p.

ZAJADACZ Friederich, 100 Jahre Deutsche Schule zu Osorno :1854-1954, Valparaíso, Impr. Victoria, 1954, $156 \mathrm{p}$.

- Journaux et périodiques : 
Valdivia's Deutsche Zeitung (Valdivia), 1886-1912.

Geschichtliche Monatsblätter. Quellensammlung und Beiträge zur Geschichte der Deutschen Einwanderung nach Chile (Osorno), 1916-1918. Publication privée de Georg Schwarzenberg, professeur d'histoire et de géographie, poursuivie par sa fille Ingeborg, ép. Schmalz, des cahiers 13 à 16 (1970-1973).

Condor (Deutsch-chilenisches Bund, Santiago), 1933-

\subsubsection{Entretiens}

Entretien avec Andrea Lindemann, en allemand, le 6 février 08, Frutillar (0:58:27)

Entretien avec Nohelia Clara Westermeier Birke, en espagnol, le 7 février 08, Frutillar (0:40:35)

\subsection{Bibliographie}

\subsubsection{Usuels}

CARRASCO G. Eduardo, GLEISNER V. Christine, Fondo Fonck, Catalogo de documentos, libros y objetos conservados en la Biblioteca y Archivo Histórico Emilio Held Winkler, Santiago de Chile, Liga Chileno-Alemana (DCB), 2007, 74 p.

CHAUNU Pierre, Histoire de l'Amérique latine, Paris, PUF, Que sais-je?, 1949, 127 p. , L'Amérique et les Amériques de la préhistoire à nos jours, Paris, Armand Colin, 1964, $470 \mathrm{p}$.

CHEVALIER François, Histoire de l'Amérique latine, de l'Indépendance à nos jours, Nouvelle Clio, PUF, 2e éd., 1993 (1973), XVI-723 p.

COLLIER Simon, SATER William F., A History of Chile, 1808-2002, Second Edition, Cambridge University Press, 2004 (1996), XXI-454 p.

COUYOUMDJIAN B. Ricardo, REBOLLEDO H. Antonio, Bibliografía sobre el proceso inmigratorio en Chile, desde la Independencia hasta 1930, Santiago de Chile, Instituto Panamericano de Geografía e Historia, 1984, pp. 121-187.

CRUZ Nicolás, WHIPPLE Pablo, Nueva historia de Chile: desde los orígenes hasta nuestros días, Santiago de Chile, Zig-Zag , 2000, 575 p.

KLEIN Karl Kurt, Literaturgeschichte des Deutschtums im Ausland, Hideslheim, New York, Georg Olms Verlag, 1979, 556 p. [Bibliographie du Deutschtum au Chili, pp. 546-548].

MORALES Félix (dir.), Nuevo diccionario ejemplificado de chilenismo y de otros usos diferenciales del Español de Chile, Valparaíso, Gobierno de Chile, Fondo del Libro y la Lectura, Editorial Puntángeles, Universidad de Playa Ancha, 2006, 3 volúmenes.

VILLALOBOS Sergio, SILVA Oswald, SILVA Fernando (et al.), Historia de Chile, Santiago de Chile, Editorial Universitaria, 1974.

\subsubsection{Ouvrages}

ANDERSON Benedict, L'imaginaire national. Réflexions sur l'origine et l'essor du nationalisme, Paris, La Découverte, 1996, 212 p.

ARIES Philippe, DUBY Georges (dir.), Histoire de la vie privée. 4. De la Révolution à la Grande Guerre, Points Seuil, Paris, 1999 (1987), 621 p. Volume dirigé par Michelle PERROT.

BEAUR Gérard, DUHAMELLE Christophe, Les Sociétés rurales en Allemagne et en France, XVIII-XIX ${ }^{e}$ siècle, Rennes, Presses Universitaires de Rennes, 2004, 302 p.

BERDING Helmut, Histoire de l'antisémitisme en Allemagne, Editions de la Maison des sciences de l'homme, Paris, 1991, VIII-282 p.

BERNEDO Patricio, Panguipulli: historia de cuatro tiempos, Panguipulli, Hans Storandt, 1994, 74 p. 
BICKELMANN Hartmut, Deutsche Überseeauswanderung in der Weimarer Zeit, Wiesbaden, Franz Steiner Verlag, 1980, 180 p.

BLANCPAIN Jean-Pierre, Les Allemands au Chili (1816-1945), Köln, Bölhau Verlag, 1974, XXXII-1162 p., 14 p. de pl.

, Los alemanes en Chile (1816-1945), traducción de Luis Enrique Jara. Santiago de Chile, Ediciones Pedagógicas Chilenas y Editorial Universitaria, 1985, 209 p.

, Francia y los franceses en Chile (1700-1980), traducción de Luis Enrique Jara, Santiago de Chile, Ediciones Pedagógicas Chilenas e Editorial Universitaria, 1987, 355 p.

, Migrations et mémoire germaniques en Amérique latine à l'époque contemporaine, contribution à l'étude de l'expansion allemande outre-mer, Presse Universitaire de Strasbourg, 1994, 353 p.

BOCK Gisela, JAMES Susan (dir.), Beyond Equality and Difference, Citizenship, feminist politics and female subjectivity, London, Routledge, 1992, 224 p.

BOSSIS Mireille, La lettre à la croisée de l'individuel et du social, Paris, Ed. Kimé, 1992, 254 p.

BOSSIS Mireille, PORTER Charles A. (dir.), L'épistolarité à travers les siècles: geste de communication et/ou d'écriture, Stuttgart, F. Steiner, 1990, 188 p.

BOURDIEU Pierre, La domination masculine, Paris, Seuil, 1998, 154 p.

De CERTEAU Michel, L'écriture de l'histoire, Paris, Gallimard, 1975, 358 p.

CHARTIER Roger (dir.), La correspondance, les usages de la lettre au XIX $X^{e}$ siècle, Fayard, Paris, 1991, $462 \mathrm{p}$.

, Au bord de la falaise. L'histoire entre certitudes et inquiétude, Paris, Albin Michel, 1998, $292 \mathrm{p}$.

COLLIN Françoise (dir. publ.), Le genre de l'Histoire. Les Cahiers du GRIF 37/38, Paris, Editions ok

Tierce, 1988, 189 p.

COUYOUMDJIAN Ricardo, Chile y Gran Bretaña durante la Primera Guerra Mundial y la postguerra, 1914-1921, Santiago de Chile, Ed. Andrés Bello, 1986, XVI-340 p.

DIAZ Brigitte et SIESS Jürgen (dir.), L'épistolaire au féminin : correspondances de femmes, XVIIIe-XXe siècle, Caen, Presses Universitaires de Caen, 258 p.

DUBY Georges, PERROT Michelle (dir.), Histoire des Femmes en Occident. 4. Le XIXe siècle, Perrin, Paris, 2002 (Plon, 1991), 764 p. Volume dirigé par Geneviève FRAISSE et Michelle PERROT.

ESTRADA Baldomero (ed.), Presencia italiana en Chile, Valparaíso, Eds. Universitarias de Valparaíso, 1993, 227 p.

FABRE Danièle, Par écrit. Ethnologie des écritures quotidiennes, Cahier d'ethnologie de la France (11), Paris, Maison des Sciences de l'Homme, 1997.

FOUCAULT Michel, L'archéologie du savoir, Paris, Gallimard, 1969, 281 p.

FRÖSCHLE Harmut, Die Deutschen in Lateinamerika, Schiksal und Leistung, Darmstadt, Horts Erdmann Verlag, Tübingen, 1979, 880 p.

GABACCIA Donna, Immigrant women in the United States: a selectively annotated multidisciplinary bibliography, New York, Greenwood Press, 1989, XIV-325 p.

, From the Other Side: Women, Gender and Immigrant Life in the US. 1820-1990, Bloomington, Indiana University Press, 1996, 192 p.

GLEISNER Christine, El kuchen: dulce tradición alemana en Chile, Santiago, RR Donelley, 2005, $85 \mathrm{p}$.

GÖTZ Karl, Brüder über Land und Meer, Schicksale und Geschichten der Ausgewanderten, Bodensee, Hohenstaufen Verlag, 1967, 404 p.

GRANDJOT Carlos, SCHMIDT Ernesto, Die beiden Heimatsprachen der Chilenen deutscher Abstammung, Ergebnisse einer statistichen Umfrage / El Bilingüismo de los chilenos de ascendencia alemana, resultado de una encuesta estadística, Santiago de Chile, Liga Chileno-Alemana, 1960, $48 \mathrm{p}$.

GRASSI Marie-Claire, Lire l'épistolaire, Paris, Armand Colin, 2005 (Dunod, 1998), XI-194 p.

GREEN Nancy L., Repenser les migrations, Paris, PUF, 2002, 138 p.

GROSSBACH Günter, Carl Anwandter, Valdivia, Instituto Alemán Carl Anwandter, 2005, 347 p. 
GUARDA Gabriel, La Sociedad en Chile austral antes de la colonización alemana 1645-1850, Santiago de Chile, Ed. Andrés Bello, 1979, 566 p.

, Nueva Historia de Valdivia, Santiago de Chile, Ed. Universidad Católica de Chile, 2001, $862 \mathrm{p}$.

HALPERIN Tulio Donghi, Historia contemporánea de América Latina, Madrid, Alianza Editorial, $1981,750 \mathrm{p}$.

HAREVEN Tamara K., Family time and industrial time : the relationship between the family and work in a New England industrial community, Cambridge, New York, Cambridge University Press, 1982, XVIII-474 p.

HARRIS BUCHER Gilberto, Inmigración y emigración en Chile durante el siglo XIX: estudios y documentos, Valparaíso, Universidad de Playa Ancha de Ciencias de la Educación Facultad de Humanidades, 1997, 178 p.

HAU Michel, Histoire économique de l'Allemagne (XIX $-X X^{e}$ siècle), Paris, Economica, 1994, 364 p.

ILG Karl, Pioniere in Argentinien, Chile, Paraguay und Venezuela. Durch Bergwelt, Urwald und Steppe erwanderte Volkskunde der deutschsprachigen Siedler, Tyrolia-Verlag, Innsbruck, Wien, München, 1976, 318 p.

JAUSS Hans Robert, Pour une esthétique de la réception, Paris, Gallimard, 1978, 305 p.

KINZEL KAHLER Enrique, HORN KLENNER Bernardo, Puerto Varas, 130 años de historia, 1852-1983, Puerto Varas, Imprenta y Liberia Horn y Cía., Ldta., 1983, 414 p.

KONRAD Kurt (éd.), Familia Konrad, Julius Konrad y Marie Püschel, 150 años, 1856-2006, Santiago, Impr. Gráfica Escorpio, 2007.

KOTT Sandrine, L'Allemagne au XIX siècle, Paris, Hachette, 1999, 254 p.

LAMAS Marta (dir.), El género, la construcción cultural de la diferencia sexual, México, UNAM, Programa Universitario de Estudios de Género, 1996, 367 p.

LANDES Joan B., Feminism, the Public and the Private, Oxford University Press, 1998, X-507 p.

LEGARRAGA RADDATZ Patricio, Frutillar, genealogías de Familias Alemanas, Santiago de Chile, KA2, 1998, 616 p.

Les migrations internationales de la fin du XVIIIe à nos jours, Commission internationale d'Histoire des mouvements sociaux et des structures sociales, Paris, Editions du CNRS, 1980, III-706 p.

LILLO Natacha, RYGIEL Philippe (dir.), Rapports sociaux de sexe et immigration. Actes de l'Histoire de l'Immigration, 6/2006, Paris, Publibook Université, 2007, 144 p.

, Images et représentations du genre en migration. Mondes atlantiques XIX ${ }^{e}-X X^{e}$ siècles. Actes de l'Histoire de l'Immigration, 7/2007, Paris, Publibook Université, 2007, 140 p.

LÜBKE Alexandra, „Welch ein Unterschied aber zwischen Europa und hier...". Diskurstheoretische Überlegungen $z u$ Nation, Auswanderung und kultureller Geschlechteridentität anhand von Briefen deutscher Chileauswanderinnen des 19. Jahrhunderts. Frankfurt am Main, London, IKO-Verlag, 2003, 311 p.

MOGE Leslie Page, Moving Europeans: Migration in Western Europe since 1650, Indiana University Press, 1992, XII-257 p.

NASH Mary, Mujeres en el Mundo, Historia, retos y movimientos, Madrid, Alianza Editorial, $2004,333 \mathrm{p}$.

NEUMANN KUSCHEL Alfredo, Presencia de la mujer en la Inmigración Alemana en el Sur de Chile. Algunos antecedentes históricos, Trabajo presentado en el Seminario de Termas de Puyehue, 4 de octubre de 1978, 26 p.

NORAMBUENA CARRASCO Carmen, Política y legislación inmigratoria en Chile, 1830-1930, Santiago de Chile, Universidad de Santiago de Chile, Facultad de Humanidades, Departamento de Historia, Impr. Multigráfica, 1990, 123 p.

OJEDA-EBERT Gerardo Jorge, Deutsche Einwanderung und Herausbildung der chilenischen Nation (1846-1920), Nürnberg, Fink Verlag München, 1984, 216 p.

PATEMAN Carole, The Disorder of Women: Democracy, Feminism, and Political Theory, Stanford, California, Stanford University Press, 1989, VIII-228 p.

PERROT Michelle, Les femmes ou les silences de l'Histoire, Champs Flammarion, Paris, 1998, XVI-493 p. 
Pioneros del Llanquihue, Edición Conmemorativa, 1852-2002, Santiago de Chile, Deutschchilenischer Bund (DCB)/Liga Chileno-alemana, 2002, 310 p.

PLANTÉ Christine (éd.), L'épistolaire, un genre féminin?, Honoré Champion, Paris, 1998, 305 p.

PRATT Mary Louise, Imperial Eyes. Travel writing and Transculturation, London, New York, Routledge, 1992, XII-257 p.

RAMOS ESCANDÓN Carmen (dir.), Género e historia: la historiografía sobre la mujer, México D.F., Instituto Moro, Universidad Autónoma de México, 1992, 200 p.

ROCHE Jean, La colonisation allemande et le Rio Grande do Sul, Paris, Institut des Hautes Etudes de l'Amérique Latine, 1959, XXVI-696 p., XIV p. de pl.

ROTH François, L'Allemagne de 1815 à 1918, Paris, Armand Colin, 2002, 192 p.

ROUSSEAU Jean-Jacques, Emile ou de l'Education, Paris, Garnier, 1900, p.

SAGREDO Rafael, GAZMURI Cristián (dir.), Historia de la vida privada en Chile, Tomo $2-E l$ Chile moderno, de 1840 a 1925, Santiago de Chile, Eds. Taurus, 2005, 394 p.

SAÏD Edward W., Culture et impérialisme, Paris, Fayard, 2000, 555 p.

SANHUEZA CERDA Carlos, Chilenos en Alemania y alemanes en Chile: viajes y nación en el siglo XIX, Santiago de Chile, Dirección de Bibliotecas, Archivos y Museos, Centro de Investigaciones Diego Barros Arana, LOM Ediciones, 2006, 269 p.

SARGET Marie-Noëlle, Histoire du Chili de la Conquête à nos jours, Paris, L'Harmattan, 1996, $319 \mathrm{p}$.

SCHOBERT Kurt, Soziale und kulturelle Intergration am Beispiel der deustchen Einwanderung und Deutschchilenen in Südchile, München, Kurt Schobert Verlag, 1983, 2 vol, p. 756.

SERRANO Sol (éd.), Vírgenes viajeras: diarios de religiosas francesas en su ruta a Chile, 18371874. Santiago de Chile, Ediciones Universidad Católica de Chile, 2000, 352 p.

SOHN Anne Marie, La correspondance, un document pour l'histoire, Publications de l'Université de Rouen, 2002, 109 p.

THÉBAUD Françoise, Écrire l'histoire des femmes et du genre, Paris, ENS Éditions, 2007, 312 p., $2^{\mathrm{e}}$ édition revue et augmentée de Écrire l'histoire des femmes, 1998.

TILLY Louise A., SCOTT Joan W, Les femmes, le travail et la famille, Paris, Payot et Rivages, 2002 (1978), 389 p.

TODD Emmanuel, L'invention de l'Europe, Paris, Seuil, 1990, 685 p.

VOVELLE Michel (et al.), Historia de las mentalidades. Homenaje a Georges Duby, Santiago de Chile, Universidad de Chile, Facultad de Filosofía y Humanidades, Departamento de Ciencias Históricas, 2000, 387 p.

WEHLER Hans-Ulrich, Essai sur l'histoire de la société allemande (1870-1914), Paris, Maison des Sciences de l'Homme, 2003, $230 \mathrm{p}$.

WETZEL KUSCH Yennis, Mis 100 mejores recetas de Cocina Alemana del Sur de Chile, Santiago de Chile, Zig-Zag, 1996, 182 p.

WOJAK Irmtrud, Exil in Chile: Die deutsch-judische und politische Emigration wahrend des National socialismus, 1933-45, Berlin, Metropol Verlag, 1994, 304 p.

YOUNG George F. W., The Germans in Chile: Immigration and Colonization, 1849-1914, NewYork, Staten Island, Center for Migration Studies of N.Y, 1974, 236 p.

ZALDÍVAR Trinidad, VIAL María José, RENGIFO Francisca, Los Vascos en Chile, 1680-1820, Santiago de Chile, Editorial de Los Andes, 1998, 272 p.

ZALDÍVAR HURTADO Paula, Italia en sueños: identidad, imágenes y recuerdos de quince mujeres italianas en Chile, Santiago de Chile, Artecien/CIES-Roma, 1994, 204 p.

\subsubsection{Thèses et mémoires}

ARAYA GÓMEZ Rodrigo, Chilenos, Huilliches e Inmigrantes. Arcaísmo y modernidad en Valdivia. 1896-1926, Tesis para optar al grado de Magíster en Historia de Chile ${ }^{1}$, Universidad de Chile, Facultad de Filosofía y Humanidades, 2006, 192 p.

\footnotetext{
${ }^{1}$ Au Chili, la thèse de Licenciatura correspondrait au mémoire de master 1 français (5e année d'études). Le Magister est une sorte de doctorat en 2 ans (bac+7), distinct du programme de Doctorado équivalent exact du
} 
BERNEDO Patricio, Bürgertum und Moderniesierungansätze in Chile im 19. Jahrhundert. Der Beitrag der Deutschen Einwanderer in Valdivia und La Frontera, Doktorabeit, Katolische Unversität Eichstätt, 1995, 265 p.

GÖDDE Claudia Barbara, Percepción del "otro" en cartas de inmigrantes alemanes alrededor de 1850, trabajo de investigación en el ramo del curso "Inmigrantes en Chile: desarrollos, aportes e impactos durante los siglos XIX y XX », Pr. Patricio Bernedo, Pontificia Universidad Católica de Chile, Instituto de Historia, 2000, 29 p.

„,, Mit begreiflicher Spannung lauschten wir auf die Echos in der Welt... “ Die Perzeption des „Dritten Reiches" in der deutschsprachigen Presse Chiles - eine Analyse von Presseartikeln zu ausgewählten politischen und militärischen Ereignissen 1933 - 1943. Magisterarbeit in Geschichtswissenschaft, TU-Chemnitz, 2002, 177 p.

GLEISNER VERGARA Christine, La conservación de la germanidad en el Sur de Chile (18711914), Tesis para optar al grado de Licenciado en Historia, Pontificia Universidad Católica de Chile, Instituto de Historia, 2004, 207 p.

KERSCHER Christof, Die Deutschen in Chile - Geschichte ihrer kulturellen Integration (von der Einwanderung bis heute), Diplomarbeit, Passau, Universität Passau, 1996, 71 p.

SINGER Christine, Zur Sonderstellung der deutschen Minderheit in Chile. Deutsche Auswanderer zwischen Mythos und Realität. Magisterarbeit, Universität Konstanz, Philosophische Fakultät, 1998, 92 p.

\subsubsection{Articles}

AUSLANDER Léora et ZANCARINI-FOURNEL Michelle, «Le genre de la nation et le genre de l'État ", Clio, 12/2000, Le genre de la nation. [Accessible en ligne à l'URL : http://clio.revues.org/document161.html, consulté le 30 avril 2008].

BERDING Helmut, "Staatliche Identität, nationale Integration und politischer Regionalismus », Blätter für deutsche Landesgeschichte, 121, 1985, pp. 371-393.

BERNEDO Patricio, «Las Iglesias alemanas frente al problema de la emigración masiva, 1816$1914 »$, Historia 27/1993, Pontificia Universidad Católica de Chile, pp. 69-87.

«Los industriales alemanes en Valdivia, 1850-1914 », Historia 32/1999, Pontificia Universidad Católica de Chile, pp. 5-42.

«Las estrategias periodísticas del periódico Valdivia's Deutsche Zeitung, 1886-1912 », Historia 33/2000, Pontificia Universidad Católica de Chile, pp. 5-61.

BLANC CHALEARD Marie-Claude, «L'histoire de l'immigration aujourd'hui. Quelques pistes de réflexion », Actes de l'Histoire de l'Immigration, Résumés d'intervention, 2000. [Accessible en ligne à l'URL :

http://barthes.ens.fr/clio/revues/AHI/articles/preprints/blanchal.html, consulté le 12 janvier 2008].

BLANCPAIN Jean-Pierre, "La tradition paysanne allemande au Chili. La colonie de Llanquihue (1850-1920) », Cahiers des Amériques latines 4/1969, pp. 3-43.

, "La tradición campesina alemana en Chile », apartado del Boletín de la Academia Chilena de la Historia, 81/1969, pp. 81-139.

, «Origines et caractères des migrations germaniques en Amérique latine au XIX ${ }^{\mathrm{e}}$ siècle », Jahrbuch für Geschichte von Staat, Wirtschaft und Gesellschaft Lateinamerikas 25/1988, pp. 349-383.

BOCK Gisela, «La Historia de la mujer y la historia de Género: aspectos de un debate internacional », Historia Social, 9/Hiver 1991, pp. 55-77.

BÖHM Günter, «Inmigración de judíos de habla alemana a Chile y Perú durante el Siglo XIX », Jahrbuch für Geschichte von Staat, Wirtschaft und Gesellschaft Lateinamerikas 25/1988, pp. 455-477.

doctorat français (quoiqu'en général plus long). En Allemagne, la thèse de Magister ou de Diplom correspond à notre mémoire de Master, puisqu'elle est considérée comme diplôme de fin d'études. 
CALAVITA Kitty, «Gender, Migration, and Law: Crossing Borders and Bridging Disciplines », International Migration Review, 40-1/2006, Center of Migration Studies, New York, pp. 104-132.

CATARINO Christine et MOROKVASIC Mirjana, «Femmes, genre, migration et mobilités », Revue Européenne des Migrations Internationales, 21-1/2005, Femmes, genre, migration et mobilités, pp. 7-27.

CHARTIER Roger, «Le monde comme représentation », Annales ESC, 6/novembre 1989, pp. 1505-1520.

CHOTARD-LIORET Caroline, «Correspondre en 1900, le plus public des actes privés ou la manière de gérer un réseau de parenté », Ethnologie française, 15-1/1985, pp. 63-72.

CLASEN Armin, " Deustsche Auswanderung nach Chile, 1850-1852 », Zeitschrift für Niedersächsiche Familienkunde, 32. Jahrgang, 2/1957, pp. 47-57.

, « Deustsche Auswanderung nach Chile, 1853-1856 », Zeitschrift für Niedersächsiche Familienkunde, 33. Jahrgang, 4/1958, pp. 86-101.

, «Deustsche Auswanderung nach Chile, 1857-1875 », Zeitschrift für Niedersächsiche Familienkunde, 34. Jahrgang, 1/1959, pp. 1-17. [Clasen a établi cette liste à partir des archives d'État de Hambourg et celles de la Commerzbibliothek, sur les indications de Kurt Bauer et Ingeborg Schwarzenberg, donnant un tableau complet de l'immigration allemande au Chili sur les voiliers Goddefroy de 1850 à 1875]

«Die Schiffe der Chile-Auswanderung über Hamburg 1850-1875 und die Schiffbauerfamilie von Somm», Zeitschrift für Niedersächsiche Familienkunde, 38. Jahrgang, 1/1963 pp. 1-7.

CONVERSE Christel, « Die Deutschen in Chile » dans FRÖSCHLE Harmut (Hrsg.), Die Deutschen in Lateinamerika, Schiksal und Leistung, Darmstadt, Horts Erdmann Verlag, Tübingen, 1979, pp. 301-372.

CORTI Paola, «Donne che vanno, donne che restano ; Emigrazione e comportamenti femminili », Annali dell'Istituto Alcide Cervi, 12, 1990, pp. 213-236

DAHINDEN Janine, ROSENDE Magdalena, BENELLO Natalie (et al.), « Édito. Migrations : genre et frontières - frontières de genre », Nouvelles Questions Féministes, 26-1/2007, Migrations : genre et frontières - frontières de genre, pp. 4-14.

DAUPHIN Cécile, FARGE Arlette, FRAISSE Geneviève (et al.), "Culture et pouvoir des femmes : essai d'historiographie », Annales ESC, 2/mars-avril 1986, pp. 271-93.

DONATO Katharine M., GABACCIA Donna, HOLDAWAY Jennifer (et al.), «A Glass Half Full? Gender in Migration Studies », International Migration Review, 40-1/2006, Center of Migration Studies, New York, pp. 3-26.

«In 120 Tagen von Hambourg über Karp Hoorn nach Valparaiso. Aus dem Reisetagebuch der Fanny Fonck von 1853», Condor, Santiago, 24 avril 1993, pp. 10-11. Exemplaire consulté dans le Fonds Fonck des Archives Emilio Held, Santiago, (Boîtier 12, Dossier 11, Document 11a)

FABRE Daniel, "Lire au féminin», Clio, numéro 11/2000, Parler, chanter, lire, écrire. [Accessible en ligne à l'URL: http://clio.revues.org/document219.html, consulté le 7 mai 2008].

FERNÁNDEZ Enrique, «La emigración francesa en Chile, 1875-1914: entre integración social y mantenimiento de la especificidad », Les Cahiers ALHIM, 12/2006, Flux migratoires du $X I X^{e}$ et $X X^{e}$ siècle en Amérique latine. [Accessible en ligne à l'URL : http://alhim.revues.org/document1252.html, consulté le 17 juillet 2007].

GÁRATE Manuel, «Guía del investigador americanista: Santiago de Chile », Nuevo MundoMundos Nuevos, 6/2006, Guía del investigador americanista. [Accessible en ligne à l'URL: http://nuevomundo.revues.org/document2615.html, consulté le 17 octobre 2006].

GREEN Nancy, "L'histoire comparative et le champ des études migratoires », Annales ESC, 6/novembre-décembre 1990, pp. 1335-1350.

GUILLON Michelle, « Editorial », Revue Européenne des Migrations Internationales, 15-2/1999, Emploi, genre et migration, p. 7-8. [Accessible en ligne à l'URL : http://remi.revues.org/document2260.html, consulté le 23 mars 2008]. 
HILY Marie-Antoinette, MEINTEL Deirdre, «Célébrer la communauté », Revue Européenne des Migrations Internationales, 16-2/2000, Fêtes et rituels dans la migration, pp. 7-8. [Accessible en ligne à l'URL : http://www.persee.fr/showPage.do?urn=remi_07650752_2000_num_16_2_1724, consulté le 23 mars 2008].

KÖNIG Mareike, «Les domestiques allemandes à Paris au XIX ${ }^{\mathrm{e}}$ siècle », Actes de l'Histoire de l'immigration, Résumés d'intervention, 2003. [Accessible en ligne à l'URL: http://barthes.ens.fr/clio/revues/AHI/articles/preprints/koenig.html, consulté le 17 janvier 2008].

LEDUC Claudine, FINE Agnès, « Femmes et religion » dans Clio, 1/1995, Femmes et religion, s.p. mis en ligne le 24 mars 2003. [Accessible en ligne à l'URL : http://clio.revues.org/document485.html, consulté le 30 avril 2008].

Von LOE Elisabeth, «Esparcimiento, sociabilidad y vida comunitaria en la colectividad alemana de Valparaíso durante el siglo XIX », Mapocho, 45/1999, pp. 181-195.

MAHLER Sarah J., PESSAR Patricia R., «Gender Matters: Ethnographers Bring Gender from the Periphery toward the Core of Migration Studies », International Migration Review, 401/2006, Center of Migration Studies, New York, pp. 27-63.

MARSCHALCK Peter, DÛPAQUIER Jacques, «La grande mutation de la population allemande » dans BARDET Jean-Pierre, DÛPAQUIER Jacques, Histoire des populations de l'Europe, «La révolution démographique 1750-1914 », Tome II, Paris, Fayard, 1998, pp. 398-415.

MARTÍNEZ Pedro Santos, « La inmigración en Chile: el caso de los colonos vascos (1882-1883) », Historia 22/1987, Pontificia Universidad Católica de Chile, pp. 287-311.

MORELLI Anne, "Jalons pour une histoire des femmes migrantes en Europe », Rapport du colloque Histoire/Genre/Migration, Paris, mars 2006. [Accessible en ligne à 1'URL : http://barthes.ens.fr/clio/dos/genre/resumpan1a3.html, consulté le 17 janvier 2008].

MOROKVASIC Mirjana, «Birds of Passage are also women... », International Migration Review, 18-4/1984, Center of Migration Studies, New York, pp. 886-907.

PEDRAZA Silvia, «Women and Migration. The social consequences of gender », Annual Review of Sociology, 17/1991, pp. 303-325.

PIPER Nicola, «Gendering the politics of migration », International Migration Review, 40-1/2006, Center of Migration Studies, New York, pp. 133-164.

OHLIGER Rainer, "L'histoire de l'immigration en Allemagne : des défis historiographiques et culturels », Hommes \& Migrations, $\mathrm{n}^{\circ}$ 1255, mai-juin 2005, p. 54-62.

ORTNER Sherry, WHITEHEAD Harriet, "Indagaciones acerca de los significados sexuales » dans LAMAS Marta (dir.), El género, la construcción cultural de la diferencia sexual, México, 1996, pp. 127-177

PERROT Michelle, «Women, Power and History », dans : OFFEN Karen, ROACH PIERSON Ruth (et al.), Writing Women's History, Oxford, Blackwell, 1992, p. 160-172.

RINKE Stefan, « Las relaciones germano-chilenas, 1918-1933 », Historia 31/1998, Pontificia Universidad Católica de Chile, pp. 217-308.

RUF Werner, «La conception de la Nation en France et en Allemagne », Hommes \& Migrations, 1223/ janvier-février 2000, Regards croisés France-Allemagne, pp. 12-19.

RYGIEL Philippe, «Les traces de la mobilité géographique», Actes de l'Histoire de l'Immigration, 0/ 2000. [Accessible en ligne à l'URL : http://barthes.ens.fr/clio/revues/AHI/articles/volumes/mobgeo.html, consulté le 17 janvier 2008].

___ «Des mondes genrés et mobiles. Introduction au colloque Histoire/Genre/Migration, Paris, mars 2006 ». [Accessible en ligne à l'URL : http://barthes.ens.fr/clio/dos/genre/com/intro.pdf, consulté le 27 mars 2008].

SCHNEIDER Dorothée, "L'immigration féminine aux Etats-Unis : un essai historiographique », Actes de l'Histoire de l'Immigration, 3/2003. [Accessible en ligne à l'URL : http://barthes.ens.fr/clio/revues/AHI/articles/volumes/wo.html, consulté le 23 avril 2008].

SCHWARZENBERG DE SCHMALZ Ingeborg, «Origen de algunas familias alemanas radicadas en Chile », Revista de Estudios Históricos, Instituto Chileno de Investigaciones Genealógicas, Santiago, n 14 (pp. 31-78), 15 (94-102), 16 (57-71), 17 (81-92), 18 (141- 
153), 19 (61-67), 20 (63-77), 22 (57-72), 24 (123-134), 25 (215-229), 26 (97-107), 27 (95107), 28 (121-140), 30 (235-249), 31 (189-209), 32 (259-280), 33 (243-258), 37 (253-272).

, « Soziale Herkunft und Entwicklung einiger deutschstämmiger Familien in Chile », Sonderdruck aus Genealogisches Jahrbuch, Bd. 5, 1965, 75 p.

SERRANO Sol, "Las mujeres y la historia » dans : KREBS Andrea, Las 100 mujeres de la historia, Santiago de Chile, Edit. Los Andes, 1991, pp. 5-7.

SCOTT Joan W., « Historia de las mujeres » dans : BURKE Peter (dir.), Formas de hacer historia, trad. José Luis Gil Aristu, Madrid, Alianza Editorial, 1993, pp. 59-88.

SINKE Suzanne, «Gender and Migration: Historical Perspectives », International Migration Review, 40-1/2006, Center of Migration Studies, New York, pp. 82-103.

VENEROS RUIZ-TAGGLE Diana, «Las mujeres en la historia de Chile. Entre la invisibilidad y el protagonismo »dans: GALLEGUILLOS Ximena, VENEROS Diana, ORTÚZAR Carmen (et al.), Mujeres que hacen historia, Santiago, LOM Eds., Consejo Nacional de la Cultura y las Artes, 2005, pp. 36-51.

WALDAMM Peter, «Conflicto cultural y adaptación paulatina. La évolucion de las colonias de inmigrantes alemanes en el sur de Chile », Jahrbuch für Geschichte von Staat, Wirtschaft und Gesellschaft Lateinamerikas 25, 1988, pp. 437-453.

YOUNG George F. W., " Bernardo Philippi, Initiator of German Colonization in Chile », The Hispanic American Historical Review, 51- 3/1971, pp. 478-496.

ZIMMERMANN Clemens, "La modernisation des campagnes allemandes (XIX ${ }^{\mathrm{e}}-\mathrm{XX}^{\mathrm{e}}$ siècles). Les apports de l'historiographie récente en Allemagne », Histoire et sociétés rurales, $11 / 1^{\text {er }}$ semestre 1999, pp. 87-108.

\subsubsection{Ressources électroniques}

América Latina : http://www.red-redial.net

[Réseau européen d'information et de documentation sur l'Amérique latine]

Biblioteca Virtual Miguel Cervantès : http://www.cervantesvirtual.com

[Voir entre autres: Víctor Sánchez Olivera, Historia de Osorno, 2002,

http://www.cervantesvirtual.com/servlet/SirveObras/12478309722361506098435/index.ht

$\mathrm{m}]$

Clio, Histoire, femmes et sociétés : http://clio.revues.org

[Quelques numéros de Clio en ligne, le reste se trouve également sur Persée]

Clio, site d'Histoire sociale : $\mathrm{http}: / /$ barthes.ens.fr/clio

[Voir en particulier :

- Rapport du colloque «Histoire, genre, migration», mars 2006, http://barthes.ens.fr/clio/dos/genre/genr.html

- Site de la revue électronique Actes de l'histoire de l'immigration hébergée par Clio, http://barthes.ens.fr/clio/revues/AHI]

Deutsch-chilenischer Bund (DCB)/Liga chileno-alemana $:$ http://www.dcbliga.cl

[Site de l'association créée en 1916 et de son centre d'archives Emilio Held Winkler]

Deutsche Botschaft Santiago de Chile/ Embajada Alemana Santiago de Chile: http://www.santiago.diplo.de

[Site de l'ambassade d'Allemagne au Chili qui propose, entre autres, une perspective historique des relations germano-chiliennes et un aperçu de la présence allemande actuelle au Chili]

DS Chile : http://www.dschile.cl

[Site de la fédération des écoles allemandes au Chili (Deutsche Schule)]

Familia Anwandter : http://www.anwandter.cl

[Site de l'illustre famille chilienne d'origine allemande implantée à Valdivia]

Gallica : http://gallica2.bnf.fr

[La bibliothèque numérique de la $\mathrm{BNF}$ ]

Genealogías de Familias chilenas http://www.genealog.cl/Alemanes

[Le site de généalogie le plus complet du Chili. Contient une rubrique «familles

allemandes du Sud du Chili »]. 
Génériques, histoire et mémoire de l'immigration : http://www.generiques.org

[Site de l'association qui publie la revue Migrance.]

Hamburg Passenger Lists, 1850-1934/Hamburger Passagierlisten, 1850-1934: http://content.ancestry.com/iexec/?htx=List\&dbid=1068\&o_iid=24018\&o_lid=24018

[Un site d'Ancestry.com et des Archives de l'Etat de Hambourg qui proposent une base de données en allemand des passagers des bateaux partis de Hambourg. L'accès aux informations détaillées et aux documents digitalisés est payant, mais on peut tout de même visualiser la liste des noms de personne à destination du Chili, et comparer avec celle que donnent Emilio Held Winkler et Armin Clasin]

Hommes et migrations : http://www.hommes-et-migrations.fr

[Mise en ligne de certains articles.]

Ibero-amerikanisches Institut : http://www.iai.spk-berlin.de

[Site de l'Institut ibéro-américain de Berlin, version allemande et espagnole, utile notamment pour son bulletin électronique et le catalogue de sa très riche bibliothèque.]

Le bulletin de l'Institut Pierre Renouvin, Université Paris I Panthéon-Sorbonne : http://ipr.univparis1.fr

Les Archives Audiovisuelles de la Recherche en sciences humaines et sociales, Fondation de la Maison des Sciences de l'Homme (FMSH) et Equipe Sémiotique Cognitive et Nouveaux Médias (ESCoM) : http://www.archivesaudiovisuelles.fr

[Voir en particulier

- Les vidéos du séminaire de Mônica Raisa SCHPUN à l'EHESS en 2007-2008 : http://www.archivesaudiovisuelles.fr/1203/home.asp?id=1203]

- Les vidéos des entretiens réalisés par Lisette Winkler sur l'immigration allemande au Sud du Chili :

- "Impactos económicos y sociales de la inmigración alemana en Valdivia en el siglo XIX", Patricio Bernedo (1:08:16)

http://www.archivesaudiovisuelles.fr/1509/introduction.asp?id=1509

- "Historia y documentos sobre la colonización alemana en Chile", Christine Gleisner et Eduardo Carrasco ( $:$ http://www.archivesaudiovisuelles.fr/1516/introduction.asp?id=1516

- "Genealogía y Colonización Alemana en el Lago Llanquihue", Germán Hoffmann Kahler : http://www.archivesaudiovisuelles.fr/1451/introduction.asp?id=1451

- "Colonización y asentamiento alemán en el lago Llanquihue", Irene Siebald :

http://www.archivesaudiovisuelles.fr/FR/_video.asp?id=1528\&ress=4611\&video=105799 $\&$ format $=68$

- "Relatos de un oriundo de Frutillar", Jacob Juginger :

http://www.archivesaudiovisuelles.fr/FR/_video.asp?id=1528\&ress=4606\&video=105649 \&format $=68$ ]

Les cahiers de l'ALHIM : http://alhim.revues.org

[Groupe de recherche " Amérique latine, Histoire et Mémoire », Université Paris VIII.]

LIEGE, Laboratoire interuniversitaire en Etudes Genre de l'Université de Lausanne : http://www2.unil.ch/liege/nqf

[Publie la revue Nouvelles Questions féministes.]

Memoria chilena: http://www.memoriachilena.cl

[Site de la DIBAM (Dirección de Bibliotecas, Archivos y Museos) du Chili qui propose une série de documents d'archive numérisés, notamment sur la colonisation allemande (http://www.memoriachilena.cl/mchilena01/temas/index.asp?id_ut=lacolonizacionalemana devaldiviayllanquihue:1850-191). Accès également aux catalogues en ligne de la Biblioteca Nacional et de l'Archivo Nacional]

Méthode quantitative pour l'historien : http://www.quanti.ihmc.ens.fr

[Présentation d'outils de statistique et méthodes quantitatives.]

Nuevo Mundo - Mundos Nuevos / Nouveau monde - Mondes nouveaux / Novo mundo - mundos novos, Ecoles des Hautes Etudes en Sciences Sociales, Paris : http://nuevomundo.revues.org

Persée, portail de revues scientifiques en sciences humaines et sociales : http://www.persee.fr [Site de numérisation rétrospective de revues françaises.] 
REMI, Revue européenne des migrations internationales $:$ http://remi.revues.org

[Mise en ligne de certains numéros]

Réseau Amérique latine : http://www.reseau-amerique-latine.fr

[Système d'information documentaire francophone sur l'Amérique latine]

The Library of Congress: http://www.loc.gov/index.html

[Site de la Bibliothèque du Congrès américain, la plus fournie au monde, utile pour la recherche de toute référence bibliographique, photographique, cartographique, audiovisuelle etc. avec possibilités de téléchargement (plus de 130 millions de titres). Comporte également des guides bibliographiques très complet, notamment :

- Wood, Virginia Steele, "Immigrant Arrivals: A Guide to Published Sources", Washington, D.C.: Local History and Genealogy Reading Room, Library of Congress, 1997. URL: http://www.loc.gov/rr/genealogy/bib_guid/immigrant] 